\title{
PowerChoice Residential Customer Response to TOU Rates
}

Jane S. Peters, Mithra Moezzi, Susan Lutzenhiser, James Woods, Linda Dethman, Rick Kunkle

Research Into Action, Inc.

October 2009 


\section{Disclaimer}

This document was prepared as an account of work sponsored by the United States Government. While this document is believed to contain correct information, neither the United States Government nor any agency thereof, nor The Regents of the University of California, nor any of their employees, makes any warranty, express or implied, or assumes any legal responsibility for the accuracy, completeness, or usefulness of any information, apparatus, product, or process disclosed, or represents that its use would not infringe privately owned rights. Reference herein to any specific commercial product, process, or service by its trade name, trademark, manufacturer, or otherwise, does not necessarily constitute or imply its endorsement, recommendation, or favoring by the United States Government or any agency thereof, or The Regents of the University of California. The views and opinions of authors expressed herein do not necessarily state or reflect those of the United States Government or any agency thereof or The Regents of the University of California. 


\section{Acknowledgements}

We would like to thank our Advisory Group-Loren Lutzenhiser, Ph.D., Iris Sulyma, and David Hungerford, Ph.D.- - who have contributed time and effort to review and support this study. We would also like to thank staff at Sacramento Municipal Utility District for their commitment and involvement, particularly Vikki Wood, Carol Novak, Ralph Carlson, Steve Van Horssen, Corey Nelson, Tom Jas, and Jason Casella.

Finally, thanks to Laurie Lago of Business Service Bureau for her production support.

Please cite this report as follows:

Peters, Jane S., Mithra Moezzi, Susan Lutzenhiser, James Woods, Linda Dethman, and Rick Kunkle. 2009. PowerChoice Residential Customer Response to TOU Rates. California Energy Commission, PIER Energy Systems Integration / Buildings Program. CEC-500-2009-XXX. 


\section{Table of Contents}

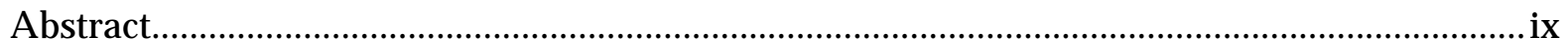

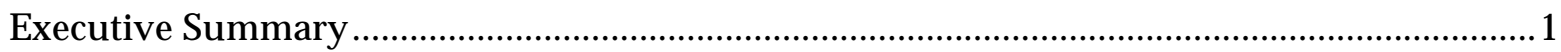

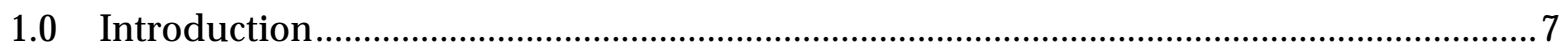

1.1. SMUD Residential TOU Rate Background ........................................................... 8

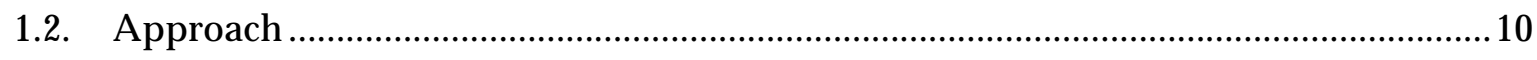

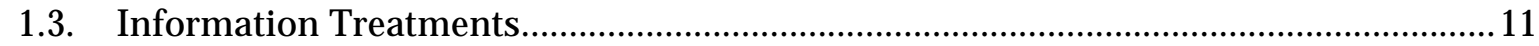

1.3.1. Enhanced Information Treatment .................................................................... 11

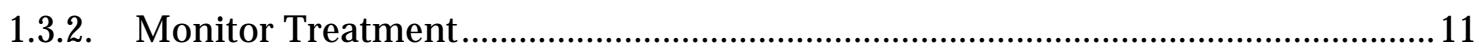

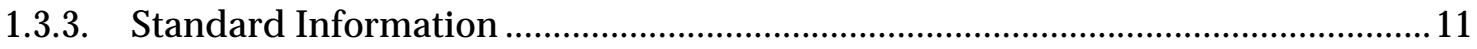

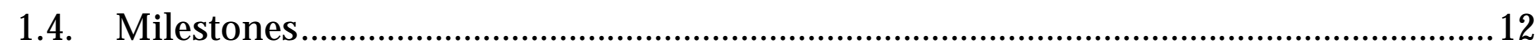

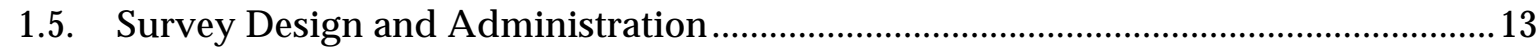

1.6. Real World Challenges for the Analysis ................................................................. 14

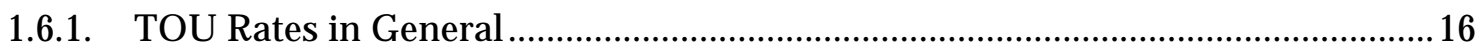

2.0 Demographic Characteristics of PowerChoice Participants.............................................19

2.1. Summary of Demographic Comparisons ................................................................. 19

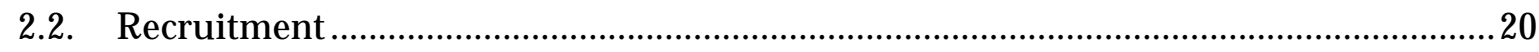

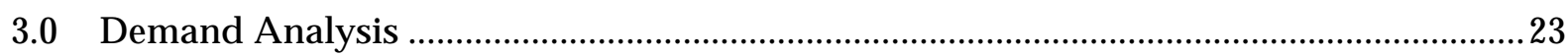

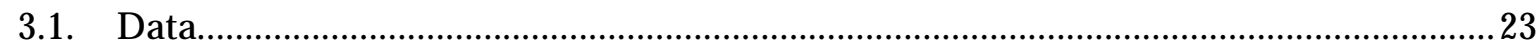

3.2. Basic Load Analysis For PowerChoice Customers...................................................24

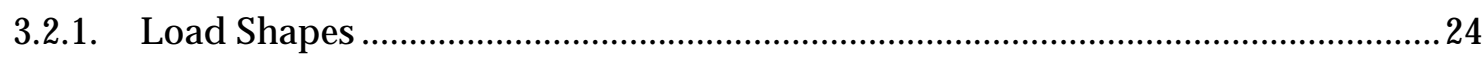

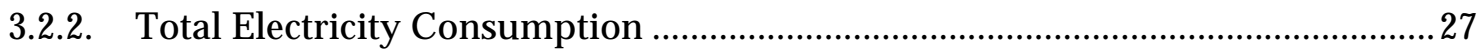

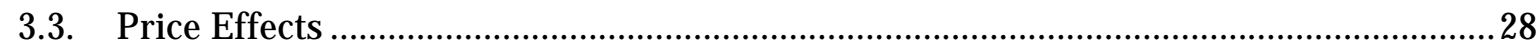

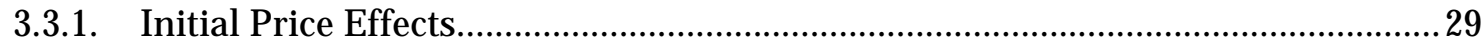

3.3.2. Transition Periods: Summer to Swing …........................................................... 30

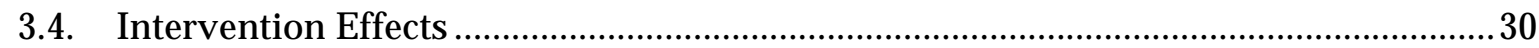

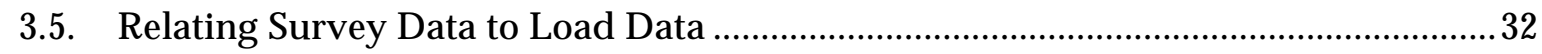

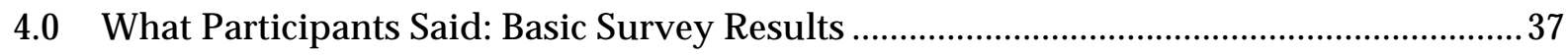

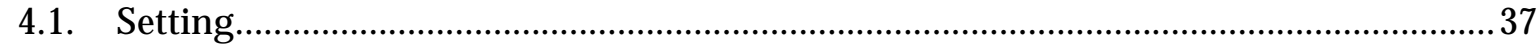

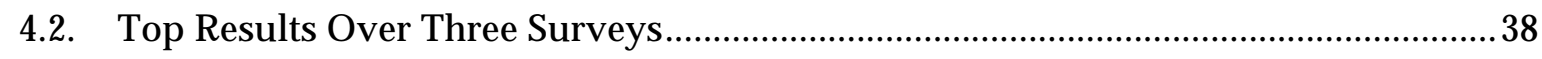

4.3. Motivation for Joining PowerChoice ............................................................................ 40

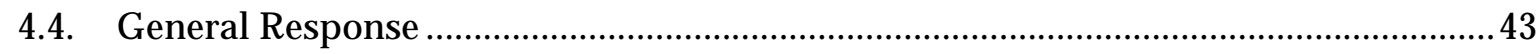

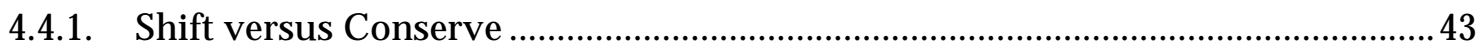

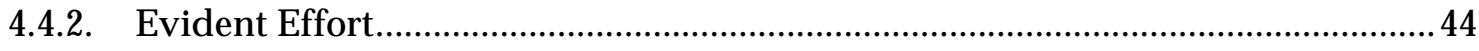

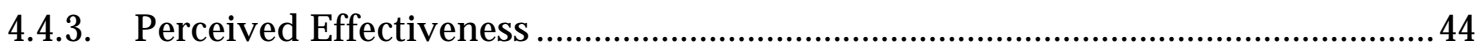

4.4.4. Most Households Said They Already Conserved .................................................... 45

4.5. What Participants Said They Did ................................................................................ 45

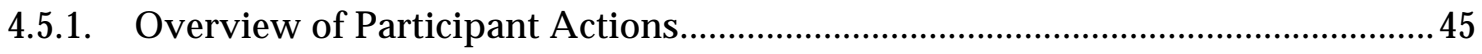

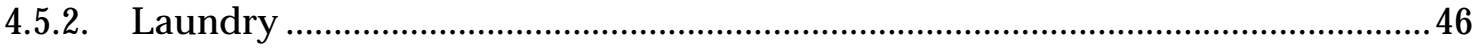




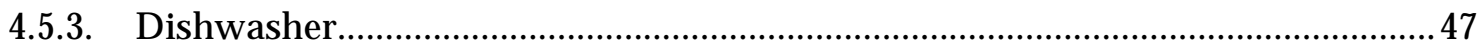

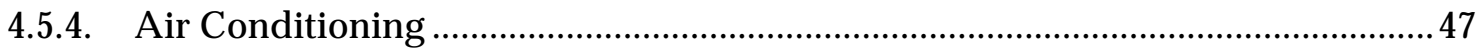

4.5.5. Change In Cooking or Meal Time....................................................................... 49

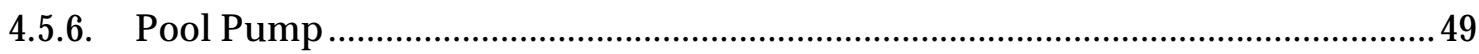

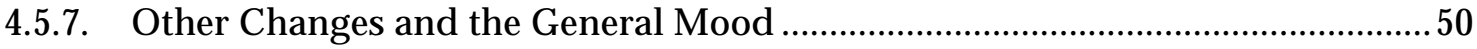

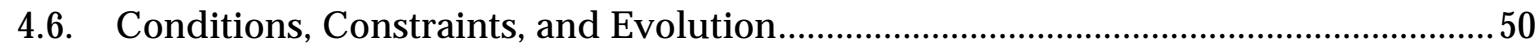

4.6.1. What Participants Resisted Changing and Why .................................................50

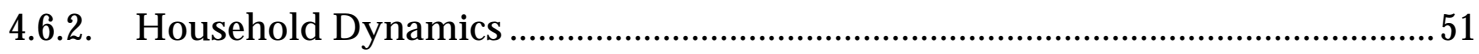

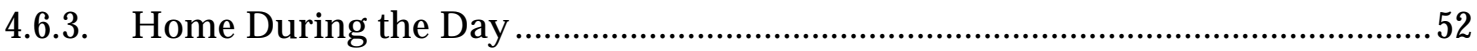

4.6.4. Household Circumstances Change …....................................................................52

4.7. Experience with the Technical Details of the Rate.....................................................53

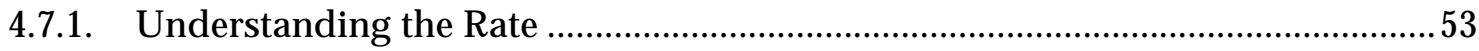

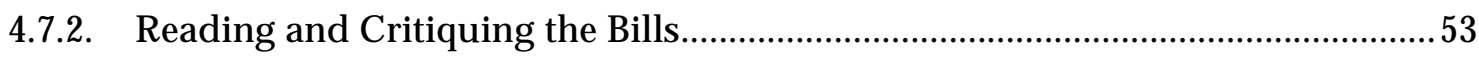

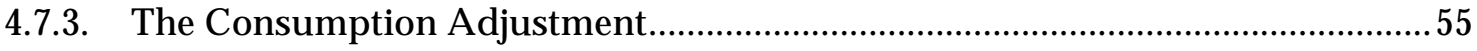

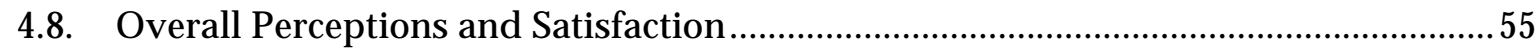

5.0 What Participants Said: Information Interventions.....................................................57

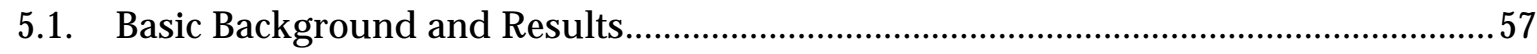

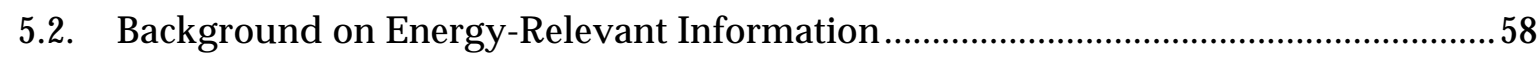

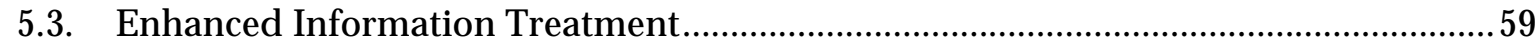

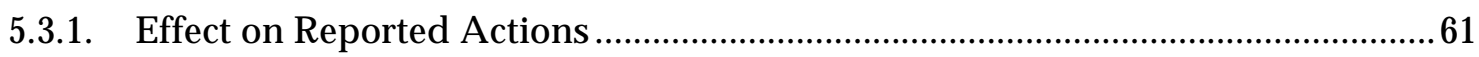

5.3.2. General Reaction to the Enhanced Information Treatment ................................63

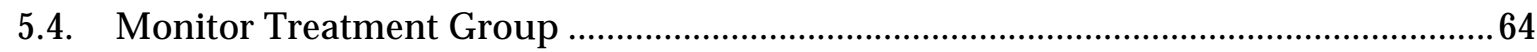

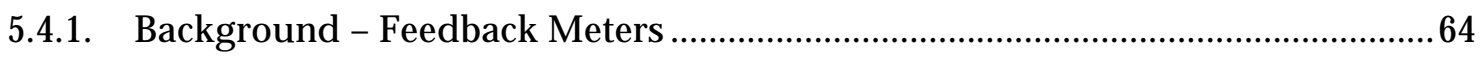

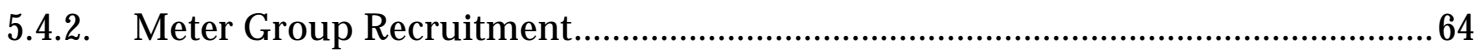

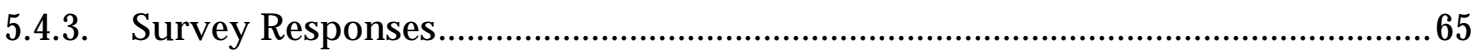

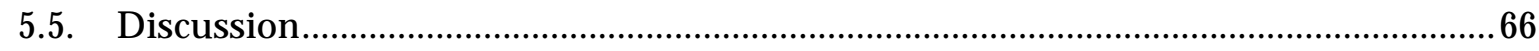

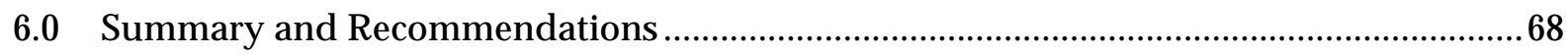

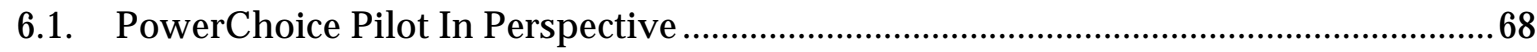

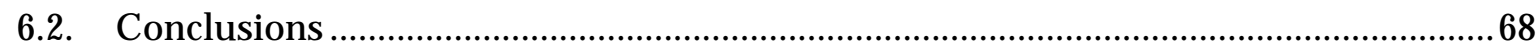

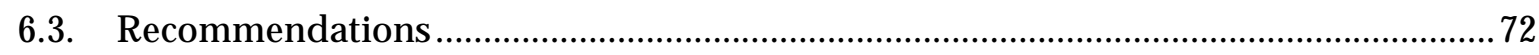

6.3.1. Recommendations for Residential TOU Programs ............................................72

6.3.2. Recommendations for Studying Residential Behavior ......................................75

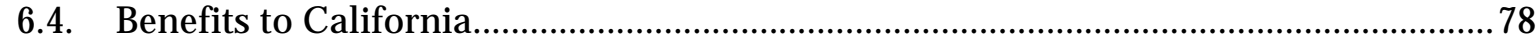

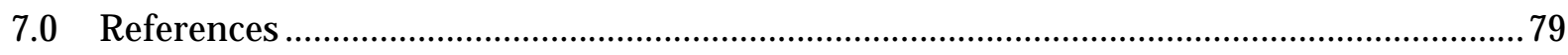

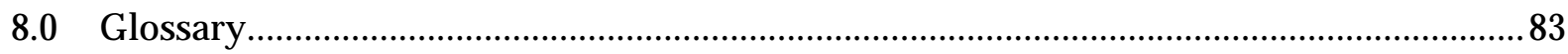

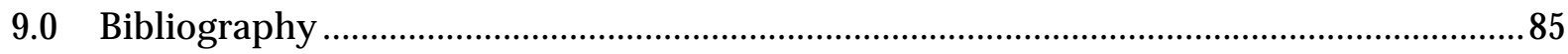

Appendix A. SMUD PowerChoice Materials

Appendix B. Enhanced Information Intervention Mailings

Appendix C. Blue Line Intervention Materials and Background Research 
Appendix D. Detail on Demographic Characteristics of PowerChoice Participants

Appendix E. Selected Wave 3 Survey Results

Appendix F. Analytical Framework and Three Survey Instruments

\section{List of Figures}

Figure 1-1. PowerChoice rate structure

Figure 3-1. Summer Weekday Normalized load shapes for Control Group compared to

PowerChoice customers

Figure 3-2. Summer Weekend Normalized load shapes for Control Group compared to

PowerChoice customers

Figure 3-3. Winter Weekday Normalized load shapes for Control Group compared to PowerChoice customers.

Figure 3-4. Winter Weekend Normalized load shapes for Control Group compared to PowerChoice customers

Table 3-5. Analysis of summer load by value of survey response for three general questions on program experience and satisfaction asked in the Wave 3 survey

Figure 3-5. Distribution of normalized load shapes on Summer weekdays for households reporting that their efforts to adjust load to the PowerChoice tariff were "very effective," as compared to all other households....

Figure 3-6. Distribution of normalized load shapes on Summer weekdays for households reporting that they had made "a great deal of effort" to adjust their consumption on the PowerChoice tariff, as compared to all other households

Figure 4-1. Reasons for joining PowerChoice (open-ended, multiple responses)

Figure 4-2. Factors playing a part in respondent's decision to participate.

Figure 4-3. Self-reported typical indoor temperature in home before joining

PowerChoice

Figure 4-4. Sample PowerChoice customer bill .54

\section{List of Tables}

Table 1-1. Consumption Adjustment component of the PowerChoice tariff. .9

Table 1-2. Summary of the PowerChoice TOU participant surveys completed .13 
Table 3-1. Time-of-Use periods used for the Summer and Swing rate season load-data

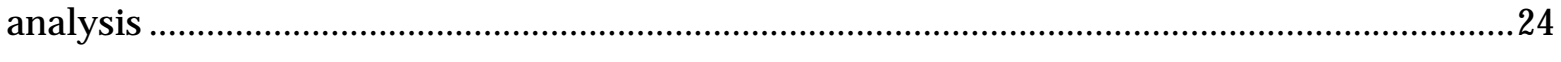

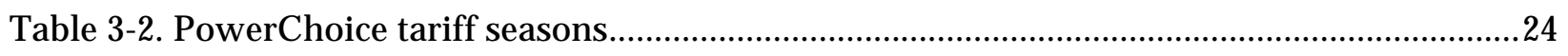

Table 3-3. Results of tests for statistically significant differences in initial price effects of

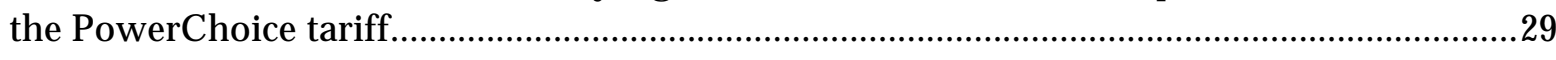

Table 3-4. Results of tests for statistically significant differences for price effect in the transition between Summer and Swing (late Summer/Fall) seasons under the PowerChoice tariff.....

Table 4-1. Reported general response to the PowerChoice tariff, Wave 3 survey

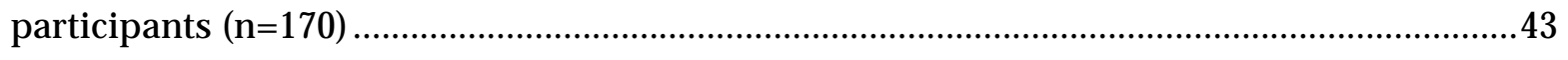

Table 4-2. Common shifting and conservation actions in response to PowerChoice, as reported by surveyed participants .......................................................................................4

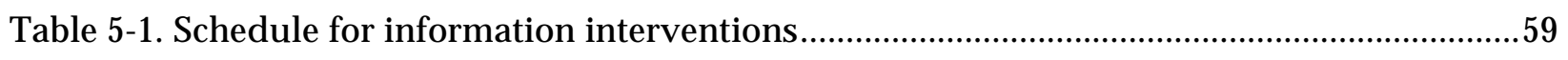

Table 5-2. Differences in stated actions between Enhanced Information Treatment group and all others, based on responses to Wave 3 survey 


\begin{abstract}
Research Into Action, Inc. and the Sacramento Municipal Utility District (SMUD) worked together to conduct research on the behaviors and energy use patterns of SMUD residential customers who voluntarily signed on to a Time-of-Use rate pilot launched under the PowerChoice label. The project was designed to consider the how and why of residential customers' ability and willingness to engage in demand reduction behaviors, and to link social and behavioral factors to observed changes in demand. The research drew on a combination of load interval data and three successive surveys of participating households. Two experimental treatments were applied to test the effects of increased information on households' ability to respond to the Time-of-Use rates. Survey results indicated that participants understood the purpose of the Time-of-Use rate and undertook substantial appropriate actions to shift load and conserve. Statistical tests revealed minor initial price effects and more marked, but still modest, adjustments to seasonal rate changes. Tests of the two information interventions indicated that neither made much difference to consumption patterns. Despite the lackluster statistical evidence for load shifting, the analysis points to key issues for critical analysis and development of residential Time-of-Use rates, especially pertinent as California sets the stage for demand response in more California residences.
\end{abstract}

Key Words: Time-of-Use rates, residential energy consumption, load shifting, consumption feedback monitors, demand response, air conditioning, advanced meters, household energy consumption behavior, social sciences of energy use, household energy practices 


\section{Executive Summary}

\section{Introduction}

Research Into Action, Inc. and the Sacramento Municipal Utility District (SMUD) worked together to conduct research on the behaviors and energy use patterns of a sample of SMUD residential customers who signed on voluntarily to a Time-of-Use rate pilot launched under the PowerChoice label. The theoretical background and the research design for the project were developed in the research plan, submitted in October 2007. This report summarizes the results of that project, which ran from May 2007 to April 2009.

\section{Purpose}

Recognizing that most past studies on residential demand response have examined only aggregate load effects, the project was designed to consider the how and why of residential customer ability and willingness to engage in demand reduction behaviors, and to link social and behavioral factors to observed changes in demand.

\section{Project Objectives}

The research project used a customer concerns, capacities, and conditions (3-Cs) framework to interpret what individuals and their households did in response to the rate. Within this basic framework, the project tested whether giving customers extra information and encouragement tailored to the Time-of-Use rate actually increased their response. Two information interventions were tested-one, a series of letters delivering tips and encouragement, the second, an electricity-use feedback monitor. The analysis relied on a combination of interval load meter data and three successive surveys of the Time-of-Use rate participants. Interval load meter data also were obtained for SMUD's Load Research Sample. These households served as the control group for load-related analyses.

\section{Project Outcomes}

PowerChoice participants were recruited by mail and phone calls. Of the 30,000 households contacted, 330 households (1 percent) signed participation agreements. This is about the same level of acceptance as the overall level for residential Time-of-Use rates among U.S. investorowned utilities that offer them. While the recruitment process helped ensure that a range of household types was represented, participating households were still self-selected and statistically their experience does not necessarily represent that of households if the Time-of-Use rate were default or mandatory. This would be true of any Time-of-Use rate study in which participation on the rate or in the experiment was voluntary. And, as in any quasi-experiment or case study on a Time-of-Use tariff, results presumably depend on the particular price structure and other details of implementation. The transferability of findings between one instantiation of a Time-of-Use tariff and another are open questions. In the PowerChoice tariff studied here, it may have been difficult for most customers to save money relative to the standard tariff.

\section{Conclusions}

The main results of this project are presented below. 
1. The initial offer of the Time-of-Use rate did not garner great interest among the SMUD customers to whom it was offered. Of the 330 who initially signed on, eventually 286 households piloted the rate.

2. PowerChoice participants were very likely to be single-family, owner-occupied households. Adult members of participant households were considerably older, on average, than in other single-family, owner-occupied households in SMUD territory. Survey respondents overall had attained substantially higher educational levels, with a somewhat higher proportion of households in the highest income group, compared to other single-family, owner-occupied households in the SMUD territory. Survey respondents also were more likely to say that someone was home during weekdays from 8:00 a.m. to 5:00 p.m., compared to SMUD's estimate for the service territory. While PowerChoice participants overall had higher than average consumption, considering all house types combined, when comparing only single-family homes, participating households' electricity consumption was, on average, lower than for other homes in SMUD's service territory.

3. For most surveyed households, the primary stated motivation for participating in the PowerChoice Time-of-Use rate was saving money or controlling costs. Few survey respondents spontaneously mentioned more altruistic reasons, although when asked directly, most agreed that potential environmental benefits, reducing the possibility of brownouts, etc., were supporting reasons. Some also said they liked the project aspect and the program enticements (e.g., gift cards), helping SMUD, or the basic logic of the rate.

4. Households were allowed to drop the rate with a 30-day notice. Overall, 16 percent left the experiment for a variety of reasons, including moving. Some customers who said that they thought they were paying more or were otherwise dissatisfied with the rate stayed with it, while others dropped out. This introduces an additional layer of selfselection to participation on the rate.

5. Although some customers said that they followed rate periods closely, the complicated rate structure was a burden to many. The PowerChoice tariff had up to five different rate periods per day, four seasonal changes per year, and different rate periods for weekends and weekdays. This complexity is not unusual for a residential Time-of-Use tariff, but survey responses revealed that it clearly took some effort for participants to remember when changes occurred. In their survey responses, participants generally claimed to understand the Time-of-Use tariff, and some implied that they closely watched the clock. A few respondents expressed anger about the complicated form of the rate or other aspects they found illogical.

6. Surveyed responses indicated that participants clearly understand that the rationale for the Time-of-Use rate was to encourage shifting of activities and loads away from peak times of day. Respondents most frequently reported the following behavioral changes to the Time-of-Use rate: shifting the timing of laundry and dishwashing; reducing air conditioner use during Super-Peak hours (weekday afternoons); installing CFLs; implementing general energy-conservation behaviors, such as turning off lights; and, among pool owners, changing the timing for operation of the pool pump. Three out of four respondents said they had shifted their usage and half said they had undertaken 
conservation actions. Across all respondents, several dozen distinct actions were reported.

7. Most participating households surveyed said that they already conserved energy, but made a greater effort to shift and to conserve under the Time-of-Use rate. Over half of surveyed participants said that they had made a great deal of effort to adjust to the rate. Many respondents' replies to open-ended survey questions indicated that their effort was genuine. In fact, some survey respondents reported going to extreme measures, such as a major overhaul of domestic schedules.

8. While the Time-of-Use rate was in force, PowerChoice participants had load shapes that fit the Time-of-Use tariff better than the control sample to which they were compared, especially during the highest-price summer period. However, it is not clear how much of this difference was due to the tariff, versus self-selection onto the rate.

9. For two of the eight daily periods tested, statistical tests for an initial price effect revealed weak shifts in electricity use after enrolling in PowerChoice, as calibrated to changes in the electricity usage of the control group. There was no statistical evidence for reduced load at super-peak. The limited amount of pre-PowerChoice data and the relatively small sample size made detection of price effects difficult.

10. There was evidence of a price effect as households transitioned from Summer tariff period rates to the fall Swing period rates. Most of the changes detected for this transition revealed a relaxation in shifting and increases in consumption during higherpriced periods, corresponding to the lowered prices (relative to Summer prices) for all usage time periods during the Swing period.

11. A modest proportion of surveyed PowerChoice participants indicated that their attempts to change their electricity consumption to better fit the Time-of-Use tariff reduced comfort and caused inconvenience, and led to some tensions within the household. Although generally considered morally good in public energy education campaigns, conservation and shifting usage may be stressful to some individuals and families. Such stress may occur whether or not efforts are effective in providing consumption reductions or demand response to the grid.

12. The research team applied and tested the effects of two information interventions on subsets of participating households: one a set of written information (Enhanced Information Treatment) and the other an electricity feedback meter (Monitor Treatment). Drawing from the principles of Community Based Social Marketing, the Enhanced Information Treatment intervention supplied tips and encouragement to a randomly selected group of households. This information included periodic content-rich letters and a refrigerator magnet displaying the tariff details, which served as a prompt. Although most of the respondents who received this information said it was useful, the team realized in retrospect that that intervention might not have been sufficiently distinguished from other program materials to allow confident conclusions about the effects of the enhanced information.

13. A test of the cumulative effects of information on observed Summer load did not indicate that the Enhanced Information Treatment group shifted more electricity than other households. Despite this, survey responses indicated that, compared to other households, the Enhanced Information Treatment members were more likely to 
emphasize shifting when they discussed what they had done, particularly for shifting actions that had been promoted in the special information they had received. The differences were moderate and, overall, are consistent with the theory that mass information may increase knowledge, but not necessarily energy savings.

14. Use of electricity feedback monitors did not seem to have much effect on electricity consumption patterns. The second experimental treatment, the Monitor Treatment, consisted of Blue Line Innovation's PowerCost electricity consumption feedback monitor. Monitors were offered free to all participants who had started on the rate in summer 2007. About a quarter of households responded positively to the offer, which suggests a modest level of interest in the device among households participating in the program. Monitors were distributed to these 50 volunteer households just before the second summer of the rate. Most of the recipient households successfully installed their monitors. The majority of monitor recipients surveyed said they referred to the monitors one or more times per day, even many weeks into the summer, and that they used the monitors both as general prompts and to deduce specific information about usage. Statistical analysis of these volunteer households' electricity loads for the second summer of the program found minor effects on electricity consumption.

15. In the general comments volunteered by surveyed participants, the consumption adjustment was one of the biggest complaints made about the program. The consumption adjustment aspect of the PowerChoice tariff was designed to reward conservation, in addition to encouraging load shifting. It consisted of discounts for low overall energy use and surcharges for higher usage levels. In some cases, the consumption adjustment resulted in substantial surcharges-in theory, up to 50 percent of the total bill pre-adjustment. Some customers who paid a surcharge said they found it expensive and disagreeable, especially if they had been making a substantial effort to conserve and shift electricity usage. Although program enrollment materials described the consumption adjustment, many customers said they were not aware of it initially, which led to some discontent early on. While lower-use customers benefited from the consumption adjustment, the possibility of a consumption adjustment surcharge added risk and made it more difficult for higher-use customers to financially benefit from the program. These higher-use customers might reduce their bills by shifting load, but the surcharge on total consumption might increase their bills overall. A tiered Time-of-Use rate, with blocks of rates that increase with consumption, and fixed time-of-day prices within the block, might be more satisfactory in terms of customer acceptance, but would mute the message about rewards for conservation.

16. Although most customers may not have accurately known if they had gained or lost money due to the Time-of-Use rate, most offered an opinion. Overall, half of surveyed participants judged that they had saved money on the rate. Customers who did not like the rate, or their electricity bills while they were on the rate, were more likely to drop off the rate. This filtering could reduce the potential benefits of the rate to the electricity system and utility, to the extent that free-riders (i.e., those whose original consumption patterns best fit the rate and may have been less motivated or less able to deliver peak savings) were most likely to remain on the rate.

17. Customers had suggestions about the bill format, information provided on the bill, and the rate itself. These suggestions are reflected in the Recommendations below. 
18. Half of surveyed households reported that they increased efforts to conserve or shift during the second summer on the rate, relative to the first. Few households said that they made less effort the second summer. These self-reports indicate persistence of behavioral change at least to the second year, although the results are hard to interpret because of the minimal load shifting actually detected and the difficulty in comparing effort over time.

\section{Recommendations}

Recommendations for residential Time-of-Use programs and for further study of behavior under residential Time-of-Use rates are provided in the final chapter. The recommendations for Time-of-Use programs stress:

- The importance of rate details from the interpretive standpoint of the customer, over and above interpretation from the standpoint of economic theory.

- Attention to the effort that households take in order to adjust their consumption to Time-of-Use rates, and the potential consequences of these efforts on the household.

- The difficulty of giving information of the quality and in the form that customers might find most useful, and the tradeoff between effort and reward, including assessment of household end-uses and activities that are promising from the standpoint of demand response (e.g., air conditioning management and clothes drying), as well as acknowledgement of less promising but common responses (e.g., household management of low-consuming end-uses).

Finally, this study also suggests the importance of considering voluntary drop-offs in assessing the effectiveness of the rate in terms of demand response, and underscores the importance of attending to the distribution of benefits and costs of Time-of-Use rates among customers.

As to recommendations for further study of residential behavior under Time-of-Use rates, the results of this research stress:

- The importance of acquiring adequate baseline data and sample sizes, and the consequences of sampling design and statistical analysis on results.

- The practical difficulties of ensuring this adequacy.

- Issues related to expectations for behavior-centered experiments, as opposed to the technically oriented analyses typical in the energy-efficiency field.

- The importance of using open-ended questions in surveying Time-of-Use rate customers.

- The need for more sociological analysis of Time-of-Use rates and high-level analyses of the observed lack of customer interest in these rates.

- More detailed analysis of information provision, design, and usage issues of various feedback meter and Time-of-Use tariff options.

- The need for a meta-analysis of past program experience on residential Time-of-Use rates, covering both published material and unpublished knowledge of these experiences, with a specific goal to extract the social scientific elements related to behavior effects. 


\section{Benefits to California}

Demand response is one of California's preferred options for meeting the state's future energy needs. By 2010, most customers in the state are expected to have had advanced meters (smart

meters) installed. These meters will facilitate demand response programs for California utilities. Although the value of demand response usually is interpreted under a largely economic lens, demand response is fundamentally based on behavioral change, which affects the experience of daily life. This is true even for demand response programs where the actual demand reduction is automated rather than manual. The behavioral aspects of demand response barely have been explored, yet they are fundamental to understanding demand response, learning how performance can be improved, and considering the costs and benefits of demand response to California residents. The collection and analysis of behavioral data for a Time-of-Use rate undertaken in this project contribute to understanding in each of these areas. In particular, it:

- Builds appreciation for the complexity of consumer choice, and for understanding residential consumer constraints in responding to Time-of-Use rates.

- Reinforces findings from other experiments about the limited uptake of Time-of-Use rates and the nature of past "successes" and "failures" with these rates.

- Stresses the importance of households' self-selection onto the rate when participation is voluntary, as well as the variation of impacts across households.

- Shows the need to appreciate more fully the nature of "information" and the difficulties of information delivery and processing.

The results provide an improved basis for future policy decisions about Time-of-Use and other demand response programs, raise a well-rounded set of questions about Time-of-Use rate performance, and help guide program design and further demand response research. 


\subsection{Introduction}

Between May 2007 and April 2009, Research Into Action, Inc. and Sacramento Municipal Utility District (SMUD) worked together to conduct research on a set of SMUD customers who voluntarily signed on to a Time-of-Use (TOU) rate pilot program launched under the PowerChoice label. This Demand Response Research Center (DRRC) funded and SMUD supported research project has the goal of exploring the complex behavioral dynamics upon which successful demand response (DR) depends. ${ }^{1}$ From an economics perspective, compared to a flat pricing throughout the day, TOU rates have the advantage of more closely matching the price of electricity to the marginal costs of producing that electricity, which varies by time. Microeconomic theory suggests that electricity customers charged closer to these "real" production costs will reduce usage during high price periods (Alexander 2007) and perhaps increase it during low price periods, leading to load shapes that are more efficient from the standpoint of electricity production costs. This constitutes the basic theoretical argument for TOU rates, as well as for the more dynamic forms of pricing used for demand response.

Recognizing that most past studies on residential demand response have examined primarily aggregate load effects, the project was designed to consider the how and why of residential customer ability and willingness to engage in demand reduction behaviors, and to link this social and behavioral view to observed changes in demand. Within this basic framework, the project sought to test whether giving customers extra information and encouragement tailored to the TOU rate actually increased their response to the rate. Two information interventions were tested. One was a series of communications delivered by mail and the second was an electricity-use feedback monitor. The analysis relied on a combination of interval load meter data for TOU rate participants and for a control group, and surveys of the TOU rate participants. This report summarizes the conduct of the research project, its findings, and recommendations for residential TOU tariffs and for future research on households' behavior under TOU tariffs.

The conceptual background and the research design for the project were developed in a research plan submitted in October 2007 (Peters \& Lutzenhiser 2007). These are minimally restated here in order to highlight project results. An earlier report gives more detail on the first eight months of the project (Peters et al. 2008). The remainder of this chapter describes the project background. Chapter 2 discusses the demographic profile of PowerChoice participants. Chapter 3 presents the results of the load data analysis, including the effects of the two experimental interventions on load, analyzed independently of the survey data, as well as in conjunction with it. Chapter 4 summarizes general results over all three surveys, while the survey analysis of the two information interventions is presented in Chapter 5. Chapter 6 recaps the main results of the project and presents recommendations for residential TOU programs and for research analyzing the behavioral aspects of such programs. Appendices provide additional information, including a more detailed tabulation of survey results.

1. Funding was awarded to Research Into Action, Inc. in May 2007 by the Lawrence Berkeley National Laboratory (LBNL) Demand Response Research Center (DRRC). 


\subsection{SMUD Residential TOU Rate Background}

In March 2007, SMUD introduced a TOU rate through their PowerChoice Pilot Program (see 2007 PowerChoice Brochure: Appendix A, p. APA-3). ${ }^{2}$ Some 330 SMUD customers signed participation agreements (Appendix A, pp. APA-4-5) to be switched from their tiered rate to a TOU rate. ${ }^{3}$ Of the initial 330 who signed agreements, 286 participated in the program for all or part of the period of the pilot rate.

These participants signed participation agreements and, except for customers who moved or asked to be taken off the rate, were enrolled in the PowerChoice Pilot Program until it ended on May 31, 2009. The 2008 TOU rate is shown in Figure 1-1. The 2008 prices represent slight increases from the 2007 TOU rates. Both the 2007 and 2008 TOU rates specified three different seasons, three different prices per weekday (five periods per calendar day) in each season, and two different prices for weekend days and holidays (three periods per calendar day). The ratio of Off-Peak to Super-Peak prices is moderate in the Summer season and fairly small in the Winter season, and the Winter Super-Peak price is less than half the level of the Summer SuperPeak price.

The tariff included a consumption bonus or charge, called a consumption adjustment, based on whether the household's monthly consumption was less than or greater than 1,000 kWh. This structure was designed to encourage lower electricity consumption, via the consumption adjustment, as well as to shift electricity use from Super-Peak to lower-cost periods in the Summer and, to a lesser extent, in Swing and Winter seasons. The level of the bonus or charge depended on how much total consumption was below or above the 1,000 kWh cutoff point, with credits of up to $20 \%$ of the calculated bill and surcharges of up to $50 \%$ of the total calculated bill. The credit or surcharge thus applied to all consumption, rather than to just that under or over the threshold. Table 1-1 shows the consumption adjustment, applied by monthly electricity consumption level.

2. In 2003, SMUD offered a pilot TOU program that included the installation of smart (programmable by time period) thermostats. This program was also called PowerChoice.

3. In 2006, approximately $77 \%$ of SMUD residential customers were on various rates, while the remaining $23 \%$ were on rates constructed for homes heated with electricity (SMUD 2007). A review of SMUD rate codes assigned to active PowerChoice participants in January 2008 revealed that $86 \%$ were on a general PowerChoice TOU rate, with 10\% of these homes further identified as qualifying for the SMUD Energy Assistance Program (http://www.smud.org/en/pay/Pages/eapr.aspx). The remaining 14\% of households on the PowerChoice rate were identified as all-electric homes, with less than a quarter of these qualifying for the Energy Assistance Program. 


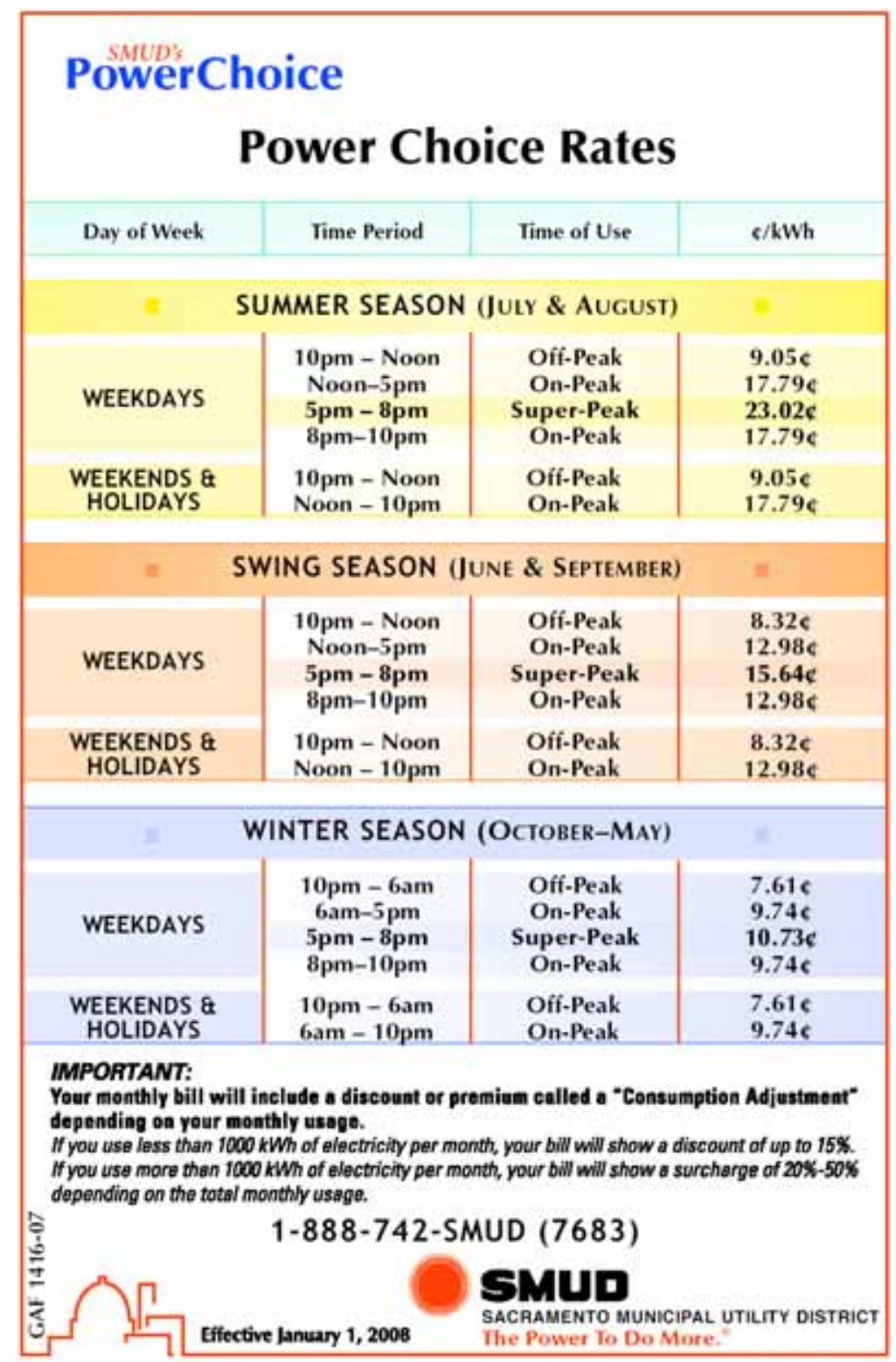

Figure 1-1. PowerChoice rate structure

Table 1-1. Consumption Adjustment component of the PowerChoice tariff

\begin{tabular}{|l|c|}
\hline Monthly Consumption (kWh/month) & Consumption Adjustment \\
\hline$<700$ & $15 \%$ discount \\
\hline $700-1000$ & $5 \%$ discount \\
\hline $1000-1500$ & $20 \%$ premium \\
\hline $1500-2000$ & $35 \%$ premium \\
\hline $2000-3000$ & $40 \%$ premium \\
\hline$>3000$ & $50 \%$ premium \\
\hline
\end{tabular}


By April 2007, SMUD had installed Centron ${ }^{\circledR}$ SmartSynch interval meters-capable of measuring electric energy consumption during TOU periods that vary by time of year, as well as time of day-in approximately 220 of these homes. Of those, 130 had transitioned onto the PowerChoice rate by June 2007. The customers with meters installed as of June 2007 are termed the early-on group, for whom load interval data were available for two summers. The remaining customers, the late-on group, had meters installed starting in November 2007 and transitioned to the TOU rate in winter $2007 / 2008$.

\subsection{Approach}

The primary focus of this project was the behavioral response that drives the aggregate load numbers that are the usual focus of TOU and DR studies. The research approach uses the concerns, capacity, and conditions (3-Cs) framework (Lutzenhiser et al. 2002) as the basis for understanding behavior, while also looking at how well customers deliver demand reduction to the system based on an examination of load interval data. The project uses an experimental design constructed to explore residential customer response in $\mathrm{kWh}$ to three interventionsprice, and on top of price, information, and whole house electricity consumption feedback-seeking to answer three fundamental research questions:

- What is the estimated impact of the TOU rate on electricity use?

- Do additional technical information and community-oriented messages improve the observed capacity of households to change their consumption patterns?

- Does a real-time kW (and total kWh) monitor of consumption levels improve customers' capacity to change their consumption behavior? (For background information see Appendix C, pp. APC-7-8)

The load data were collected at 15-minute intervals from participants in SMUD's residential TOU program and, for comparison, from residential customers included in SMUD's Load Research Sample for which load data were already being collected. The Load Research Sample contains data for approximately 108 premises selected to be representative of SMUD residential customers overall. ${ }^{4}$ For all load analyses, load data were aggregated, on a daily basis, by the Time-of-Use bins defined in the tariff. Load data for PowerChoice customers were obtained for May 2007 through December 2008. For the Load Research Sample, load data were obtained for the same period.

Survey data on household behaviors and demographics were also collected for PowerChoice households, via three successive surveys fielded over thirteen months. These surveys, developed by the research team, asked PowerChoice households about their concerns, capacities, and conditions for providing demand reductions, as well as about their response to the interventions and the PowerChoice TOU rate overall.

4. Depending on the analysis, various subsets of the Load Research Sample were used in our analyses. In particular, data for 72 single-family homes in the Load Research Sample were used for most of the priceeffect and information-effect analyses presented in this report. 


\subsection{Information Treatments}

Two information treatments were applied experimentally.

\subsubsection{Enhanced Information Treatment}

All households received some information about managing their electricity use on the PowerChoice tariff as a standard part of the program, explained below. An Enhanced Information Treatment was designed to test the effect of providing additional information. This intervention was informed by a Community Based Social Marketing (CBSM) strategy, as outlined in McKenzie-Mohr and Smith (1999). It was applied to a randomly selected subset of PowerChoice participants via a series of periodic mailings addressed from the SMUD program manager. These consisted of five letters giving PowerChoice participants tips for managing their electricity under the TOU rate and encouraging participants to share their experiences via a postage-paid card. Participant responses about their experiences were analyzed by the research team and reported in a subsequent newsletter. Also included in the treatment was a refrigerator magnet that provided the detailed rate schedule for the 2008 PowerChoice tariff for easy reference. ${ }^{5}$ Appendix B reproduces the letter sent to participants in the Enhanced Information Treatment group. Figure 1.1 is an image of the magnet distributed to these participants.

\subsubsection{Monitor Treatment}

The second treatment was a feedback intervention using Blue Line Innovation's PowerCost Monitor $^{\mathrm{TM}}$ (Appendix C, p. APC-3) to help consumers understand details of electricity use in their homes, including differences in the costs of using electricity services by time of use. The PowerCost monitor is a wireless energy monitor that provides information on nearinstantaneous, as well as cumulative, electricity usage and costs. Just before the second summer, PowerCost monitors were distributed to 50 households who accepted the project's offer to provide a free monitor. ${ }^{6}$ These households were each provided with a guidebook prepared by the research team that provided detailed information on setting up the monitor along with training experiments to familiarize participants with monitor capabilities (Appendix C, pp. APC-4-6). Further details of the Monitor Treatment and the distribution of the monitors are provided in Chapter 5.

\subsubsection{Standard Information}

In addition to the two formal information treatments applied as part of this experiment, there were other channels of information on PowerChoice affecting participating households. All households had signed an agreement to participate in the project. They received, from SMUD, an introductory pamphlet explaining the program and supplying tips for managing household

5. Participants in an Ontario, Canada, residential TOU program found that a refrigerator magnet was the single most helpful reference for managing their energy use under the TOU rate (Ontario Energy Board 2007).

6. The research team surmised in advance that randomly assigning households to receive the monitorsideal as a statistical treatment-would work poorly, because customers must have some interest in the monitors, including the will to install them, for them to have a real effect. In fact, exactly 50 of 191 (26\%) of the early-on participant households that were offered a monitor volunteered to accept one. 
electricity usage on the PowerChoice TOU rate. Each household also received regular program mailings. These included postcard reminders of rate changes sent at tariff seasonal transition, as well as occasional other communications on administrative matters. Also, most households were surveyed at least once. The surveys themselves served as a source of information to surveyed participants, conveying both technical elements (in that questions about whether households undertook a certain activity or not implicitly invite this activity), as well as reinforcing the framing of the PowerChoice pilot as forming a community or group. Surveying possibly created some social pressure or reflected expected social norms. This routine information forms the baseline information specific to the PowerChoice TOU rate, relative to which the effects of the applied information interventions were tested.

\subsection{Milestones}

From a SMUD perspective, the PowerChoice pilot offered both the opportunity to test a unique TOU rate and to test several advanced meter infrastructure (AMI or Smart Meter) options meters capable of measuring electrical energy consumption during TOU periods that vary by time of year. The following milestones serve to describe the flow of meter installs, household transitions onto the TOU rate, program dropouts, interventions, data collection and analysis, and reporting:

- April 2007: 220 households had new Centron ${ }^{\circledR}$ SmartSynch interval meters installed, of which 130 had transitioned onto TOU rate by June 2007.

- May-June 2007: study population selected, along with basic data collection.

- July 2007: SMUD verifies 211 actively on the TOU rate after counting for move-outs and withdrawals (Wave 1 sample, 123 respond).

- August 2007: SMUD verified 240 were now on the TOU rate; basis for random assignment to Enhanced Information Treatment group (125 participants assigned).

- September 2007: Wave 1 survey completed.

- October 2007: Treatment groups selected and information treatment begun.

- November-December 2007: SMUD installed new Centron ${ }^{\circledR}$ Sentinel interval meters with the late-on group of 110; these household began transition onto the rate.

- January 2008: Wave 2 survey completed; information treatment continues for the selected population.

- May 2008: Blue Line PowerCost Monitors ${ }^{\mathrm{TM}}$ distributed to a subset of 50 participants, along with additional installation and training materials.

- June 2008: SMUD verified that 237 households were currently on the TOU rate; according to SMUD records, 44 participants had dropped, whether because they moved or because they opted out of the program; the research team called each Blue Line PowerCost Monitors ${ }^{\mathrm{TM}}$ household to verify and encourage installation, and to troubleshoot problems by referral to Blue Line Innovations.

- August-September 2008: surveys attempted on 235 active participants in survey Wave 3 (162 early-on and 63 late-on; 170 responded). 
- December 2008-June 2009: analysis of interval meter data by treatment group, in conjunction with survey data; analysis of combined survey data; integrated analysis and interpretation, and preparation of final report.

The rest of this chapter discusses the remaining key aspects of these steps and the real-world conditions in which they were performed.

\subsection{Survey Design and Administration}

Surveys were designed by the research team and were administered in three waves throughout the study period, as summarized in Table 1-2.

Table 1-2. Summary of the PowerChoice TOU participant surveys completed

\begin{tabular}{|l|c|l|c|c|}
\hline Survey & Dates & \multicolumn{1}{|c|}{ Main Purpose of Survey } & $\begin{array}{c}\text { Number of } \\
\text { Responses }\end{array}$ & $\begin{array}{c}\text { Percent of } \\
\text { TOU } \\
\text { Households }\end{array}$ \\
\hline Wave 1 & $\begin{array}{c}\text { August- } \\
\text { September } \\
2007\end{array}$ & $\begin{array}{l}\text { Collect demographic data, information } \\
\text { on household equipment, rationale for } \\
\text { joining PowerChoice, and baseline } \\
\text { data on participant actions. Surveys } \\
\text { attempted for all households on the } \\
\text { rate at that time. }\end{array}$ & 123 & $58 \%$ \\
\hline Wave 2 & $\begin{array}{c}\text { December } \\
2007\end{array}$ & $\begin{array}{l}\text { Collect first reactions to information } \\
\text { treatment, winter actions, and } \\
\text { additional questions on first summer. } \\
\text { Surveys attempted only for } \\
\text { households already surveyed in } \\
\text { Wave 1. }\end{array}$ & 91 & $47 \%$ \\
\hline Wave 3 & September & $\begin{array}{l}\text { Collect post-treatment actions from all } \\
\text { participants, details on monitor use } \\
\text { for monitor group, and final } \\
\text { respondent comments on program. } \\
\text { Also collected demographic and } \\
\text { equipment data for households not } \\
\text { surveyed in Wave 1. Surveys } \\
\text { attempted for all households that } \\
\text { were currently on the rate. }\end{array}$ & 170 & \\
\hline
\end{tabular}

* The number of households on the rate varied throughout the study period.

The Wave 1 survey collected demographic data, baseline behavioral data, information on participant motivation for signing on to the PowerChoice pilot, and early reactions to the program at the end of the first summer on the tariff. The Wave 2 survey was conducted during the 2007/2008 winter rate season and covered only those households who had responded to the 
Wave 1 survey. ${ }^{7}$ The Wave 3 survey, conducted at the end of the second summer that most participants had been on the PowerChoice TOU tariff (September 2008), was designed to capture the practices of Summer 2008, to allow a comparison among the various treatment groups, and to get participants "final" assessment of their experience on the tariff. This last survey was attempted for all customers who were then on the PowerChoice rate.

To achieve the most complete survey results possible, multiple attempts were made to survey most households in each survey round-up to 16 tries in the Wave 3 survey. This practice-in addition to a five-dollar bill inserted with the Wave 3 survey notification letters-resulted in a capture rate of $72 \%$ in the Wave 3 survey. ${ }^{8}$ Toward collecting richer information on household actions and attitudes, each survey included many open-ended questions, allowing respondents to respond freely to questions in their own words, in addition to fixed-choice questions. These open-ended questions provided a useful counterpoint to the traditional closed-choice method, revealing the issues most salient to participants (Geer 1991) and helping to distinguish between passive and active agreement.

Some participants who signed up for the rate eventually dropped off, whether because they moved or because they opted out for some other reason. About 16\% dropped off the rate between May 2007 and December 2008. Customers who dropped out were no longer surveyed. ${ }^{9}$

\subsection{Real World Challenges for the Analysis}

Natural or quasi-experiments present difficulties beyond those found in a laboratory setting. From a statistical standpoint, extraneous sources of variation and change cannot be perfectly controlled. ${ }^{10}$ Because treatment effects may be small relative to the natural variability of electricity use, large samples may be required to isolate a treatment effect from other sources of change and variation. There may also be effects of the experiment itself-such as from surveying, or from the participant's knowledge that it is an experiment-that affect the transferability of findings from an experiment to a non-experimental situation. The only major difficulties experienced in the experimental component were a sample size that was smaller and data duration that was shorter than had been anticipated, but the following circumstances bear consideration in interpreting the results of the research project and in designing future studies:

- Meter Installation and Performance. The meters originally selected exhibited performance problems and many had to be replaced with a different meter. This resulted in some gaps and errors in data. The discovery of these problems delayed the

7. Ten percent of the Wave 1 survey respondents did not agree to be interviewed in Wave 2, and they were not contacted.

8. The cash insertion is a method for increasing response rate described by Dillman (2000).

9. Thus, the Wave 3 results may be slightly more positive than had the households who opted out of the rate been included.

10. That is, though realism is the point of real-world experiments, the variability and possible biases they inject cannot completely be disentangled from the test treatments. The use of the control group, as we have done here, helps, but cannot completely overcome this. 
installation of subsequent meters, while alternative meters were explored, and therefore shortened the length of experience for some participants on the program.

- Limited Before-Rate Data for Many Participants. Because of meter installation difficulties, for a number of households, the period for which pre-rate interval meter data were available is short, making it difficult to distinguish post-rate changes from load before PowerChoice. This is one of the most important limitations for interpreting the project results.

- Demographics and Self-Selection. A project testing the effects of a mandatory TOU rate would assign households to the rate and make it difficult for them to refuse the assignment. This was not possible for SMUD's TOU tariff, and since the fundamental questions were not framed around mandatory TOU rates, it would not necessarily have been desirable to do so. ${ }^{11}$ Acceptance of the TOU rate was voluntary by nature.

PowerChoice pilot rate participant households were almost entirely living in singlefamily, owner-occupied houses. The adults in these participating households were, on the whole, older than other adults in the SMUD area, with slightly smaller household sizes and higher educational levels. Higher educational levels were expected, but the elevated age was not. The demographic differences do not per se suggest a nonrepresentative sample relative to who would accept a Time-of-Use rate in a fully ramped-up, voluntary Time-of-Use program. However the special characteristics of the volunteer sample highlight questions about self-selection onto voluntary TOU rates and experiments about them. Details and some of the possible consequences of the demographic differences are discussed in Chapter 2.

- Rate Change. SMUD residential rates increased on January 1, 2008. The overall rate increase was about $7 \%$. For the PowerChoice TOU rate, the percentage increase varied by time period and season, ranging from a 3\% (for Summer Super-Peak) to an 11\% (for Winter Off-Peak) increase relative to the 2007 rates. $^{12}$

- Information Treatments. SMUD has carefully crafted relationships with its customers, including households participating in the PowerChoice TOU program. SMUD had the final say in what information went out to customers and in what form. This arrangement contrasts with a more controlled experiment, where a CBSM-oriented information campaign could be developed independently of normal utility channels. Also, all information treatment communications were branded as from SMUD.

- Weather and Air Quality Events. In 2007, the weather in SMUD territory was milder than the previous several years, with relatively few very hot days. In 2007, there were 5 Spare the Air days declared, the fewest in seven years-with 15 declared in 2006 and 16 in $2005 .{ }^{13}$ In 2008, wildfires severely deteriorated the air quality in many parts of the

11. At least one recent experiment in residential TOU rates, conducted by BC Hydro (Tiedemann 2007), started with a group of volunteer households, but used random assignment of these volunteering customers to develop control versus treated TOU tariff groups.

12. Under the new rates, the proportional advantage of using Off-Peak, as compared to Super-Peak, was slightly reduced relative to the 2007 tariff; the ratio of the Summer Super-Peak price to Off-Peak was 2.5 in the 2008 rates, as compared to 2.7 in the 2007 rates.

13. From http://www.sparetheair.com/sparetheairdays.cfm (accessed December 14, 2007). 
Sacramento region during a week in late June and another in early July. Local media advised residents in affected areas to stay inside and run the air conditioning. ${ }^{14}$ None of this is very exceptional, as there is no "normal" year. The statistical methods used net out weather through comparison, but as air conditioning is a targeted end-use for shifting load off-peak, weather conditions have a bearing on understanding and extrapolating the air conditioning-related behaviors that PowerChoice TOU rate participants reported.

- Tariff Design. In economic theory, the behavioral changes that TOU tariff participants would undertake in response to the tariff would depend on comparative prices they experienced under that rate. The results of TOU rates in one jurisdiction do not necessarily apply to those in another jurisdiction, nor to the same jurisdiction under different tariff characteristics. Compared to other residential TOU tariffs that have been offered, the PowerChoice TOU tariff had relatively low ratios of peak to off-peak prices, ranging from 1.4 for winter to 2.5 for summer. ${ }^{15}$ Also, as it turned out, it was difficult for participating households to save money in comparison to the household's previous rate, especially during summer. Participation bonuses aside, however, residential TOU tariffs in the past have often offered only modest savings on average, and can result in substantial premiums for some customers, compared to the standard rate (e.g., Alexander 2007; Mountain \& Lawson 1992; Ontario Energy Board 2007). It is not clear how important the size of potential savings are to customer behavior.

- Tariff Duration. The results of a TOU rate in the short-term, over a year or two, do not necessarily reflect results over a longer term. Some researchers have suggested that temporary TOU rates have substantively different results than permanent TOU rates (Tiedemann 2007), and results for a tariff running for a year or two may be different than long-run results.

\subsubsection{TOU Rates in General}

The idea of TOU rates in the United States is nearly as old as the electricity industry. Recognizing that flat pricing throughout the day was inefficient for the power industry, early debates on electricity pricing deliberated on both demand charges and time-of-day rates (Hausman \& Neufeld 1984). Demand charges for large customers became firmly established by 1912 , but pricing by time of day did not, and by 1920, virtually no TOU rates were offered (Hausman \& Neufeld 1984). Around the time of the energy crises of the 1970s, a number of utilities offered rates on an experimental basis in the residential sector (Sexton et al. 1989), with many published studies resulting (e.g., Aigner 1985). The Public Utilities Regulatory Policies Act of 1978 also set requirements for considering Time-of-Use (at that time, more commonly called time-of-day) rates, for which the Energy Policy Act of 2005 specified additional standards

14. Survey 3 asked respondents whether they had changed their air conditioning practices during that time; a third said that they had.

15. This refers to the ratio of Super-Peak to Off-Peak period rates using the PowerChoice rate terminology. Tiedemann (2007) provides a summary of residential TOU rates for 24 utilities. The median ratio of Peak to Off-Peak prices among the utilities summarized was 3.6. Sexton et al. (1989) tested rates with considerably higher ratios of Peak to Off-Peak prices (ratios of 3, 5, 7, and 9). On the other hand, SMUD's Off-Peak (and Peak) prices were higher than the medians of 3.6 and 16.07 U.S. cents/kWh, respectively, among the utilities reviewed in Tiedemann (2007). 
(Hill et al. 1983; Faruqui \& Earle 2006; U.S. DOE 2006). Alexander (2007) discusses some implications of these requirements for investor-owned utilities (IOUs), publicly owned utilities (such as SMUD), and cooperatives.

Some utilities outside the United States have mandatory TOU rates, but most, if not all, residential TOU rates in the United States are voluntary. Citing an Electric Power Research Institute (EPRI) study, King (2001) notes that over half of 123 U.S. IOUs offer TOU rates to their customers, but less than $1 \%$ of the customers of these IOUs subscribe to these TOU rates. ${ }^{16}$ Though residential TOU rates are sound from certain conceptual standpoints (Energy \& Environmental Economics, Inc. 2006), so far, few consumers adopt the rates when offered.

Meanwhile, millions of residential customers in California are scheduled to receive advanced electricity meters in the coming years (California Energy Commission and California Public Utilities Commission 2008), as are residential customers in a number of other jurisdictions (Alexander 2007). The expectation is that with advanced meters in place, time-varying rates may become mandatory for many customers. Alexander (2007) notes that for TOU and RealTime-Pricing (RTP) offered as residential rate options, "very little research has been done on the widespread costs, bill impacts, usage patterns, and system benefits of these programs," despite their wide discussion in many states.

This sets a broader context for the current project. TOU rates are available to many residential customers but, so far, unpopular. Why they are unpopular is a matter of speculation.

Presumably, most potential customers are not aware of them; and even if they were, the complications they present and the imperative to actively manage household electricity use may be unattractive to many customers. TOU rates are also riskier for the consumer than most standard tariffs because rates during peak periods are often considerably higher than on the standard tariff. To the extent that TOU rates are designed to be revenue-neutral for the utility, some households will save money on TOU rates, while others will lose money. Presuming the TOU rates encourage at least some peak-flattening and energy conservation, these changes likely come at the cost of a net increase in households' aggregate efforts to manage electricity use. ${ }^{17}$ In other words, while some shifting and conservation may come naturally, there may be non-monetary, as well as monetary, costs for participants in providing this response.

Thus the current project has sought to contribute to a better understanding of: who joins TOU rates and why; what they do and what they do not, cannot, or will not do, to change energy use; and what effects these efforts have on total load-albeit with a voluntary set of program participants. Older work studying residential TOU rates is largely dedicated to detecting aggregate effects and measuring price elasticity. Only recently has there been attention to the behavior behind these load effects (Wood et al. 2004). This report makes comparisons to two Canadian residential TOU projects that have paid special attention to behavior: BC Hydro's

16. Another recent survey of TOU and DR rates, covering the past and current offerings of 65 U.S. and international utilities, found that 50 of these utilities (41 out of 50 in the U.S.) offered residential TOU rates (Energy \& Environmental Economics, Inc. 2006).

17. Alternatively, pricing policies could conceivably result in a reduction of energy-relevant efforts in homes, in particular, if they led to different and lower-energy standards of conduct (e.g., less washing). 
Power Smart Conservation Research Initiative (Pederson 2007; Tiedemann 2007) and the Ontario Energy Board Smart Price Pilot (Ontario Energy Board 2007). The overall intent is to help turn the focus to the customer side of residential TOU programs, while at the same time enriching the understanding of the behavioral and social mechanics that create and limit the demand response that these programs deliver. 


\subsection{Demographic Characteristics of PowerChoice Participants}

PowerChoice TOU rate customers were volunteers who agreed to join the program after being invited from among a set of SMUD customers. This chapter summarizes the demographic and dwelling characteristics of these program participants compared to other households in SMUD territory, and reports on how participants were recruited onto the program. Demographic patterns observed for the PowerChoice group were compared to those for two other recent residential TOU rate pilots, one in Ontario and one in British Columbia (Ontario Energy Board 2007; Pederson 2007). The remainder of this chapter gives details on recruitment and demographic characteristics. (Appendix D presents a more detailed demographic comparison.)

\subsection{Summary of Demographic Comparisons}

The following are key demographics of participants:

- PowerChoice participant households were more likely to live in owner-occupied, single-family homes $(89 \%)$, as compared to other SMUD residential customer households (61\%). Participant households, on average, accordingly had somewhat higher electricity consumption than the SMUD average for all dwelling types. Almost all surveyed participants (95\%) said that they had a central air conditioner and a quarter of surveyed participants reported having a pool. Saturation of electric dryers and dishwashers was also high (see Appendix D, p. APC-13). Dwelling age and household size of PowerChoice participants matched those for other single-family homes in the SMUD service territory. The sex of survey respondents was evenly matched between males and females.

- Survey respondents tended to be substantially older than the typical head of household in single-family homes in Sacramento County. The median age of surveyed participants was 60, as compared to the median age of 51 for heads of household in Sacramento County. Participant households were more likely to have someone aged 65 or older in the home ( $44 \%$ vs. $26 \%$ ), less likely to include more than two members $(32 \%$ vs. $46 \%$ ), and less likely to include children. Analysis of project survey data confirms intuition: participant households with older members were more likely to have someone home during the day, which may affect their capacity to reduce On-Peak and SuperPeak electricity usage. This upward shift in age was the most striking difference in PowerChoice participants relative to the overall SMUD customer population. Whether the older ages of surveyed PowerChoice participants is an artifact of the recruitment strategy or a reflection of more basic differing levels of interest in TOU rates among demographic segments is unknown.

- Survey respondents, on the whole, were more educated than are other adults in SMUD territory, a pattern that is similar to what has been seen in two recent Canadian residential TOU pilots (Ontario Energy Board 2007; Pederson 2007).

- Participant households were slightly more likely to report having incomes over $\$ 100 \mathrm{~K}$ than others in Sacramento, but the differences in income distribution between PowerChoice participants and Sacramento County owner-occupied households were modest. In contrast, participant groups in both the Canadian residential TOU pilots-at 
Ontario Electricity Board and BC Hydro-had more markedly higher incomes than the corresponding customer populations (Pederson 2007; Ontario Electric Board 2007). ${ }^{18}$

Because voluntary participation is a response to the recruitment approach and to interest in the tariff, there is no reason that demographic characteristics of PowerChoice participants should match those of other SMUD residential customers. ${ }^{19}$ Statistically, the project represents volunteers to the PowerChoice rate, not what would happen if the TOU rate were mandatory or the default. ${ }^{20}$

\subsection{Recruitment}

To recruit participants for the PowerChoice TOU rate, SMUD randomly selected 30,000 residential customers equally from each of six annual consumption tiers defined by the utility. Recruitment letters were sent to the first 4,000 (in random order) describing the program and offering a \$25 Home Depot gift card for participation. In addition, follow-up recruitment phone calls were made to these customers in random order, prefaced by a brief survey on demographic characteristics.

This initial process did not yield enough volunteers, ${ }^{21}$ so the same recruitment letter was sent to the remaining 26,000 customers. In the end, about $1.1 \%$ of contacted households signed up for PowerChoice-comparable to the less than $1 \%$ of residential customers participating in TOU tariffs in the U.S. IOUs that offer them (King 2001). But this $1.1 \%$ acceptance of the PowerChoice rate is after active recruitment. The low acceptance rate gives pause in thinking about how interested consumers are or can be in TOU rates.

Not all studies report their participant recruitment procedures and acceptance rates, but some do. ${ }^{22}$ A variety of explanations might apply for the low acceptance rate seen for the PowerChoice tariff: the complexity of the rate compared to the standard tiered rate; the

18. In the case of the Ontario Electric Board's Smart Price pilot, just 34\% of participating households had annual household incomes of less than $\$ 75,000$ in Canadian dollars (Ontario Electric Board 2007, Appendix G). In the BC Hydro case, $45 \%$ of participants had a total annual household income greater than $\$ 80,000$ in Canadian dollars, as compared to $34 \%$ among the customer base (Pederson 2007).

19. Nor, even if demographic characteristics of PowerChoice participants matched those of SMUD residential customers overall, would this be evidence that the greater population would behave similarly to the recruited PowerChoice participants if faced with the same TOU rate.

20. There is nothing "wrong" with this situation. Economic studies of residential TOU rates sometimes use procedures to adjust for self-selection bias in order to better represent DR for the entire customer population; this was not called for in this case.

21. Since savings from TOU rates tend to be small, such rewards can represent a substantial portion of the financial benefit to participants, especially in programs such as this one, which run for a few years or less.

22. A 1970s TOU pilot study for Los Angeles Department of Water and Power, for example, reported that $92 \%$ of several thousand residential customers solicited for a Time-of-Use rate experiment accepted the rate (Mitchell and Acton 1980). An experimental residential TOU rate by Ontario Hydro in the 1980s similarly found only a $9 \%$ opt-out rate for residential customers who were assigned to the TOU rate (Mountain \& Lawson 1992). Some pilot rates offer guaranteed minimum savings to participants, making up any shortfall in customer utility bills from the rate itself by lump-sum payments at the end of the experiment (e.g., Ontario Electric Board 2007). Experiments that appear risk-free in terms of expenses may attract quite a different set of customers than experiments in which the customer takes on the risk. 
uncertainty of benefit over the standard tiered rate; the two-year commitment (albeit with the possibility of opting out with a 30-day notice); households having too many other

responsibilities; or a basic lack of interest in the potential savings, or in managing electricity use by time of day. Redoubling the self-selection issue noted earlier, the low acceptance rate makes it tenuous to extrapolate, based on the experience of these voluntary participants, as to what would be expected if TOU rates were mandatory or offered as part of a comprehensive rate restructuring and marketing/education campaign. 


\subsection{Demand Analysis}

This chapter provides background on load data collected and presents the results of the load data analysis, including the modeling procedures used to examine the effects of tariff prices and of the two types of information interventions. For the tariff analysis, the control group is SMUD's Load Research Sample. The following questions were examined:

1. How did load shapes for PowerChoice participants differ from those not in PowerChoice?

2. How did changes in electricity price affect electricity consumption?

3. How did the two experimental intervention treatments-Enhanced Information and Feedback Monitor-affect load?

4. What relationships can be detected between survey responses and load data?

Ideally, there are two basic dimensions of this demand analysis. First is the baseline load shape, as it would be in the absence of the tariff or-for question 3, above-the interventions. Second, are changes in the load shape relative to the corresponding baseline? Examining this latter dimension for questions about price effects (especially question 2, above) is limited by data availability. For most PowerChoice participants, detailed load data were available only for a few weeks before the household joined the tariff. Prior to that, only billing data were available, which cannot be used for load-shape comparisons.

\subsection{Data}

The Load Research Group used in this study consists of 108 households on non-TOU residential tariffs, drawn from the SMUD territory. ${ }^{23}$ These households were equipped with interval meters capable of recording the load every 15 minutes-similar to the meters used by the 220 PowerChoice households for which consumption data were collected. In total, the load data stream contains over 10 million data points. Hour-by-hour or even higher resolution analyses are possible, but these tend to be no more illuminating than results obtained by aggregating use over well-defined timeframes. For the questions addressed here, the most useful timeframes are defined by the tariff itself, as defined in Table 3-1 for the Summer and Swing seasons, except that the long Off-Peak period was divided into Early (7 a.m. to Noon) and Late segments (10 p.m. to 7 a.m.) for a more refined system of testing. ${ }^{24}$ Tariff seasons are defined in Table 3-2; Table 1-1 gives the rate information for each period.

23. Analyses reported in this chapter used data only from single-family households (72 households).

24. That is, since load reductions are unlikely for the middle of the night, separating these hours from the standard morning waking hours (7 a.m. to Noon) makes it easier to detect the sorts of shifting expected. 
Table 3-1. Time-of-Use periods used for the Summer and Swing rate season loaddata analysis

\begin{tabular}{|l|c|}
\hline Tariff Period & Hours \\
\hline Weekday Off-Peak Early & 7:00 a.m. to Noon \\
\hline Weekday Off-Peak Late & $10: 00$ p.m. to 7:00 a.m. \\
\hline Weekday On-Peak Early & Noon to 5:00 p.m. \\
\hline Weekday On-Peak Late & $8: 00$ p.m. to 10:00 p.m. \\
\hline Weekday Super Peak & 5:00 p.m. to 8:00 p.m. \\
\hline Weekend Off-Peak Early & $7: 00$ a.m. to Noon \\
\hline Weekend On-Peak & Noon to 10:00 p.m. \\
\hline Weekend Off-Peak Late & $10: 00$ p.m. to 7:00 a.m. \\
\hline
\end{tabular}

Table 3-2. PowerChoice tariff seasons

\begin{tabular}{|l|c|}
\hline Months & Tariff Season \\
\hline June & Swing (early summer) \\
\hline July and August & Summer \\
\hline September & Swing (late summer/fall) \\
\hline October through May & Winter \\
\hline
\end{tabular}

\subsection{Basic Load Analysis For PowerChoice Customers}

This section addresses how load shape and electricity consumption for PowerChoice participants differ from households not in PowerChoice, as represented by SMUD's Load Research Sample comparison group.

\subsubsection{Load Shapes}

Summer and Swing season average load shapes across PowerChoice participants are strikingly different than for the comparison group. The differences are consistent with what would be expected from the TOU rate structure relative to that of the standard rate: lowered afternoon peak and higher mid-morning load shares, especially during the Summer tariff season. Because of the limited before data, however, it cannot be determined whether or how much these differences are due to pre-existing differences in load shapes between the two groups and how much they are due to the changes made in response to the PowerChoice rate schedule after joining.

\section{Details}

For each day of the PowerChoice rate, the research team computed an average load shape (normalized to consumption) across PowerChoice participants and, for comparison, across the Load Research Sample. To reduce extraneous variability, only single-family households were compared, which covers almost all PowerChoice households. The distributions of the normalized hourly loads between PowerChoice participants and the Load Research Sample (hereafter, control group) were graphically compared for each season and day type. ${ }^{25}$ Figure 3-1

25. This analysis combined 2007 and 2008 data. 
through Figure 3-4 show these distributions for the Summer tariff season weekend and weekday and the Winter tariff season weekend and weekday.

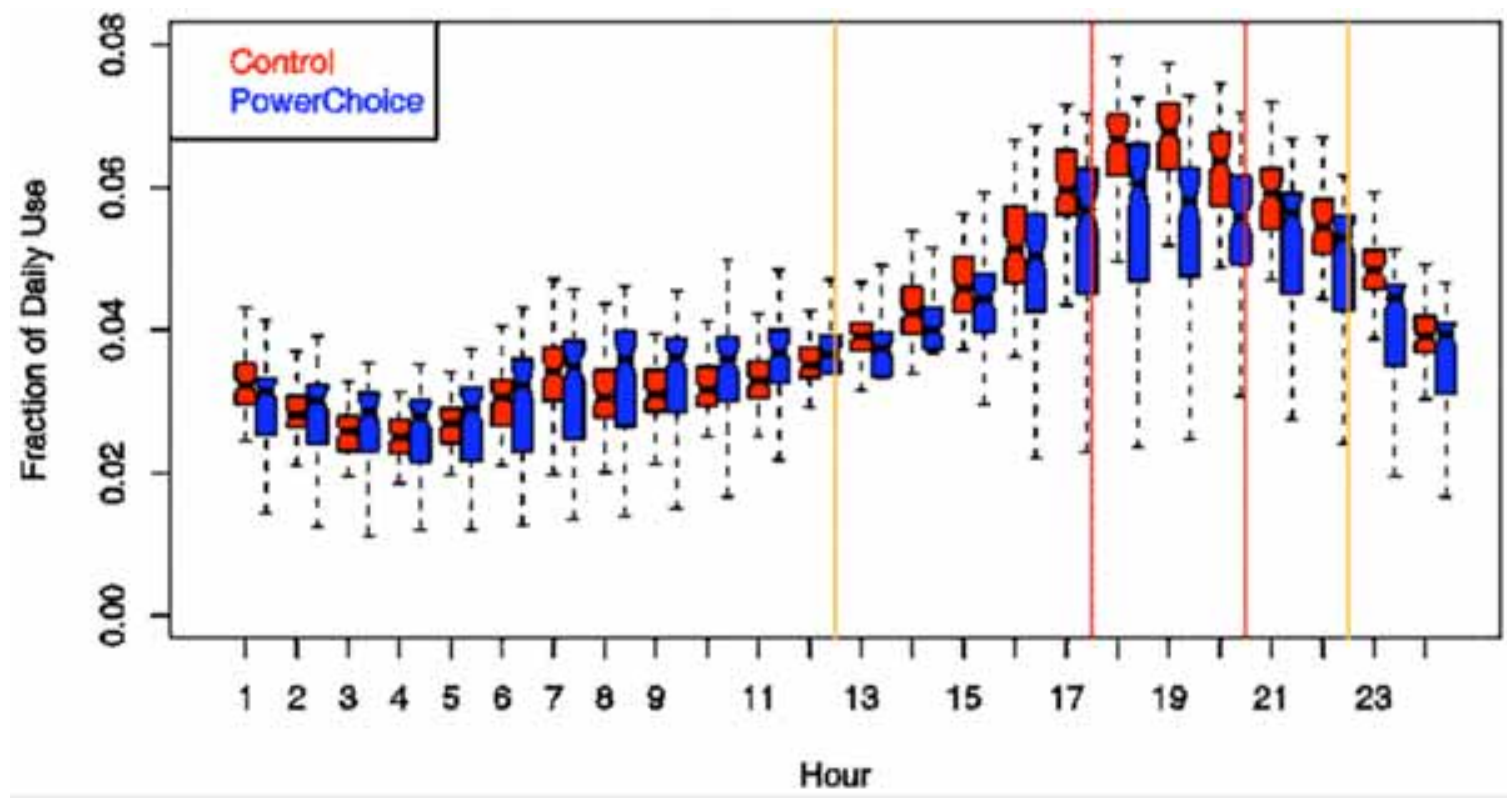

Figure 3-1. Summer Weekday Normalized load shapes for Control Group compared to PowerChoice customers

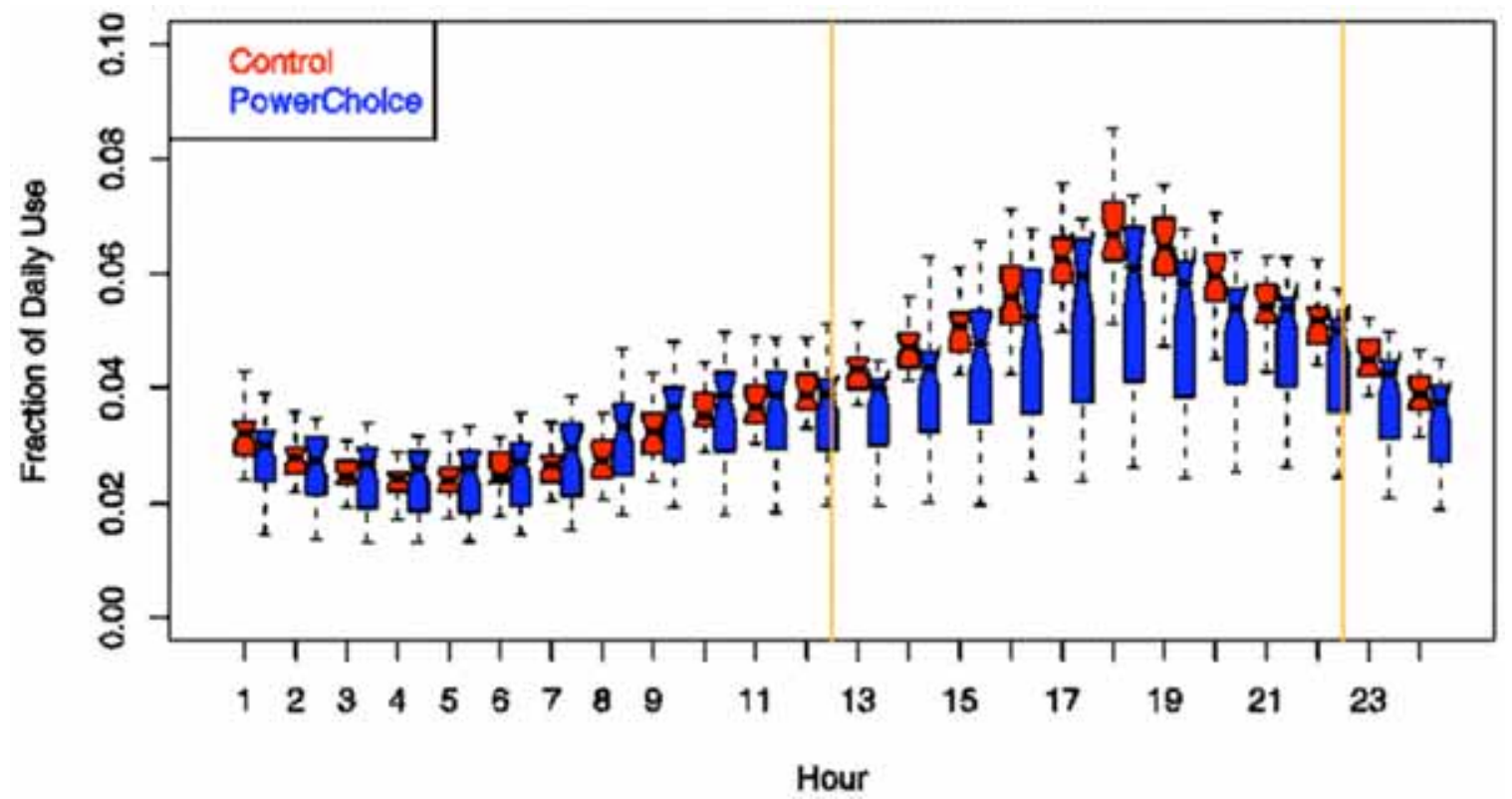

Figure 3-2. Summer Weekend Normalized load shapes for Control Group compared to PowerChoice customers 


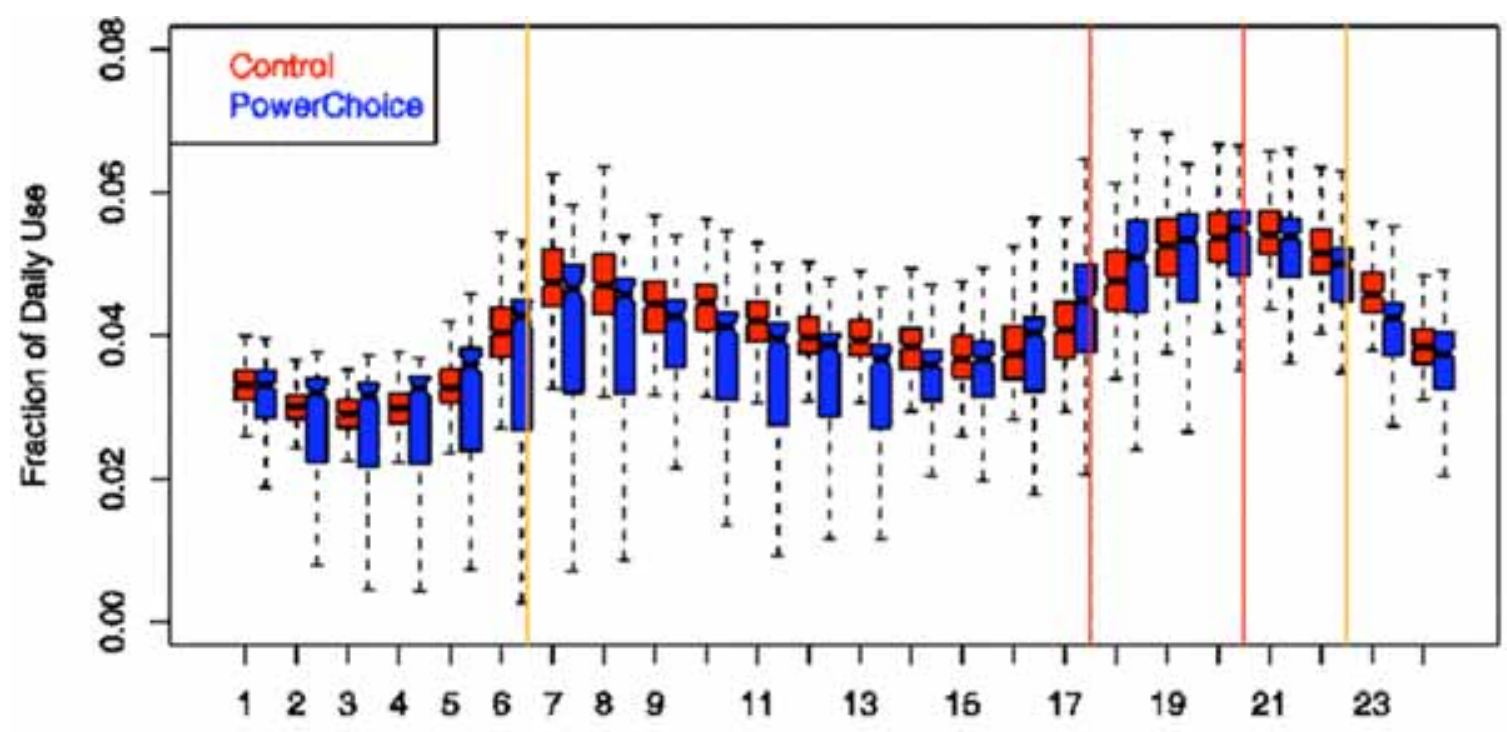

Hour

Figure 3-3. Winter Weekday Normalized load shapes for Control Group compared to PowerChoice customers

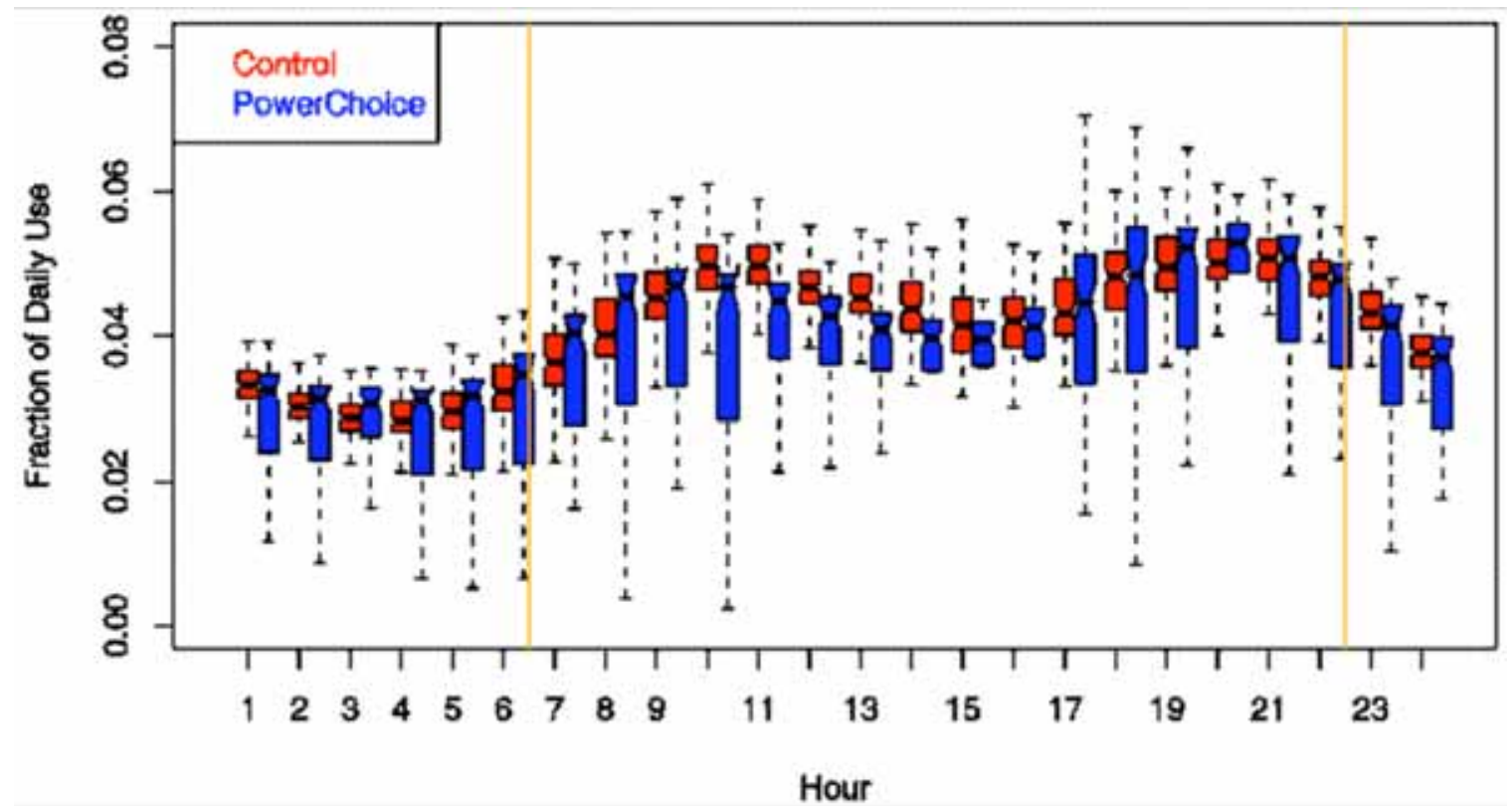

Figure 3-4. Winter Weekend Normalized load shapes for Control Group compared to PowerChoice customers

The median percentage load for each hour is marked by a line at the "waist" of the corresponding box or hourglass. The lower and upper ends of each box represent the first and third quartile, respectively, of the distribution of load shares for the given hour; the top and 
bottom lines mark the $10^{\text {th }}$ and $90^{\text {th }}$ percentiles, respectively. ${ }^{26}$ Toward a proper statistical comparison, each box also shows the upper and lower confidence bound for a $90 \%$ confidence interval on the median. These are shown as notches, where the hourglass sides turn from angled to straight.

The weekday load shape comparison for the Summer tariff season (Figure 3-1) shows that midand late afternoon load shapes for the PowerChoice participants are flattened relative to those for the control group. Load shares for the mid-morning hours, from 8 a.m. to 11 a.m., are correspondingly higher (in terms of percentage load) for PowerChoice participants than for the control group. The differences are strongest for Summer tariff season weekdays, but are also evident for Summer weekends. On the weekend load shape comparison (Figure 3-2), the higher load shares during the mid-morning hours suggest that some domestic chores may have been shifted to weekend mornings. Results for the two Swing season months-June and September (not shown) - are both similar to the Summer tariff season results. These comparisons do not consider absolute differences in load, so that conservation action undertaken roughly equally across all hours-a plausible reaction to a Time-of-Use tariff-would not change the normalized load shape.

These comparisons for Summer show that the load shapes of PowerChoice participants under the tariff are different than load shapes of those not on the tariff, and in a pattern that is consistent with the price differentials between the PowerChoice TOU rate and the standard tariff. These graphical comparisons do not prove that the differences are due to changes that households made on the PowerChoice tariff relative to previous patterns, as opposed to selection onto the rate.

For the Winter tariff season, however, the normalized load shapes of PowerChoice participant households match those of the control sample much more closely, as shown in Figure 3-3 and Figure 3-4. ${ }^{27}$ In Winter, the price per $\mathrm{kWh}$ on the PowerChoice rate is substantially lower than it is in the Summer, and Super-Peak is just $41 \%$ higher than Off-Peak rates in the Winter, as opposed to $154 \%$ higher in the Summer. If PowerChoice households were responding to these price differentials accordingly, a closer match between their load shapes and those of the control group would be expected for Winter as compared to Summer. The fact that this fits the data collected provides some suggestion that participant households' adjustments to the PowerChoice rate schedule may have been responsible for some of the differences between PowerChoice households and other households seen in the Summer-e.g., that they actually did shift some load from Super-Peak to lower-cost hours.

\subsubsection{Total Electricity Consumption}

Considering only single-family homes, PowerChoice participants had lower average Summer electricity consumption than the Load Research Sample. The average annual consumption in

26. For the statistically minded, the $90 \%$ confidence intervals for the median are indicated at the notches, where the hourglass shape changes from diagonal to vertical.

27. They are not identical, however; the PowerChoice households show lower load shares in the midmorning and early afternoon. 
summer 2008 for PowerChoice participants was $30.6 \mathrm{kWh} /$ day, while that for the Load Research Sample was $39.8 \mathrm{kWh} /$ day, and the pattern for summer 2007 was similar. ${ }^{28}$

\subsection{Price Effects}

Tests as to whether households transitioning onto the PowerChoice rate adjusted consumption patterns according to price changes indicated some price-related changes. In particular, across the eight tariff periods compared, two statistically significant price effects were detected for single-family PowerChoice participant households: increased electricity use in weekend mornings and decreased electricity use in weekday late evenings, both judged relative to the non-PowerChoice comparison group. No decreased consumption during weekday Super-Peak or On-Peak periods was detected. The transition from Summer rates to lower Swing season rates during the month of September tended to show increases in consumption among PowerChoice households for the highest price periods. This is consistent with the expected price effect, since these prices were lower in the swing season than they were in the summer season.

If participating households change electricity usage patterns fairly quickly due to tariff changes, this response may be visible at each of the tariff transition points-in switching from their standard tariff to the PowerChoice tariff, and then later, as the tariff changes from Summer to Swing season, from Swing to Winter season, and from Winter again to Swing, and then to Summer. ${ }^{29}$ The research team's approach was to define a statistical model that detects changes of individual households in the PowerChoice participant group, as compared to the average of SMUD's Load Research Sample, which served as the control group. ${ }^{30}$ Only single-family homes were analyzed for both samples. A linear mixed-effect model was used to relate the average $\mathrm{kWh}$ use of the control group linearly to the individual PowerChoice $\mathrm{kWh}$, first before the tariff transition and again after the transition. The relationship between the average $\mathrm{kWh}$ use of the control group and the individual households' kWh is modeled as a linear relationship. Each household has an estimated offset-defining how different their use is, on average, from the control group - and then two parameters that define how much an increase in use is observed for each $\mathrm{kWh}$ increase in use by the control groups. If the relationship changes right after the transition period, then this is considered a price effect. Thus, the Load Research Sample serves

28. The single-family households in the Load Research Sample were weighted according to the corresponding proportion of the population in the three strata (the unweighted average was $48.3 \mathrm{kWh} /$ day). PowerChoice households, on average, had a somewhat higher historical average consumption compared to SMUD residential customers as a whole, likely due to the fact there were very few multifamily homes among PowerChoice participants.

29. There may instead, or in addition, be a longer-run effect, in which households adjust consumption patterns gradually rather than quickly.

30. Single-family households from the Load Research Sample are intended to reflect single-family households for the SMUD service territory overall. Technically, it would be possible to integrate more detailed demographic information, but this would defeat the purpose of representation (e.g., because PowerChoice volunteer households themselves cannot be interpreted as being "like" other households in the SMUD service territory in ways transcending demographic differences, as discussed in Chapters 1 and 2). 
to calibrate changes in consumption for the PowerChoice group. This model was constructed for each of the rate periods defined on weekdays and weekends, as shown in Table 3-1.

\subsubsection{Initial Price Effects}

To test initial price effects when the household entered onto the PowerChoice rate, the models were based upon on-tariff observations that were within 30 days of the date the participating household went onto the PowerChoice tariff. Data more than 30 days after the transition point were excluded because they are too likely to be different for some cause other than the introduction of the PowerChoice tariff. As to the pre-tariff period, households with less than 16 days of pre-PowerChoice data were excluded from analysis, as there would be too much noise to reasonably detect effects. ${ }^{31}$

The models indicated statistically significant price effects for transition onto the tariff during two of the eight periods: weekend mornings and weekday early evenings. Table 3-3 summarizes results from the eight statistical tests. During weekday mornings, PowerChoice customers used slightly more on weekday mornings (Off-Peak Early) after the tariff started, versus before, as calibrated to usage in the Load Research Sample. This increment, while only $3 \%$ greater than changes in the control sample for that period, suggests that in some households, some electricity-consuming tasks-perhaps laundry, dishwashing, or cookingwere delayed until weekend mornings, rather than being done during the higher-price periods during the week. During weekday evenings (Off-Peak Late), PowerChoice customers used an average of about $3 \%$ less after the tariff began than before, again as calibrated to the Load Research Sample. As one participant had noted, tasks started in the Off-Peak Late period (starting at 10 p.m.) must be finished even later, making the Off-Peak Late period too late for completing domestic tasks for some people's schedules. This consideration may have contributed to the Power Choice participant household's relatively lowered Weekday Off-Peak Late consumption.

Table 3-3. Results of tests for statistically significant differences in initial price effects of the PowerChoice tariff

\begin{tabular}{|l|c|}
\hline Tariff Period & Statistically Significant Change $(\mathbf{p}=\mathbf{0 . 1 0})$ \\
\hline Weekday Off-Peak Early & None \\
\hline Weekday Off-Peak Late & Decrease \\
\hline Weekday On-Peak Early & None \\
\hline Weekday On-Peak Late & None \\
\hline Weekday Super Peak & None \\
\hline Weekend Off-Peak Early & Increase \\
\hline Weekend On-Peak & None \\
\hline Weekend Off-Peak Late & None \\
\hline
\end{tabular}

31. Because many households had less than a month of pre-tariff load interval data available, we used a relatively short limit in order to maximize the number of households for which comparisons were possible. 
In summary, statistical tests revealed a small increase in load for the Weekend Off-Peak period, which might be explained as load-shifting to lower-priced hours, but also a decrease in load for the evening On-Peak period during the weekdays. There were no statistically significant effects suggesting a reduction in load during the Super-Peak period.

There are a variety of possible explanations for this lackluster evidence on initial price effects. It is possible that the rates did not induce much change, but it is also true that the sample is small relative to the natural variability of load data, which makes changes more difficult to detect. It also may have taken a while for customers to react to the new rate and to learn how to adjust their loads.

\subsubsection{Transition Periods: Summer to Swing}

The research team also tested what happened when households transitioned off the Summer rates to the fall Swing season rates, which were in effect during the month of September. The Swing season rate schedule has lower rates in every price period, compared to the corresponding period in the Summer season, but retains the basic three-level price structure. The statistical significance of the test for each rate period is shown in Table 3-4.

Table 3-4. Results of tests for statistically significant differences for price effect in the transition between Summer and Swing (late Summer/FalI) seasons under the PowerChoice tariff

\begin{tabular}{|l|c|}
\hline Tariff Period & Statistically Significant Change $(\mathbf{p}=\mathbf{0 . 1 0})$ \\
\hline Weekday Off-Peak Early & None \\
\hline Weekday Off-Peak Late & Decrease \\
\hline Weekday On-Peak Early & Increase \\
\hline Weekday On-Peak Late & None \\
\hline Weekday Super Peak & Increase \\
\hline Weekend Off-Peak Early & None \\
\hline Weekend On-Peak & Increase \\
\hline Weekend Off-Peak Late & None \\
\hline
\end{tabular}

Here, several statistically significant increases in consumption were detected: during Weekday Super-Peak, and both Weekend and Weekday On-Peak Early periods. These suggest some relaxation of load shifting activity or, alternatively, a basic price effect in which consumption increases in response to lowered price. That is, since the price decreased in all tariff periods, increased consumption might be expected. During the Weekday Off-Peak Late period, there was a statistically significant decrease in consumption, perhaps in balance to the increased consumption during Super-Peak and On-Peak periods earlier in the day-since usage in higherprice periods began to command less of a premium than it did in Summer.

\subsection{Intervention Effects}

The research team tested the effectiveness of the two types of information interventionsEnhanced Information Treatment and Monitor Treatment. As described in Chapter 1, the Enhanced Information Treatment consisted of a series of mail communications to a randomly 
selected subset of PowerChoice participants, beginning in late summer 2007, while the Monitor Treatment consisted of distributing feedback monitors to 50 volunteer households among PowerChoice participants. ${ }^{32}$ Monitors were distributed in June 2008. The survey data indicate that most households that received a monitor successfully installed it (Chapter 5). Some households (31) received both treatments. Both treatments were tested by comparing load between the summer of 2007, before treatments began, and the summer of 2008.

A random effects model was used to test the effects of each treatment. This modeled differences in the consumption of individual households, rather than considering the treatment groups as aggregates. Models for the Enhanced Information Treatment and Monitor Treatment were estimated separately for each of eight different tariff periods (Table 3-1). ${ }^{33}$

Among the many (16) tests, just two statistically significant differences were found. ${ }^{34}$ During the Weekend On-Peak period, households that received Enhanced Information in addition to the Monitor Treatment had slightly lower consumption than in the previous year, compared to those who had a monitor alone. And, again, during the Weekend On-Peak period, those in the Monitor Treatment group had slightly reduced consumption relative to the previous year, compared to other households. So there is rather weak evidence that the feedback monitors made a difference. Both changes are in the expected direction-i.e., indicate that the treatment reduced consumption.

There are several possible explanations as to why there was so little evidence of significant changes in load in response to these information interventions. Perhaps the most important to consider is the possibility that the treatments had no real effect on electricity consumption patterns, over and above the rate itself-which itself had relatively modest effects as an initial price change. While the Enhanced Information Treatment was more customized than most mass information programs, finding that mass information about energy use has little effect on energy consumption is probably more typical than not (Lutzenhiser 2002; Owens \& Driffill 2006; Sexton et al. 1989).

The difficulty of developing effective information may be especially pronounced in this situation, since many PowerChoice households are evidently already more engaged with their electricity consumption than average households, in that they agreed to accept the TOU rate in the first place. Furthermore, all PowerChoice households received some information from the program, through the introductory materials for the rate (Appendix A, pp. APA-3-5) and through SMUD's mailings to remind them of rate changes (Appendix A, p. APA-6), and surveyed participants may have learned from the surveys themselves. Any participant with Internet access could also consult the SMUD consumer website, which provided general

32. See Chapters 1 and 5 for details on participation in the Monitor Treatment group.

33. There is a caveat to the tests for the Monitor Treatment group: the validity of these statistical tests for inference rests on the assumption that the treatment group was randomly assigned, which was not the case here.

34. When doing multiple tests, there is also a good chance of getting false positive results-inferring a statistically significant difference for the tested samples that does not reflect real differences in the corresponding population. 
electricity conservation tips, and doing so was advised in the introductory material sent to participants. So the information and encouragement provided in the Enhanced Information Treatment may not have provided much new over baseline knowledge and traditional sources. As to the Monitor Treatment, a number of studies have shown that feedback via in-home monitors can often reduce electricity consumption (Darby 2006). But for the current project, again, the Monitor Treatment is layered on top of a rate treatment, with which households had already had a year's experience.

A second possibility is that the treatments are effective for some customers, but the effects are simply small, and that most cannot be detected due to a combination of "natural" consumption variability and a relatively small sample size and short duration.

\subsection{Relating Survey Data to Load Data}

Each of the three survey instruments deployed emphasized aspects of the 3-Cs framework (Chapter 1), whereby recognizing participants concerns, conditions, and capacities is key to understanding how and why these customers acted as they did, and what barriers and opportunities remain. This provides an alternative to a top-down view, where households are undifferentiated and all that matters is aggregate load response. There is, however, a great deal of natural variability in residential electricity consumption and a diverse collection of households participating in PowerChoice. While a 3-C approach helps an understanding of why households did what they did, there are so many reasons for electricity consumption variability across households that, in ordinary circumstances, it is difficult to distinguish signals, such as caused by price changes or other interventions. This variability limits the prospects for undertaking informative modeling of survey characteristics in conjunction with load data, except for perhaps the largest or narrowest of samples.

The project did, however, test some basic relationships between survey responses on the one hand, and consumption and load shapes on the other. The simplest result is that households who used less electricity tended to more satisfied with the program and were more likely to judge their efforts effective, as detailed below. This result is as one would expect, especially since higherconsuming households (over $1,000 \mathrm{kWh} /$ month) were levied a bill premium as a percentage of their total bill, while those with lower consumption were credited (see Chapter 1). So these patterns are reassuring, but not very illuminating in terms of the fundamental questions about customer reactions to the TOU rate.

At the end of the second summer (Wave 3 survey), three basic questions were asked about customer experience on the rate: a self-assessment of the effort participants felt that they had put into adjusting to the PowerChoice tariff; the respondent's view of how effective these efforts had been, however the survey participant chose to define success; and the respondent's statement on program satisfaction. Details on these survey questions are reported in the next chapter. Table 3-5 shows the results of a Welch two-sample t-test on the differences of average daily 
electricity consumption during the Summer tariff period by level of survey response, along with consumption at the $75^{\text {th }}$ percentile of the consumption distribution by survey response group. ${ }^{35}$

Table 3-5. Analysis of summer load by value of survey response for three general questions on program experience and satisfaction asked in the Wave 3 survey

\begin{tabular}{|c|c|c|}
\hline Survey Question Response & $\begin{array}{c}75^{\text {th }} \text { Percentile of } \\
\text { Distribution of Summer } \\
\text { Average Daily } \mathrm{kWh}\end{array}$ & $\begin{array}{l}\text { Statistical Significance of } \\
\text { Test On Differences }\end{array}$ \\
\hline \multicolumn{3}{|c|}{$\begin{array}{l}\text { Effort: "In response to PowerChoice, how much effort would you say that you and your household } \\
\text { have been making this summer to adjust how and when you use electricity?" }\end{array}$} \\
\hline "A great deal" & 42 & \multirow{2}{*}{$\mathrm{p}=0.02$} \\
\hline All others & 33 & \\
\hline \multicolumn{3}{|c|}{ Effectiveness: "Would you say that your efforts have been...?" } \\
\hline "Very successful" & 35 & \multirow{2}{*}{$p=0.14$} \\
\hline All others & 47 & \\
\hline \multicolumn{3}{|c|}{ Satisfaction: "How satisfied have you been with the PowerChoice Program during Summer 2008?" } \\
\hline $\begin{array}{c}\text { "Very satisfied" or "Somewhat } \\
\text { satisfied" }\end{array}$ & 33 & \multirow[t]{2}{*}{$p=0.001$} \\
\hline All others & 47 & \\
\hline
\end{tabular}

For example, participants who said that they had made a great deal of effort to adjust how and when they used electricity had higher consumption than other participants ( $p=0.02$ for a t-test on differences), with the $75^{\text {th }}$ percentile of the distribution of average Summer Average Daily $\mathrm{kWh}$ over households who said that they made a great deal of effort-42 kWh/day-as opposed to $33 \mathrm{kWh} /$ day for others. So those who said that they tried harder used more, perhaps because their higher bills lead to higher motivation, or because they had more usage they could potentially change. Households who judged their efforts effective tended to have lower Summer tariff season consumption ( $\mathrm{p}=0.14$, marginally missing significance at $90 \%$ confidence), as did those who were satisfied with PowerChoice ( $\mathrm{p}=0.001)$. These three factorseffort, effectiveness, and satisfaction-are more outcomes of concerns, capacities, and conditions, than reflections of them.

In addition to looking at consumption by survey responses for these three questions, the research team also looked at corresponding load shapes. Figure 3-5 compares the distribution of normalized weekday load shapes for the group who considered their efforts very effectiveconstituting $34 \%$ of those who said they had made at least some effort - to all others. ${ }^{36}$

35. The Kolmogorov-Smirnov and Welch two-sample t-test yielded similar results. The comparison shown in the table is non-parametric because of the high variance and skewness of the data. The $75^{\text {th }}$ percentile is used as illustration; the median or other percentile could equally well be used, though the distributions increasingly diverge at higher percentiles, making the upper tail the "most interesting" part of a comparison.

36. Only households who said they made some effort were asked this question. 


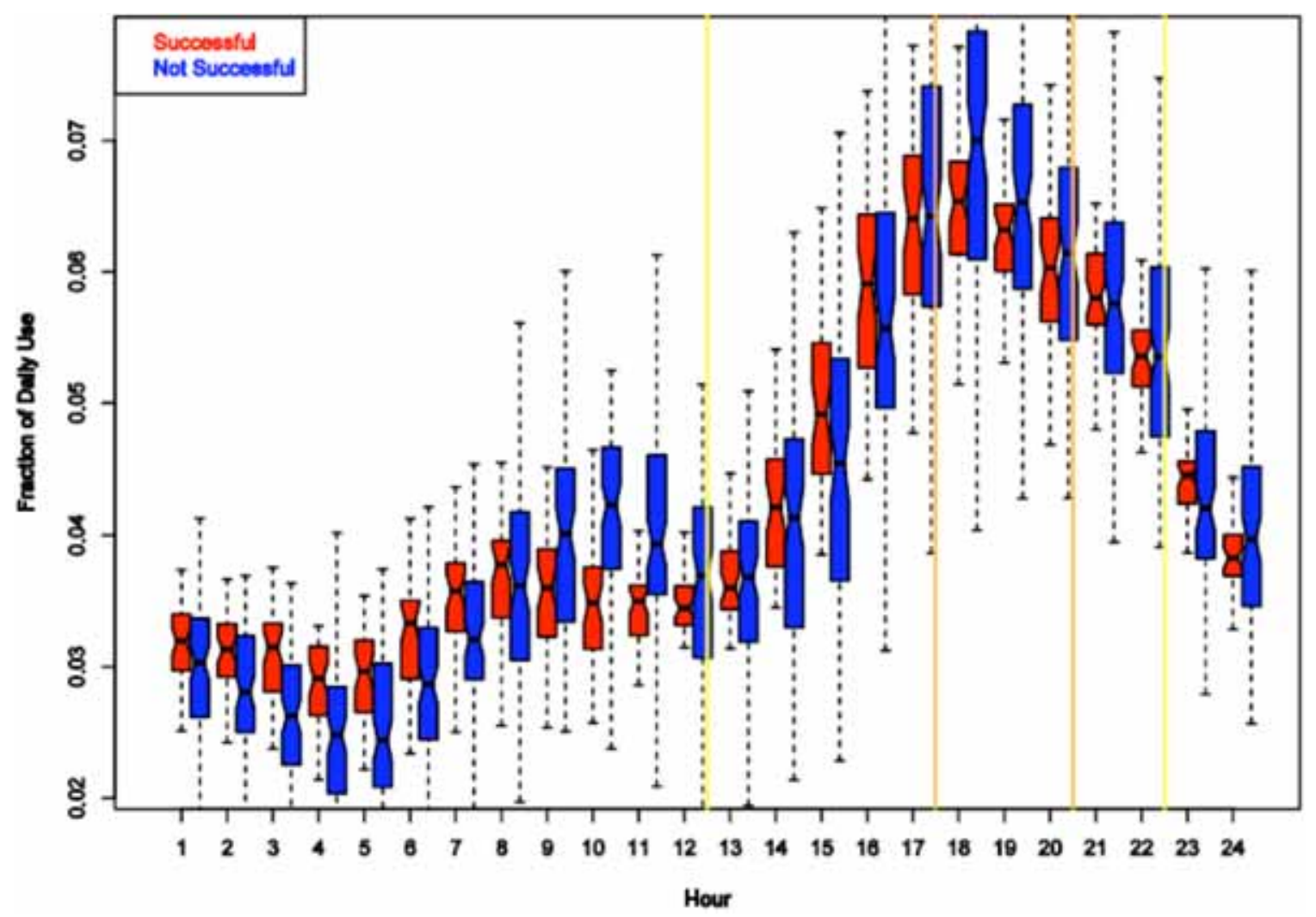

Figure 3-5. Distribution of normalized load shapes on Summer weekdays for households reporting that their efforts to adjust load to the PowerChoice tariff were "very effective," as compared to all other households

The tariff periods are marked by vertical lines. On weekdays, households who judged their efforts very effective had significantly lower load shares during the Super Peak period as compared to all others. They also had lower load shares during mid-morning, which is the OffPeak Early period. Overall, the load shapes of participants who considered their efforts very effective were somewhat flatter overall than for other households. This pattern hints that participants judging their efforts very effective were less likely to be home in the daytime, and this was confirmed by the survey data. ${ }^{37}$ Households who judged their efforts very effective also tended to have lower consumption overall, though the difference was not statistically significant. ${ }^{38}$

37. Based on the Wave 3 survey, 31\% of households where nobody was typically home on the weekdays from 8 a.m. to 5 p.m. said that their efforts were very effective, as compared to $21 \%$ of those where somebody was typically home during those hours.

38. Ranked low to high, the $75^{\text {th }}$ percentile of average daily summer consumption for households who considered their efforts successful was $35 \mathrm{kWh} /$ day, as opposed to $47 \mathrm{kWh} /$ day for households who did not consider their efforts to be successful. 
Figure 3-6 compares the distribution of normalized weekday load shapes for households for which the survey respondent said that they had made a great deal of effort to change how and when they used electricity-constituting $58 \%$ of Wave 3 respondents.

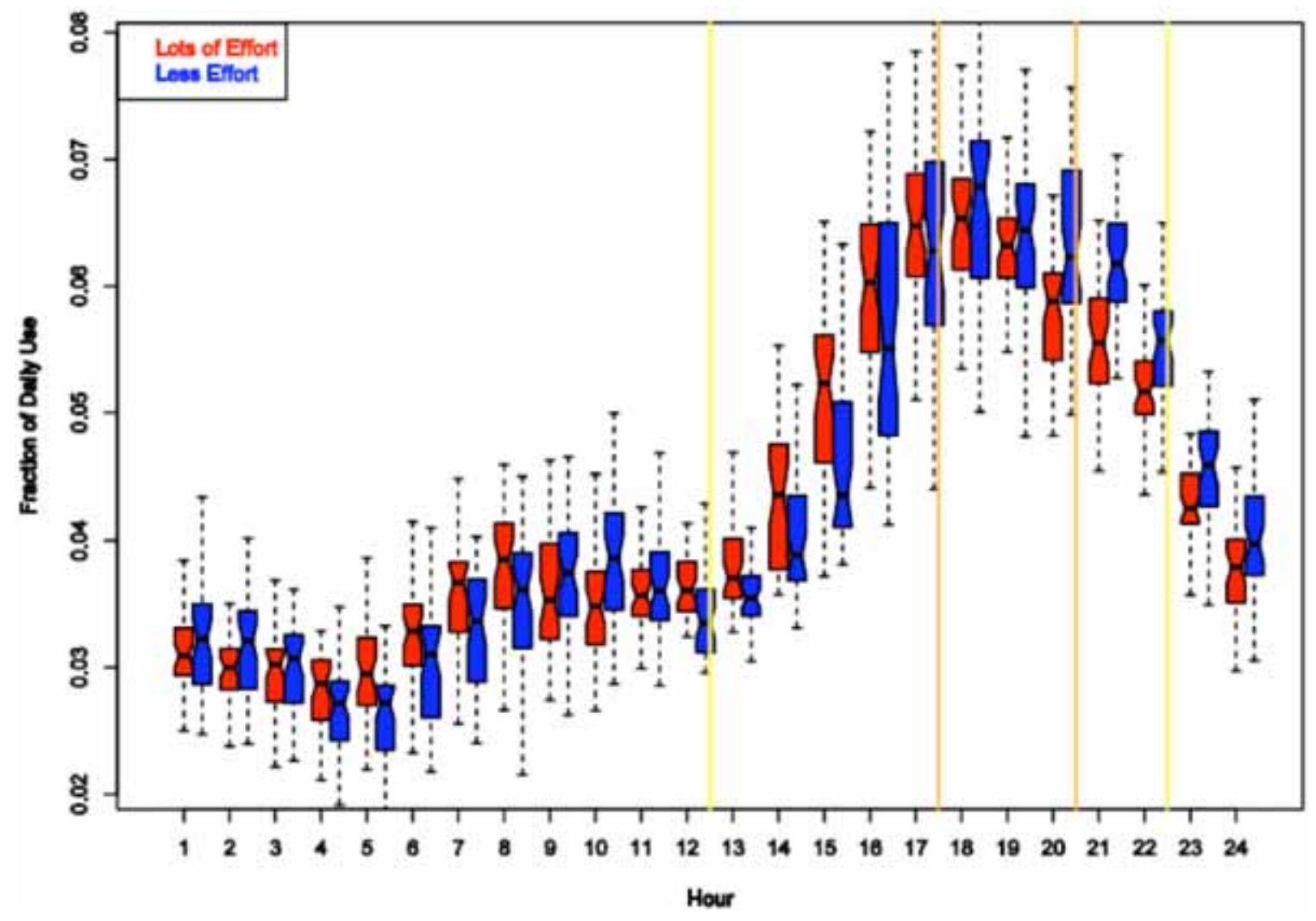

Figure 3-6. Distribution of normalized load shapes on Summer weekdays for households reporting that they had made "a great deal of effort" to adjust their consumption on the PowerChoice tariff, as compared to all other households

These households also had flatter load shapes than other households, showing lower load shares from 6:00 p.m. through midnight. That period covers not only Super-Peak, but also OnPeak Late and Off-Peak periods. They had lower shares, instead, during parts of the On-Peak Early period, from afternoon until the beginning of Super-Peak.

As to absolute levels of consumption, the distribution of average daily summer consumption for households who said they made lots of effort to adjust to the rate was statistically significantly lower than for other households (Kolmogorov-Smirnov test, $\mathrm{p}=0.07$ ). Similarly, the distribution of average daily consumption among participants who stated that they were satisfied with the PowerChoice program was also statistically significantly lower than those who said they were not satisfied (Kolmogorov-Smirnov test, $\mathrm{p}=0.002){ }^{39}$

39. Median average daily consumption during the summer months for households who said that they were satisfied with the PowerChoice program was $26 \mathrm{kWh} /$ day, much lower than the median of 35 $\mathrm{kWh} /$ day among those who did not say that they were satisfied. 
In addition to testing relationships between load and self-assessed effort, effectiveness, and satisfaction, the research team also completed exploratory analyses testing the relationship between Average Summer Daily Consumption and a bevy of survey responses. This yielded a few cases of statistically significant differences. The most educated group (Ph.D. and professional degrees) used less energy than those with college degrees or less (Welch twosample t-test, $\mathrm{p}=0.05)$. Households where somebody was almost always home during the Weekday Super-Peak had higher consumption, on average, than other households (Welch twosample t-test, $\mathrm{p}=0.01){ }^{40}$

40. Average daily consumption was $35 \mathrm{kWh} /$ day for those who said that they were almost always home weekdays from 5:00 p.m. to 8:00 p.m., compared to $25 \mathrm{kWh} /$ day for other households. 


\subsection{What Participants Said: Basic Survey Results}

The three surveys of PowerChoice participants are used in two ways in this report: as a description of participant demographics, and participant actions and reactions in response to the rate and PowerChoice program; and for analysis in conjunction with load data in order to see connections between load data and survey responses. The previous chapter reported on these connections, while the current chapter presents highlights of the survey data independently of load data analysis. The following chapter (Chapter 5) analyzes the survey results with respect to the two experimental information interventions. Detailed survey results for many questions in the Wave 3 survey are summarized in Appendix E. The survey instruments used to field each of the three telephone surveys are reproduced in Appendix F. This chapter begins with a brief depiction of the setting within which participants were surveyed, followed by a summary of the top results across three surveys and then the details behind the key results.

\subsection{Setting}

The survey data turns attention away from the typical aggregate focus of demand response to the energy users themselves, and to the environment they face in managing electricity use in response to a new tariff and concomitant information-information stemming from both the PowerChoice program and the research project itself. As described in Chapter 1, the research project sought to uncover participant concerns about electricity use and the rate, their capacity to deliver demand response and lower consumption, and the conditions and limitations under which they take these actions. Previous research has shown that all three elements-sufficient concern, sufficient capacity, and sufficient conditions-are necessary for successful conservation behavior change (Lutzenhiser et al. 2002). This 3-C framework guided the construction of the surveys and the analyses presented in this chapter.

Given that such a low percentage of households solicited for the PowerChoice program agreed to participate, the participants who did may have had special concerns related to energy use. In particular, they may have been more attentive to energy use or to their bills and ways to save on these bills, as compared to other SMUD residential customers. And, as the survey results suggest, some may have also have liked the project aspect of the pilot rate and of the research.

As to capacity, for almost all PowerChoice participants, requests from the utility, the state, or other parties to manage electricity use would have been nothing new. All but those recently in California would have experienced California's 2000-2001 electricity crisis, for example, and half of participants said that they had earlier been enrolled in SMUD's PeakCorps program, which offered monthly bill credits in exchange for the periodic direct load control of the participant's air conditioner. ${ }^{41}$ This past experience may have lead to increased know-how in energy management, but also-though no comparative information is available-may have lead to higher "normal" levels of energy conservation habits and correspondingly less capacity to deliver additional demand response or conservation.

41. The PeakCorps enrollment estimate is based on self-reports of Wave 1 participants. 
For most households-PowerChoice participants, as well as others-the information typically available to efficiently manage electricity use is poor. It is difficult for even interested household members to find out how much any particular energy use decision might cost for a specific household or situation-or even "on average." Nor are the relative costs of various electricity uses intuitive. For SMUD customers, as for most California households, bills come only once a month and are highly aggregated forms of information. In short, there is little guidance as to the most important things to do to manage electricity use, even while there is abundant messaging to "do anything that you can" that might reduce electricity use. In part, because of this poor information environment and the natural invisibility of electricity use, efforts to conserve and shift may not be well-spent in terms of their effect on the grid.

Even when actions have no financial costs, conservation and shifting actions may often be neither free nor easy. As survey respondents reported, some actions caused inconvenience, created stress in the home, increased workload, and may have had adverse health effects. Feedback monitors, as tested for a subset of PowerChoice participants as part of this research project, can improve the information environment for households willing to engage and experiment.

Finally, any household has conditions that create and limit their reactions to the rate, whether information availability, household circumstances that shape habits, temperature preferences and their flexibility, time constraints, work schedules, or how well they believe the benefits of their efforts to conserve and shift are realized.

\subsection{Top Results Over Three Surveys}

The following are the primary results from the three surveys of participants:

- Most households said that they joined PowerChoice to save money on their electricity use, above all else. For many, the apparent reason for joining might be stated as "saving money while helping the environment, SMUD, or the community."

- Early confusion about the consumption adjustment aside (see below), surveyed participants appeared to clearly understand the basic structure of the rate and the impetus the rate provides to reduce On-Peak and Super-Peak electricity usage.

- Over half of surveyed participants agreed to the statement that they had made "a great deal of effort" to change how and when they used energy. Most of the rest said that they had made a moderate effort.

- Few households said they made less effort in their second summer on the rate than the first, and nearly four in ten said that they made more effort the second summer.

- The most common summertime actions reported taken in reaction to the PowerChoice program were reducing run-time of air conditioners or increasing the thermostat setpoint for air conditioning, changing timing of laundry and dishwashing, installing CFLs, and general conservation, such as turning off lights. Some two dozen other strategies were reported. Nearly all pool owners surveyed said that they changed their pool pump timing to run at Off-Peak hours.

- Some households said they made more dramatic changes, such as changing cooking and meal times, changing cooking methods, turning off "everything" during Super- 
Peak, leaving the house during Super-Peak hours, or getting up very early in the morning to start chores.

- Though surveys concentrated on the summer season, it appears that participants undertook fewer shifting and conservation actions in the winter, when the differential between Off-Peak and Super-Peak period rates was much less steep than in the summer, and rates were generally lower.

- Relatively few survey respondents reported stiff barriers or outright resistance to conservation or shifting. Most PowerChoice participant households may have been more willing than the "average household" to make changes, as suggested by their participation on the TOU rate itself. Reducing the use of the air conditioner was problematic for some households, due to the presence of individuals with health conditions, such asthma or allergies-more generally the elderly, or pets. While others said that their comfort was more important, few surveyed participants seemed willing to frequently rack- or line-dry their clothes instead of using the clothes dryer. While electric, rather than gas water heating was not common among participants (as in the SMUD service territory overall), survey participants did not spontaneously mention managing hot water use as a means of shifting or conserving.

- Some households reported domestic tensions about the use of energy, such as when teenagers could watch television, when to do the baking or have meals, and so on. A few participants mentioned the PowerChoice rate as a sort of household "project," even one that they enjoyed.

- One difficulty in interpreting the impact of the stated conservation and shifting actions is that most households conserved even before PowerChoice. They may have increased the degree or frequency of actions they had done before, or they may have done something new. For example, when looking at the details of what survey participants said that they did about air conditioning, the overall picture is ambiguous. Very few participants surveyed said that they used their air conditioning more than they had before PowerChoice and $60 \%$ said that they used it less. Yet the distributions of selfreported typical indoor temperatures for before PowerChoice, as compared to during PowerChoice (Summer 2008), are nearly identical. Comparing across surveys for households who reported in both surveys, nearly as many households reported a lower temperature under PowerChoice (30\%) as a higher, more energy-conserving, temperature $(35 \%)$.

- Another difficulty in understanding the conservation and shifting actions that survey respondents reported is that most energy-relevant behavior is far more complex than can be verbally transmitted-varying by household member and by momentary circumstances. Energy management, energy behavior, and behavioral change are difficult to capture accurately and precisely by survey. Furthermore, there may be a tendency to overstate conservation and shifting actions because it would have been clear during the survey that these were socially desirable responses.

- Over the span of our surveys, many households reported changes to the house structure, to their electricity-using equipment, or to the number of household members. Nearly a third said that they added equipment over the course of joining PowerChoice-especially large-screen televisions. One in four surveyed participants 
said that they remodeled over the course of the year. About $15 \%$ reported a change in the number of household members. Few of these changes may be a result of PowerChoice, but all may affect electricity consumption, creating a complication in disentangling PowerChoice effects from other sources of change.

- At the end of Summer 2008, nearly $40 \%$ of surveyed participants said that their summer bills under PowerChoice had been higher than expected, while less than half as many said their bills were lower than expected. Still, half thought that, overall, they had saved money on the rate, while about two in ten said that they thought they had paid more.

- Most surveyed households remaining on the rate said that they were satisfied with the program. It is unclear how much of this satisfaction has to do with the perception of saving money. Some appeared to have liked the closer contact with SMUD/surveyors that being in PowerChoice entailed (especially those in the Information Treatment group), while others found it a nuisance. Regardless, over half (55\%) of respondents said they would like to continue on the PowerChoice rate if given the opportunity and an additional $10 \%$ said they would consider going on another, but different, TOU rate when the PowerChoice pilot concludes.

- Some customers were dissatisfied with the rate structure, complaining in particular about the consumption-adjustment element of the tariff. Some said the rate was too complicated and too hard to remember. Households with higher bills were more likely to drop off the rate.

- Many surveyed participants suggested bill improvements, such as a format that was simpler to read, more detail about usage during various periods (such as a day-to-day comparison), and, above all, a comparison that showed whether or not they were saving money on the rate.

The remainder of this chapter discusses these results in more detail.

\subsection{Motivation for Joining PowerChoice}

Financial reasons-including both bill reductions and controlling costs-are the primary motivation for joining PowerChoice. Environmental reasons, reducing the possibility of blackouts and brownouts, and energy security are secondary reasons for most customers. The best summary for why the vast majority of households joined may be "saving money while helping the environment, SMUD, or the community."

One of the first tasks of the research was to determine the energy-relevant concerns of PowerChoice customers. The Wave 1 survey, conducted shortly after the PowerChoice tariff started for most households, asked participants why they joined the PowerChoice program. Money was the key impetus for joining, though not to the exclusion of something altruistic. Figure 4-1 summarizes the open-ended (spontaneous) responses. One-third of surveyed participants mentioned only money and an additional one-third mentioned money in addition to other reasons. ${ }^{42}$ Participants stated that they thought that they would save money on the

42. An additional 11\% mentioned conserving energy, which may sometimes also imply financial motivation. 
tariff, but often mentioned liking the fact that they could control costs through the option of changing when they used electricity. Some customers seemed desperate to save, while, for most, it was more a matter of saving a few dollars when possible. By the same token, while the TOU tariff imposes a penalty for using electricity during system peak hours, it also produces times when electricity is "on sale" — the off-peak periods and, more generally, in winter. So, conceivably households might focus on the sale periods as an opportunity to use more electricity at lowest rates, versus curtailment or simply shifting timing of things they would do otherwise.

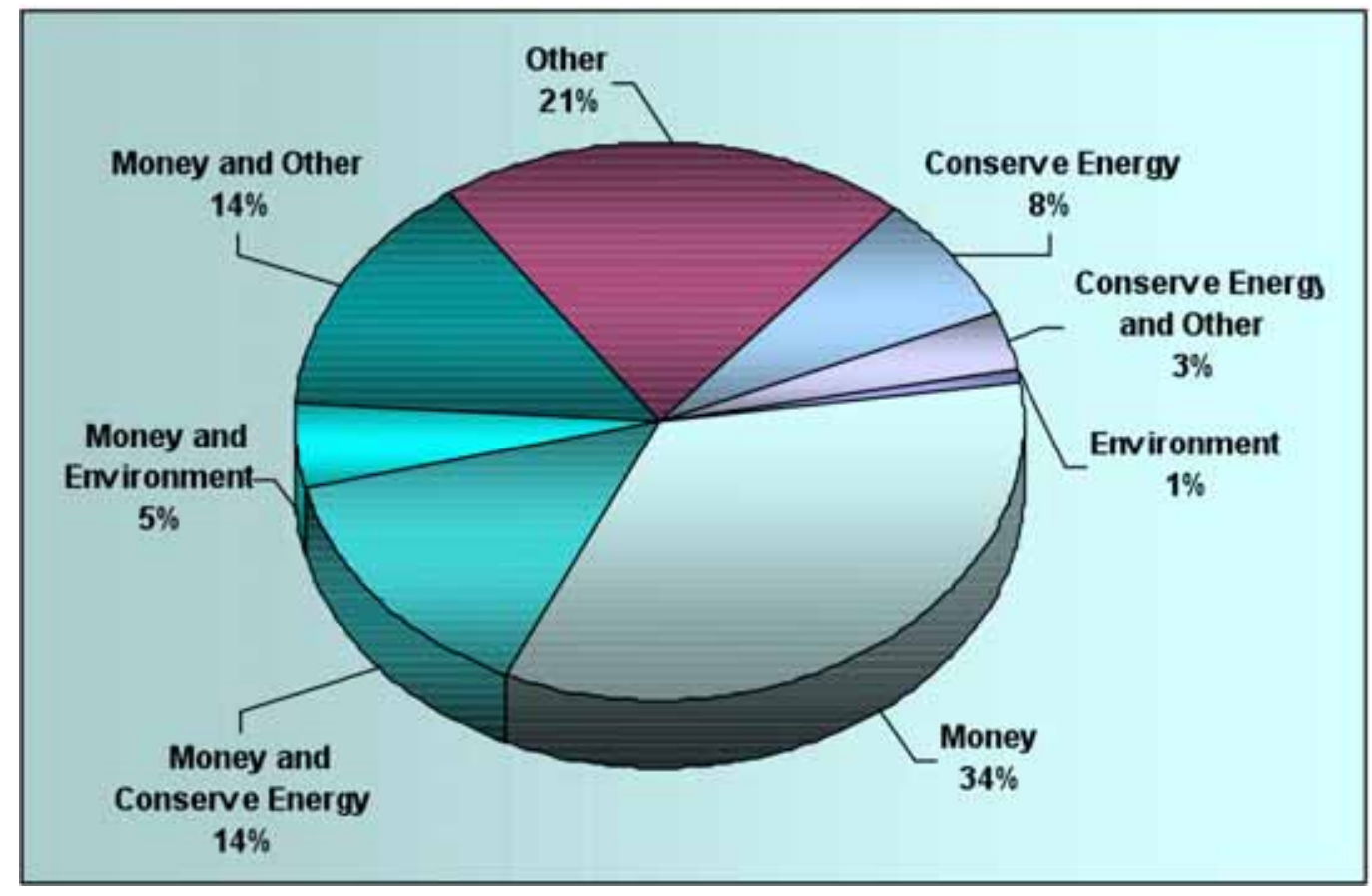

\section{Figure 4-1. Reasons for joining PowerChoice (open-ended, multiple responses)}

Only a handful of survey respondents spontaneously mentioned environmental reasons for joining, and nobody spontaneously mentioned preventing brownouts or improving energy security. When offered a series of possible reasons for joining PowerChoice, most households selected all of the provided reasons for joining. Saving money, environmental protection, and preventing brownouts, garnered Yes responses from $76 \%$ or more of respondents; the lowest rated reason, energy security, still had $62 \%$ responding positively. ${ }^{43}$ Figure $4-2$ shows the results. A survey of participating Ontario, Canada, customers who were also on a pilot TOU rate were asked a similar question. Insofar as their answers can be compared, the Canadian results are consistent with the PowerChoice survey. ${ }^{44}$

43. The open-ended and fixed response question results are not inconsistent with each other, but tell much different stories: the virtual absence of the latter three reasons from the open-ended responses demonstrates the importance of using open-ended questions.

44. The Ontario study found that $60 \%$ said that the potential to reduce bills or better control costs were the top benefit of TOU programs for customers, and all named these among the top three factors. Only 


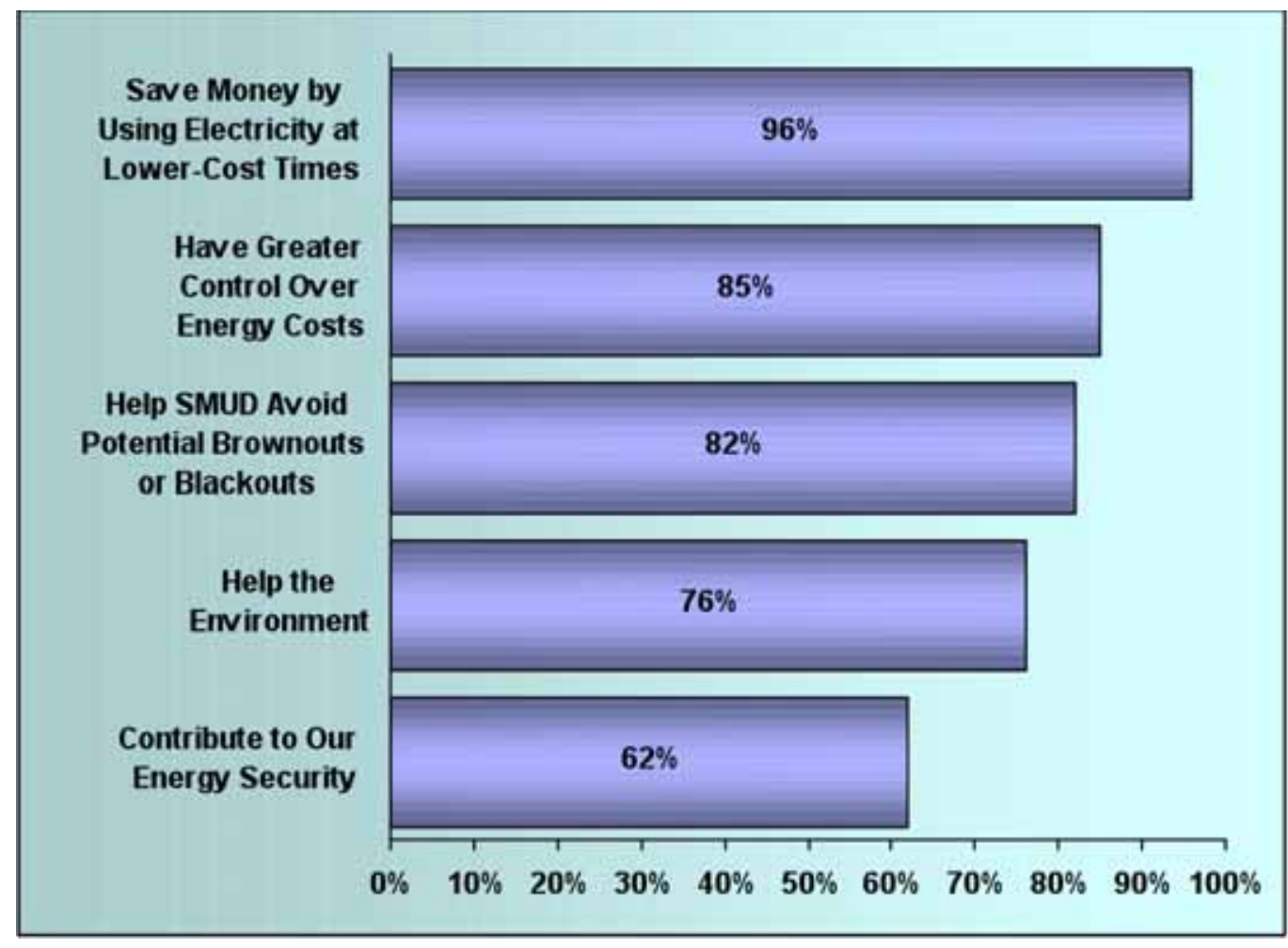

Note: In the SMUD recruitment brochure, "more control over your SMUD bill"," "cost of supplying electricity," "helping the environment," and "to save money... by shifting usage" were specifically mentioned.

Figure 4-2. Factors playing a part in respondent's decision to participate

Some participants also mentioned that they liked the game or project aspects of the rate, or just the fact of helping SMUD—all of which were promoted in the introductory materials sent to potential participants. In the final survey, retrospectively, participants tended to mention more general altruistic or public-good reasons-liking to contribute, or support for the logic of Timeof-Use rates-as reasons for satisfaction with the program. This may be a manner of speaking, a shift in values, a realization that their savings from the rate may not be very high, or a combination of reasons.

Respondents' stated motivation for joining the PowerChoice pilot match the way the tariff was marketed: as a way to save money and control energy costs, while simultaneously helping the environment and the power system. But this raises questions. First, a tariff that does not, or does not seem to offer monetary savings may be unsatisfactory to most customers. To emphasize the obvious, tariff design and the matching of tariffs to participants and their shifting conservation capabilities is of utmost importance to demand response, even in a behaviorcentered study. In this case, customers had no immediate way of knowing whether they had saved money over the previous rate, as their bills did not indicate savings over alternative tariffs or previous bills. PowerChoice bills did not provide a comparison to the previous year's

$1 \%$ of the Ontario customers mentioned benefiting the environment as the top benefit to consumers, though over half counted it among the top three (Ontario Energy Board 2007). 
bill or to the bill calculated on the standard rate. Second, the extent to which shifting load offpeak is good for the environment has not been addressed with much complexity. There are long-run, as well as short-run, perspectives and answers that depend on the particularities of supply and how environmental benefits are credited. One study suggests that demand response can have negative effects on the levels of certain pollutants (Holland \& Mansur 2004).

Time-of-Use tariffs reward subscribers financially for actions that they could have taken regardless of the tariff. The extra information, encouragement, and support a programespecially a pilot program-might provide, may motivate and facilitate behavioral change, but the association of the rate itself with altruism is more symbolic than logical. Shifting and conserving, independent of the rate, has public benefits, and there are private monetary benefits (energy-cost savings) from conservation. The structure of the TOU rate, however, sends different messages than the increasing block rate that is standard in California and creates alternative standards relative to which actions are judged. For example, with the TOU rate, a household can save money by doing something at off-peak rather than peak times (i.e., savings relative to alternative timing), while on a standard rate, money can be saved only by reducing use.

\subsection{General Response}

\subsubsection{Shift versus Conserve}

The PowerChoice tariff is designed to reward shifting, especially from weekday late afternoons to off-peak times-late evenings, early mornings, and weekends. Via the consumption adjustment, the tariff is also designed to reward lower levels of electricity use and penalize higher levels. ${ }^{45}$ Most survey respondents understood the PowerChoice Time-of-Use program to be fundamentally about shifting. At the end of the second summer, participants were asked whether they conserved, shifted, did both, or did neither. Table 4-1 shows the results. Threequarters of survey respondents said they had shifted electricity usage, with half of these stating that they shifted only, and the other half saying that they both shifted and conserved. Just $10 \%$ stated that they conserved only, with the remaining one in eight saying that they did not change much.

Table 4-1. Reported general response to the PowerChoice tariff, Wave 3 survey participants $(n=170)$

\begin{tabular}{|l|c|}
\hline Reported Response & Percentage \\
\hline Shift & $37 \%$ \\
\hline Conserve & $11 \%$ \\
\hline Both shift and conserve & $40 \%$ \\
\hline Neither & $8 \%$ \\
\hline Don't know / Refused & $4 \%$ \\
\hline
\end{tabular}

45. The introductory information sent to potential PowerChoice volunteers discussed both conservation and shifting as routes to saving money on the PowerChoice rate, suggesting especially that households should conserve during the peak period to save money. 
Though TOU rates are assumed to be generically about shifting, the terminology is vague and perhaps inadequate for asking people what actions they took. Certain tasks can be shifted to other hours of the day, but air conditioning, for example, is time-dependent, even while some coolth might be stored. When asked specifically, a fair number of households said that they precooled their homes. ${ }^{46}$ Some shifting of air conditioning may also have doubled as conservation. As some survey respondents mentioned, a Time-of-Use rate may also lead to deferral of various domestic tasks, such as laundry, dishwashing, or cooking. This at first seems to be clearly about shifting, but can also lead to a conservation effect, since needs for particular domestic tasks or services may be much less fixed than usually assumed (Shove 2003; Strengers 2008).

\subsubsection{Evident Effort}

Most surveyed participants reported that they made real efforts to modify their electricity consumption and that this effort did not drop off in the second year on the rate. As seen in the previous chapter, however, that the effort made a detectable difference in electricity use patterns was less clear.

Saving money on a TOU tariff relative to the default tariff does not necessarily require any changes from a household. In theory, a household's normal patterns of electricity use could fit the tariff well enough to provide savings. The first survey, fielded near the end of Summer 2007-soon after most households had joined the rate-indicated that only $15 \%$ of surveyed households thought that they would have to make "lots of changes" to save money. At the end of the second summer of the tariff (Wave 3 survey), however, more than half (58\%) of those surveyed said that they had been making a great deal of effort to change their electricity use to fit the rate. ${ }^{47}$ Less than $10 \%$ said that they had made little or no effort. Granted, the surveying process may have encouraged positive responses, but based especially on the open-ended responses, it seems clear that some customers tried hard to work with the rate. Some households reported undertaking extensive measures, both habitual—changing meal times and cooking methods, otherwise reorganizing schedules, leaving the house when it was hot rather than turning on the air conditioner, avoiding any optional electricity use during Super-Peak-as well as one-time changes, such as changing the pool-pump timing or installing CFLs throughout the home. These efforts, however, are not evident in the load analysis-perhaps because they were too small to detect with the limited sample size. Rather, what was most detectable in the price effect analysis of the load interval data was an increase in consumption in the lower-priced periods.

\subsubsection{Perceived Effectiveness}

Most participants said that their efforts on the rate had been effective. At the end of the second summer, participants were asked about how effective they thought their efforts had been, without defining what effective meant. Three-quarters said that they thought they had been

46. In the Wave 3 survey, 17\% said that they always pre-cooled their homes in preparation for SuperPeak, while $31 \%$ said that they occasionally did so. But it is unclear how much of this pre-cooling was due to PowerChoice and a desire to reduce Super-Peak use, as opposed to practices that would have taken place regardless of the rate.

47. An additional one-third said that they had been making moderate effort. 
successful-more often somewhat successful (50\%) than very successful $(34 \%)^{48}$-however, there is probably a tendency to see one's own efforts as successful, just because one made them. Only a handful (5\%) said that they judged their efforts "barely successful." Some participants who judged their efforts unsuccessful dropped out.

\subsubsection{Most Households Said They Already Conserved}

Conservation was nothing new for most PowerChoice customers. Not only had nearly all probably experienced the 2001 California electricity crisis, based on the ages of participants, most were also old enough to remember the U.S. energy crises of the 1970s and, for some, national efforts at conservation during World War II. When surveyed soon after they started on the rate, most surveyed PowerChoice participants $(85 \%)$ reported that they already conserved energy before going on the rate. ${ }^{49}$ They would have to conserve even more at system peak hours in order to deliver demand reduction. For whatever reason-conservation or something elsethey also had lower average electricity consumption than other single-family households in the comparison group (Chapter 3). In general, lower consumption may work against demand response and customer direct benefit from TOU rates, which has led to debate about the equity of such programs (e.g., Alexander 2007; Robinson \& Rowlands 2007). In the PowerChoice case, half of surveyed households said that they had previously participated in PeakCorps, a SMUD program that offered bill credits in exchange for signing up for moderate levels of direct-loadcontrol air conditioning.

\subsection{What Participants Said They Did}

\subsubsection{Overview of Participant Actions}

Table 4-2 provides a high-level view of what surveyed participants said they changed after joining PowerChoice, with one exception, as collected at the end of the second summer. ${ }^{50}$ In addition to these actions, many households stated that they "turned off lights" or "turned things off generally" in open-ended responses (Peters et al. 2008). ${ }^{51}$ Details on common shifting and conservation actions are discussed below.

Table 4-2. Common shifting and conservation actions in response to PowerChoice, as reported by surveyed participants

\begin{tabular}{|l|c|}
\hline Activity & $\begin{array}{c}\text { Percentage Reporting a } \\
\text { Change in Usage }\end{array}$ \\
\hline Clothes dryer ${ }^{*}$ - changed timing or used less & $91 \%$ \\
\hline Dishwasher - changed timing or used less & $68 \%$ \\
\hline
\end{tabular}

48. Only participants who said they had made at least a moderate effort were asked.

49. This is not necessarily a higher level of conservation than other households-most households may consider themselves conserving, and the term is relative.

50. With the exception of the data on CFL installation, which is from the Wave 2 survey, all survey results are from the Wave 3 survey (Summer 2008) and in response to direct (closed-end) questions about what activities the household changed.

51. Statistics on actions collected from open-ended responses are not comparable to those from closedended responses, so open-ended responses are not collated here. 


\begin{tabular}{|l|c|}
\hline $\begin{array}{l}\text { Central Air Conditioner - changed hours of use, used fewer hours, or } \\
\text { increased set-point }\end{array}$ & $63 \%$ \\
\hline Installed CFLs & $62 \%$ \\
\hline Cooking - changed timing, method, or foods prepared & $28 \%$ \\
\hline Pool pump - timing or duration & $20 \%^{* *}$ \\
\hline
\end{tabular}

* Many generally said laundry or mentioned clothes washing in open-ended responses

** Of the quarter of surveyed households who said that they had a pool, nearly 4 in 5 said that they changed the timing of the pool pump in response to PowerChoice.

\subsubsection{Laundry}

For many households, laundry tends to be less time-linked than most other household electricity uses, being a "background" task, separate from core family schedules, such as meal times, as well as from thermal comfort, etc. This time flexibility makes laundry relatively amenable for load shifting, whether from "regular" laundry schedules or from more haphazard practices.

Nine out of ten surveyed participants said they changed their clothes-drying habits, indicating high flexibility for this task. ${ }^{52}$ Most (75\%) shifted when they used the clothes dryer. About onethird said that they used the dryer less overall. These statements must be compared to those made by PowerChoice participants early on in discussing their practices before PowerChoiceone-third of households said that they already tended to do laundry in the early morning and late evenings. Surveying households as to their habitual actions and changes in these actions is a rough science. Other research indicates that a given household, as a survey subject, often does not "remember" the same conservation actions from one survey to the next (Woods 2003). The regular timing of domestic tasks may be fluid and variable within certain parameters, held into place by various "external" factors (e.g., when one gets home from work), and not easily reported as "absolutes." 53

In contrast to the flexibility in timing of clothes drying, few participants who did not already do so seemed willing to even partly replace automatic clothes drying with line- or rack-drying. In the Wave 2 survey (December 2007), 12\% said they always line- or rack-dried clothes, but half never did so and most of the rest did so only occasionally. Not many (18\%) said that they changed habits toward more line-drying after joining PowerChoice. The surveys probed these constraints and found that those who did not want to line-dry clothes were often emphatic about it-e.g., "I have no time for a rack or clothesline," and "Left the hanging-out clothes 20 years ago for the dryer ... we are going forward, not backward." Others mentioned that clotheslines were disallowed in their neighborhood, that they did not have space, that they did

52. The Wave 3 survey asked about changing clothes-washing habits only of those participants who had electric water heaters; 8 of the 11 respondents asked $(78 \%)$ said that they had. The open-ended responses from Wave 1 indicated a high proportion of participants shifted laundry, whether or not they had electric water heating.

53. For example, a respondent may have rarely done laundry in the late afternoons, but "shifted" by being careful to never do laundry during that period, and others who do laundry in the household may not have changed anything at all. 
not like the texture of line-dried clothes, and that it was too difficult physically due to age or disability.

Since the generally dry Sacramento climate would be amenable to line- or rack-drying most of the year, these constraints and complaints need to be taken seriously. In some developed countries (i.e., France, Italy), however, residential clothes dryers are far less common than in the United States, and domestic systems for line- and rack-drying are well established. But the results above suggest that it is not a task for which people will easily move "backward"perhaps especially under a TOU rate, which is explicitly constructed to be "rational," and, more generally, as a point of conflict between the traditional efficiency-through-technology message and conservation. Clothes drying thus presents an interesting test case for behavioral change. Making line- and rack-drying routine would require that households develop new habits, new equipment, and a new sensibility of properly doing laundry, as well as a market and social system that supports these changes (e.g., equipment availability, relaxation of neighborhood restrictions on line-drying). Relative to other behavioral measures, however, giving up the clothes dryer is potentially quite effective in terms of saving electricity, even if costly in terms of effort and time.

\subsubsection{Dishwasher}

Two-thirds of surveyed households said they changed how they did dishwashing, primarily by shifting timing (49\% of total), but also by reducing the number of cycles $(30 \%)$. One-fifth said they changed by doing the dishes by hand-which probably uses more energy (if not electricity) and water than washing by automatic dishwasher. And others did something unexpected, such as using paper plates instead of their ordinary dishware.

These reactions underscore two findings: some households took the rate very seriously and some may have unnecessarily increased their workload for possibly negative environmental or energy consumption effects. And these are not the only environmentally-wrong turns households took in trying to reduce electricity use-barbequing (air pollution) and using portable electric heaters, for example, were also mentioned.

\subsubsection{Air Conditioning}

At the end of the second summer, nearly two-thirds of surveyed participants (63\%) said they were running the air conditioner differently than before PowerChoice-most of these saying that the change was because of PowerChoice. More than half of households with central air conditioning said that they ran the air conditioning less than they used to, and only a few percent said that they ran it more. Just one in three said that they ran the central air conditioner most days during the summer. And most reported that when they did not run the air conditioner, or increased the cooling set-point to a higher temperature (less cooling), they were at worst "somewhat uncomfortable" and did so with little to no inconvenience. ${ }^{54}$

54. These are Wave 2 survey results from closed-end questioning on air conditioning and other specific actions undertaken in the first summer. 
Since air conditioning was a particularly targeted end use of the PowerChoice rate, these selfreport actions and attitudes indicate an encouraging amount of flexibility: most people seemed willing to change their usage and were able to do so without great burden.

Yet drilling down in the survey results reveals interesting contradictions and ambiguities. In the first survey, participants were asked the typical indoor temperature for a summer afternoon before PowerChoice. In the final survey, a year later, participants were asked the typical indoor temperature during summer afternoons on PowerChoice. Figure 4-3 shows the distribution of temperatures before PowerChoice. They cluster at $78^{\circ} \mathrm{F}\left(25.6^{\circ} \mathrm{C}-20 \%\right)$ and $80^{\circ} \mathrm{F}\left(26.7^{\circ} \mathrm{C}-27 \%\right)$, although one quarter reported temperatures of $83^{\circ} \mathrm{F}\left(28.3^{\circ} \mathrm{C}\right)$ and higher. Just one in ten $(12 \%)$ reported that the typical indoor temperature was lower than SMUD's typical recommendation of $78^{\circ} \mathrm{F}\left(25.6^{\circ} \mathrm{C}\right)$ as a thermostat set-point for conservation. In the expectation that older customers might prefer lower temperatures, the research team tested for correlation between age and typical temperature, and found none. Of course, these are self-reported temperatures, which do not necessarily have a close relationship to "real" temperatures.

But, in fact, the distribution of reported temperatures during PowerChoice was nearly identical to the temperatures reported for before PowerChoice. And among those who answered the questions in both surveys, nearly as many households reported a lower temperature after PowerChoice $(29 \%)$ as reported a higher temperature $(35 \%) .{ }^{55}$ There are a variety of possible explanations for this apparent inconsistency: typical temperature is an abstraction; temperature (even more than thermostat set-point) is difficult to estimate; temperatures are not uniform throughout the house; changes in air-conditioning use and indoor temperature are not in lockstep; differences in weather; and so on. However, the rocky correspondence between the two types of evidence casts some doubt on how much air conditioning practices changed overall in response to PowerChoice. If the before and after typical temperature reports are similarly biased for most surveyed households, then one might conclude that, on average, households were as conserving after PowerChoice as they were before. If this is the case, then the lack of evidence for strong changes in load, in response to the rate, are not surprising. ${ }^{56}$

55. A total of 83 participants answered the "typical temperature" question in both the Wave 1 and the Wave 3 surveys. There was no statistically significant correspondence between the difference in reported temperatures and reported changes in air conditioner use.

56. The likelihood that self-reports may not be very accurate does not, in itself, invalidate this argument. 


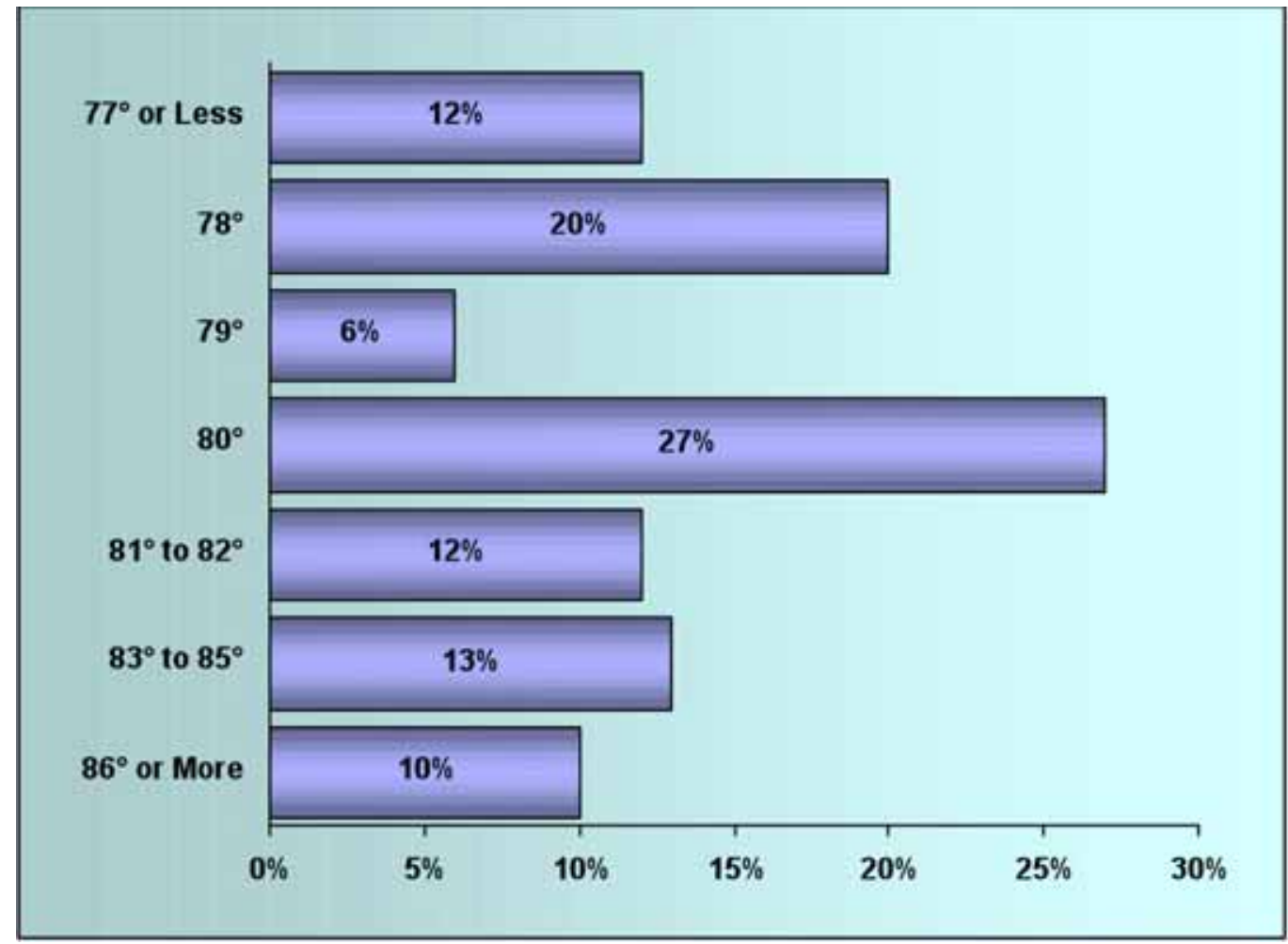

\section{Figure 4-3. Self-reported typical indoor temperature in home before joining PowerChoice}

\subsubsection{Change In Cooking or Meal Time}

Cooking and meal times can require fairly intricate orchestration for households of more than one person. Yet quite a few participants reported making changes to cooking or meal routines. More than one in four households said that they changed something related to meals, whether by shifting timing (16\%), changing cooking methods-such as barbequing or using the microwave $(9 \%)$ - or eating and cooking less, or eating cold meals $(8 \%)$.

\subsubsection{Pool Pump}

A quarter of surveyed households reported having pools. Apart from solar-heated pools, none were electrically heated, yet pool pumps can have high annual loads. ${ }^{57}$ For pool filtering practices, there was a remarkable level of reported change in practices. Four out of five pool owners said that they changed how they managed their pool pumps after joining PowerChoice. Including the few who already ran their pool pumps Off-Peak, $90 \%$ of pool owners said that they avoided running the pool pump during the Super-Peak hours, and most of these (35 out of 45) said they changed timing in response to PowerChoice. Many also reduced the duration that the pump ran.

57. Incidentally, only $18 \%$ said that they regularly used a pool cover. 
Pool pumps are a relatively easy thing to change, in that usually the change involves setting the timer once, and there are otherwise probably little or no costs in terms of inconvenience, comfort, or effort. There may, however, be costs to pool maintenance, and pool maintenance professionals might recommend against reductions in pool pump run time or changes in timing. ${ }^{58}$ The introductory material for PowerChoice sent by SMUD mentioned changing the timing of a pool pump as a possible measure to take under PowerChoice, along with many other tips. While SMUD has a residential pool program, to the research team's knowledge, this is the only communication about pool pump timing that PowerChoice participants receivedother than the fact that each of the three surveys fielded for this research project asked about pool pumps. So it is interesting that almost all pool owners figured out that it was an effective, easy, action to take.

\subsubsection{Other Changes and the General Mood}

Survey respondents mentioned over two dozen other shifting, conservation, and purchase responses to the PowerChoice tariff. Some described generic actions ("we try not to use any electricity during Super-Peak hours"), while others indicate fairly elaborate attempts to change electricity use patterns. To give examples:

- "We go for a walk instead of watching TV."

- "We try to use our crock pot or grill rather than using our oven, turning down AC during that period."

- "We cook dinner before 5:00 p.m. and we go to bed early."

- "Don't use the dishwasher between 5:00 and 8:00, or the iron, or turn the AC as high or keep it on as long. Close doors."

- "I only eat or watch TV between 5:00 to 8:00. I do things in early morning."

- "A lot more barbequing and outside stuff."

- "Not doing laundry, and have lights off in bedrooms when not in there; use computers in the morning."

\subsection{Conditions, Constraints, and Evolution}

\subsubsection{What Participants Resisted Changing and Why}

There were certain actions that some customers said they would not or could not change, or could do so only with difficulty.

- Reducing air conditioning was difficult for households with sensitive members, such as the elderly, the sick, people with medical conditions (such as asthma), or, in at least one case, a pet. But only $10 \%$ of households mentioned such special needs.

- As noted above, one conservation action that few households seemed willing to undertake was line- or rack-drying clothes, as opposed to using the clothes dryer.

58. Personal communication, Vikki Wood, SMUD. 
- Probing the household's interest in getting more detailed and customized information on their household's energy use, participants were asked about home energy audits. Just one in five said they had ever done a home energy audit, one third of these in reported response to PowerChoice. But, of the rest, most said that they were not planning on getting one, and when asked why, some answers seemed defensive-“I don't need anybody to tell me how to conserve energy," or "I am pretty sure I have a fair handle on our electricity use" - while others had never thought about it and said they would not know how to go about it.

- Asked whether they could think of reasons why they would be either less successful or more successful at adjusting to PowerChoice, half said that there were reasons they would be more successful at adjusting to PowerChoice. Only a handful said that they could think of reasons that they would be less successful.

\subsubsection{Household Dynamics}

Households are not static over time, nor are they equivalent to individual decision-makers. Each household is an organization, with households containing more than one person managed by multiple people. Surveys, however, almost invariably capture the responses of only one person. The same is true with the surveys administered for this research project, though all tried to capture information about other household members and the dynamics among them.

Some survey respondents also noted tensions within the household, such as disagreements between spouses or with children about when to eat, when to do chores, or when entertainment devices could be used. Others mentioned different preferences for air conditioning among members of the household. In fact, one-third of households with more than one member mentioned that some household members were affected more than others were by the household's response to PowerChoice.

Some one out of ten mentioned disagreements about energy management among household members. Among those, disagreements turned around differences in opinion about when to run appliances, forgetting to turn off lights, temperature-setting levels, time-shifting, and the degree to which household lifestyle should change. Some of the open-ended responses reveal internal tensions (e.g., "cheating" by turning on the air conditioning because of feeling too uncomfortable) and, for others, familial strains concerning meal times and the timing and execution of cooking, baking, and household chores, e.g.:

- "I told my wife, never run the dishwasher before 10:00 at night; also advised her we shouldn't do laundry between noon and 10:00 p.m. during the summer."

- "Bake only in the evening."

Among households with more than one person, $60 \%$ said attention to power bills was shared by more than one individual.

A recent Swedish study on household energy conservation suggests that impacts from increases in household energy conservation may fall disproportionately on women (Carlsson-Kanyama \& Lindén 2007). Their interviews showed that women's workload increased in response to TOU rates and to general calls for conservation-more so than for men, since women tended to take on more household chores than did men. Pressure to shift times of use led to washing late at night or on weekends. Pressure to not use the clothes dryer translated to greater time required 
to complete the laundry process. A gender differential cannot be tested with the structure of the study of SMUD PowerChoice participants, but the Swedish study's argument opens a more general line of inquiry. As seen in these responses, conservation and Time-of-Use shifting, generally considered morally good in public energy education campaigns, may be stressful to individuals and families, whether or not efforts are needed or effective from a power system point-of-view.

\subsubsection{Home During the Day}

While having someone routinely home during the day may give a household more flexibility in when household tasks are performed, it also increases the likelihood of discretionary (i.e., not baseline) demand for energy services during the period. Almost two out of three surveyed respondents said there was usually somebody home during the weekday daytime hours (8:00 a.m. to 5:00 p.m.). SMUD's 2001 Residential Appliance Saturation Survey (RASS) suggests that comparable levels-only slightly lower-may be typical for the SMUD service territory, indicating 57\% of SMUD customer households have someone at home using the air conditioner during summer weekdays between 1:00 p.m. and 5:00 p.m. ${ }^{59}$ Though being away during the mid-afternoon would presumably be a favorable routine for savings on a TOU rate, only one in ten of the PowerChoice survey respondents said it was rare for someone to be at home during the day.

\subsubsection{Household Circumstances Change}

One problem in tracking changes across multiple years is that people's lives-and their households-evolve. For example, a third of households said that they rarely or never followed a set routine. One in ten households said they had more or fewer members during the course of the year.

Furthermore, the technical characteristics of the house often changed over the year as well. One in three households said that they added or replaced major equipment during the course of PowerChoice-often adding a large-screen TV, for example. In some cases, the respondent implied that some changes made may have been partly motivated by PowerChoice, such as a whole-house fan or replacing an electric dryer with a natural gas dryer. A handful of households also undertook major remodeling during the year, such as all new kitchen equipment, new windows, or new doors.

A simple analysis of those who said (in the Wave 3 survey) that they had remodeled or made a major appliance purchase over the previous nine months revealed that these households were somewhat more likely to report that they had made a "great deal of effort" to adjust to the PowerChoice rate (75\% vs. $60 \%$ ). So the PowerChoice rate or the attention it focused on energy use may have served as the rationale for some of these changes. Those who said that they had made changes were more likely to judge their efforts to have been very or moderately

59. Personal communication, Vikki Wood, SMUD. 
successful than those who did not report changes (100\% vs. $80 \%$ ); it was not determined whether these households were more successful in reducing energy use or bills. ${ }^{60}$

\subsection{Experience with the Technical Details of the Rate}

\subsubsection{Understanding the Rate}

Judging from survey responses, generally, most participants appeared to understand the rate fairly well. However, some mentioned that it was hard to remember the times of day that the rates changed and quite a few said that the rate was too complicated.

\subsubsection{Reading and Critiquing the Bills}

Most customers found their TOU bills useful, but many wanted more information or said they preferred a simpler or easier-to-read format. The most common request was for the bill to provide comparative information, showing whether the households had saved money on the rate. Since there was not such comparative information, customer perceptions of savings or losses on the rate were based on their own calculations, their own bill comparisons, or intuition.

The PowerChoice bill contained the essential information, but was not designed for easy reading. Figure 4-4 provides a sample with customer information removed. The bill is technical, in that it includes information for all TOU tariff periods, whether or not they are applicable during the particular billing period. Asked directly, most survey respondents said they understood their PowerChoice bill and found it useful. ${ }^{61}$ Ontario's study on residential pilot TOU found that participants said that their monthly usage statements were very useful in adjusting to the TOU rates (Ontario Energy Board 2007), confirming other studies suggesting that bills are potentially a very important tool for customer learning (Iyer et al. 2006; Wilhite \& Ling 1995).

60. The sample size for this analysis is not large (73 households), since only Wave 3 respondents who had also responded to Wave 2 were asked this question.

61. Among Wave 3 respondents, 35\% said they found it very useful, and $46 \%$ said "somewhat useful." Obviously, bills are generally useful, in that they say how much one has to pay. 


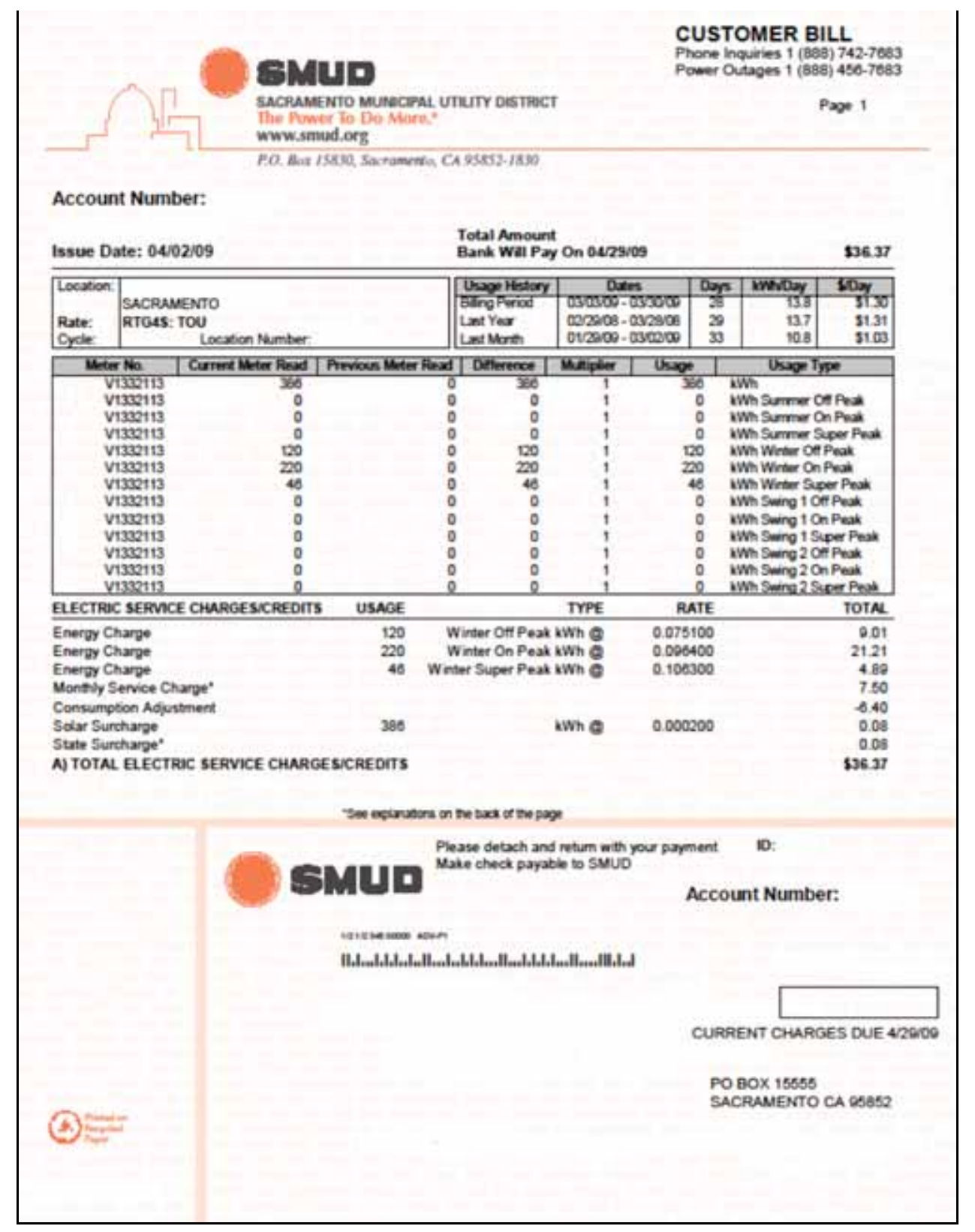

Figure 4-4. Sample PowerChoice customer bill

Many surveyed customers commented that PowerChoice bills were too complicated and too technical, and should be recast in plainer language. Others said that the bills showed some information not needed by the customers, such as line items for billing periods that were inapplicable that month, but not other information that they would like-for example, the times for each rate period or more information about particular charges. Some said they wanted more detailed information about their usage, such as a day-by-day breakdown. Especially for households without feedback monitors, the latter comment points to the sparse data environment that PowerChoice customers faced in trying to manage electricity use relative to an intricate rate, but with only crude information about relative costs of various usage decisions. The rate itself, some said, was far too complicated-with up to five different periods in a single day, plus variations by weekend versus weekday and four seasonal transitions per 
year. This level of complexity of the PowerChoice schedule is not exceptional; most residential TOU rates, for example, have five different periods in a day (i.e., Super-Peak, plus Off-Peak and On-Peak periods both in the morning and the afternoon). Most (80\%) of those surveyed said that they found SMUD's postcard reminders of rate changes very useful. Some took the bill as is, saying that they "trust[ed] SMUD not to cheat them."

Given that the primary motivation for signing on to the PowerChoice rate was bill savings, it is not surprising that one suggestion that came through repeatedly was that the bill should show how much money was being saved by being on the rate. The comparison could be either the bill calculated on the standard rate or the customer's same-house bill for the previous year. Without such a comparison, participants stated, it was difficult to know whether shifting and conservation efforts were successful or not. Clearly, providing this information could cause dissatisfaction, to the extent that customers may have been paying more on the TOU rate despite their efforts. This is especially problematic with the seasonal design of the rates, in which it would be harder to save money on the rate in the summer as compared to the winter.

\subsubsection{The Consumption Adjustment}

The PowerChoice tariff's consumption adjustment troubled many customers whose monthly electricity consumption exceeded the 1,000 kWh level, as evidenced by survey responses. Though in most cases the surcharge was modest, it could be up to $50 \%$ of the base bill amount (for consumption over 3,000 kWh) —even $\$ 200$ or more. For electricity usage less than 1,000 $\mathrm{kWh}$ per month, a credit would be applied. No surveyed customer using less than 1,000 kWh explicitly mentioned the corresponding consumption credit. The credit or charge showed up as a line item on the bill. The consumption adjustment was intended to reward customers for lower consumption, as opposed to just shifting, but customers tended to read it as a fine.

Though high-usage customers might be able to shift usage a great deal, if they could not reduce their consumption to 1,000 kWh overall—unlikely for a customer habitually using 1,500 kWh per month, for example-they would pay a surcharge that eroded savings from shifting. Some criticized the risk structure, where a difference of a single kWh over a month could make the difference between a percentage credit versus a percentage surcharge. A tiered TOU rate, where only the excess usage over a certain amount was charged at higher rates, would have been preferable from the perspective of reducing risk to customers.

An analysis of customers who dropped off the rate showed that they were most often customers with high usage who had been assessed the consumption charge for several months. However, many customers who received the consumption charge remained on the rate and, based on survey results, some appeared not to have noticed the charges.

\subsection{Overall Perceptions and Satisfaction}

According to the first survey, during the first months of PowerChoice, many customers thought that they would be saving more on the rate than they actually did. Other residential TOU pilots have also shown that customers expected more savings than they received. Ontario customers on a TOU rate showed average savings of about five dollars over the entire seven-month study period, ranging from a $\$ 63$ net gain to a $\$ 41$ net loss, with $36 \%$ having no savings or a loss 
(Ontario Energy Board 2007). ${ }^{62}$ Despite these modest financial gains, when asked whether they would recommend the TOU tariff to a friend (Ontario Energy Board 2007), only 3\% (10 out of 298) said that the rewards were not worth the trouble. ${ }^{63}$

In the case of PowerChoice, at the end of the second summer, after adjusting expectations and practices, half of surveyed participants said that they thought they had saved money on PowerChoice, with two in ten saying that they thought they spent more on PowerChoice than they would have otherwise.

At the end of the second summer, seven out of ten surveyed customers said that they were satisfied with PowerChoice. Those who thought they had spent more on PowerChoice than they would have otherwise tended to be the least satisfied, but even in those households where the respondent thought they had spent more, less than half said they were dissatisfied with PowerChoice.

62. The cited results are for TOU-only customers, without critical peak pricing (CPP). Those with CPP showed somewhat higher, but still modest, savings.

63. As to the high rate of positive response, some survey respondents may have been reticent to be less than positive in their evaluation, given the probably frequent assumption that survey staff were Ontario Energy Board representatives that had stakes in the respondents' answers. 


\subsection{What Participants Said: Information Interventions}

Two information interventions were applied experimentally to subsets of PowerChoice participants - an Enhanced Information Treatment and a Monitor Treatment. As shown in Chapter 3, these treatments had little statistically detectable effect on electricity load in terms of increasing the capacity of participants to adjust their patterns of electricity use to the PowerChoice TOU tariff. Analysis of the survey data, however, found modest but coherent differences between what the Enhanced Information Group reported doing and what others on the PowerChoice rate reported doing. As to the Monitor treatment, telephone follow-up and surveying indicated that almost everybody in the Monitor Treatment group seems to have successfully installed the feedback monitor in their homes and most found the monitor useful. This chapter presents survey results analyzed with respect to both of these experimental treatments. It also includes a summary of what survey respondents said when asked directly about their experience with these treatments. The detailed analysis of selected survey questions presented in Appendix E also tabulates most results separately for the Enhanced Information Treatment group.

\subsection{Basic Background and Results}

As discussed in Chapter 1, two formal information treatments were administered to PowerChoice participants:

- Enhanced Information Treatment. This treatment was administered to a randomly selected set of participants, comprising about half of the total PowerChoice participant population who had begun on the rate in summer 2007. ${ }^{64}$ It consisted of a series of "newsy" (content-rich) letters sent periodically throughout the project period and a magnet, where tariff details were presented for easy reference. This treatment was intended to provide some technical information in combination with elements of Community-Based Social Marketing. An example letter is presented in Appendix B.

- Monitor Treatment. This treatment was administered to 50 households who volunteered to accept and install a wireless electricity-use feedback monitor. ${ }^{65}$ Recruitment offers were directed to households who had started on the rate in summer 2007, including some already assigned to the Enhanced Information Treatment.

The research team analyzed the survey data in the final survey results (Wave 3) with respect to the presence or absence of each treatment.

- Based on the survey data, the Enhanced Information Treatment had an effect on what treated participants reported doing in response to PowerChoice. In their survey responses, households in the Enhanced Information Treatment group were more likely

64. As discussed in Chapter 1, some households were added onto the rate in late 2007, due to problems with meter installations. These late-on households thus do not have summer 2007 load data and were not used in the comparisons of the treatment vs. non-treatment group presented in this chapter.

65. Prior to receiving their monitor, volunteers were asked to sign an agreement stating their commitment to install the monitor and to be a participant in a follow-up survey regarding their opinion of the monitor and their use of it. 
to emphasize shifting and more likely to say that they had undertaken some of the suggestions made in the extra information that they received, but were perhaps less likely to say that they had undertaken other actions. They reported using the central air conditioner more infrequently than other surveyed households, though no difference in self-reported "typical indoor summer temperature" was detected between the Enhanced Information Treatment group and other surveyed participants. The differences in reported actions between the treatment and non-treatment group were moderate, but consistent, and sometimes statistically significant. If not exhibiting actual differences in actions, the Enhanced Information Treatment group learned to "speak the language" somewhat more than non-treated households. Asked whether they found the extra information they received useful, most in the Enhanced Information Treatment group said "yes."

- Almost all the Monitor Treatment group households surveyed said that they successfully installed the monitor and all but a handful said that they found the monitor useful. Some mentioned specific changes that they made that were prompted by using the monitor and others mentioned a more general consciousness. There were no particular differences in the actions that the Monitor Treatment group said that they undertook compared to other surveyed PowerChoice households. Because people in the Monitor Treatment group were volunteers, rather than randomly assigned to the group, their experience does not statistically represent what would happen if monitors were given to other households. Also, as participants in a rate pilot and research project, the Monitor Treatment group received assistance and encouragement that the average monitor customer would generally not be given.

The remainder of this chapter presents more detailed results for each of the treatments, and interprets results in light of the literature on providing energy-relevant information to households and the prospects for future residential TOU rates.

\subsection{Background on Energy-Relevant Information}

In the literature on influencing the energy-relevant behavior of residential energy users, there are two theories on the usefulness of information. One theory frames lack of information as a barrier to more "rational" use of energy. In this case, information is seen as one of the two important levers - the other being financial incentives-that increase the adoption of energyefficient technologies or energy-conserving actions. But another theory is that information may increase people's level of knowledge, but not their propensity to act more energy efficiently or toward conserving more energy. In this view, information may do little if any good, since there are other reasons that people do not adopt the measures that a given program would like them to. Furthermore, the information provided may be inaccurate, not trusted, only partly applicable, non-actionable, or irrelevant. The promised benefits of the action may not outweigh its perceived costs, or intended recipients may not want or feel that they need more information. There is no fundamental conflict between these two views-information is too vague a term. How information changes energy use depends on which information, delivered to which people, in what form, and toward what ends.

In the case of a TOU rate, residential customers operate in a clearly information-poor environment relative to the intricacy of the rate. Even energy professionals may usually have at 
best a vague idea of the energy implications of one energy-relevant action over another when managing energy in the home. From a rationalistic perspective, more information would be critical for a residential consumer to adjust efficiently to the TOU rate, but how much effect this information would have, if any, is unknown.

To examine the effect of information on behavior, the research project tested two information interventions on PowerChoice customers. The Enhanced Information Intervention was influenced by McKenzie-Mohr's (1999) Community-Based Social Marketing (CBSM) strategy. The intervention was structured to enhance the normative perceptions of program participation by encouraging a sense of community among participants. The second was a feedback intervention, using a readily available whole-house meter to help consumers understand their use of electricity in their homes.

Thus, the research project was designed to test whether providing some specific types of extra information would increase a household's capacity to best adjust their actions to the rate. This increased capacity should manifest as either increased demand response from the consumer or as decreased effort to deliver demand response, or some combination of the two. Only the load response aspect of the possible response can be tested.

\subsection{Enhanced Information Treatment}

The information approaches for the Enhanced Information Treatment were originally conceived as newsletters sent independently of the utility itself. As it turned out, sending independent newsletters was against SMUD policy. The solution was for the research team to draft letters, rather than newsletters, and to have this material reviewed by SMUD and sent out under the SMUD brand as letters from the PowerChoice program manager. In the spirit of CBSM, the letters thus further promote a sense of partnership between the treatment group and SMUD-a relationship already established with all PowerChoice customers, not only as regular SMUD customers, but also through other PowerChoice-related mailings (program recruitment materials, administrative letters, and rate-change postcards). However, this approach fails to distinguish itself as an independent, non-routine source of information.

The Enhanced Information Treatment began in the fall of 2007, with 125 randomly selected households assigned to this group. By the end of the summer of 2008, the households in the Enhanced Information Treatment group had received four special letters. These letters suggested ways that households could adjust their electricity usage to fit the PowerChoice TOU rate, promoted challenges to the households' normative energy use, and attempted to promote a sense of community for the selected customers. In addition to the letters, each household in the treatment group received a refrigerator magnet showing the PowerChoice rate periods and prices. This magnet was intended as a prompt, a frequent element in Community-Based Social Marketing.

Table 5-1 summarizes the intervention stream.

Table 5-1. Schedule for information interventions

\begin{tabular}{|l|c|c|}
\hline $\begin{array}{l}\text { Information } \\
\text { Intervention }\end{array}$ & Timing & \multicolumn{1}{c|}{ Topics } \\
\hline$\# 1:$ & $\begin{array}{c}\text { October 5, } \\
2007\end{array}$ & $\begin{array}{c}\text { Letter from program manager establishing contact. Topics covered: } \\
\text { • Coming to a Refrigerator Near You upcoming magnet }\end{array}$ \\
\hline
\end{tabular}




\begin{tabular}{|c|c|c|}
\hline $\begin{array}{l}\text { from } \\
\text { Program } \\
\text { Manager }\end{array}$ & & $\begin{array}{l}\text { - Saving by Degrees (AC may be over, but did you know AC can } \\
\text { account for up to } 40 \% \text { of summer bill?) } \\
\text { - Fall's Natural Cooling System (close-up during day and open-up at } \\
\text { night) } \\
\text { - More Resources (SMUD.org or call to talk to auditor about } \\
\text { residential programs) } \\
\text { - Help The PowerChoice Community (asking for input/stories/ideas) }\end{array}$ \\
\hline $\begin{array}{l}\text { \#2: } \\
\text { Second } \\
\text { Letter }\end{array}$ & $\begin{array}{l}\text { December 13, } \\
2007\end{array}$ & $\begin{array}{l}\text { Letter from program manager. Topics included: } \\
\text { - A Whole Lotta Changes Going On (summer changes reported in } \\
\text { Wave } 1 \text { survey: laundry AC and cooking) } \\
\text { - Keep On Saving This Winter (make it a habit to do laundry and } \\
\text { cooking off peak, challenge family members, install a CFL, let } \\
\text { sunshine in, seal and insulate, connect to experts) } \\
\text { - PowerChoice Rate Magnet Coming Soon! } \\
\text { - Thanks for Your Help (for participating in the survey) }\end{array}$ \\
\hline $\begin{array}{l}\# 3 \text { : } \\
\text { Magnet and } \\
\text { Feedback } \\
\text { Reply } \\
\text { Postcard } \\
\end{array}$ & $\begin{array}{l}\text { February } 1 \\
2008\end{array}$ & $\begin{array}{l}\text { Mailing of magnet. Included was a postcard contest asking for input/ } \\
\text { stories/ideas. Ten respondents were sent } \$ 25 \text { Home Depot gift cards. }\end{array}$ \\
\hline $\begin{array}{l}\# 4: \\
\text { Third Letter } \\
\text { from } \\
\text { Program } \\
\text { Manager }\end{array}$ & $\begin{array}{l}\text { April 11, } \\
2008\end{array}$ & $\begin{array}{l}\text { Letter from program manager. Customer-reported actions/tips } \\
\text { (postcard replies) included: } \\
\text { - Running major appliances after 10:00 pm } \\
\text { - Doing laundry and dishes on the weekend } \\
\text { - Running laundry on light wash and with full loads } \\
\text { - Bundle up (bed and body) } \\
\text { - Avoid super-peak electricity use } \\
\text { - Make it fun for the family to participate } \\
\text { - Get a whole-house fan and screens now to prepare for summer }\end{array}$ \\
\hline $\begin{array}{l}\# 5: \\
\text { Fourth Letter } \\
\text { from } \\
\text { Program } \\
\text { Manager }\end{array}$ & $\begin{array}{c}\text { August 7, } \\
2008\end{array}$ & $\begin{array}{l}\text { Letter from program manager. Focus on Summer } 2008 \text { rate period: } \\
\text { - Set } A C \text { (to } 78^{\circ} \text { or higher, or } 85^{\circ} \text { when not home) } \\
\text { - Change } A C \text { Filter } \\
\text { - Pre-cool (house before Super-Peak) } \\
\text { - Shift (heat-producing appliance use to Off-Peak-from 10:00 pm } \\
\text { to noon-air-dry dishes, and cook when cooler) } \\
\text { - Close (windows and drapes during the day) } \\
\text { - Install (CFLs) } \\
\text { - Turnoff (lights, electronics, and appliances when not in use) }\end{array}$ \\
\hline
\end{tabular}

* The mailing of the magnet was delayed because of increases in SMUD residential tariffs beginning January 1, 2008 (see Chapter 1).

Though only a small proportion ( $8 \%$ ) responded to the contest announcement, nearly a quarter of households in the Enhanced Information Treatment group wrote in throughout the course of the treatment. The interchanges created some active community experience as well. The fact that customers in the Enhanced Information Treatment group were more likely to say that there 
were discussions about energy use in the home also reflects an increased community emphasis. ${ }^{66}$

\subsubsection{Effect on Reported Actions}

As indicated in Chapter 3, the Enhanced Information Treatment resulted in no or little statistically detectable difference in price response to the TOU rate. However, according to survey responses, the Enhanced Information Treatment group participants were found to be:

- More likely to stress shifting rather than conservation in stated actions.

- More likely to say they avoided air conditioning during the Super-Peak period.

- More likely to undertake actions encouraged in newsletters.

- Possibly less likely to undertake actions that were not mentioned in the newsletters.

More detailed evidence from the survey data is presented below. These differentials may reflect an actual increased propensity to shift among the Enhanced Information Treatment group relative to others; but they could also reflect that this group, because of the extra information they received, became more attuned to talking in a framework that fit the shifting paradigm.

For major survey questions where the answers given by the Enhanced Information Treatment group were notably different than those of other survey participants, Table 5-2 shows the Wave 3 results for the treatment group as compared to all others. With a few exceptions (as marked), the majority of differences shown in the table are statistically significant. Nearly all survey respondents seemed to understand the importance of the emphasis on shifting or otherwise reducing electricity use during Super-Peak in order to save money on the rate. But based on survey responses, participants in the Enhanced Information Treatment group were even more likely to emphasize shifting over conservation. Among the Enhanced Information Treatment group participants surveyed, $45 \%$ said that they only shifted, as compared to $29 \%$ of other surveyed participants. And nearly a quarter of non-treatment group participants agreed that they "used electricity whenever they wanted," while just one in ten Enhanced Information Treatment group participants did.

66. In the Wave 3 survey, 32\% of Enhanced Information Treatment households with more than one member said there were discussions in the home about changes in energy use due to PowerChoice, compared to $20 \%$ of non-treatment households with more than one member. 
Table 5-2. Differences in stated actions between Enhanced Information Treatment group and all others, based on responses to Wave 3 survey

\begin{tabular}{|c|c|c|c|}
\hline $\begin{array}{l}\text { Question } \\
\text { Relevant Answer }\end{array}$ & $\begin{array}{c}\text { Enhanced } \\
\text { Information } \\
\text { Group }\end{array}$ & All Others & $\begin{array}{l}\text { Statistically } \\
\text { Significant } \\
\text { at } p=0.10\end{array}$ \\
\hline \multicolumn{4}{|l|}{ Emphasis on shifting: } \\
\hline $\begin{array}{l}\text { Would you say that the PowerChoice rate prompted you to? } \\
\text { Answer: Shift only }\end{array}$ & $45 \%$ & $29 \%$ & Yes \\
\hline $\begin{array}{l}\text { Would you say that the PowerChoice rate...? } \\
\text { Answer: Did not make much difference how you used energy }\end{array}$ & $4 \%$ & $13 \%$ & Yes \\
\hline $\begin{array}{l}\text { In July and August, we used electricity whenever we wanted: } \\
\text { Answer: } \mathrm{Yes}^{2}\end{array}$ & $10 \%$ & $24 \%$ & Yes \\
\hline $\begin{array}{l}\text { In July and August, we lowered usage during the Super-Peak: } \\
\text { Answer: Yes }\end{array}$ & $94 \%$ & $87 \%$ & No \\
\hline \multicolumn{4}{|l|}{ Changes in central air conditioner use: } \\
\hline $\begin{array}{l}\text { Are you running your AC differently now? } \\
\text { Answer: Yes }\end{array}$ & $68 \%$ & $58 \%$ & No \\
\hline $\begin{array}{l}\text { Compared to before PowerChoice, how often do you use air } \\
\text { conditioning between noon and } 5 \text { p.m.?: } \\
\text { Answer: About the same as you did before }\end{array}$ & $29 \%$ & $41 \%$ & Yes \\
\hline $\begin{array}{l}\text { Between } 5 \text { p.m. and } 8 \text { p.m., do you use the AC less than you } \\
\text { used to? } \\
\text { Answer: Yes }\end{array}$ & $73 \%$ & $58 \%$ & Yes \\
\hline $\begin{array}{l}\text { This summer, did you pre-cool your home before Super- } \\
\text { Peak? } \\
\text { Answer: Yes }\end{array}$ & $21 \%$ & $13 \%$ & No \\
\hline $\begin{array}{l}\text { How often do you use air conditioning? } \\
\text { Answer: Only a few times a week }\end{array}$ & $31 \%$ & $15 \%$ & Yes \\
\hline \multicolumn{4}{|l|}{ Other changes: } \\
\hline $\begin{array}{l}\text { Did you shift dishwashing to a different time? } \\
\text { Answer: Yes }\end{array}$ & $56 \%$ & $42 \%$ & Yes \\
\hline $\begin{array}{l}\text { Did you change the timing of pool pump use? } \\
\text { Answer: Yes }\end{array}$ & $71 \%$ & $83 \%$ & No \\
\hline $\begin{array}{l}\text { Do you run the pool pump less often now? } \\
\text { Answer: Yes }\end{array}$ & $24 \%$ & $38 \%$ & No \\
\hline \multicolumn{4}{|c|}{$\begin{array}{l}\text { Respondents chose among five answers: shift (change times when you use electricity), conserve (use less electricity), both shift } \\
\text { and conserve, didn't make much difference, and don't know/refused. }\end{array}$} \\
\hline \multicolumn{4}{|c|}{$\begin{array}{l}\text { A positive response to this question (we used electricity whenever we wanted) seems to conflict with a positive response on the } \\
\text { next one (we lowered usage during the Super-Peak). Yet some respondents said "yes" to both questions, revealing, in part, the } \\
\text { flexibility of the term want when it comes to energy use. }\end{array}$} \\
\hline \multicolumn{4}{|c|}{$\begin{array}{l}\text { Among the Enhanced Information group participants surveyed, } 62 \% \text { said a lot less or somewhat less, compared to } 53 \% \text { among } \\
\text { all other surveyed participants. }\end{array}$} \\
\hline \multicolumn{4}{|c|}{$\begin{array}{l}4 \text { Respondents chose among six options: every day, on most days, only a few times a week, only a few times a month, less than a } \\
\text { few times a month, and never. The table shows results only for the third option; combining across a few times a week and all less } \\
\text { frequent uses, the differences between the Enhanced Information group and all others is less dramatic than that shown in the } \\
\text { table- } 48 \% \text { of the Enhanced Information Treatment group say a few times a week or less, compared to } 40 \% \text { of all others. }\end{array}$} \\
\hline
\end{tabular}


Managing central air conditioning was also especially emphasized in the letters sent to the Enhanced Information Treatment group and surveyed treatment group participants also appeared to be more focused on air conditioning as a key end-use, as compared to other survey respondents. For example, compared to non-information treatment group participants, treatment group participants were more likely to say that they had reduced air conditioning use between 5:00 p.m. and 8:00 p.m., relative to previous practices, and more likely to say that they used air conditioning only a few times per week. Treatment group participants were also more likely to say that they pre-cooled their homes before Super-Peak ( $21 \%$ vs. $13 \%)$, though the practice is still relatively rare.

There is a flip side to the apparent increased emphasis on shifting seen among Enhanced Information Group participants. Based on other survey responses, the Enhanced Information Treatment group may have been less likely to undertake specific actions that were not mentioned in the intervention letters. For example, as shown in Table 5-1, adjusting the pool pump was slightly less common among Enhanced Information Treatment group participants as compared to others, as was using the pool pump less-neither of which were actions discussed in the treatment letters. In addition to the differences shown in the table, there were additional marginal differences. For example, participants in the Enhanced Information Treatment group were slightly more likely to say that they shifted cooking and meal times (31\% vs. $27 \%)$ and less likely to say that they cooked less ( $7 \%$ vs. $12 \%)$ compared to other households. Such differences take on significance, not individually, but because of the direction and consistency.

The increased emphasis on shifting may have decreased conservation actions-with uncertain effects on demand response and a possibly negative effect on the environment, since conservation generally reduces pollution, but shifting does not necessarily do so. Honing down to particular shifting actions, one possible consequence of the Information Treatment may have been to decrease the number of actions that treated participants took-decreasing the effort required to manage electricity relative to the rate, but not increasing demand responsiveness. But neither of these possible consequences can be definitively proven and, again, the survey responses may not reflect actual differences in actions. In any case, the findings raise the possibility of "unintended consequences" of information that goes along with a TOU program, insofar as these programs are intended to be consistent with absolute reductions in energy consumption or greenhouse gas emissions.

Whether these differences are in what people did, or what they said they did, cannot be answered. As Abrahmse et al. (2005) note in their discussion of behavioral interventions aimed at residential energy consumption-information can make people better informed, it just does not necessarily make them act differently. ${ }^{67}$

\subsubsection{General Reaction to the Enhanced Information Treatment}

Asked whether they found the periodic letters they received useful, a moderate majority (58\%) of the Enhanced Information Treatment Group said that they were. Nearly three in ten said that they were not useful at all, and a substantial minority said that they did not recall getting them,

67. Though also note that, statistically, it is easier to test differences in survey responses than in load data, which exhibits more variation and noise, accordingly making signals more difficult to detect. 
did not read them, or did not know (15\% of total). For this question, there may have been some difficulty in distinguishing the treatment correspondence from routine PowerChoice communications. ${ }^{68}$ Open-ended comments by survey participants also indicated that some customers engaged with the letters and used the tips expressed there. But the only conclusion that can solidly be made here is the mild one that some of the letters sent as part of the Enhanced Information Treatment were useful to some customers.

The Enhanced Information Treatment seemed to make a difference as to how participants viewed their experience on the program. While stated satisfaction levels were about even, those in the Enhanced Information Treatment group were less likely to say that they had spent more on the rate, as compared to other participants (12\% of the treatment group versus $23 \%$ of others), and more likely to say that they thought there were reasons why their household would be more successful than other households at adjusting to PowerChoice (54\% of the treatment group versus $29 \%$ of others).

\subsection{Monitor Treatment Group}

\subsubsection{Background - Feedback Meters}

Feedback on electricity consumption, in various forms, has gained recognition as one of the most successful forms of interventions for decreased residential electricity use. Savings estimates vary, depending on the situation and form of feedback, but are usually quoted to be in the range of 5\% to 15\% (Darby 2006). Residential feedback meters, displaying electricity consumption in near-real time for residential electricity users, have gained recognition as one of the most successful forms of intervention.

The research team did extensive analysis of potential monitors to use for the experiment, deciding ultimately on Blue Line Innovation's PowerCost monitor. The fact that consumers could install the meter on their own, as well as its functionality-especially the cost information it provided-fit well with the research emphases to use interventions that would fit consumers' lifestyles. In allowing users to track absolute prices, the monitors could also convey to the consumers what energy-use choices were more or less expensive than were others.

\subsubsection{Meter Group Recruitment}

In spring 2008, PowerCost monitors were offered free of charge to all customers on the PowerChoice tariff who had started on the rate in summer $2007 .{ }^{69}$ Because analyses would require a comparison of interval meter data between Summer 2007 and Summer 2008, late-

68. As a control, we asked survey respondents who were not in the Enhanced Information Group the same question-whether they found the letters useful or not-expecting that most would say, "Did not receive them." This was not the case. Nearly as large a proportion of the non-treatment group also said that these communications were useful (51\%), apparently referring to routine mailings from SMUD about PowerChoice. Many in the Enhanced Information Treatment Group likely did not readily distinguish the information treatment from the routine mailings.

69. The research project had 50 monitors available to distribute to PowerChoice customers. Since monitor users must install the monitor and try to use it for it to have any effect, to avoid too small a sample size, it was necessary to seek volunteers to accept and use the monitor, rather than to randomly assign the Monitor Treatment. A total of 191 households were offered a monitor, on a first-come, first-served basis. 
starting households were excluded from the offer. Exactly fifty households accepted, matching the number of monitors available. The modest uptake suggests limited enthusiasm, even among PowerChoice participants. ${ }^{70}$ Some of these households were also in the Enhanced Information Treatment Group. In June, just before the second summer of the PowerChoice tariff, PowerCost monitors were distributed to participating households, preset with the summer TOU rates.

Review of other programs where monitors were used indicated that some recipients had trouble setting up and using the monitor. Thus, the research team made special efforts to ensure that households were able to install and knew how to use the monitor. All households who accepted a monitor were also given a guidebook, designed by the project team, providing detailed set-up information and additional information, such as experiments that the customers could undertake to learn how to use and properly interpret the monitor feedback (Appendix C, APC4-7). This material supplemented the standard instruction book that accompanied the monitor. Follow-up phone calls were also made to every household to check that the monitor had been received and installed. SMUD also fielded calls from customers and, though problems were rare, the utility sent out a technician to assist the customer with set-up on at least one occasion.

The 50 households comprise the Monitor Treatment group. They are a self-selected population subset of the PowerChoice customer base, rather than a randomly selected one, as is the case for the Information Treatment group. Because the monitors were provided free to these volunteers, this subset may not represent what would happen if the monitors were sold. ${ }^{71}$ But the fundamental question remains: do monitors help households adjust their energy use to the PowerChoice Time-of-Use tariff? Analysis of load data detected only weak effects on consumption, as discussed in Chapter 3. In particular, a reduction of weekend On-Peak usage was the only effect noted-in the "right" direction, but without suggesting much of a shifting pattern overall (e.g., lower Super-Peak use, or lower On-Peak usage during the week). One possible explanation is that participating households tended to have more household members home during the weekend than during the weekdays, and thus may have been more available to actively manage load during weekends (and have had more load to shift).

\subsubsection{Survey Responses}

To learn how households used the monitors, the project's Wave 3 survey asked monitor recipients a series of survey questions about their experience with the monitor. As detailed

70. A few offered explanations as to why they did not accept the offer-for example, that they already had enough information to conserve or had low power bills, were too busy or felt too old to take on such a project, or that there was no handyperson readily available. The research team also analyzed recruitment disposition as to the demographics of the Wave 1 survey respondents. Analysis revealed that households that accepted the monitor were more likely to have had a survey respondent holding a college-degree or higher (66\% versus $44 \%$ ), more likely to have the survey respondent be male (37\% of households with male survey respondent in the Wave 1 survey accepted the monitor, as opposed to $28 \%$ with a female respondent in Wave 1), and more likely to have a survey respondent aged 50 or younger ( $42 \%$ of surveyed households with a survey respondent aged 50 or younger, as opposed to $29 \%$ of households with an older Wave 1 survey respondent).

71. Currently, SMUD is selling PowerCost monitors to SMUD customers at a price of $\$ 39.95$, citing a regular cost of $\$ 149.95$ (http://www.smud.org/en/residential/saving-energy/pages/monitor.aspx; accessed April 2009). 
below, respondents from households in the Monitor Treatment group largely reported that they found the device useful in managing electricity consumption and would recommend it to others.

Of the 50 households who accepted a monitor, 43 responded to this survey. Most reported that they had successfully set up the monitor and it was still working correctly $(75 \%)$, while $10 \%$ said that they had never successfully set it up. ${ }^{72}$ This is a high success rate, especially for a device that is not plug-and-play.

Four out of five said that when they first got the monitor, they looked it at least once a dayand usually more than once. The novelty did not seem to wear off very quickly: two months after the monitor was received, four out of five surveyed households still said that they looked at the monitor at least once a day in the week before they were surveyed, and two out of three said that the monitor had led to discussions about energy use in the home. This sort of aid to discussion is perhaps one of the most important uses of a feedback monitor, especially if it leads to realizations that challenge perceived norms of domestic energy use practices (Strengers 2008).

As to whether the monitor prompted direct, identifiable changes in electricity usage, $75 \%$ of the households for which the monitor was still working said that it did. As to what changes were made, a few cited an aha!, such as figuring out that having the pool filter running during SuperPeak was costly, or determining the cost of running various appliances. Others pointed to the monitor as a reminder of when rates changed or to turn something off, or as a means of keeping track of total consumption. Almost all surveyed participants agreed that it was useful to be able to move the monitor from room to room. All who had a monitor working said that they planned on keeping it. Most said that they would definitely recommend the monitor to a friend $(78 \%)$, while a handful-some with the monitor working, others not-said that they would not recommend it. ${ }^{73}$

The research also team tested whether survey respondents in the Monitor Treatment group answered Wave 3 questions differently than did others, but these comparisons revealed little of significance. Furthermore, since the Monitor Treatment group was self-selected, no differences could be fairly attributed to the monitor itself, as opposed to self-selection into the Monitor Treatment group.

\subsection{Discussion}

Both information interventions seemed to have an effect on what treated participants did. There are a variety of explanations as to why these differences in actions did not show up as increases in demand responsiveness:

72. Almost everybody who recalled receiving the booklet on monitor set-up said that the booklet was useful (22 out of 27). Four households had installation problems that they could not resolve. SMUD itself provided additional assistance to customers who had trouble with installation, even sending out an agent to help with installation in at least once circumstance.

73. The PowerCost Monitor uses four batteries, which need to be replaced every four to six months, depending on weather and temperature conditions. 
- The information provided by the treatment may not have added much new information over that that PowerChoice participants had already received as part of the program, what they already knew, or what they could figure out on their own. A BC Hydro study on residential TOU rates also found that customers tended to view load shifting and conservation tip sheets as only somewhat useful, since they contained information that customers already knew or said that they knew (Tiedemann 2007).

- The information may not have been compelling evidence to shift or save, nor easy to use. For example, a feedback monitor provides raw information about electricity use and costs, but it takes effort and experimentation to interpret this information and to use it to adjust household practices. And some questions-for example, the cost advantage or disadvantage of pre-cooling on weekday early afternoons, as opposed to cooling during Super-Peak-would be difficult to answer well, except with elaborate experimentation. Furthermore the user's interpretation of the information provided by a feedback monitor may not support the frequently assumed or desired conservation response. Rather, a feedback monitor can make it clear that the cost of many electricity end-uses is trivial.

- The treatments may have changed what participants said, rather than what they did.

- The variability of electricity consumption is large, relative to the types of changes that TOU rate participants might be expected to make. Because of the relatively small sample size and the minimal before information, customers' load adjustments may be present, but too small to detect.

The lack of detectable load response for the Enhanced Information Treatment is consistent with the generally lackluster evidence for detectable effects of mass information campaigns on energy conservation and efficiency. Without dismissing this accumulated evidence, it is also possible that better information could yield better results. In general, TOU rate customers (as well as other customers) may be interested in more sophisticated information about energy use than is standard-for example, realistic estimates of the savings from any particular action, or even-handed accounts of the advantages and disadvantages of any particular energy management strategy. Many of the monitor recipients in this experiment received more guidance than a typical household purchasing a monitor might-in the form of assistance from the research team and from SMUD (who even made at least one house call to assist a customer), and the guidebook that the research team prepared. 


\subsection{Summary and Recommendations}

\subsection{PowerChoice Pilot In Perspective}

For decades, Time-of-Use rates have been promoted as a logical way to encourage many customer types, residential customers included, to contribute to lower peak loads via rate structure. From the standpoint of economic logic, this may make perfect sense. Many studies have found that residential customers do shift load under TOU rates (Acton et al. 1983; King 2001; U.S. DOE 2006) and, as noted in Chapter 1, plans are in place to continue introducing smart meters, amenable to TOU pricing, in California (California Public Utilities Commission \& California Energy Commission 2008) and elsewhere in North America (Alexander 2007).

The SMUD TOU rate pilot studied in this research project provides limited evidence of shifting and conservation by participating customers in response to this particular TOU rate. That is, whatever electricity load shifting and conservation that took place within the households who voluntarily joined this rate, little could be statistically detected in the load interval data reflecting their electricity consumption patterns. This is despite the fact that surveyed participants seemed to clearly understand that the rate was about shifting, and most reported that they had undertaken substantial shifting and conservation activities.

There are a variety of possible explanations. One important statistical consideration is that the size of the sample available for this study was unexpectedly small and the length of the before data was unexpectedly short. These factors, in combination, make any true differences statistically more difficult to detect, since the expected effect size is small as well. But there are other studies that similarly found limited evidence of Time-of-Use rate effectiveness (Alexander 2007). There is no reason that all studies should find similar results: the transferability of findings of residential TOU studies is a long-running question (Aigner 1985; Taylor 1985). What is more interesting is to understand why results differ from study to study and from household to household. A meta-analysis of residential TOU results is beyond the scope of this research project, but the rest of this chapter summarizes the most important and interesting results from this study as relevant to such a meta-analysis, highlights behavioral findings, and provides recommendations for TOU programs and for future behavior-oriented research on residential TOU programs.

\subsection{Conclusions}

The main results of this project are as follows:

1. The initial offer of the Time-of-Use rate did not garner great interest among the SMUD customers to whom it was offered. Of the 330 who initially signed on, eventually 286 households piloted the rate.

2. PowerChoice participants were very likely to be single-family, owner-occupied households. Adult members of participant households were considerably older, on average, than in other single-family, owner-occupied households in SMUD territory. Survey respondents overall had attained substantially higher educational levels, with a somewhat higher proportion of households in the highest income group, compared to other single-family, owner-occupied households in the SMUD territory. Survey respondents also were more likely to say that someone was home during weekdays 
from 8:00 a.m. to 5:00 p.m., compared to SMUD's estimate for the service territory. While PowerChoice participants overall had higher than average consumption, considering all house types combined, when comparing only single-family homes, participating households' electricity consumption was, on average, lower than for other homes in SMUD's service territory.

3. For most surveyed households, the primary stated motivation for participating in the PowerChoice TOU rate was saving money or controlling costs. Few survey respondents spontaneously mentioned more altruistic reasons, although when asked directly, most agreed that potential environmental benefits, reducing the possibility of brownouts, etc., were supporting reasons. Some also said they liked the project aspect and the program enticements (e.g., gift cards), helping SMUD, or the basic logic of the rate.

4. Households were allowed to drop the rate with a 30-day notice. Overall, $16 \%$ left the experiment for a variety of reasons, including moving. Some customers who said that they thought they were paying more or were otherwise dissatisfied with the rate stayed with it, while others dropped out. This introduces an additional layer of self-selection to participation on the rate.

5. Although some customers said that they followed rate periods closely, the complicated rate structure was a burden to many. The PowerChoice tariff had up to five different rate periods per day, four seasonal changes per year, and different rate periods for weekends and weekdays. This complexity is not unusual for a residential TOU tariff, but survey responses revealed that it clearly took some effort for participants to remember when changes occurred. In their survey responses, participants generally claimed to understand the Time-of-Use tariff, and some implied that they closely watched the clock. A few respondents expressed anger about the complicated form of the rate or other aspects they found illogical.

6. Surveyed responses indicated that participants clearly understand that the rationale for the TOU rate was to encourage shifting of activities and loads away from peak times of day. Respondents most frequently reported the following behavioral changes to the TOU rate: shifting the timing of laundry and dishwashing; reducing air conditioner use during Super-Peak hours (weekday afternoons); installing CFLs; implementing general energy-conservation behaviors, such as turning off lights; and, among pool owners, changing the timing for operation of the pool pump. Three out of four respondents said they had shifted their usage and half said they had undertaken conservation actions. Across all respondents, several dozen distinct actions were reported.

7. Most participating households surveyed said that they already conserved energy, but made a greater effort to shift and to conserve under the TOU rate. Over half of surveyed participants said that they had made a great deal of effort to adjust to the rate. Many respondents' replies to open-ended survey questions indicated that their effort was genuine. In fact, some survey respondents reported going to extreme measures, such as a major overhaul of domestic schedules.

8. While the TOU rate was in force, PowerChoice participants had load shapes that fit the TOU tariff better than the control sample to which they were compared, especially 
during the highest-price summer period. However, it is not clear how much of this difference was due to the tariff, versus self-selection onto the rate.

9. For two of the eight daily periods tested, statistical tests for an initial price effect revealed weak shifts in electricity use after enrolling in PowerChoice, as calibrated to changes in the electricity usage of the control group. There was no statistical evidence for reduced load at super-peak. The limited amount of pre-PowerChoice data and the relatively small sample size made detection of price effects difficult.

10. There was evidence of a price effect as households transitioned from Summer tariff period rates to the fall Swing period rates. Most of the changes detected for this transition revealed a relaxation in shifting and increases in consumption during higherpriced periods, corresponding to the lowered prices (relative to Summer prices) for all usage time periods during the swing period.

11. A modest proportion of surveyed PowerChoice participants indicated that their attempts to change their electricity consumption to better fit the TOU tariff reduced comfort and caused inconvenience, and led to some tensions within the household. Although generally considered morally good in public energy education campaigns, conservation and shifting usage may be stressful to some individuals and families. Such stress may occur whether or not efforts are effective in providing consumption reductions or demand response to the grid.

12. The research team applied and tested the effects of two information interventions on subsets of participating households: one a set of written information (Enhanced Information Treatment) and the other an electricity feedback meter (Monitor Treatment). Drawing from the principles of Community Based Social Marketing, the Enhanced Information Treatment intervention supplied tips and encouragement to a randomly selected group of households. This information included periodic content-rich letters and a refrigerator magnet displaying the tariff details, which served as a prompt. Although most of the respondents who received this information said it was useful, the team realized in retrospect that that intervention might not have been sufficiently distinguished from other program materials to allow confident conclusions about the effects of the enhanced information.

13. A test of the cumulative effects of information on observed Summer load did not indicate that the Enhanced Information Treatment group shifted more electricity than other households. Despite this, survey responses indicated that, compared to other households, the Enhanced Information Treatment members were more likely to emphasize shifting when they discussed what they had done, particularly for shifting actions that had been promoted in the special information they had received. The differences were moderate and, overall, are consistent with the theory that mass information may increase knowledge, but not necessarily energy savings.

14. Use of electricity feedback monitors did not seem to have much effect on electricity consumption patterns. The second experimental treatment, the Monitor Treatment, consisted of Blue Line Innovation's PowerCost electricity consumption feedback monitor. Monitors were offered free to all participants who had started on the rate in summer 2007. About a quarter of households responded positively to the offer, which suggests a modest level of interest in the device among households participating in the 
program. Monitors were distributed to these 50 volunteer households just before the second summer of the rate. Most of the recipient households successfully installed their monitors. The majority of monitor recipients surveyed said they referred to the monitors one or more times per day, even many weeks into the summer, and that they used the monitors both as general prompts and to deduce specific information about usage. Statistical analysis of these volunteer households' electricity loads for the second summer of the program found minor effects on electricity consumption.

15. In the general comments volunteered by surveyed participants, the consumption adjustment was one of the biggest complaints made about the program. The consumption adjustment aspect of the PowerChoice tariff was designed to reward conservation, in addition to encouraging load shifting. It consisted of discounts for low overall energy use and surcharges for higher usage levels. In some cases, the consumption adjustment resulted in substantial surcharges-in theory, up to $50 \%$ of the total bill pre-adjustment. Some customers who paid a surcharge said they found it expensive and disagreeable, especially if they had been making a substantial effort to conserve and shift electricity usage. Although program enrollment materials described the consumption adjustment, many customers said they were not aware of it initially, which led to some discontent early on. While lower-use customers benefited from the consumption adjustment, the possibility of a consumption adjustment surcharge added risk and made it more difficult for higher-use customers to financially benefit from the program. These higher-use customers might reduce their bills by shifting load, but the surcharge on total consumption might increase their bills overall. A tiered TOU rate, with blocks of rates that increase with consumption, and fixed time-of-day prices within the block, might be more satisfactory in terms of customer acceptance, but would mute the message about rewards for conservation.

16. Although most customers may not have accurately known if they had gained or lost money due to the TOU rate, most offered an opinion. Overall, half of surveyed participants judged that they had saved money on the rate. Customers who did not like the rate, or their electricity bills while they were on the rate, were more likely to drop off the rate. This filtering could reduce the potential benefits of the rate to the electricity system and utility, to the extent that free-riders (i.e., those whose original consumption patterns best fit the rate and may have been less motivated or less able to deliver peak savings) were most likely to remain on the rate.

17. Customers had suggestions about the bill format, information provided on the bill, and the rate itself. These suggestions are reflected in the Recommendations below.

18. Half of surveyed households reported that they increased efforts to conserve or shift during the second summer on the rate, relative to the first. Few households said that they made less effort the second summer. These self-reports indicate persistence of behavioral change at least to the second year, although the results are hard to interpret because of the minimal load shifting actually detected and the difficulty in comparing effort over time. 


\subsection{Recommendations}

\subsubsection{Recommendations for Residential TOU Programs}

The following recommendations for residential TOU programs are made:

1. Beyond economic arguments, rate details are important. Microeconomic explanations for TOU rates in the residential sector rely on the theory that consumers, by virtue of rationality, trade utility - the economics term for satisfaction derived from the consumption of goods and services-for money. Compared to Real Time Pricing or Critical Peak Pricing (CPP) schemes, TOU rates generally give up precision in reflecting market costs of electricity for the sake of price structures that are easier to implement and for customers to use. In focusing on behavior, the structure of the TOU rate itself matters: it should be easy enough to remember and use; it should encourage the desired actions; and it should reward customers for those right actions in a way that customers recognize and feel is fair. The risk structure of the consumption adjustment was called out by some customers, who noted that, contrary to a traditional tiered rate, the bill premium for going over $1,000 \mathrm{kWh}$ in a month was levied on all consumption, rather than applying to just the consumption in excess of $1,000 \mathrm{kWh} .{ }^{74} \mathrm{~A}$ tiered form of a TOU rate may thus be preferable to the consumption adjustment form, both for goodwill and to make the rate reasonably enticing for higher-use customers.

2. Bill design matters. Several studies have documented the importance of bill design as a means of feedback (Iyer et al. 2006; Wilhite \& Ling 1995). While a monthly bill can provide only retrospective and crude information relative to the intricacy of electricity use, a user-friendly, information-rich bill design may encourage goodwill and more exacting Time-of-Use response from participants. As noted above, many survey respondents said that they wanted their PowerChoice bill to tell them how much they were saving (or not) on the rate. In the case of Time-of-Use rates, however, if the information provided on the bill leads a participant to believe that their household is spending more on the TOU rate than on alternative rates offered, the household may drop off the rate, possibly with corresponding loss of any peak reduction that the customer provided while on the rate.

3. Changes in energy use take effort and have consequences. Viewed from the top down, conservation and shifting actions by residential consumers seem to be simple, relatively costless actions, justifiable on moral grounds, and of little consequence other than possible energy savings. From the perspective of energy users, these assumptions are more untrue than true. Rather, as is regularly recognized for analyzing demand response in businesses, load shifting and conservation take effort and have non-financial costs to occupants. This effort and its consequences change the experience of everyday life in little, and possibly larger, ways. Residential consumers may rarely judge these efforts in stereotypical cost-benefit form. However, the survey responses in this project made it clear that changing energy habits could have tangible consequences in the home,

74. Thus, a difference of a few $\mathrm{kWh}$ in a month could make a large difference in the monthly bill, and going from just under to just over 1,000 kWh could mean the difference between a bill credit and an additional charge. 
and often costs, even if not financial ones. The importance of such costs has been noted by least one other study of domestic energy habits (Carlsson-Kanyama \& Lindén 2007). Judging from survey responses in the current project, shifting and curtailment sometimes created tensions between family members, caused discomfort, had possibly negative impacts on health or concerns thereof, led to inconvenience in pushing chores to the borders of the day, and increased the effort or time required to complete these chores. ${ }^{75}$ And only some of these efforts made much difference to bills or system load.

4. Giving quality information deserves special consideration. In most efforts dedicated to encouraging behavior-based energy conservation or load shifting in the home, information is the chief lever for action. Studies have repeatedly shown that the effects of this information may be quite limited (Abrahamse et al. 2005; Lutzenhiser 2002; Owens \& Driffill 2006). In the case of a TOU or other DR rate, voluntary acceptance of the rate already succeeds in targeting customers who are interested in managing household electricity use in exchange for monetary savings-as well as those who expect that their existing patterns of electricity use to advantageously fit the rate. Even among such volunteers, there are no guarantees when it comes to their reactions to energy messages-recipients may be very to not at all receptive. They may, for example, feel that they already know what to do, distrust the information given them, or feel that the information is not precise enough. The challenge for utilities and other energy programs is to provide mass information about residential energy use that is correct, useful, engaging, and not too off-putting, and that fits a wide range of circumstances, capabilities, and interests of the recipients. From the standpoint of rational energy use, this information should guide customers to the most effective things to do and away from wasted effort and symbolic actions. For most residential shifting actions, it may not be possible to achieve this ideal with much precision; even information that is correct on average may be quite misleading for many households. Any information disseminated must also compete with past experience, intuition, and many other information sources. Information also takes effort to process and use. Energy use feedback devices, for example, may provide very valuable information, but relatively few households may be willing to take on the task of learning how to effectively use these devices.

5. Promising or interesting behavioral changes should be explored. Despite the recent interest in energy-relevant behaviors, there is surprisingly little published information on how people shift or conserve energy-what they do or do not do, which changes are difficult, which are easy, and for which customers. In most cases where there is any data, the data is the result of people checking off options in a mass survey. So, though the current study goals were modest in this regard, and all conservation and shifting actions were still self-reported, some of what people told about their efforts is of more general use. In particular:

- Air conditioning. Over half of surveyed customers reported typical summer indoor temperatures under the PowerChoice tariff higher than the $78^{\circ} \mathrm{F}$

75. As noted earlier, some households reported that they enjoyed the rate or parts of it, mentioning particularly the project aspect of it and a feeling of contributing, and perhaps even a pleasure in not using electricity. 
$\left(25.6^{\circ} \mathrm{C}\right)$ minimum conservation set-point recommended by SMUD in their residential customer literature. ${ }^{76}$ Only $14 \%$ reported setting temperature lower than $78^{\circ} \mathrm{F}\left(25.6^{\circ} \mathrm{C}\right)$. In reporting what they did to conserve energy, $40 \%$ said they usually or always turned the air conditioner off on July and August afternoons-and among those who said that they at least sometimes turned the air conditioner off, two-thirds said that this did not make them at all uncomfortable. These are self-reports, and may not represent measured average temperatures, but they do suggest fair flexibility in air conditioner use for some households. Since the distribution of typical temperatures reported pertaining to before PowerChoice were nearly the same as those after PowerChoice, it is unclear how much of this flexibility is related to the TOU rate design itself. ${ }^{77}$ This also suggests a need for better information on how households actually use air conditioning - beyond self-reports on typical settings - so that programs to reduce air conditioning can be most effectively designed and their potential savings estimated. Here, a good review of the social science literature on air conditioning is essential.

- Pool pump. Nearly all pool owners said that they changed the timing of the pool pump from higher-cost to lower-cost hours under PowerChoice. As far as we can tell, there was no separate effort by the utility or other party to elicit this change. Rather, pool-owners may have picked up on this possibility because it is an easy one-time task to perform, whether they read it among the many tips noted in the introductory material or figured it out on their own. So, once motivated - as by the price differential afforded by the TOU rate-switching the timing of the pool pump seems to be an easy change for households to make, and an effective change from the perspective of the peak demand reduction. ${ }^{78}$

- Clothes drying. Most households reported that they had shifted clothesdrying to off hours and some said that they did less laundry all together. But many survey respondents balked when we asked them about using line- or

76. For example, the SMUD Connections newsletter for July 2008 recommends $78^{\circ} \mathrm{F}$ or higher ((http://www.smud.org/en/about/connections/Documents/ConnectionsJul2008.pdf). The recommendation of setting home thermostat at " $78^{\circ} \mathrm{F}$ " or " $78^{\circ} \mathrm{F}$ or higher" when people are home is typical for California (e.g., residential energy tips web site for PG\&E customers at http://www.pge.com/myhome/saveenergymoney/savingstips/index.shtml, and for SDG\&E customers at http://www.sdge.com/residential/eeHeatingCooling.shtml).

77. That is, though most surveyed participants reported that they used less air conditioning under PowerChoice (Wave 3 survey) than they did before (Wave 1), the reported "typical" temperatures reflected a reduction in temperature for less than half of the participating households that had been surveyed in both rounds. Customers on a standard tariff, as well as a TOU tariff, would be financially rewarded for using less air conditioning. The rewards for doing so during peak-price periods can be seen as higher on the TOU tariff, simply because the prices as higher, especially since air conditioning can only be partially shifted to lower-price periods.

78. There may be competing interests, however; pool repair and maintenance services may often shift settings back to run more frequently and/or at different times, on the argument that this is better for the pool (personal communication, Vikki Wood, May 27, 2009). 
rack-drying as an alternative to machine drying, suggesting it as an untouchable or boundary behavior worthy of further analysis (see Hackett 1993).

- Small-time behaviors. Many households reported actions that, technically speaking, would result in differences in energy use that would be statistically undetectable, at least on a one-by-one basis, relative to typical levels and variability of aggregate total electricity use-for example, making afternoon coffee in the morning and heating it in the microwave, avoiding using computers or sewing machines during Super-Peak, or unplugging a mobile phone charger. Some of these actions could be bellwethers for higher savings or more consciousness toward household energy use overall, but some can also be viewed as ineffective, in that they are costly in terms of customer effort, with little benefit to either the household or the utility. Certain actions intended to save energy may even create other environmental damages (e.g., air pollution from barbecuing, indirect energy consumption, etc.). They may also deflect attention from more effective conservation or shifting actions, as Crompton and Thøgersen (2009) argue for "simple things you can do save the environment" more generally. The extent to which these missed understandings can be corrected-and whether they even should be-are open questions.

\subsubsection{Recommendations for Studying Residential Behavior}

The following areas of residential behavior should be explored:

1. Baseline data and sample size. Because of meter installation problems and slower-thanexpected recruitment, in the end, the project had to work with less baseline data than in the original plan. An entire year of baseline data, or at least an entire summer season would have improved the statistical reliability of results. Also, because TOU rate effects can be fairly subtle, large sample sizes may be required to detect effects or to determine which households can best provide demand response.

2. Expectations about behavior-centered experiments. This research project combined social scientific and quantitative energy analysis perspectives. ${ }^{79}$ There were formal hypotheses to test -- the information treatments and price effects, more generally -- but most of the social science content of the project lies outside such hypotheses. As with most social scientific research, the quantitative components are descriptive and the nonquantitative portions do not result in the clear and unambiguous results that are the ideal of natural science and quantitative energy analysis approaches. Surveying households as to their habitual actions related to energy use, and changes in these actions, is a rough science. In this case, for example, survey responses for a single household may contain somewhat conflicting evidence (e.g., in comparing typical temperatures before and after PowerChoice, relative to other survey answers).

Responses to closed-end questions do not always track spontaneous responses. Nor do

79. Certainly, some social sciences, such as economics and experimental psychology, are quantitatively focused, but generally with the quantification intended to support a social theory. 
households necessarily do, or say, the same things from survey to survey. ${ }^{80}$ It is furthermore sometimes hard to make behavioral data on energy use interesting to read about, or even to appear usable, since in raw form such data are a collection of mundane actions and opinions. While there is cohesiveness across various elements of an individual household, it is not clear how well this sparse evidence on intricate patterns can be unfolded into a tractable number of household types, as would be ideal in a segmentation study. In short, many standard natural science tools and expectations common in the energy efficiency field do not apply easily to social science research. Thus the research team recommends that in devising and evaluating research, more attention and debate be directed to different modes of evidence and to the limits of provability in any disciplinary framework, and to how these frameworks and approaches might jointly converge on useful knowledge.

3. TOU rates, generically. Most scholarly papers on TOU rates speak positively about them. In turning attention to behavior, it is also fair to look at more popular evidence and sentiments on TOU rates. This scant evidence available from a popular perspective reveals more mixed results. For example, the apparent very low interest among residential customers in joining TOU rates, and the disappointing level of financial rewards many rates seem to offer, all suggest that, as yet, rates are not enticing and rewards do not appear enticing enough. It seems evident that, outside of experiments, most people who volunteer to join a TOU rate do so because they think they can save money on the rate, even if that is not their only motivation. Most work on residential TOU rates cover only those who volunteer on the rate, usually as very closely tied to the rate and its results. But sociological or anthropological methods can go further. They might also be used, for example, to understand more about those who do not volunteer, as well as to better understand the experience of TOU rate volunteers at a higher level, such as through interviews, as presently only covered in journalistic sources (e.g., Belson 2008; Pulp Network 2007). This perspective could help in positively transforming TOU programs for equity and cost-effectiveness, in devising better estimates of the potential welfare effects of TOU tariffs, and in understanding the limits of TOU pricing. For many households, the sustained and consistent load shifting envisioned by TOU pricing may be more difficult to achieve, and more burdensome to subscribers, than the "rare" requests for demand response implicit in Critical Peak Pricing or in emergency demand response.

4. TOU rates, technically. In the PowerChoice rate, the Off-Peak to Super-Peak price ratios were somewhat low relative to other residential TOU rates. This raises the question of whether the response would have been different had peak rates been higher, or what the behavioral issues would have been on a dynamic rate, such as Critical Peak Pricing, as tested earlier in the State of California (Herter et al. 2007).

5. Devising and distinguishing information. Testing the effects of information dissemination on energy-relevant knowledge and behavior is notoriously difficult (e.g., Owens \& Driffill 2006), and many studies do not even use control groups. In this study,

80. See, for example, Woods (2003) for an analysis tracking open-ended responses on household conservation actions from one survey to the next. 
the Enhanced Information Treatment was applied to a randomly-selected subset of customers, with a proper control group. The intent was to make this treatment readily distinct from other SMUD and PowerChoice communications, and to incorporate, insofar as possible, a community-based marketing approach. This was more difficult than expected. SMUD, as would any participating utility, must approve the format and content of electricity- and program-related material sent to its customers. For example, a social network community or blog-related forum may have been useful for building a community feeling or for addressing specific technical questions in a more customized fashion, but presented practical difficulties from the standpoint of information control and customer relations. In this research project, the best option seemed to be to prepare "newsy" (content rich) letters sent to customers on SMUD letterhead. The research team also discovered, in retrospect, that customers did not readily distinguish these from other program material. While a strategy such as a colored envelope might have helped customers distinguish these letters for the purposes of the surveys, the underlying problem is rather in providing good information, as outlined in the Recommendations for Residential TOU Programs section above.

6. Using open-ended questions. The research team decided to incorporate many openended questions in addition to the more traditional closed-end survey questions. As it turned out, this was an important move. It helped manage positive response biases, it made customer experience real, and it provided information (such as emotion, why responses, etc.) that could not have been obtained with closed-ended questions.

7. Compare different types of residential consumption feedback monitors. The interface and information display on feedback monitors, as well as other basic characteristics, may have important impact on how effectively households can use the monitor. A study of the advantages and disadvantages of a variety of models and contexts for feedback monitors could cover many usability aspects: information displayed, different locations (e.g., next to thermostat), wireless versus wired models, batteries used only for display so as to maximize battery life, etc.. The results could help understand what works best, as well as lend insight to how users interpret the monitor, such as, cognitive processing of the information displayed and its consequences. For example, how do consumers react to the information displayed for low-consuming versus high-consuming end uses (e.g., a light versus a pool pump)?

8. Compare different types of TOU billing options. Various bill design options and other supplemental information for interested customers (e.g., daily feedback from an Internet site) could be compared. Different options for showing how customers are faring on a TOU rate relative to the standard tariff or other alternative could be tested. These experiments could analyze, for example, how customers react if they find that they are paying more on the TOU rate than on an alternative.

9. Additional review and meta-analysis of industry experience with residential TOU rates. A number of review articles on residential TOU rates have been published (e.g., Aigner 1985; Alexander 2007; King 2001). Additional analysis across this past experience, comparing and contrasting quantitative estimates and statistical methods, but focusing on the behavioral aspects, insofar as they can be deduced, could be quite useful. Such a review could also attempt to gather unrecorded knowledge by 
interviewing professionals that have been involved in TOU rates over the past several decades.

\subsection{Benefits to California}

Demand response is one of California's preferred options for meeting the future state's energy needs (California Energy Commission and California Public Utilities Commission 2005). By 2010, most customers in the state are expected to have had advanced meters ("smart meters") installed. These meters will facilitate demand response programs for California utilities (California Energy Commission and California Public Utilities Commission 2008). Though the value of demand response is usually interpreted under a largely economic lens, demand response is fundamentally based on behavioral change and affects the experience of daily life. This is true even for demand response programs where the actual demand reduction is automated rather than manual. The behavioral aspects of demand response have barely been explored, yet are fundamental to understanding demand response, learning how performance can be improved, and considering the costs and benefits of demand response to California residents from a broad perspective. The collection and analysis of behavioral data for a Time-ofUse rate undertaken in this project offers contributions to understanding in all of these areas. In particular, it:

- Builds appreciation for the complexity of consumer choice, and for understanding residential consumer constraints in responding to Time-of-Use rates;

- Reinforces findings from other experiments about the limited uptake of Time-of-Use rates and the nature of past "successes" and "failures" with these rates;

- Stresses the importance of self-selection onto the rate when rates are voluntary, and the differential impacts of rates;

- Draws out the need to fully appreciate the nature of "information" and the difficulties of information delivery and processing;

Thus the results provide an improved basis for future policy decisions about Time-of-Use and other demand response programs, in raising a well-rounded set of questions about Time-of-Use rate performance, and provide guidance in designing programs and in conducting further research on demand response. 


\subsection{References}

Abrahmse, W, L. Steg, C, Vlek, and T. Rothengatter. 2005. "A Review of Intervention Studies Aimed at Household Energy Conservation." Journal of Environmental Psychology 25(3):273-291.

Acton, Jan Paul, Bridger M. Mitchell, Rolla Edward Park, Mary E. Vaiana. 1983. Time-of-Day Electricity Rates for the United States. Prepared for the John A. Hartford Foundation. November. R-3086-HF. Rand. Santa Monica, CA.

Aigner, Dennis J. 1985. “The Residential Electricity Time-of-Use Pricing Experiments: What Have We Learned," pp. 11-41 of Jerry Hausman and David A.Wise, eds, Social Experimentation. Chicago. University of Chicago Press. Available online: http://www.nber.org/chapters/c8372

Aigner, Dennis J. and Khalifa Ghali. 1989. "Self-Selection in Residential Electricity Time-of-Use Rates." Journal of Applied Econometrics, Supplement Special Issue on Topics in Applied Econometrics 4: S131-S144.

Bartiaux, Françoise. 2006. "Do Information and Awareness Work?," in the Proceedings on Radical Changes in Sustainable Consumption and Production, Copenhagen, 20-21 April. Postworkshop version. 28 April. Available online http://www.scorenetwork.org/files/548_Proceedings_SCORE_WS1_20060428.pdf\#page=23/

Belson, Ken. 2008. "Rewarding Those Who Wait to Flip the Switch," The New York Times. July 21, 2008. Available at http:/ / www.nytimes.com/2008/07/21/nyregion/21peak.html.

Carlsson-Kanyama, Annika and Anna-Lisa Lindén. 2007. “Energy Efficiency in ResidencesChallenges for Women and Men in the North." Energy Policy 35(4):2163-2172.

Crompton, Tom and John Thorgersen. 2009. Simple E Painless. The Limitations of Spillover in Environmental Campaigning. WWF-UK.

Darby, Sarah. 2006. The Effectiveness of Feedback on Energy Consumption: A Review For DEFRA of the Literature on Metering, Billing and Direct Displays. Oxford, England: Environmental Change Institute, University of Oxford.

Dillman, Don. 2000. Mail and Internet Surveys: the Tailored Design Method. John Wiley \& Sons.

Energy \& Environmental Economics. 2006. A Survey of Time-of-Use (TOU) Pricing and DemandResponse (DR) Programs. Washington, D.C.: U.S. Environmental Protection Agency.

Faruqui, Ahmad and Robert Earle. 2006. "Demand Response and Advanced Metering." Regulation (Spring):24-27.

Geer, John G. 1991. “Do Open-Ended Questions Measure 'Salient' Issues," The Public Opinion Quarterly 55(3): 360-370.

Hackett, Bruce. 1993. "Clothelines: assessing the 'instrumental' character of everyday practical conduct." Unpublished paper. Department of Sociology, University of California Davis. Davis, CA. 
Hausman, William J. and John L. Neufeld. 1984. "Time-of-Day Pricing in the U.S. Electric Power Industry at the Turn of the Century." The Rand Journal of Economics 15(1):116-26.

Herter, K., P. McAuliffe, and A. Rosenfeld. 2007. “An Exploratory Analysis of California Residential Critical Peak Pricing of Electricity." Energy 32(1):25-34.

Hill, Daniel H., Deborah A. Ott, Lester D. Taylor, and James M. Walker. 1983. “Incentive Payments in Time-of-Day Electricity Experiments: The Arizona Experience," The Review of Economics and Statistics 65(1):59-65.

Holland, Stephen P., and Erin T. Mansur. 2004. Is Real-Time Pricing Green? The Environmental Impacts of Electricity Demand Variance. CSEM WP 136. Berkeley, Calif.: Center for Study of Energy Markets, University of California Energy Institute.

Iyer, Maithili, Willett Kempton, Christopher Payne. 2006. “Comparison Groups on Bills: Automated, Personalized Energy Information," Energy and Buildings 38(8):988-996.

King, Chris S. 2001. "The Economics of Real-Time and Time-of-Use Pricing for Residential Customers." June. Update of a paper presented at the Third Annual International Demand Side Management Conference.

Lutzenhiser, L. 2002. "Marketing Household Energy Conservation: The Message and the Reality," Chapter 3 of T. Dietz and P.C. Stern (eds.), New Tools for Environmental Protection: Education, Information, and Voluntary Measures. The National Academies Press. Washington, D.C.

Lutzenhiser, L., K. Janda, R. Kunkle, and C. Payne. 2002. Understanding the Response of Commercial and Institutional Organizations to the California Energy Crisis. Report \# 400-020018C. Sacramento, Calif.: California Energy Commission.

Available online at: http://www.energy.ca.gov/reports/2002-11-21_400-02-018C.PDF.

Mitchell, Bridger M. and Jan P. Acton. 1980. The Effect of Time-of-Use Rates In the Los Angeles Electricity Study. Prepared for the Los Angeles Department of Water and Power and the John A. Harford Foundation. N-1533-DWP/HF. Rand. Santa Monica, CA.

McKenzie-Mohr, D. and William. Smith. 1999. Fostering Sustainable Behavior - An Introduction to Community-Based Social Marketing. Gabriola Island, B.C.: New Society Publishers.

Ontario Energy Board. 2007. Ontario Energy Board Smart Price Pilot. Final Report and Appendices A-G. Toronto, Ontario, Canada: Ontario Energy Board. Available online: http:/ / www.oeb.gov.on.ca/documents / cases/EB-20040205/smartpricepilot/ OSPP\%20Final\%20Report\%20-\%20Final070726.pdf.

Owens, S. and L. Driffill. 2006. How to Change Attitudes and Behaviours in the Context of Energy. Version 1.0. Foresight. Commissioned by the Office of Science and Innovation. U.K. July.

Pederson, Marc. 2007. Quantitative Analysis of Self-Reported On-Peak Behaviours. Vancouver, B.C.: BC Hydro. 
Peters, Jane S., Mithra Moezzi, Susan Lutzenhiser, James Woods, and Rick Kunkle. 2008. First Year Results: PowerChoice Residential Customer Response to TOU Rates. Research Into Action.

Public Utility Law Project of New York (PULP) blog, http:/ / pulpnetwork.blogspot.com/2007/04/not-so-smart.html (Accessed April 2008).

Sexton, Richard J., Terri A. Sexton, Joyce John-Wen Wanm, and Catherine L. Kling. 1989. “The Conservation and Welfare Effects of Information in a Time-of-Day Pricing Experiment," Land Economics 65(3).

Shove, Elizabeth. 2003. Comfort, Cleanliness, and Convenience. Oxford: Berg.

Strengers, Yolande. 2008. "Challenging Comfort \& Cleanliness Norms through Interactive InHome Feedback Systems,"

Taylor, Lester D. 1985. Comments on 'Aigner, Dennis J. 1985. "The Residential Electricity Timeof-Use Pricing Experiments: What Have We Learned," in erry Hausman and David A.Wise, eds, Social Experimentation. Chicago. University of Chicago Press. Available online: http://www.nber.org/chapters/c8372

Tiedemann, Ken. 2007. Conservation Rate Initiative. Milestone Report. Vancouver, B.C.: BC Hydro.

U.S. Department of Energy. 2006. Benefits of Demand Response in Electricity Markets and Recommendations for Achieving Them. A Report to the United States Congress Pursuant to Section 1252 of the Energy Policy Act of 2005. February. Washington, D.C.: U.S. Department of Energy.

Wilhite, Harold and Rich Ling. 1995. "Measured Energy Savings from a More Informative Energy Bill," Energy and Buildings 22(2):145-155. 


\subsection{Glossary}

\begin{tabular}{|l|l|}
\hline Original Term & \multicolumn{1}{|c|}{ Acronym/Abbreviation } \\
\hline Community Based Social Marketing & CBSM \\
\hline concerns, capacity, and conditions framework & 3-Cs framework \\
\hline critical peak pricing & CPP \\
\hline demand response & DR \\
\hline Demand Response Research Center & DRRC \\
\hline Electric Power Research Institute & EPRI \\
\hline Energy Policy Act of 2005 & EPACT 2005 \\
\hline investor-owned utilities & IOUs \\
\hline kilowatt / kilowatt-hours kW & kW / kWh \\
\hline Lawrence Berkeley National Laboratory & LBNL \\
\hline Public Interest Energy Research Program & PIER Program \\
\hline research, development, and demonstration & RD\&D \\
\hline Residential Appliance Saturation Survey & RASS \\
\hline Sacramento Municipal Utility District & SMUD \\
\hline Time-of-Use & TOU \\
\hline
\end{tabular}




\subsection{Bibliography}

Aigner, Dennis J. and Edward E. Leamer. 1984. “Estimation of Time-of-Use Price Response in the Absence of Experimental Data: An Application of the Methodology of Data Transferability." Journal of Econometrics 26: 205-227.

Atkinson, Scott E. 1979. “Responsiveness to Time-of-Day Electricity Pricing." Journal of Econometrics 9: 79-95.

Baladi, S. Mostafa, Joseph A. Herriges, and Thomas J. Sweeney. 1998. "Residential Response to Voluntary Time-of-Use Electricity Rates." Resource and Energy Economics 20: 225-244.

Caves, Douglas W. and Lauritis R. Christensen. 1980. "Econometric Analysis of Residential Time-of-Use Electricity Pricing Experiments." Journal of Econometrics 15: 287-306.

Dobson, John and J.D. Anthony Griffin. 1992. Conservation Effect of Immediate Electricity Cost Feedback on Residential Consumption Behaviour. Toronto, Ontario: Ontario Hydro.

Ek, K. and P. Söderholm. 2008. “Analyzing Energy Conservation Behavior Among Swedish Households: The Role of Information," pp. 1-11, $31^{\text {st }}$ IAEE International Conference, Istanbul.

Faruqui, Ahmad and S. George. 2004. "Demise of PSE's TOU Program Imparts Lessons." Electric Light $\mathcal{E}$ Power January: 1.

Available online: http:/ / uaelp.pennnet.com/articles/article_display.cfm?article_id=165800.

Faruqui, Ahmad and S. George. 2005. Impact Evaluation of the California Statewide Pricing Pilot. Oakland, Calif.: Charles River Associates.

Available online: http:/ /www.calmac.org/publications/2005-03-

24_SPP_FINAL_REPES.pdf.

Faruqui, Ahmad and Sanem Sergici. 2008. "The Power of Experimentation: New Evidence on Residential Demand Response." May 11. Discussion Paper. The Brattle Group. Available at http:/ / www.brattle.com/_documents/uploadlibrary/upload683.pdf

Fishbein, M., and I. Ajzen. 1975. Belief, Attitude, Intention, and Behavior: An Introduction to Theory and Research. Reading, Mass.: Addison-Wesley.

Herter, Karen. 2006. Residential Implementation of Critical-Peak Pricing of Electricity. Berkeley, Calif.: Lawrence Berkeley National Laboratory. Available online: http:/ / btech.lbl.gov/papers/60719.pdf.

Hutton, R. Bruce, and Gary Mauser. 1986. "Effects of Cost-Related Feedback on Consumer Knowledge and Consumption Behavior: A Field Experiment Approach." The Journal of Consumer Research 13(3): 327-336.

Gecas, Viktor. 1989. "The Social Psychology of Self-Efficacy." Annual Review of Sociology 15:291-316.

Geller, E. Scott, Richard A. Winett, and Peters B. Everett. 1982. Preserving the Environment: New Strategies for Behavior Change. New York: Pergamon General Psychology Series. 
Gram-Hanssen, Kirsten, and Eric Gudbjerg. 2006. "Reducing Standby Consumption in Households: By Means of Communication or Technology?." In Proceedings of the ACEEE 2006 Summer Study on Energy Efficiency in Buildings. Washington, D.C.: American Council for an Energy-Efficient Economy.

Janda, K., C. T. Payne, R. Kunkle, and L. Lutzenhiser. 2002. “What Organizations Did (and Didn't) Do: Three Factors that Shaped Conservation Responses to California's 2001 'Crisis'." In Proceedings of the ACEEE 2002 Summer Study on Energy Efficiency in Buildings, 8.117-8.128. Washington, D.C.: American Council for an Energy-Efficient Economy.

Kempton, Willett, and M. Neiman. 1986. Energy Efficiency: Perspectives on Individual Behavior. Washington, D.C.: American Council for an Energy-Efficient Economy.

Kohler, Daniel F. and Bridger M. Mitchell. 1983. "Response to Residential Time-of-use Rates: How Transferable are the Findings?" RAND Report R-2999. RAND. Santa Monica, CA.

Kunkle, R., L. Lutzenhiser, S. Sawyer, and S. Bender. 2004. "New Imagery and Directions for Residential Sector Energy Policies." In Proceedings of the ACEEE 2004 Summer Study on Energy Efficiency in Buildings. Washington, D.C.: American Council for an EnergyEfficient Economy.

Lafferty, Ronald, David Hunger, James Ballard, Gary Mahrenholz, David Mead, and Derek Bandera. 2001. Demand Responsiveness in Electricity Markets. January 15. Office of Tariffs and Markets.

Laird, N.M. and Ware, J.H. 1982. "Random-Effects Models for Longitudinal Data." Biometrics 38: 963-974.

Lillard, L.A. and D. J. Aigner. 1984. “Time-of-Day Electricity Consumption Response to Temperature and Ownership of Air Conditioning Appliances," Journal of Business $\mathcal{E}$ Economic Statistics 2(1):40-53.

Lutzenhiser, Loren. 1993. "Social and Behavioral Aspects of Energy Use." Annual Review of Energy and the Environment: Society, Behavior and Energy Use 18: 247-89.

Mountain, Dean. 2006. The Impact of Real-Time Feedback on Residential Electricity Consumption: The Hydro One Pilot. Toronto, Ontario: Hydro One.

[NPR] National Public Radio. 2007. “NStar Energy Monitors May Lower Consumption.” Morning Edition Business New Report May 17, 2007.

Available online: http:/ / www.npr.org/templates/story/story.php?storyId=12476742.

Parker, Danny, David Hoak, and Jamie Cummings. 2008. "Pilot Evaluation of Energy Savings from Residential Energy Demand Feedback Devices." Prepared for the U.S. Department of Energy. Florida Solar Energy Center. FSEC-CR-1742-08. Cocoa, FL.

Peters, Jane S. and Susan Lutzenhiser. 2007. Examination of Concerns, Conditions, and Capacities for Consumer Response to TOU Rates, Final Research Design, October 31. Research Into Action, Inc. 
Robinson, J. and I.H. Rowlands. 2007. "Who Benefits? The Impacts of Time-of-Use Electricity Pricing on Demographic Groups in Ontario, Canada," Proceedings of the 2007 ECEEE Summer Study on Energy Efficiency in Buildings. European Council for an Energy Efficient Economy.

Sacramento Municipal Utility District [SMUD]. 2007. SMUD Public Goods Report. Available online: http://www.smud.org/en/about/Documents/reportspdfs /2007\%20Public\%20Good\%20Final.pdf . Sacramento, CA.

Sacramento Municipal Utilities District [SMUD] and Summit Blue Consulting. 2004. PowerChoice Pilot Program Evaluation Report. March.

Stein, Lynn Fryer. 2004. "California Information Display Pilot Technology Assessment." Rosemead, Calif.: Southern California Edison.

Stern, Paul, and E. Aronson, eds. 1984. "Energy Use: the Human Dimension." Committee on Behavioral and Social Aspects of Energy Consumption and Production, National Research Council. New York, N.Y.: Freeman and Co.

U.S. Department of Census. 2005. "American Housing Survey for the Sacramento Metropolitan Area 2004." Current Housing Reports. H170/04-53. Washington, D.C.: U.S. Department of Housing \& Urban Development.

Wood, Vikki, J.Erickson, L. Lutzenhiser, S. Lutzenhiser, M. Ozog, and S. Bender. 2004. "What Goes on Behind the Meter: Real Customer Response to Residential Time-of-Use Pricing." In Proceedings of the ACEEE 2004 Summer Study on Energy Efficiency in Buildings, 7: 358379. Washington, D.C.: American Council for an Energy-Efficient Economy.

Wood, G., and M. Newborough. 2003. "Dynamic Energy-Consumption Indicators for Domestic Appliances: Environment, Behaviour and Design." Energy and Buildings 35(2003): 821841.

Woods, J. 2006. "Fiddling with Thermostats: Energy Implications of Heating and Cooling Set Point Behavior," pp. 7.279-7.287, 2006 ACEEE Summer Study on Energy Efficiency in Buildings. Washington, D.C. ACEEE. 
Appendix A

SMUD PowerChoice Materials 
APA-2 


\section{PowerChoice Brochure}

\section{Conservation Makes \\ a Difference}

Anytime you reduce the amount of electricity you use, you are helping the environment by reducing the need to generate more power. You may be asking yourself 'What difference can one person or family make? Think of it this way:

When an average residential custome reduces their total energy usage by just $10 \%$ a year, the environmental impact is similar to taking a car off the road for a month.

Now, that's making a difference!

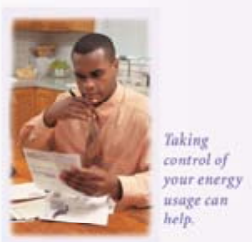

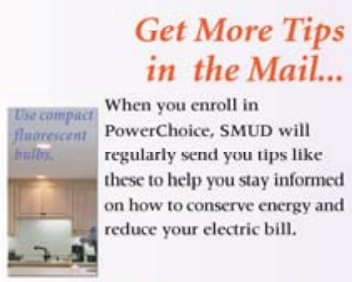

... and Online at smud.org

SMUD's web site - smud.org - provides specific energy efficiency tips, as well as information on rebates and promotions that may help you purchase energy efficient appliances or make energy efficient improvements to your home.

Conduct a FREE Online Home Energy Audit

Conduct a Free Online Home Energy Audit at smud.ong to find out where your home is using the most energy and how you can save on your monthly bill.

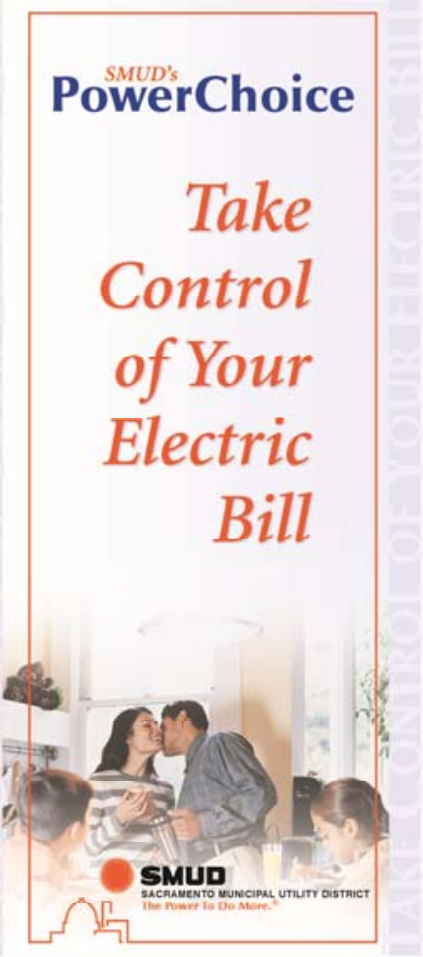

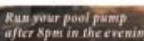

How Does PowerChoice Work?

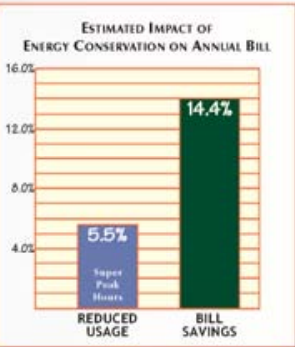

Tips to Help You Save

- In hot weather, set your (air conditioner) hermostat at $78^{\circ} \mathrm{F}$ or higher.

- Run major appliances, such as your clothes dryer, after $8 \mathrm{pm}$ weekdays or on the weekends.

Add a timer to your pool pump and ru the pump in the evening.

- Replace your light bulbs with compact fluorescent bulbs.

- Use ceiling fans to make rooms feel cooler

- In cold weather, set the thermostat on your electric or gas heater to $68^{\circ} \mathrm{F}$ when you are home and $55^{\circ} \mathrm{T}$ at night or when you are not home.

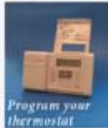

Each year is divided into three seasons: Summer, "swing season", and winter

Customers use the most electricity during the swing season, customers use a moderate amount of electricity, so the prices are moderote. The winter is when oustemers use the lest c winter is when customers usc

You will benefit from these lower prices for eight months out of the year!

\begin{tabular}{|c|c|c|c|c|}
\hline \multirow{7}{*}{$\begin{array}{l}\text { Pay the } \\
\text { lowest } \\
\text { price during } \\
\text { these times } \\
\text { everyday! }\end{array}$} & WEEKDAYS & $\begin{array}{l}\text { SUMMER } \\
\text { Suly \& Auruat }\end{array}$ & $\begin{array}{l}\text { SWING } \\
\text { June \& September }\end{array}$ & 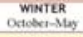 \\
\hline & $\begin{array}{l}\text { Off-1kak } \\
\text { (lowet price) }\end{array}$ & 10pm - Noon & $10 p m$ - Nowo & 10pm - fam \\
\hline & $\begin{array}{l}\text { Onfintak } \\
\text { (mididprice) }\end{array}$ & 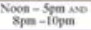 & 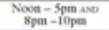 & 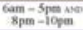 \\
\hline & 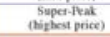 & Spe - $-8 \mathrm{pm}$ & Spem-spm & $5_{\mathrm{ppm}}-\mathrm{sp \textrm {m }}$ \\
\hline & $\begin{array}{c}\text { WEERENOS \& } \\
\text { HOLDAYS }\end{array}$ & $\begin{array}{l}\text { SUMMER } \\
\text { July \& Autzint }\end{array}$ & $\begin{array}{l}\text { SWING } \\
\text { June \& September }\end{array}$ & $\begin{array}{c}\text { Wowter } \\
\text { Octoter-Shy }\end{array}$ \\
\hline & 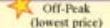 & 10pm - Noonan & 10pen - Novea & $10 \mathrm{pm}$ - 6am \\
\hline & 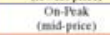 & Niove $-10 \mathrm{pm}$ & Noon - 10pen & 6ens - 10pm \\
\hline
\end{tabular}

Make the Switch... and Save!

Anytime you reduce your overall electricity use, you can save on your SMUD bill. With PowerChoice, you can also save by switching as much of your electricity use as possible to Off-Peak times since you will pay less for electricity during those periods."

It's not possible to shift all of your energy use, but making some changes to when you use electricity - such as running major appliances during Off-Peak hours - can lead to annual savings on your electric bill.

If you use just 5\% less energy throughout the year, and focus those reductions during the Super-Peak periods, you can save more than $14 \%$ on your annual SMUD bill! see the cherr at hof summer, so the prices are highest. During the
Each day is divided into three pricing periods.

The price you pay for electricity is different during each period, with Super-Peak priced the highest, On-Peak in the middle, and Off-Peak he lowest. (See charts below)

Regardless of the season, you will always pay during the Off-Peak hours.

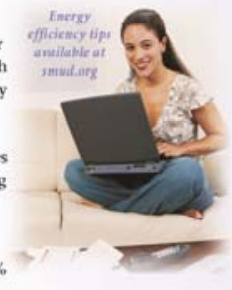
the lowest price by focusing your electricity use
Take Control

of Your SMUD Bill

PowerChoice gives you more control over your SMUD bill by offering a new way to pay for electricity. The result could mean more money in your pocket.

SMUD's cost of supplying electricity increases during the hours that customer use the most electricity. But, the cost decreases during the times customers use the least amount of electricity. PowerChoice reflects this fluctuation by providing different rates for electricity based on when you use it.

When you enroll in PowerChoice, you che save on your SMUD bill by reducing your overall electricity use and by yifting your usage to the periods when Heriods when

It's that easy!

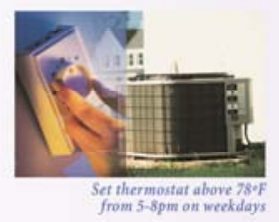

Free PowerChoice

Meter

When you enroll in PowerChoice, SMUD will install a special PowerChoice meter at your home that tracks the amount of electricity you use during each daily pricing period and each season. There is pricing period and each seaso

We Want Your Feedback [7]

You were selected from over 500,000 customers to participate in this special pilot program. If you decide to participale in Powerchoice, your feedback will be essential in guiding SMUD in our efforts to offer this program to more customers in the future. We'll be looking for your feedback in the form of periodic surveys and/or focus groups.

\section{Enrollment \\ Details}

If you are ready to enroll now or have additional questions about PowerChoice, please call (916) 732-5085, or send an email to: eansweresmud.org.

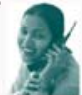




\section{Customer Agreement Form}

\section{PowerChoice Pilot Program Residential Participation Agreement}

This Participation Agreement for the PowerChoice Pilot Program ("Agreement") is entered into between the Sacramento Municipal Utility District (District) and ("Customer'), singularly referred to herein as a "Party. " collectively as "Parties." The Parties agree as follows:

1. Term. This Agreement is effective upon the date of last execution by the Parties and shall continue until September 31, 2009, unless earlier terminated by default or by either Party on thirty (30) days prior written notice. Upon termination or expiration of this Agreement, Customer may receive electric service under any of the District's rate schedule(s) (e.g. otherwise applicable standard rate, as amended from time to time).
2. Scope. The Customer agrees to participate in the District's PowerChoice Pilot Program, for the term of the Agreement, and have the opportunity to manage the cost of their energy usage.

3. PowerChoice Rate. The following rate will be used for the duration of the pilot, unless amended by the District upon prior written notice. Service shall be metered through one metering device capable of measuring electrical energy consumption during various times each energy charge is in effect.

\section{MONTHLY RATES}

Customer Charge ..........\$7.50 per month or portion thereof

Energy Charge - SUMMER (July - August)

High (Super-Peak) ........\$ $0.2247 / \mathrm{kWh} \ldots$ 5-8 p.m. weekdays

Medium (On-Peak) ........\$ 0.1706/kWh _......... 12 noon-5 p.m. \& 8-10 p.m. weekdays; 12 noon-10 p. m. weekends Low (Off-Peak) ..............\$ $0.0835 / \mathrm{kWh} \ldots \ldots . . . .10 \mathrm{p} . \mathrm{m}-12$ noon daily

Energy Charge - SWING SEASON (June \& September)

High (Super-Peak) ........\$ 0.1491/kWh _........ 5-8 p.m. weekdays

Medium (On-Peak)........\$ 0.1255/kWh.......... 12 noon-5 p.m. \& 8-10 p.m. weekdays; 12 noon-10 p.m weekends Low (Off-Peak)..............\$ $0.0759 / \mathrm{kWh} \ldots 10 \mathrm{p} . \mathrm{m}-12$ noon daily

Energy Charge - WINTER (October - May)

High (Super-Peak) ........\$ 0.1000/kWh …....5-8 p.m. weekdays

Medium (On-Peak)........\$ 0.0901/kWh ........ 6 a.m. -5 p.m. \& 8-10 p.m. weekdays; 6 a m-10 p.m. weekends Low (Off-Peak)..............\$ 0,0688/kWh ........ 10 p.m -6 a.m daily

$\%$ Discount / Premium on Rate Based on Monthly Usage

$0-700 \mathrm{kWh} \quad-15 \%$

$700-1000 \mathrm{kWh} \quad-5 \%$

$1000-1500 \mathrm{kWh} \quad 20 \%$

$1500-2000 \mathrm{kWh} \quad 35 \%$

$2000-3000 \mathrm{kWh} \quad 40 \%$

$>3000 \mathrm{kWh} \quad 50 \%$
The pricing periods for the following observed holidays will be the same as the weekend hour price level, for the month in which the holiday occurs:

- New Year's Day

- Martin Luther King Jr.'s Birthday

- President's Day

- Memorial Day

- Independence Day

- Labor Day

- Thanksgiving Day

- Day after Thanksgiving

- Christmas Day 
Customer agrees to be charged and billed for electric service at the Powerchoice rate for the term of this Agreement

The District may elect to continue this rate, adjust the rate and make it available to the Customer, or discontinue the rate at the end of the pilot period. If the District adjusts the rate. the District will provide the Customer with 30 days prior written notice before the effective date of the amended rate

4. Premises. The PowerChoice Meter shall be installed at the following address:

(Premises).

5. Installation. The District or its contractor shall remove the existing meter and install, at the District's sole expense, a PowerChoice Meter. The District or its contractor shall perform the work as soon as is reasonably practical upon approval of the Customer's application. Under this Agreement, the District or its contractor shall have the exclusive right to install, operate, maintain, and perform warranty services on the PowerChoice Meter. During the term of this Agreement, under no circumstances shall Customer attempt to maintain, perform warranty services on, or remove the PowerChoice Meter.

6. Access to Premises. Customer grants the District or its contractor, the right to install, operate, maintain. and perform warranty services on the PowerChoice Meter at the Premises. Customer also grants the District the right of ingress and egress on the Premises for the purposes set forth herein.

7. Ownership. The PowerChoice Meter is the sole property of the District.

8. Cost. There is no cost to the Customer for the PowerChoice Meter, the installation, and reasonably anticipated warranty services

9. Eligibility Requirements. Customer must meet all the following participation and eligibility requirements:

a. Customer must have a single-metered, singlephase residential account that meets the District's electrical metering specifications

b. Customer must not plan on moving during the next 12 months.

10. Incentive. As a condition of participating in the PowerChoice Pilot Program, Customer agrees to remain on the program for a minimum of 12 months from the time of the PowerChoice Meter installation. As consideration for Customer's agreement to participate for the above detailed period, the District will provide Customer with a twenty-five dollar $(\$ 25.00)$ valued Home Depot gift card.

11. Research.

Customer agrees to have the District owned metering equipment installed, at no cost, to the Customer, for the purpose of the District determining energy and/or demand electricity savings
12. Rules and Regulations. This Agreement shall, at all times be subject to the District's Rules and Regulations, as amended from time to time.

13. Warranty. The District makes no warranties, implied or express, written or oral, with respect to the goods and services provided under this Agreement including, but not limited to, the warranties of merchantability and fitness for a particular purpose.

14. Notices. All written communications or notices under this Agreement shall be directed as follows:

District: Sacramento Municipal Utility District Attention: Maria Monterrubio, MS A203 PO. Box 15830

Sacramento, CA 95852-1830

Customer:

Print Name

Malling Addreses

City $\quad$ State Zip

Home Telephone Number

E.Mail Address

15. Amendments: The District reserves the right, at its sole discretion, to amend the terms of this Agreement. The District will notify Customer in writing of the amendment, which will become effective as of the amendiment effective date stated in the notice. If Customer objects to the amendment. Customer may terminate this Agreement by giving written notice to the District within 30 days of the effective date of the amendment.

16. Applicable law. This Agreement shall be interpreted, governed by and construed under the laws of the State of California, as if executed and to be performed wholly within the State of California.

17. Entire Agreement. This Agreement constitutes the entire understanding between the Parties as to the subject matter hereof.

Customer

Signature

Print Name Date

District Signature

Print Name

Date 


\section{Transition to Summer Rates Reminder Postcard}

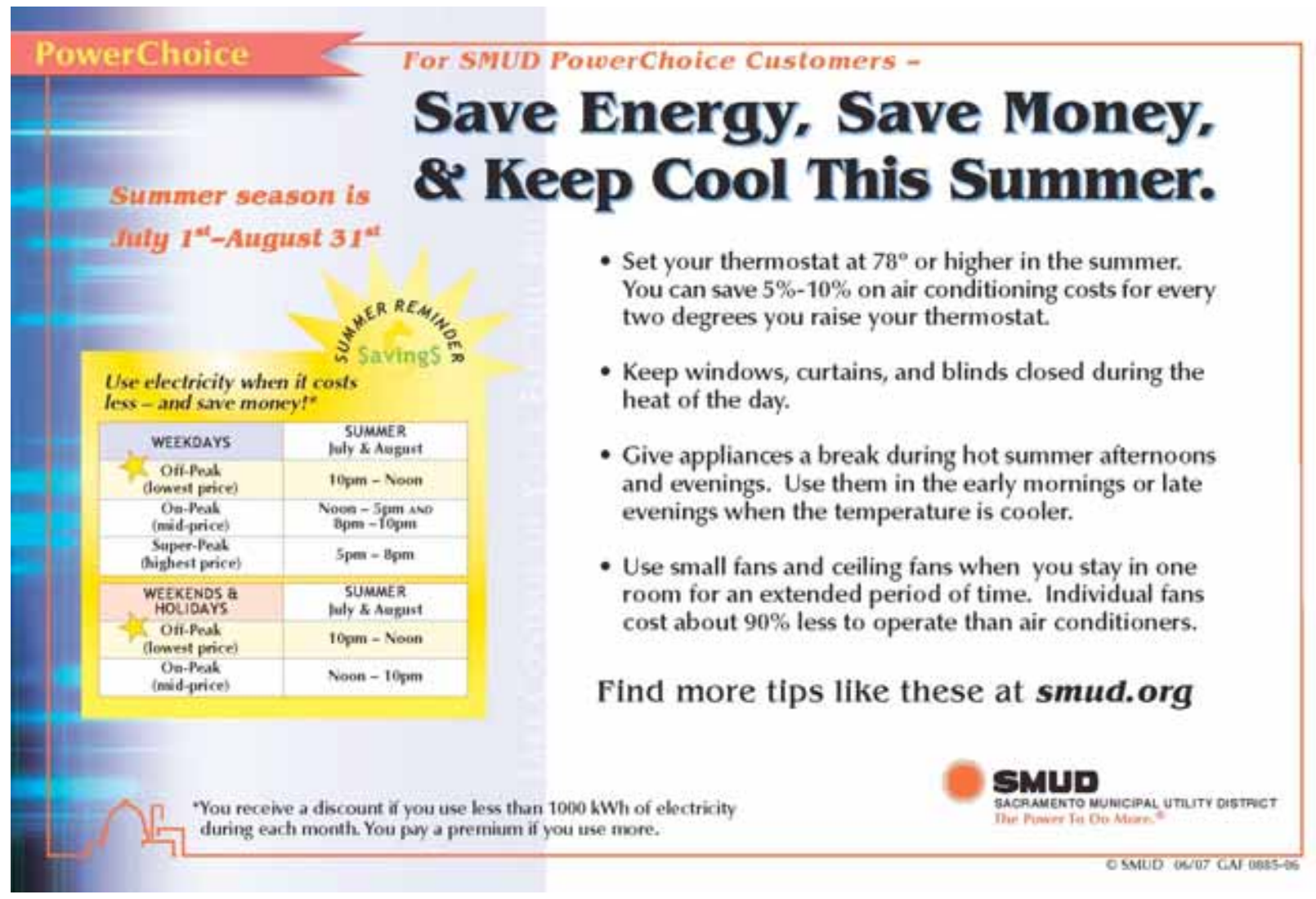




\section{Appendix B}

Enhanced Information Intervention Mailings 
APB-2 


\section{Example of Enhanced Information Letter}

[Letters were produced by SMUD, printed on company letterhead and mailed in company envelop]

April 11, 2008

Name

Address

Dear PowerChoice Customer,

I hope by now you are all making good use of your PowerChoice magnet. I especially want to thank the 27 customers who sent back the return post card and who shared their energy saving tips and other feedback about the program. After a random drawing, ten lucky customers were rewarded with a \$25 Home Depot Gift Card for returning the reply card. Your active participation can help everyone succeed on PowerChoice and makes the program better too.

Here are just some of the great ideas you told us about:

- Run major appliances after 10 p.m. when it's practical, such as turning on the dishwasher or clothes washer when you go to bed.

- Try to do the laundry and dishes on the weekend.

- Run less dirty loads on "light wash" and do only full loads. "Air dry" clothing when you can, but if you use the dryer, be sure to clean out the lint filters (both inside the dryer and on the outside vent).

- Use extra blankets on the beds and wear extra clothes.

- Actively avoid running any electric device during super-peak hours.

- Make PowerChoice a game and have fun. . Make one of your kids a "light" monitor.

- Arrange for a whole house fan and screen doors now, to get ready for the warm weather.

I welcome any tips and comments you have - or topics you'd like to see covered in my letters to you. Please email them to me at [email address inserted]. Together we can save electricity and money and help protect the planet.

Thanks so much for your continued participation and suggestions!

Sincerely,

[Actual signature, blue ink]

Program Manager, PowerChoice 
APB-4 


\section{Appendix C}

Blue Line Intervention Materials and Background Research 
APC-2 


\section{Blue Line PowerCost Monitor Display}

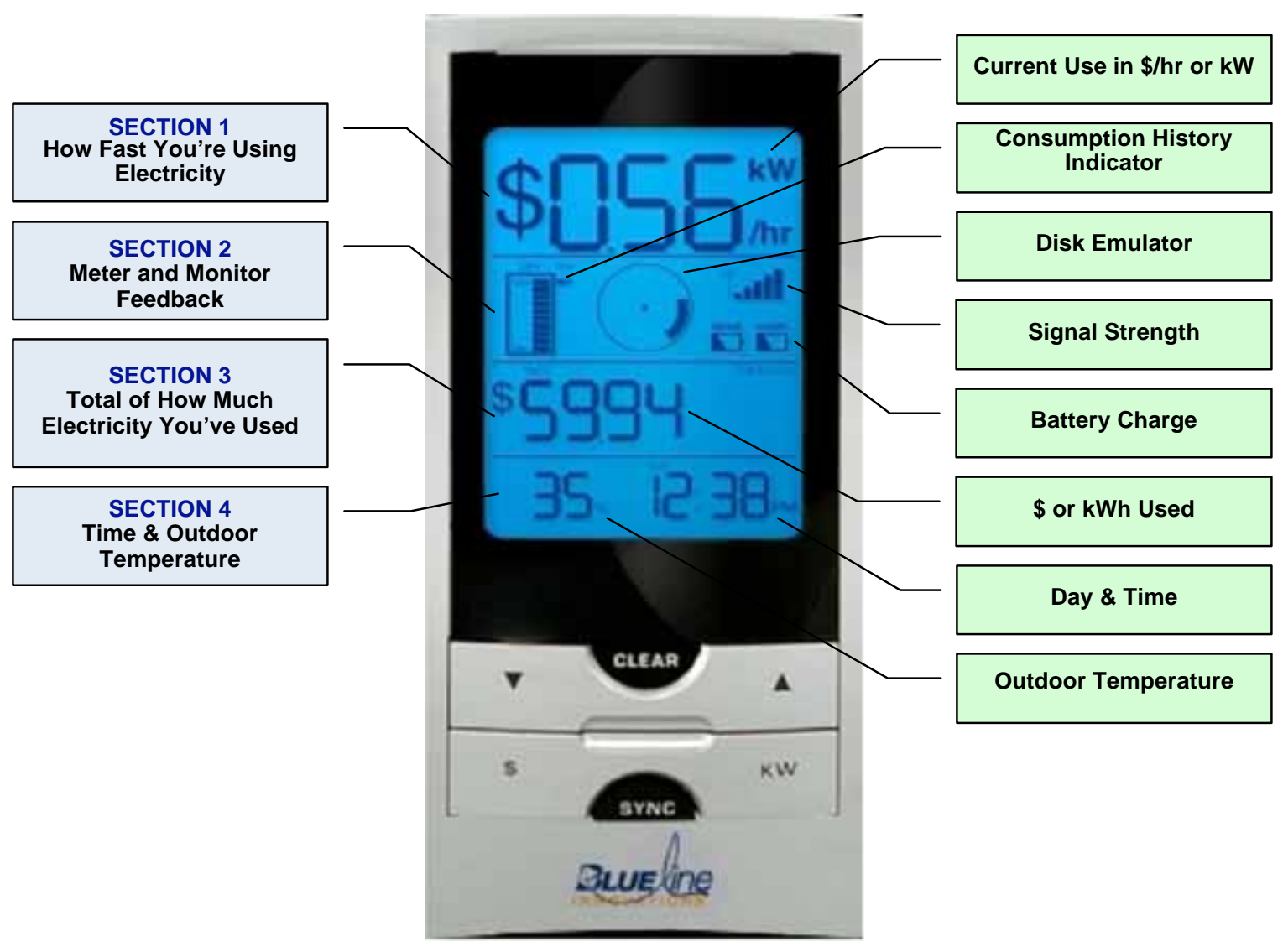




\section{Blue Line PowerCost Monitor ${ }^{\mathrm{TM}}$ Extra Tips \#1}

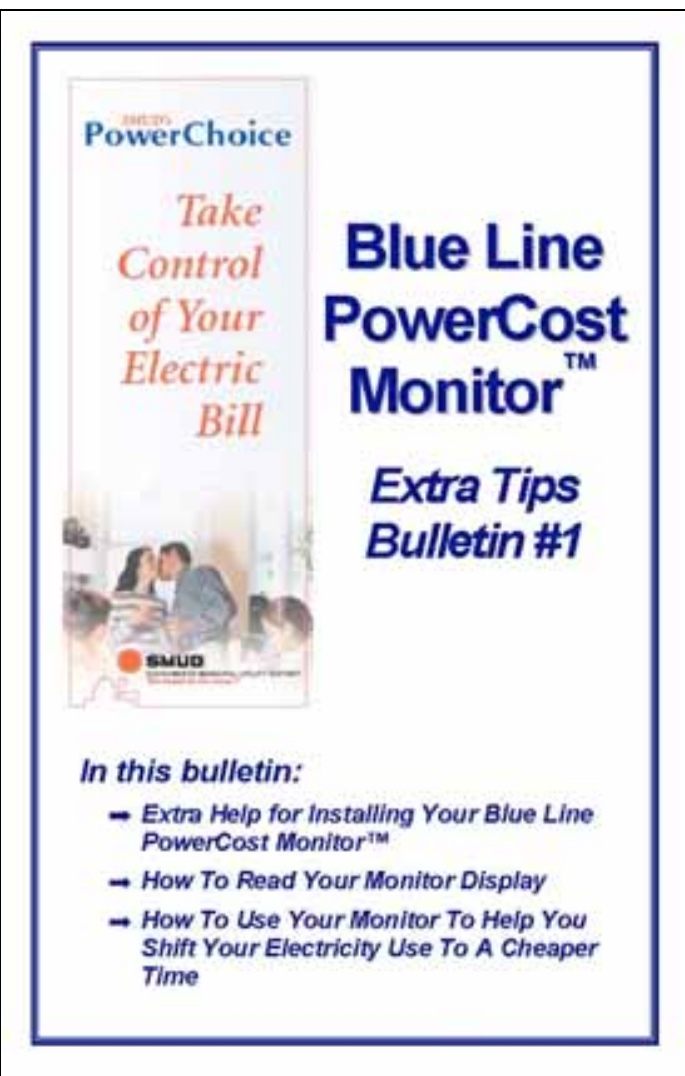

Hello from the Research into Action Team! Our goal is to help you make the most out of your new Blue Line PowerCost Monitor. This is the first in a series of bulletins we will send you with tips. We'll be checking in with you later, but tips. We you need us in the meantime, please feel free to call.

Susan Lutgenhuer

Proiect Director, Research into Action, inc BB8-492-9100 (Toll Free)

EXTRA HELP FOR INSTALLING YOUR BLUE LINE POWERCOST MONITOR

This sheet provides tips to help you install yout Blue Line PowerCost Montor. The tips cortespond to the sections of the instatation process doscribed in the PowerCost Monitor User Manuaf.'

NOTE: If you have any problems installing your monitor, please contact Bive Line innovations at 1.866-607-25:3

Installation Tips

Sections 1 and 2 - Welcome and Your PowerC ost Monitor Review the safoty and care, and the maintenance instructions Section a - Determine Your Utility Meter Type: PowerChoise eustomers have an itron Centron Meter - an electronic motor (with a dgital readout with a top optical port. Your meter should look like the last set of pictures on page 6 in the User Manual.

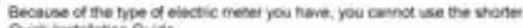
Qice intatation Quide
Section 4 - Unpacking and Verifying Basic Operation: Foltew the instructions for installing the batteries in the Sensor and Display Units and veritying basic operation.

Section 8 - Sensor Unit Installation: Some people find this is the trickiest step. Read Section 5.1 and then carefully follow the and install the Sensor Unit on an electronic metor with an opocal port on top. The sensor needs to read the signal from the optical port on top. The sensor needs to read the signal trom the optcal the Display Unit.

Section 6 - Setting Up Your Display Unit: PowerChoice eustomers have Time-of-Use Baing. First neview Section 62 about the Display Unit, then go to Section 6.5 for Time-of Uso Biling. Follow steps $1-8$ to set the time and day. You will then be prompted to shange your rates and Kh. You don't need to complete the remaining set-up steps because your Display Unit is pre-programmed with the PowerChoice electricity rate information for the Summer, Weekday period.' To skip these fral seps, press the SET button on the back of your unt several tmes unbl your display shows dashes (- - - )

This completes the installation process.

If You Want To Check Your Installation

- Look to see that the disk on your Display Unit is "spinning". This indicates the unit is receiving electricty use information from your moter.

- To 900 i your electricty use seems reasonabio, press the $\mathrm{kW}$ symbol on the Display Unit to put it in the $\mathrm{kW}$ mode. Turn on your eloctric oven or electric dryer and waht a minute of two. You should see the reading on your Diaplay Unit jump by 3 to $5 \mathrm{~kW}$. If the readings aro much lower, your monitor may not be opecating property. Check the boubloshooting section in the User Manual for possibie solutions

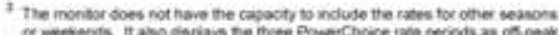

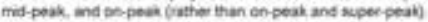




\section{HOW TO READ YOUR MONITOR DISPLAY}

The moritor display screen has four sections

- SECTION 1 - Shows how fast you are using electrioty

- SECNON 2 - Gres you meter and monitor feedback. Including a consumption history ind cator, an image of the meter disk rotating the strengti of the signal from you meler, and the strength of the battery charge

- SECTION 3 - Shows the fotal de electricity yourve used

- SECTION 4 - Cives the tme and outdoor temperature

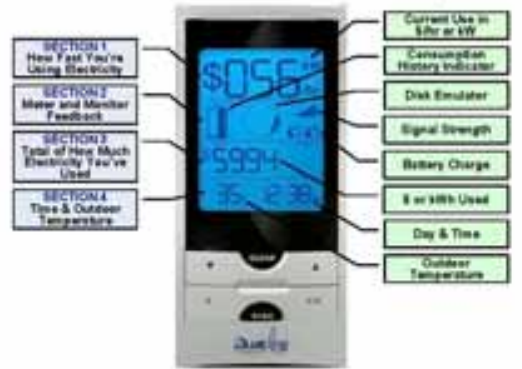

The buttons at the botlom of your monitor do these things

- CLEAR - Resets back to zero cwhen held for a few seconds) the Consumption History indicator in Section 2 and how muct electricity you ve used in Section 3

- Up and Down Arrows - Used only during setup to set tie time and rases on the monitor (Powerchaice summer weekday rates are already programmed into your montor;

- SYNC - Used ondy during setup to synchronize the montor with the sensor on your meter

- S and KW - Buttons that let you switch back and forn between displaying electriaty use in dolars (5) or in wilowatts (NW)

EXERCISE: USING YOUR MONITOR TO SHIFT USE TO LOWER COST PERIODS

You can save money by redueing how fast you use electricity during supec-peak and on-peak periods when you afe paying up to $2 \%$ times more, You wil save the most by sheting use from super-poak to oft-poak periods. In this exercise, you can use the information trom Section 1 on the monitor to track the speed of your electricity use and to detect ways you can shef more use : lower cost peetods

Uee the diary below to record how fast you use electrichy $(\mathrm{kW}$ ) for difterent PowerChoice rate periods. Try to do a for five days.

Compare how fast you are using electricity actoss the days and rate perisds

If you see you are using electricily faster during the suppr-peak of on-poak periods, try to identify what electrical uses $(e \mathrm{~g}$.

appliances, air conditioner) are causing 2 . To do this, try turning

off applantes or other electric cavipment during On Posk and

Supet-Pask petiods to see what drterence this makes in your speed of electrichy use.

Now consider $t$ you can change when you use the applances of equiprsont, or if yed can use them less. For instance, can you use your electric dryer at a lower-cost time? Or raise your thermostat temperature for your air condisoner so that in runs less?

\begin{tabular}{|c|c|c|c|c|c|c|c|}
\hline \multirow[t]{2}{*}{$\begin{array}{l}\text { OAYOP } \\
\text { WEEK: }\end{array}$} & \multirow[t]{2}{*}{$\begin{array}{l}\text { Tuar } \\
\text { PEROCO }\end{array}$} & \multirow{2}{*}{$\begin{array}{l}\text { tuve } \\
\text { of } \\
\text { use }\end{array}$} & \multicolumn{5}{|c|}{ 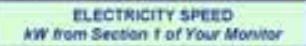 } \\
\hline & & & Dart & ourz & DAY 3 & Dur 4 & DAYs \\
\hline \multirow[t]{4}{*}{ Weasdays } & $\begin{array}{l}\text { fo.00 pm } \\
\text { to Noon }\end{array}$ & $\begin{array}{l}\text { Ools. } \\
\text { poak }\end{array}$ & & & & & \\
\hline & $\begin{array}{l}\text { Noson to } \\
\text { sido pm }\end{array}$ & $\begin{array}{l}\text { On } \\
\text { Poak }\end{array}$ & & & & & \\
\hline & $\begin{array}{l}600 \mathrm{pm} 10 \\
0.00 \mathrm{pm}\end{array}$ & $\begin{array}{l}\text { Siper } \\
\text { Paak }\end{array}$ & & & & & \\
\hline & $\begin{array}{l}.00 \mathrm{pm} \text { to } \\
10.00 \mathrm{pm}\end{array}$ & $\begin{array}{l}\text { Oon. } \\
\text { Ploak }\end{array}$ & & & & & \\
\hline \multirow[t]{2}{*}{$\begin{array}{l}\text { Weotends } \\
\text { s. Hoidere }\end{array}$} & $\begin{array}{l}10.00 \mathrm{pm} \\
\text { mo Noon }\end{array}$ & $\begin{array}{l}\text { Oos: } \\
\text { Poak }\end{array}$ & & & & & \\
\hline & $\begin{array}{l}\text { Noon } 10 \\
\text { foos gm }\end{array}$ & $\begin{array}{l}\text { On: } \\
\text { Pouk }\end{array}$ & & & & & \\
\hline
\end{tabular}

We all hnow that traveling 100 miles per hour in a car is fast, or traveling 1,000 miles is a long trip. But is using electricily at the speed of $1 \mathrm{~kW}$ fast? Or is using $1,000 \mathrm{kWh}$ of electricity during a woek a loc?

Your monitor can help you answer these questions. You monitor is like the speedometer and odometer on your car. It can tell you how fast you are using electricity (tike your speedometer) and how much electricity you ve used (ike the miles on your odometer). Now let's locus on Sections 1 and 3 of your monitor.

SECNON 1 - How fast you are using electricity and dollars. When you press the $k W$ buttion, you can see the "speed" of yout electricty use in klowatss $(\mathrm{kW})$ in Soction 1 . The higher the $\mathrm{kW}$ reading, the faster you are using electricity. If you pross the s button, the montor shows you how much money you would spend button, the montor shows you how much money you would spend at you cu ine next PowerChoce retes.

SECTION 3 - The total amount of electricity you have used. When you pross the kW buttion, you can seo how much eloctrictiy you have used in kilowatt-hours (KWh) in Secton 3 since the monitor was last reset to zeeo." If you hold down the CLEAR button for a fow soconds, you can reset your electricity use to zeno. Our noxt bulotin wil show you how to use this foature to bettec track your use, so that you can got a discount, of avod paying an extra premium, under poreechoice.

Now, please furn the page and try the exercise

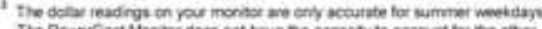

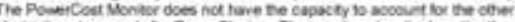

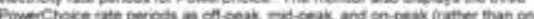
peak and wiper-peusp

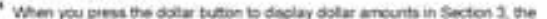

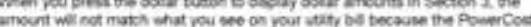

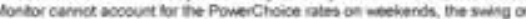

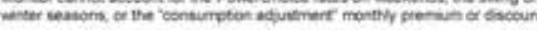

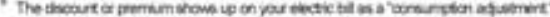

Now, try charting the month..

Week

\begin{tabular}{|c|c|c|c|c|c|c|c|}
\hline \multirow[t]{2}{*}{$\begin{array}{l}\text { DAYOF } \\
\text { WEEK }\end{array}$} & \multirow[t]{2}{*}{$\begin{array}{c}\text { TIME } \\
\text { PEROSO }\end{array}$} & \multirow{2}{*}{$\begin{array}{l}\text { Tue } \\
\text { of } \\
\text { use }\end{array}$} & \multicolumn{5}{|c|}{$\begin{array}{l}\text { ELECTkiciTY SPEEO } \\
\text { AW trom Section } t \text { of Your Monvor }\end{array}$} \\
\hline & & & Day, & DAY 2 & DAY 3 & DaY 4 & DAYS \\
\hline \multirow[t]{4}{*}{ Weatars } & $\begin{array}{l}10.00 \mathrm{pm} \\
10 \mathrm{NoOn}\end{array}$ & $\begin{array}{l}\text { On. } \\
\text { Pouk }\end{array}$ & & & & & \\
\hline & 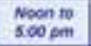 & $\begin{array}{l}\text { On } \\
\text { Paak }\end{array}$ & & & & & \\
\hline & $\begin{array}{c}5.00 \mathrm{parm} n \\
0.00 \mathrm{pm}\end{array}$ & $\begin{array}{l}\text { Supur } \\
\text { Pank }\end{array}$ & & & & & \\
\hline & $\begin{array}{l}2.00 \mathrm{pm} \text { is } \\
\text { N0.00 pim }\end{array}$ & $\begin{array}{l}\text { On: } \\
\text { Poak }\end{array}$ & & & & & \\
\hline \multirow[t]{2}{*}{$\begin{array}{l}\text { Weekends } \\
\text { A Holders }\end{array}$} & $\begin{array}{l}+10.00 \mathrm{pm} \\
\text { no Noon }\end{array}$ & $\begin{array}{l}\text { Oos. } \\
\text { Pask }\end{array}$ & & & & & \\
\hline & $\begin{array}{l}\text { Noon is } \\
\text { Poos pmm }\end{array}$ & $\begin{array}{l}\text { On: } \\
\text { Poak }\end{array}$ & & & & & \\
\hline
\end{tabular}

Week 2

\begin{tabular}{|c|c|c|c|c|c|c|c|}
\hline \multirow[t]{2}{*}{$\begin{array}{l}\text { DAY OF } \\
\text { WEEK }\end{array}$} & \multirow[t]{2}{*}{$\begin{array}{l}\text { TuEE } \\
\text { PERODOO }\end{array}$} & \multirow{2}{*}{$\begin{array}{l}\text { The } \\
\text { of } \\
\text { use }\end{array}$} & \multicolumn{5}{|c|}{$\begin{array}{l}\text { ELECTRICTYY SPEED } \\
\text { wW from Section if of Your Montor }\end{array}$} \\
\hline & & & Dar: & DAY 2 & Dar 3 & our 4 & Dars \\
\hline \multirow[t]{4}{*}{ Woesdays } & $\begin{array}{l}10.00 \mathrm{pm} \\
\text { fo Noon }\end{array}$ & $\begin{array}{l}\text { On: } \\
\text { Pank }\end{array}$ & & & & & \\
\hline & $\begin{array}{l}\text { Noson } 10 \\
500 \mathrm{pm}\end{array}$ & $\begin{array}{l}\text { Os: } \\
\text { Poak }\end{array}$ & & & & & \\
\hline & $\begin{array}{c}500 \mathrm{pm} \text { to } \\
2 \infty \mathrm{pm}_{\mathrm{pm}}\end{array}$ & $\begin{array}{l}\text { Super. } \\
\text { Pouk }\end{array}$ & & & & & \\
\hline & $\begin{array}{l}200 \mathrm{pm} 10 \\
1000 \mathrm{pmm}\end{array}$ & $\begin{array}{l}\text { On: } \\
\text { Pouk }\end{array}$ & & & & & \\
\hline \multirow[t]{2}{*}{$\begin{array}{l}\text { Weekends } \\
\text { s Holdars }\end{array}$} & $\begin{array}{l}10.00 \mathrm{pm} \\
\text { to Noon }\end{array}$ & $\begin{array}{l}\text { Oos. } \\
\text { Peak }\end{array}$ & & & & & \\
\hline & $\begin{array}{l}\text { Noons so } \\
\text { No.0opm }\end{array}$ & $\begin{array}{l}\text { On: } \\
\text { Anok }\end{array}$ & & & & & \\
\hline
\end{tabular}

Please turn the page for weoks 384 


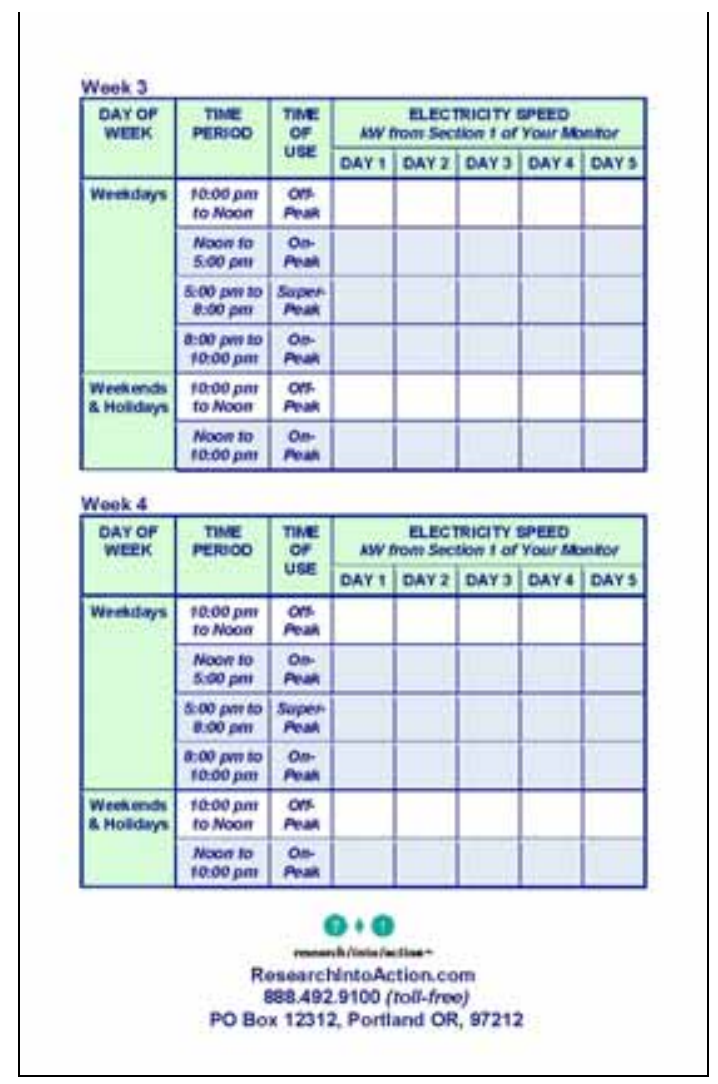




\section{Summary Information on Other Feedback Monitor Studies}

\section{Review}

Insofar as the research team could see from a review conducted in late 2007, previous pilots and deployments of power monitors did not appear to have taken special steps to help users apply the monitors. Participating consumers may have volunteered to be in the pilot program, but may not have volunteered to get a monitor. The results from these pilot studies gave an indication of what happens when people are given the monitors as they are supplied from Blue Line. In short, savings did occur, but there were problems, and some of the people who got monitors seemed not to have been interested in them. A short description of some of these pilot efforts is given below. At the time of our review, there are also studies of the monitor underway or planned in Massachusetts and Oregon.

\section{Hydro One}

Hydro One drew a sample of 500 households to receive the monitor and a control group of 52 . They stratified the sample by consumption and by geography. They ended up with useful data from 382 participants and 42 controls. Households did not receive any other information or interventions besides the monitor. The report does not say whether households received information on how to use the monitor or whether households installed the monitor themselves. The report said little about the application of the monitors, but it mentioned that there were "technical difficulties with the device that needed to be corrected." A footnote states that: "Technical problems fell into the following categories: installation problems (15\%), battery issues $(30 \%)$, missing transmitter $(1 \%)$, dropped receivers $(3 \%)$, potting issues $(29 \%)$, range issues $(10 \%)$ and other and unknown (12\%)." The report does not say how widespread these problems were.

Hydro One also offered 30,000 monitors for free on a first-come first-serve basis in the summer of 2006.

\section{BC Hydro}

Monitors were installed in 325 households, according to Blue Line, Inc. Households were randomly assigned to different treatment groups and the Blue Line monitor group also received general energy tips. People voluntarily agreed to participate in the overall TOU pilot after being sent information by mail, but the monitors went to everyone randomly assigned to the monitor sample group. The results show that $22 \%$ of participants said there were problems with installation and that it should be performed by a BC Hydro technician. There were a variety of problems with the monitors working properly. The results also suggest that a significant portion of the people that received the Blue Line really did not want to have it.

\section{Newfoundland Power and BC Hydro}

The sample was 100 units each in Newfoundland and British Columbia. The report indicates they identified potential participants and then did telephone recruitment, but does not provide information on how the monitors were provided to participants, what information was provided these participants, or who installed the meters. There was no any information in the results on issues related to installation or the application of the monitors. In general, the results 
were similar to the BC Hydro and Hydro One cases, although the savings in Newfoundland were fairly high.

\section{NSTAR Study}

In late 2007, an evaluation of a Blue Line PowerCost Monitor ${ }^{\mathrm{TM}}$ pilot just got under way in Massachusetts. NSTAR offered a limited number of monitors to customers for the reduced cost of \$29.95. National Public Radio (NPR) aired a segment on this earlier in the year. All NSTAR customers requesting a monitor received them in the mail and were expected to install them themselves. NSTAR is not aware of any particular problems with installations, but customers were asked to contact Blue Line directly with any concerns. There will be a customer survey to learn more about how customers used the monitor.

\section{NGRID Study}

At National Grid, installation of Blue Line PowerCost Monitors ${ }^{\mathrm{TM}}$ (PCM) was implemented using two different methods. One hundred were installed through a statewide energy audit program, where the auditor explained the use of the monitor and installed it for the customer. Another 270 were distributed through the mail using direct mail marketing materials, where Blue Line did the direct mail marketing and distribution of the PCMs. The customer was required to install the monitor themselves. They will learn more how each of these customer segments dealt with the installation process through the customer survey fielded in late 2007 early 2008.

\section{Energy Trust of Oregon / Future of Energy Input}

Energy Trust did some initial testing of the Blue Line PowerCost Monitor ${ }^{\mathrm{TM}}$ and fielded a survey with 23 participants. Some interesting findings are: $30 \%$ stated they had difficulty setting up the sensor unit on their meter (for some it did not fit); $27 \%$ waited more than five days to install the unit; $45 \%$ stated they had difficulties programming the display unit (mostly figuring out and programming rates); $62 \%$ valued the instantaneous consumption the most; and $64 \%$ believe they did not alter consumption. People who believed they did save thought they saved on lighting and computers.

They have a few units in permanent locations and the batteries appear to wear out in about three-four months, so people need to be motivated to change them out. The study did not consider savings from the monitors, just experience with them.

At the time of this review, the Energy Trust was planning to launch two pilots in January 2008. One pilot, to be implemented by Conservation Services Group, would distribute to 200 homes through Home Energy Review. This will be a controlled sample by geography, heating fuel, house vintage, and other demographics. Beginning, mid- and end-surveys are planned, and after a year, an impact and process evaluation will be conducted.

The other pilot will involve about 100 units sold for $\$ 30$ to households that come to the Energy Trust. For this pilot, the Trust will recruit volunteers through very limited and targeted marketing, mostly through their website. The objective is to find out who the early adopters are and what types of people want the product (monitor). The same surveys and evaluation used for the first pilot will be used for this pilot. 
APC-9 


\section{Appendix D}

Detail on Demographic Characteristics of PowerChoice Participants 
APD-2 
Chapter 2 in the body of the report provides an overview of demographic characteristics of PowerChoice TOU rate customers and compares these characteristics to those of other residential customers in the SMUD service territory. This appendix provides further details.

\section{Demographic Comparisons Made}

Data on demographic characteristics were collected in two of the three surveys conducted for this project. Combining results over two surveys (Wave 1 and Wave 3), nearly 90\% of PowerChoice participants were surveyed as to demographic characteristics. For some variables, data collected by SMUD during the recruitment process are also available. In the following analyses, both data sources are used to describe characteristics of the PowerChoice participants.

Besides comparing participant households to the Sacramento population, we also compared demographic characteristics of the two treatment groups to those of the participant population overall. The Enhanced Information Treatment Group was assigned randomly from the participant pool that was current as of July 2007. The demographic characteristics of this group were essentially the same as those of other surveyed PowerChoice participants. The Monitor Treatment Group was comprised of volunteers among program participants, but even then no particular biases were evident in comparing the demographic characteristics of the Monitor Treatment group and other surveyed participants.

\section{Dwelling Characteristics}

Table D-1 compares the basic characteristics of PowerChoice participant dwellings and housing tenure to Sacramento County, the approximate area of the SMUD service territory. ${ }^{81}$

81. SMUD provides electricity to Sacramento County and to a small portion of Placer County. In this table, statistics for PowerChoice participants are derived from the dwelling information compiled by SMUD, with the exception of the owner-occupied statistic, which is derived from responses on Wave 1 and Wave 3 surveys and applies only to the TOU participants who responded to the survey. Information on dwelling characteristics for Sacramento County are derived from American Housing Survey Metropolitan Area Survey for Sacramento 2004 (U.S. Bureau of the Census 2005), using Sacramento City and Sacramento County Less City areas (Areas One and Two) data for owner-occupied units and from the American Community Survey 2006 (factfinder.census.gov). Exceptions: the data on median household income for the County excludes Sacramento City (approximate median household income, including city, would be about $\$ 64 \mathrm{~K})$, and the data on speaking English in the home is for the population and is derived from the American Community Survey 2006 for Sacramento (factfinder.census.gov). 
Table D-1. Dwelling Characteristics of PowerChoice Participants and Sacramento County

\begin{tabular}{|l|c|c|}
\hline \multicolumn{1}{|c|}{ Characteristic } & $\begin{array}{c}\text { Power Choice } \\
\text { Participants }\end{array}$ & Sacramento County \\
\hline Number of Households & 286 & 500,777 \\
\hline Percent in Single-Family Homes & $90 \%$ & $70 \%{ }^{82}$ \\
\hline Percent Owner-Occupied & $89 \%$ & $61 \%$ \\
\hline Median Year Structure Built: Owner-Occupied Units & 1983 & 1977 \\
\hline Median Size: Owner-Occupied Units & 1,748 sq.ft. & 1,760 sq.ft. \\
\hline
\end{tabular}

Statistics for Sacramento County are from the American Community Survey Three-Year Estimates 2005-2007 for Sacramento County (U.S. Departmetn of the Census 2008) and U.S. Bureau of the Census (2005).

PowerChoice participants are more likely to live in single-family dwellings (90\%) and more likely to own their home $(89 \%)$, compared to Sacramento County overall - that is, renters and non-single family homes are under-represented relative to Sacramento County. Renters and apartment-dwellers were thus evidently less interested in taking on the PowerChoice rate than those who owned single-family homes. Median house size for households of PowerChoice participants is nearly identical to that in the county, while the typical house is slightly newer. This high representation of owner-occupied single-family units is similar to what has been seen in other residential TOU pilots (Ontario Energy Board 2007; Pederson 2007). It is likely a reflection of self-selection onto the rate. ${ }^{83}$

\section{Household Equipment}

Table D-2 summarizes electrical equipment present in the home, according to survey responses. Respondents for nearly all surveyed households (95\%) said they had a central air conditioner and a few $(5 \%)$ reported more than one. The penetration of central air conditioning among owner-occupied households county-wide is comparable (91\%). ${ }^{84}$ Most surveyed households also had portable or ceiling fans (70\%) and 40\% reported other electric alternatives to cooling, such as whole house fans $(30 \%)$, evaporative coolers $(7 \%)$, or window/wall air conditioners $(7 \%)$. As it turns out, in survey questions about shifting and conservation actions, respondents mentioned only natural ventilation and whole house fans as alternatives to central air conditioning during Peak and Super-Peak periods.

Nearly all households had an automatic dishwasher (95\%) and most had an electric dryer (78\%). Roughly half of stove tops and ranges were electric. A quarter of the households reported having a swimming pool, rather high for the area.

82. Includes single-family attached and single-family detached units only.

83. This is expected, since single-family owner-occupied households generally have higher bills than multi-family units, and usually pay their own power bills and make their own decisions about energy investments - mapping to higher concern (about bills), and higher capacity (to change consumption). The other possibility (in any study) is a recruitment procedure that invites such a bias.

84. Table 3 of U.S. Bureau of the Census (2005). 
Table D-2. Reported Electric Equipment in the Home

\begin{tabular}{|l|c|}
\hline \multicolumn{1}{|c|}{ Electric Equipment } & Percent \\
\hline Cooling and Ventilation & $95 \%$ \\
\hline Central Air Conditioner (One or More) & $8 \%$ \\
\hline More than One Central Air Conditioner & $7 \%$ \\
\hline Window / Wall Air Conditioner & $7 \%$ \\
\hline Evaporative Cooler & $30 \%$ \\
\hline Whole-House Fan & $70 \%$ \\
\hline Portable Fan (One Or More) & $70 \%$ \\
\hline Ceiling Fan (One Or More) & \\
\hline Appliances & $64 \%$ \\
\hline Electric Oven & $46 \%$ \\
\hline Electric Stove Top & $78 \%{ }^{*}$ \\
\hline Electric Dryer & $95 \%$ \\
\hline Dishwasher & \\
\hline Other & $18 \%$ \\
\hline Heat Pump & $21 \%$ \\
\hline Electric Heating as Main Heating Equipment & $13 \%$ \\
\hline Electric Water Heater & $26 \%$ \\
\hline Pool & \multicolumn{2}{|c|}{} \\
\hline
\end{tabular}

${ }^{*}$ An additional $21 \%$ have natural gas dryers, and a few households have neither electric nor natural gas dryers.

\section{Household Characteristics}

Table D-3Error! Reference source not found. compares demographic characteristics of survey respondents and their households to those of Sacramento County. Unless otherwise noted, the county statistics include only owner-occupied units, providing a better comparison for the PowerChoice participants. Age and education level are the striking differences between PowerChoice participants who responded to the survey, as compared to the county.

\section{Age}

The median age of survey respondents is 60, nearly a decade older the median age of 51 among heads of household in owner-occupied dwellings in Sacramento County. ${ }^{85}$ This upward shift in age is reflected in the other life cycle-related comparisons shown in Error! Reference source not found..

Table D-3. Demographics of Survey Respondents versus Sacramento County ${ }^{1}$

\begin{tabular}{|c|c|c|}
\hline Demographic & $\begin{array}{c}\text { Survey } \\
\text { Respondents }\end{array}$ & Sacramento County \\
\hline
\end{tabular}

85. For the surveyed PowerChoice households, we used the age of the survey respondent. Survey respondents could be any adult living in the household, and not necessarily the head of household in the technical sense (i.e., as defined by the Bureau of the Census). 


\begin{tabular}{|c|c|c|}
\hline Average Household Size & 2.3 & 2.7 \\
\hline $\begin{array}{l}\text { Median Age of Respondent (Survey) or Householder } \\
\text { (County) }\end{array}$ & 60 & 51 \\
\hline Percent of One-Person Households & $25 \%$ & $21 \%$ \\
\hline Percent of Two-Person Households & $43 \%$ & $33 \%$ \\
\hline $\begin{array}{l}\text { Percent of Households with One or More Persons } \\
\text { Under } 18\end{array}$ & $25 \%$ & $38 \%$ \\
\hline $\begin{array}{l}\text { Percent of Households with One or More Persons } \\
\text { Aged } 65 \text { or Older }\end{array}$ & $44 \%$ & $26 \%$ \\
\hline \multicolumn{3}{|l|}{ Household Income in 2007} \\
\hline Percent of Households with Incomes less than $\$ 35 \mathrm{~K}$ & $25 \%$ & $30 \%^{2}$ \\
\hline Percent of Households with Incomes Over $\$ 100 \mathrm{~K}$ & $28 \%$ & $22 \%{ }^{2}$ \\
\hline Median Household Income & $\$ 50 \mathrm{~K}$ to $\$ 75 \mathrm{~K}$ & $\$ 67 \mathrm{~K}$ \\
\hline \multicolumn{3}{|l|}{ Other Characteristics } \\
\hline Percent of English-Speaking Households/Population & $90 \%$ of Households & $71 \%$ of Population \\
\hline $\begin{array}{l}\text { Percent with a Four-Year College Degree or Higher } \\
\text { (Respondent for Survey Respondents; Householder } \\
\text { for County Data) }\end{array}$ & $54 \%$ & $34 \%$ \\
\hline
\end{tabular}

Sources for County statistics are: American Community Survey 3-Year Estimates 2005-2007 (U.S. Bureau of the Census 2008); and American Housing Survey Metropolitan Series for Sacramento County 2004 (U.S. Bureau of the Census 2005).

${ }^{1}$ For survey participants demographic data are combined across the Wave 1 and Wave 3 surveys,

${ }^{2}$ This statistic is based on all homes, rather than just single-family homes.

Survey respondent households are more likely to include adults over 65 as compared to the county as a whole $(44 \%$, versus $26 \%$ for Sacramento county overall), and less likely to include children under 18 (25\% for participant households, as compared to 38\% for owner-occupied households countywide). But the percentage of one-person households among PowerChoice participants is only slightly elevated over that in the county, according to survey results. Average household size for PowerChoice participants is still smaller, with only one-third of households having more than two people, as compared to $46 \%$ for the rest of the county - likely a reflection of the older demographic of PowerChoice participants.

The age distribution and the concomitant differences in household composition are remarkable. The result differs from that seen in the $\mathrm{BC}$ Hydro residential TOU pilot, where age distribution for participants matches that of the service territory (Pederson 2007). ${ }^{86}$ It is not clear why the PowerChoice participants are older or if these households have more or less capacity to reduce afternoon load or perform other shifting, as compared to other households. For example, smaller households may mean more control over energy use, since there are fewer users. And though being home more hours may give a household more flexibility in when domestic chores

86. To the authors' knowledge, the TOU experiment by Ontario Electricity Board (2007) did not collect data on participant ages. 
are performed, space conditioning and other incidental uses may be required for more hours. ${ }^{87}$ Households with nobody home during Super-Peak may already have low loads during that period and thus low capacity to deliver demand response by reducing further. Analysis of Wave 3 survey data revealed that households where the survey respondent was 60 or older were far more likely than other households to have someone usually home during the day time between 8 a.m. and 5 p.m.: 65\% for households where the survey respondent was 60 or older, compared to $35 \%$ for other households. But during the Super-Peak period, when TOU rate prices are highest, about $50 \%$ of both younger and older respondents report that someone is usually home during those hours. ${ }^{88}$

A comparison of survey data to SMUD data for PowerChoice TOU participants revealed that the survey population had no apparent bias relative to the larger PowerChoice participant population on the basis of householder age, number of children, electric bills, annual electricity use, square footage, presence of pools, year dwelling was built, square footage, or expected gain or loss on the PowerChoice rate. ${ }^{89}$ Thus the differences shown in Error! Reference source not found. do not seem to be the result of survey response bias, but instead self-selection into the PowerChoice program, or conceivably in the nature of the recruitment process, even as the process was designed to recruit proportionally across consumption strata.

\section{Education}

Educational levels are a further major difference between PowerChoice participants and Sacramento County as a whole. Over half of survey respondents (54\%) report having a fouryear college degree or higher, as compared to $34 \%$ of householders in owner-occupied dwellings in Sacramento County. A fifth of survey respondents report holding graduate or professional degrees..$^{90}$ Both of the two other recent TOU pilot programs for which demographic data was collected show similar or greater differences in levels of education between pilot participants and the corresponding larger population (Ontario Energy Board 2007; Pederson 2007). ${ }^{91}$ If higher education translates to higher capacity to respond to TOU rates, this pattern has implications for equity if mandatory TOU rates were to be established. A study on TOU rates in Ontario, Canada found that if no changes were made in household consumption patterns, smaller, wealthier households tended to save money while larger, lower-income

87. Analysis of load data for households who said somebody was usually home between 5 p.m. and 8 p.m. showed that households who did tend to be home had significantly higher summer average electricity consumption.

88. The younger or working households presumably still have an energy advantage here (in terms of the possibility of lower afternoon loads), since they are probably less likely be home during the entire SuperPeak period (e.g., they may arrive home from work at 6:30 p.m., midway in the Super-Peak period).

89. PowerChoice population data is from "Toupop_annual_PC_cust_part.xls." This data set includes most, but not all, PowerChoice participants.

90. Further analyses showed that these most highly educated households had lower consumption than other PowerChoice households.

91. In the Hydro Ottawa TOU pilot, $76 \%$ had a four-year college degree or higher (Ontario Electric Board 2007; see Appendix G of that report). In the BC Hydro Conservation Research Initiative TOU pilot, $44 \%$ of main household contacts (e.g., householder) had a four-year college degree or higher, as compared to $25 \%$ in the utility's service territory. 
households tended to lose money on a TOU tariff (Robinson \& Rowlands 2007). But again results from one TOU rate are not necessarily translatable to another case: they depend on the details of the TOU rate, implementation, and characteristics of the jurisdiction.

\section{Language, Ethnicity/National Origin, and Sex}

Not unexpectedly, survey respondent were more likely to speak English as their primary language at home as compared to Sacramento County adults as a whole. ${ }^{92}$ Basic racial characteristics roughly matched those of the county. Respondent sex was evenly divided between males and females.

\section{Income}

Table A2.4 compares household income between survey participant households and Sacramento county households. Surveyed participants report higher income than others in the county, but the difference is moderate, and the lowest-income group is only moderately underrepresented. According to the survey results, PowerChoice households are slightly less likely to have household annual incomes less than $\$ 25 \mathrm{~K}$ (13\% of surveyed households compared to $20 \%$ countywide) and more likely to have incomes over $\$ 100 \mathrm{~K}(30 \%$ of surveyed households as compared to $22 \%$ countywide) compared to households in Sacramento County ${ }^{93}$ The median reported income for survey respondents ( $\$ 50 \mathrm{~K}$ to $\$ 75 \mathrm{~K} /$ year) is broadly comparable to that for owner-occupied households in the county $\left(\$ 67 \mathrm{~K} /\right.$ year) ${ }^{94}$ In contrast, participant groups in both the Canadian residential TOU pilots, Ontario Electricity Board's and BC Hydro's, had more markedly higher incomes. ${ }^{95}$ While the higher educational levels of PowerChoice participants would be expected to be correlated with higher incomes, the older age distribution of participants likely has a dampening effect on the higher end distribution of participant income, since older respondents are apt to be retired.

Table D-4. Annual Household Income of Wave-3 Survey Respondents

\begin{tabular}{|l|c|c|}
\hline \multicolumn{1}{|c|}{ Annual Income } & $\begin{array}{c}\text { W-3 Survey } \\
\text { Respondents }\end{array}$ & $\begin{array}{c}\text { Sacramento } \\
\text { County }\end{array}$ \\
\hline Less than $\$ 25 \mathrm{~K}$ & $10 \%(19)$ & $21 \%(105,230)$ \\
\hline
\end{tabular}

92. Spanish-speaking surveyors were available for households that preferred completing the interview in Spanish.

93. Figures combine results from Wave 1 (August 2007, for 2006 income) and Wave 3 (August 2008, for 2007 income) surveys. Family income for the county, as opposed to household income, matches the survey data quite closely.

94. Twenty percent of survey respondents declined to give an estimate (in $\$ 10 \mathrm{~K}-25 \mathrm{~K}$ slices), which makes comparisons rough. Median income among households in owner-occupied units in the County is $\$ 67 \mathrm{~K}$ for Sacramento County, excluding Sacramento City, for which the median household income is $\$ 58 \mathrm{~K}$. Median annual household income overall, regardless of housing type, is $\$ 64 \mathrm{~K}$ for Sacrament County (U.S. Bureau of the Census 2008).

95. In the case of the Ontario Electric Board Smart Price pilot, just 34\% of participating households had annual household incomes of less than $\$ 75,000$ in Canadian dollars (Ontario Electric Board 2007). In the BC Hydro case, $45 \%$ of participants had a total annual household income greater than $\$ 80,000$ in Canadian dollars, as compared to $34 \%$ among the customer base (Pederson 2007). 


\begin{tabular}{|l|c|c|} 
\$25K-\$35K & $10 \%(11)$ & $11 \%(54,944)$ \\
\hline$\$ 35 \mathrm{~K}-\$ 50 \mathrm{~K}$ & $20 \%(26)$ & $14 \%(72,438)$ \\
\hline$\$ 50 \mathrm{~K}-\$ 75 \mathrm{~K}$ & $20 \%(29)$ & $19 \%(97,91)$ \\
\hline$\$ 75 \mathrm{~K}-\$ 100 \mathrm{~K}$ & $20 \%(25)$ & $13 \%(67,100)$ \\
\hline$\$ 100 \mathrm{~K}$ or more & $30 \%(41)$ & $22 \%(103,089)$ \\
\hline Total & 151 & 500,292 \\
\hline
\end{tabular}

PowerChoice results include combined Wave-1 and W-3 responses for W-3 respondents. Source for Sacrament County data: American Community Survey 2005-2007 Three-Year Estimates (U.S. Bureau of the Census 2008) for Sacramento County data. Income categories greater than $\$ 100 \mathrm{~K}$ are combined.

\section{Dropouts}

As part of the participation contract, participants were allowed to switch back from the TOU rate, with a 30 -day notice. ${ }^{96}$ In total $16 \%$ did so, through December 2008 . Some dropped because they moved house, while others did so, by implication, because of other factors related to the rate. This introduces another element of self-selection into PowerChoice participation. Customers who opted out had higher PowerChoice bills on average than those who stayed on the rate. Also, among the customers surveyed in the first survey wave, early in the PowerChoice rate, everyone who opted out had said that their PowerChoice bill was higher or much higher than expected. ${ }^{97}$ The pattern of dropouts underscores participants' stated concern with saving money (Chapter 4).

\section{References}

Ontario Energy Board. 2007. Ontario Energy Board Smart Price Pilot. Final Report and Appendices A-G. http://www.oeb.gov.on.ca/documents/cases/EB-20040205/smartpricepilot/ OSPP\%20Final\%20Report\%20-\%20Final070726.pdf. Toronto, Ontario, Canada: Ontario Energy Board.

Pederson, Marc. 2007. Quantitative Analysis of Self-Reported On-Peak behaviours. Vancouver, B.C.: BC Hydro.

Robinson, J. and I.H. Rowlands. 2007. "Who Benefits? The Impacts of Time-of-Use Electricity Pricing on Demographic Groups in Ontario, Canada," Proceedings of the 2007 ECEEE Summer Study on Energy Efficiency in Buildings. European Council for an Energy Efficient Economy.

96. This was announced in the enrollment materials. Surveys did not verify if customers were aware that they could drop out.

97. In the first survey (Wave 1, Summer 2007), over half of all of survey respondents who had received their bill said it was higher than expected, so such answers are not unusual. However, five of these nine program dropouts $(55 \%)$ by December 2007 noted that they realized their summer electricity costs overall would be higher - even much higher - than expected, whereas only $18 \%$ of all participants (whether or not they had received their bill) said the same thing. 
U.S. Department of Census. 2005. "American Housing Survey for the Sacramento Metropolitan Area 2004." Current Housing Reports. H170/04-53. Washington, D.C.: U.S. Department of Housing \& Urban Development.

U.S. Bureau of the Census. 2008. American Community Survey 3-Year Estimates 2005-2007

(Factfinder for Sacramento County 2008, http:/ / factfinder.census.gov). Washington, D.C.: U.S. Department of Housing \& Urban Development. 


\section{Appendix E}

\section{Selected Wave 3 Survey Results}


APE-2 
Survey responses to selected inquiries.

Table E-1. "How satisfied have you been with the Power Choice program in Summer 2008?" [By whether or not respondent was in the Enhanced Information treatment group]

\begin{tabular}{|l|c|c|c|}
\hline \multicolumn{1}{|c|}{ Level of Satisfaction } & $\begin{array}{c}\text { Enhanced } \\
\text { Information } \\
\text { Treatment } \\
{[\% \text { (count)] }}\end{array}$ & $\begin{array}{c}\text { All Others - } \\
\text { Non- } \\
\text { Information } \\
\text { Treatment } \\
\text { Group } \\
{[\% \text { (count)] }}\end{array}$ & $\begin{array}{c}\text { Total } \\
{[\% \text { (count)] }}\end{array}$ \\
\hline Very Satisfied & $51 \%(43)$ & $44 \%(38)$ & $48 \%(81)$ \\
\hline Somewhat Satisfied & $19 \%(16)$ & $24 \%(21)$ & $22 \%(37)$ \\
\hline Neither Satisfied nor Dissatisfied & $8 \%(7)$ & $12 \%(10)$ & $10 \%(17)$ \\
\hline Somewhat Dissatisfied & $19 \%(16)$ & $7 \%(6)$ & $13 \%(22)$ \\
\hline Very Dissatisfied & $2 \%(2)$ & $5 \%(4)$ & $4 \%(6)$ \\
\hline Don't Know/Refused & $0 \%(0)$ & $8 \%(7)$ & $4 \%(2)$ \\
\hline All & $100 \%(84)$ & $100 \%(86)$ & $100 \%(170)$ \\
\hline
\end{tabular}

Table E-2. "Compared to LAST summer, how would you rate THIS summer's efforts to change how and when you used electricity?" [Asked only of those who were on the PowerChoice rate in Summer 2007]

\begin{tabular}{|l|c|c|c|}
\hline \multicolumn{1}{|c|}{ Effort } & $\begin{array}{c}\text { Information } \\
\text { Treatment } \\
\text { Group }\end{array}$ & All Others & Total \\
\hline Made about the same effort in both summers & $42 \%(35)$ & $42 \%(24)$ & $42 \%(59)$ \\
\hline Made a greater effort this summer & $50 \%(42)$ & $43 \%(25)$ & $47 \%(67)$ \\
\hline Made a greater effort to change last summer & $1 \%(1)$ & $3 \%(2)$ & $2 \%(3)$ \\
\hline Don't Know/Refused/Other & $7 \%(6)$ & $12 \%(7)$ & $8 \%(13)$ \\
\hline All & 84 & 58 & 142 \\
\hline
\end{tabular}

Table E-3. Percentage responding "Yes" for each option of the question: "Tell me if any of the following describe your household's electricity use habits during July and August."

\begin{tabular}{|l|c|c|c|}
\hline \multicolumn{1}{|c|}{ Option } & $\begin{array}{c}\text { Information } \\
\text { Treatment } \\
\text { Group }\end{array}$ & All Others & Total \\
\hline We used electricity whenever we wanted & $10 \%(8)$ & $24 \%(21)$ & $17 \%(29)$ \\
\hline We lowered usage during the Super-Peak & $94 \%(79)$ & $87 \%(75)$ & $91 \%(154)$ \\
\hline $\begin{array}{l}\text { We shifted as much usage as possible to OFF-PEAK } \\
\text { hours }\end{array}$ & $98 \%(82)$ & $84 \%(72)$ & $91 \%(154)$ \\
\hline We generally tried to use less energy & $82 \%(69)$ & $79 \%(68)$ & $81 \%(137)$ \\
\hline $\begin{array}{l}\text { To get ready for higher summer rates we increased } \\
\text { the energy efficiency of our home }\end{array}$ & $43 \%(36)$ & $47 \%(40)$ & $45 \%(76)$ \\
\hline
\end{tabular}


Table E-4. "How much would you say that your household sticks to a general routine (for meal time, being home, etc.)?" [Summarized by whether respondent is in Information Treatment Group or not]

\begin{tabular}{|l|c|c|c|}
\hline \multicolumn{1}{|c|}{ Household Sticks to General Routine } & $\begin{array}{c}\text { Information } \\
\text { Treatment } \\
\text { Group }\end{array}$ & All Others & Total \\
\hline Almost always & $68 \%(57)$ & $67 \%(58)$ & $68 \%(115)$ \\
\hline Occasionally & $18 \%(15)$ & $13 \%(11)$ & $15 \%(26)$ \\
\hline Rarely-we don't have much of a routine & $12 \%(19)$ & $18 \%(15)$ & $15 \%(25)$ \\
\hline Don't Know/Refused & $2 \%(2)$ & $2 \%(2)$ & $4 \%(4)$ \\
\hline All & $100 \%(84)$ & $100 \%(86)$ & $100 \%(170)$ \\
\hline
\end{tabular}

Table E-5. Summary of survey responses on swimming pool presence and changes to pool use after joining Power Choice, by Enhanced Information Treatment group versus all others.

\begin{tabular}{|l|c|c|c|c|}
\hline \multicolumn{1}{|c|}{ Pool Use } & $\begin{array}{c}\text { Information } \\
\text { Treatment } \\
\text { Group } \\
\text { (Yes) }\end{array}$ & $\begin{array}{c}\text { All Others - } \\
\text { Non- } \\
\text { Treatment } \\
\text { Information } \\
\text { Group } \\
\text { (Yes) }\end{array}$ & $\begin{array}{c}\text { All } \\
\text { (Yes) }\end{array}$ & $\begin{array}{c}\text { Respondent } \\
\text { Total }\end{array}$ \\
\hline Have a pool & $25 \%(21)$ & $28 \%(24)$ & $26 \%(45)$ & 170 \\
\hline $\begin{array}{l}\text { Heat pool with electricity (other than } \\
\text { solar) }\end{array}$ & $0 \%(0)$ & $0 \%(0)$ & $0 \%(0)$ & 45 \\
\hline Almost always use a pool cover & $10 \%(2)$ & $25 \%(6)$ & $18 \%(8)$ & 45 \\
\hline $\begin{array}{l}\text { Changed the timing of pool pump use } \\
\text { after PowerChoice }\end{array}$ & $71 \%(15)$ & $83 \%(20)$ & $78 \%(35)$ & 45 \\
\hline Run the pool pump less often & $24 \%(5)$ & $38 \%(9)$ & $31 \%(14)$ & 45 \\
\hline $\begin{array}{l}\text { Avoid running the pool between } 5 p m \\
\text { and 8pm }\end{array}$ & $90 \%(19)$ & $92 \%(23)$ & $91 \%(42)$ & 46 \\
\hline
\end{tabular}


Table E-6. Drying Clothes: Now Compared to Before Joining PowerChoice [Asked of those with electric or natural gas dryer]

\begin{tabular}{|l|c|c|c|c|}
\hline \multicolumn{1}{|c|}{ Dryer Use } & $\begin{array}{c}\text { Information } \\
\text { Treatment } \\
\text { Group } \\
\text { (Yes) }\end{array}$ & $\begin{array}{c}\text { All Others } \\
\text { (Yes) }\end{array}$ & $\begin{array}{c}\text { All } \\
\text { (Yes) }\end{array}$ & $\begin{array}{c}\text { Respondent } \\
\text { Total }\end{array}$ \\
\hline Run the dryer less often now & $\mathbf{0 . 3 9}$ & $\mathbf{0 . 3 6}$ & $\mathbf{0 . 3 8}$ & 168 \\
\hline $\begin{array}{l}\text { And do you tend to run it at different } \\
\text { times of the day? }\end{array}$ & $76 \%(63)$ & $75 \%(64)$ & $76 \%(127)$ & 168 \\
\hline $\begin{array}{l}\text { Would you say that you've changed } \\
\text { your drying habits because of } \\
\text { PowerChoice? }\end{array}$ & $89 \%(64)$ & $94 \%(63)$ & $91 \%(127)$ & 139 \\
\hline $\begin{array}{l}\text { Do you run the dryer between } 5 p m \\
\text { and 8pm less often than before? }\end{array}$ & $54 \%(45)$ & $47 \%(40)$ & $51 \%(85)$ & 168 \\
\hline $\begin{array}{l}\text { Compared to before joining } \\
\text { PowerChoice, do you rack or line dry } \\
\text { laundry more? }\end{array}$ & $15 \%(13)$ & $20 \%(17)$ & $18 \%(30)$ & 170 \\
\hline
\end{tabular}

Table E-7. Cooking: Percentage Who Said Yes/Mentioned This Change. [Asked of all]

\begin{tabular}{|l|c|c|c|c|}
\hline \multicolumn{1}{|c|}{ Cooking Practices } & $\begin{array}{c}\text { Information } \\
\text { Treatment } \\
\text { Group }\end{array}$ & All Others & All & $\begin{array}{c}\text { Respondent } \\
\text { Total }\end{array}$ \\
\hline $\begin{array}{l}\text { Have you altered cooking times or } \\
\text { practices since joining? }\end{array}$ & $31 \%(26)$ & $26 \%(22)$ & $28 \%(48)$ & 170 \\
\hline $\begin{array}{l}\text { Did you shift cooking to a different } \\
\text { time period? }\end{array}$ & $17 \%(14)$ & $15 \%(13)$ & $16 \%(27)$ & 170 \\
\hline Did you change methods? & $8 \%(7)$ & $8 \%(7)$ & $8 \%(14)$ & 170 \\
\hline $\begin{array}{l}\text { Did you cook less, such as preparing } \\
\text { cold meals? }\end{array}$ & $7 \%(6)$ & $12 \%(10)$ & $9 \%(16)$ & 170 \\
\hline Did you change in any other way? & $4 \%(3)$ & $5 \%(4)$ & $4 \%(7)$ & 170 \\
\hline
\end{tabular}

Table E-8. Dishwashing: [Asked only of those with an automatic dishwasher]

\begin{tabular}{|l|c|c|c|}
\hline \multicolumn{1}{|c|}{ Dishwashing Practices } & $\begin{array}{c}\text { Information } \\
\text { Treatment } \\
\text { Group }\end{array}$ & All Others & $\begin{array}{c}\text { All } \\
\mathbf{( N = 1 7 0 )}\end{array}$ \\
\hline Have you changed dishwashing routines & $75 \%(63)$ & $62 \%(53)$ & $68 \%(116)$ \\
\hline Did you shift dishwashing to a different time? & $56 \%(47)$ & $42 \%(36)$ & $49 \%(83)$ \\
\hline Do you do dishes by hand rather than machine? & $18 \%(15)$ & $23 \%(20)$ & $21 \%(35)$ \\
\hline $\begin{array}{l}\text { Did you otherwise change methods, such as air drying } \\
\text { or "energy saver" setting? }\end{array}$ & $12 \%(10)$ & $16 \%(14)$ & $14 \%(24)$ \\
\hline Did you change by washing less often? & $30 \%(25)$ & $26 \%(22)$ & $0 \%(47)$ \\
\hline Did you change in any other way? & $1 \%(1)$ & $3 \%(3)$ & $2 \%(4)$ \\
\hline
\end{tabular}


Table E-9. Clothes Washing: [Asked only of those with electric water heater]

\begin{tabular}{|l|c|c|c|}
\hline \multicolumn{1}{|c|}{ Clothes Washing Practices } & $\begin{array}{c}\text { Information } \\
\text { Treatment } \\
\text { Group }\end{array}$ & All Others & $\begin{array}{c}\text { All } \\
\text { (N=23) }\end{array}$ \\
\hline $\begin{array}{l}\text { Have you changed clothes washing routines because } \\
\text { of PowerChoice? }\end{array}$ & $67 \%(8)$ & $91 \%(10)$ & $78 \%(18)$ \\
\hline $\begin{array}{l}\text { Did you change by shifting clothes washing to a } \\
\text { different period? }\end{array}$ & $58 \%(7)$ & $73 \%(8)$ & $65 \%(15)$ \\
\hline $\begin{array}{l}\text { Did you change by changing methods like using cold } \\
\text { water or using "light" wash? }\end{array}$ & $25 \%(3)$ & $36 \%(4)$ & $30 \%(7)$ \\
\hline Did you change by running clothes washer less often? & $0 \%(0)$ & $36 \%(4)$ & $17 \%(4)$ \\
\hline
\end{tabular}

Table E-10. Lighting: "Because of PowerChoice have you changed lighting by..."

\begin{tabular}{|l|c|c|c|}
\hline \multicolumn{1}{|c|}{ Lighting Practices } & $\begin{array}{c}\text { Information } \\
\text { Treatment } \\
\text { Group }\end{array}$ & All Others & All \\
\hline Installing more CFL or twisty bulbs? & $58 \%(49)$ & $65 \%(56)$ & $62 \%(105)$ \\
\hline Installing lower wattage bulbs? & $20 \%(17)$ & $30 \%(26)$ & $25 \%(43)$ \\
\hline $\begin{array}{l}\text { Other than CFLs, replacing regular fixtures with } \\
\text { fluorescent bulbs? }\end{array}$ & $20 \%(17)$ & $19 \%(16)$ & $19 \%(33)$ \\
\hline Installing timers to reduce run times? & $12 \%(10)$ & $15 \%(13)$ & $14 \%(23)$ \\
\hline Changed in any other way? & $13 \%(11)$ & $7 \%(6)$ & $10 \%(17)$ \\
\hline Don't Know/Refused & $18 \%(15)$ & $15 \%(13)$ & $16 \%(28)$ \\
\hline Total & 84 & 86 & 170 \\
\hline
\end{tabular}

Table E-11. "Have there been any discussions or disagreements in PowerChoice about the changes you've been making?" [Asked only of households with more than one member]

\begin{tabular}{|l|c|c|c|}
\hline \multicolumn{1}{|c|}{ Discussions in Household } & $\begin{array}{c}\text { Information } \\
\text { Treatment } \\
\text { Group }\end{array}$ & All Others & $\begin{array}{c}\text { All } \\
(\mathbf{N}=126)\end{array}$ \\
\hline Yes, discussion & $24 \%(15)$ & $14 \%(9)$ & $19 \%(24)$ \\
\hline Yes, disagreements & $8 \%(5)$ & $6 \%(4)$ & $7 \%(9)$ \\
\hline No discussions or disagreements & $67 \%(42)$ & $78 \%(49)$ & $72 \%(91)$ \\
\hline
\end{tabular}


Table E-12. "Prior to joining PowerChoice, would you say that in July and August you typically used the air conditioning?" [Asked only of those with air conditioning]

\begin{tabular}{|l|c|c|c|}
\hline \multicolumn{1}{|c|}{ Air Conditioning Use } & $\begin{array}{c}\text { Information } \\
\text { Treatment } \\
\text { Group }\end{array}$ & All Others & All \\
\hline Everyday & $27 \%(21)$ & $38 \%(34)$ & $33 \%(55)$ \\
\hline On most days & $26 \%(20)$ & $22 \%(20)$ & $24 \%(40)$ \\
\hline Only a few times a week & $31 \%(24)$ & $15 \%(13)$ & $22 \%(37)$ \\
\hline Only a few times a month & $14 \%(11)$ & $15 \%(13)$ & $14 \%(24)$ \\
\hline Less than a few times a month & $3 \%(2)$ & $7 \%(6)$ & $5 \%(8)$ \\
\hline Never & $0 \%(0)$ & $3 \%(3)$ & $2 \%(3)$ \\
\hline Don't Know/Refuse & $0 \%(4)$ & $0 \%(6)$ & $0 \%(10)$ \\
\hline All & 82 & 95 & 177 \\
\hline
\end{tabular}

Table E-13. "This summer, would you say you have been using the air conditioner less in each of the following time periods?"

\begin{tabular}{|l|c|c|c|c|}
\hline \multicolumn{1}{|c|}{ Air Conditioner Use } & $\begin{array}{c}\text { Information } \\
\text { Treatment } \\
\text { Group }\end{array}$ & All Others & All & $\begin{array}{c}\text { Statistically } \\
\text { Significant }\end{array}$ \\
\hline $\begin{array}{l}\text { Are you running your AC differently } \\
\text { now? }\end{array}$ & $68 \%$ & $58 \%$ & $63 \%$ & No \\
\hline $\begin{array}{l}\text { Between noon and 5pm, do you use } \\
\text { the AC less than you used to? }\end{array}$ & $62 \%$ & $52 \%$ & $57 \%$ & No \\
\hline $\begin{array}{l}\text { Between 5pm and 8pm, do you use } \\
\text { the AC less than you used to? }\end{array}$ & $73 \%$ & $58 \%$ & $66 \%$ & Yes \\
\hline $\begin{array}{l}\text { During the off-peak period from 10pm } \\
\text { to noon, do you use the AC less than } \\
\text { you used to? }\end{array}$ & $51 \%$ & $47 \%$ & $49 \%$ & No \\
\hline
\end{tabular}

Note: The "statistically significant" column is simple chi-square test on 'less' vs. 'not', for each time period (and for 'different' vs. 'not' for the first row)

Table E-14. "This summer, did you pre-cool your home before SuperPeak?"

\begin{tabular}{|l|c|c|c|}
\hline \multicolumn{1}{|c|}{ Frequency of Pre-Cooling } & $\begin{array}{c}\text { Information } \\
\text { Treatment } \\
\text { Group }\end{array}$ & All Others & $\begin{array}{c}\text { All } \\
\mathbf{( N = 1 6 6 )}\end{array}$ \\
\hline Regularly & $21 \%(17)$ & $13 \%(11)$ & $17 \%(28)$ \\
\hline Once in a while & $32 \%(26)$ & $29 \%(25)$ & $31 \%(51)$ \\
\hline Never & $46 \%(38)$ & $58 \%(49)$ & $52 \%(87)$ \\
\hline
\end{tabular}


Table E-15. Temperature preference for household, if cost is no object

\begin{tabular}{|l|c|c|c|}
\hline \multicolumn{1}{|c|}{ Temperature } & $\begin{array}{c}\text { Information } \\
\text { Treatment } \\
\text { Group }\end{array}$ & All Others & All \\
\hline Feeling "cool or almost cold" inside & $12 \%(10)$ & $7 \%(6)$ & $10 \%(16)$ \\
\hline Just at a comfortable level & $72 \%(60)$ & $71 \%(59)$ & $72 \%(119)$ \\
\hline $\begin{array}{l}\text { Would let the temperature get somewhat warmer than } \\
\text { a comfortable level }\end{array}$ & $13 \%(11)$ & $19 \%(16)$ & $16 \%(27)$ \\
\hline Would let it get uncomfortably warm inside & $2 \%(2)$ & $2 \%(2)$ & $2 \%(4)$ \\
\hline $\mathrm{N}$ & 83 & 83 & 166 \\
\hline
\end{tabular}

Table E-16. "On hot afternoons or early evenings this summer, how would you say the house actually felt?"

\begin{tabular}{|l|c|c|c|}
\hline \multicolumn{1}{|c|}{ How House Felt } & $\begin{array}{c}\text { Information } \\
\text { Treatment } \\
\text { Group }\end{array}$ & All Others & All \\
\hline Cool or almost cold inside & $4 \%(3)$ & $8 \%(7)$ & $6 \%(10)$ \\
\hline Just comfortable & $49 \%(41)$ & $54 \%(45)$ & $51 \%(86)$ \\
\hline Somewhat warmer than a comfortable level & $42 \%(35)$ & $35 \%(29)$ & $38 \%(64)$ \\
\hline Uncomfortably warm inside & $6 \%(5)$ & $5 \%(4)$ & $5 \%(9)$ \\
\hline Don't Know/Refused & $0 \%(0)$ & $1 \%(1)$ & $1 \%(1)$ \\
\hline $\mathrm{N}$ & 84 & 83 & 167 \\
\hline
\end{tabular}

Table E-17. Crosstabulation of Temperature Preference vs. Actual Temperature $(\mathbf{N}=165)$

\begin{tabular}{|l|c|c|c|c|}
\hline \multicolumn{1}{|c|}{ How House Felt } & $\begin{array}{c}\text { Cool or } \\
\text { almost cold }\end{array}$ & $\begin{array}{c}\text { Just } \\
\text { comfortable }\end{array}$ & $\begin{array}{c}\text { Somewhat } \\
\text { warmer than } \\
\text { comfortable }\end{array}$ & $\begin{array}{c}\text { Uncomfort- } \\
\text { ably warm } \\
\text { inside }\end{array}$ \\
\hline Cool or almost cold inside & $31 \%(5)$ & $31 \%(5)$ & $31 \%(5)$ & $6 \%(1)$ \\
\hline Just comfortable & $3 \%(3)$ & $59 \%(70)$ & $33 \%(39)$ & $5 \%(6)$ \\
\hline $\begin{array}{l}\text { Somewhat warmer than a } \\
\text { comfortable level }\end{array}$ & $7 \%(2)$ & $26 \%(7)$ & $67 \%(18)$ & $0 \%(0)$ \\
\hline Uncomfortably warm inside & $0 \%(0)$ & $25 \%(1)$ & $25 \%(1)$ & $50 \%(2)$ \\
\hline
\end{tabular}


Table E-18. "What would you say the temperature inside your house was on a typical summer afternoon?"

\begin{tabular}{|l|c|c|c|c|c|}
\hline \multicolumn{1}{|c|}{ Preferred Temperature } & $\begin{array}{c}\text { Cool Or } \\
\text { Almost Cold }\end{array}$ & $\begin{array}{c}\text { Just } \\
\text { Comfortable }\end{array}$ & $\begin{array}{c}\text { Somewhat } \\
\text { Warmer } \\
\text { Than } \\
\text { Comfortable }\end{array}$ & $\begin{array}{c}\text { Uncomfort- } \\
\text { ably Warm } \\
\text { Inside }\end{array}$ & All \\
\hline Cool or almost cold inside & $3 \%$ & $3 \%$ & $3 \%$ & $1 \%$ & $10 \%$ \\
\hline Just comfortable & $2 \%$ & $42 \%$ & $24 \%$ & $4 \%$ & $72 \%$ \\
\hline $\begin{array}{l}\text { Somewhat warmer than a } \\
\text { comfortable level }\end{array}$ & $1 \%$ & $4 \%$ & $11 \%$ & $0 \%$ & $16 \%$ \\
\hline Uncomfortably warm inside & $0 \%$ & $1 \%$ & $1 \%$ & $1 \%$ & $2 \%$ \\
\hline
\end{tabular}

Table E-19. "Do you regularly use the following methods for cooling your home?"

\begin{tabular}{|l|c|c|c|c|}
\hline \multicolumn{1}{|c|}{ Cooling Method } & $\begin{array}{c}\text { Information } \\
\text { Treatment } \\
\text { Group }\end{array}$ & All Others & All & Statistically \\
Significant \\
\hline Ceiling fans & $65 \%$ & $79 \%$ & $72 \%$ & Yes \\
\hline Portable fans & $68 \%$ & $52 \%$ & $60 \%$ & Yes \\
\hline $\begin{array}{l}\text { Closing blinds/curtains to keep sun } \\
\text { out }\end{array}$ & $94 \%$ & $93 \%$ & $94 \%$ & No \\
\hline Opening windows during cooler times & $89 \%$ & $88 \%$ & $89 \%$ & No \\
\hline $\mathrm{N}$ & 84 & 86 & 170 & \\
\hline
\end{tabular}

Note: Some statistically significant differences -- Info Treatment group has higher levels of Portable Fan use and lower levels of

Ceiling Fan use -- both with $p<0.10$ on chi-square test $2 \times 2$

Table E-20. "Was somebody home during the daytime?"

\begin{tabular}{|l|c|c|}
\hline \multicolumn{1}{|c|}{ Someone Home During Day } & $\begin{array}{c}\text { Weekdays } \\
\text { (percent of all } \\
\text { respondents) }\end{array}$ & $\begin{array}{c}\text { Weekends } \\
\text { (percent of all } \\
\text { respondents) }\end{array}$ \\
\hline Almost all the time & $46 \%$ & $69 \%$ \\
\hline More than half the time & $8 \%$ & $7 \%$ \\
\hline About half the time & $8 \%$ & $13 \%$ \\
\hline Less than half the time & $13 \%$ & $5 \%$ \\
\hline
\end{tabular}


Table E-21. "Would you say that your summer 2008 PowerChoice time-of-use bills have been?"

\begin{tabular}{|l|c|c|c|}
\hline \multicolumn{1}{|c|}{ Summer Billing } & $\begin{array}{c}\text { Information } \\
\text { Treatment }\end{array}$ & All Others & All \\
\hline Much higher than expected & $11 \%(9)$ & $7 \%(6)$ & $9 \%(15)$ \\
\hline Higher than expected & $26 \%(22)$ & $31 \%(27)$ & $29 \%(49)$ \\
\hline About what you expected & $38 \%(32)$ & $38 \%(33)$ & $38 \%(65)$ \\
\hline Lower than expected & $14 \%(12)$ & $14 \%(12)$ & $14 \%(24)$ \\
\hline Much lower than you expected & $2 \%(2)$ & $2 \%(2)$ & $2 \%(4)$ \\
\hline Don't Know & $8 \%(7)$ & $7 \%(6)$ & $8 \%(13)$ \\
\hline $\mathrm{N}$ & 84 & 86 & 170 \\
\hline
\end{tabular}

Table E-22. "Compared to your old electricity rate, would you say that you..."

\begin{tabular}{|l|c|c|c|}
\hline \multicolumn{1}{|c|}{ Bill } & $\begin{array}{c}\text { Information } \\
\text { Treatment } \\
\text { Group }\end{array}$ & All Others & All \\
\hline Saved money on PowerChoice & $55 \%(40)$ & $50 \%(37)$ & $52 \%(77)$ \\
\hline Came out about even & $33 \%(24)$ & $27 \%(20)$ & $30 \%(44)$ \\
\hline Spent more for electricity compared to your old rate & $12 \%(9)$ & $23 \%(17)$ & $18 \%(26)$ \\
\hline $\mathrm{N}$ & 73 & 74 & 147 \\
\hline
\end{tabular}

Table E-23. "How useful have you found the Information on your SMUD Time-of-Use bill to be?”

\begin{tabular}{|l|c|c|c|}
\hline \multicolumn{1}{|c|}{ Information on Bill } & $\begin{array}{c}\text { Information } \\
\text { Treatment } \\
\text { Group }\end{array}$ & All Others & All \\
\hline Somewhat useful & $50 \%(42)$ & $43 \%(37)$ & $46 \%(79)$ \\
\hline Not useful at all & $12 \%(10)$ & $7 \%(6)$ & $9 \%(16)$ \\
\hline Other/don't read it/don't know & $5 \%(4)$ & $14 \%(12)$ & $9 \%(16)$ \\
\hline $\mathrm{N}$ & 84 & 86 & 170 \\
\hline
\end{tabular}

Table E-24. "How useful have you found SMUD's Connections newsletter?"

\begin{tabular}{|l|c|c|c|}
\hline \multicolumn{1}{|c|}{ Usefulness of Newsletter } & $\begin{array}{c}\text { Information } \\
\text { Treatment } \\
\text { Group }\end{array}$ & All Others & All \\
\hline Very useful & $12 \%(10)$ & $15 \%(13)$ & $14 \%(23)$ \\
\hline Somewhat useful & $51 \%(43)$ & $53 \%(46)$ & $52 \%(89)$ \\
\hline Not useful at all & $18 \%(15)$ & $12 \%(10)$ & $15 \%(25)$ \\
\hline Don't get them & $5 \%(4)$ & $6 \%(5)$ & $5 \%(9)$ \\
\hline Don't read them & $11 \%(9)$ & $10 \%(9)$ & $11 \%(18)$ \\
\hline Don't Know & $4 \%(3)$ & $3 \%(3)$ & $4 \%(6)$ \\
\hline $\mathrm{N}$ & 84 & 86 & 170 \\
\hline
\end{tabular}


Table E-25. "How useful have you found Postcard reminders of seasonal rate period changes to be?"

\begin{tabular}{|l|c|c|c|}
\hline \multicolumn{1}{|c|}{ Usefulness of Postcard } & $\begin{array}{c}\text { Information } \\
\text { Treatment } \\
\text { Group }\end{array}$ & All Others & All \\
\hline Very useful & $50 \%(42)$ & $60 \%(52)$ & $55 \%(94)$ \\
\hline Somewhat useful & $30 \%(25)$ & $21 \%(18)$ & $25 \%(43)$ \\
\hline Not useful at all & $15 \%(13)$ & $9 \%(8)$ & $12 \%(21)$ \\
\hline Don't recall getting them & $1 \%(1)$ & $3 \%(3)$ & $2 \%(4)$ \\
\hline Didn't read them & $1 \%(1)$ & $3 \%(3)$ & $2 \%(4)$ \\
\hline Don't Know & $2 \%(2)$ & $2 \%(2)$ & $2 \%(4)$ \\
\hline N & 84 & 86 & 170 \\
\hline
\end{tabular}

Table E-26. "How Useful Have You Found Periodic letters from the PowerChoice Program Manager?"

\begin{tabular}{|l|c|c|c|}
\hline \multicolumn{1}{|c|}{ Usefulness of Letter } & $\begin{array}{c}\text { Information } \\
\text { Treatment } \\
\text { Group }\end{array}$ & All Others & All \\
\hline Very useful & $21 \%(18)$ & $14 \%(12)$ & $18 \%(30)$ \\
\hline Somewhat useful & $37 \%(31)$ & $37 \%(32)$ & $37 \%(63)$ \\
\hline Not useful at all & $27 \%(23)$ & $19 \%(16)$ & $23 \%(39)$ \\
\hline Don't recall getting them & $4 \%(3)$ & $16 \%(14)$ & $10 \%(17)$ \\
\hline Didn't read them & $7 \%(6)$ & $8 \%(7)$ & $8 \%(13)$ \\
\hline Don't know & $4 \%(3)$ & $6 \%(5)$ & $5 \%(8)$ \\
\hline $\mathrm{N}$ & 84 & 86 & 170 \\
\hline
\end{tabular}

Table E-27. "Your free PowerCost monitor arrived in June. Is it operating properly?"

\begin{tabular}{|l|c|c|}
\hline \multicolumn{1}{|c|}{ Is Monitor Working } & Percent of Total & N \\
\hline Yes & $74 \%$ & 32 \\
\hline No, never did install it & $2 \%$ & 1 \\
\hline No, tried to install it but was never able to get it to work & $9 \%$ & 4 \\
\hline No -- it was working, but now it isn't & $5 \%$ & 2 \\
\hline Uncertain if monitor is working properly & $7 \%$ & 3 \\
\hline Other & $2 \%$ & 1 \\
\hline All & $100 \%$ & 43 \\
\hline
\end{tabular}


Table E-28. "When you first got you monitor set up and working, how often did household members look at it to check electricity usage?" [Asked only of those who said it was ever working properly]

\begin{tabular}{|l|c|c|}
\hline \multicolumn{1}{|c|}{ How Often Was Monitor Checked } & Percent of Total & N \\
\hline More than once a day & $65 \%$ & 24 \\
\hline Once a day & $14 \%$ & 5 \\
\hline Several times a week & $8 \%$ & 3 \\
\hline Once a week & $5 \%$ & 2 \\
\hline Don't know & $8 \%$ & 3 \\
\hline All & $100 \%$ & 37 \\
\hline
\end{tabular}

Table E-29. "In the past week, how often would you say that household members looked at it to get usage information?" [Asked only of those who report that the monitor is still working properly]

\begin{tabular}{|l|c|c|}
\hline \multicolumn{1}{|c|}{ How Often Someone Looked at Monitor } & Percent of Total & N \\
\hline More than once a day & $53 \%$ & 17 \\
\hline Once a day & $25 \%$ & 8 \\
\hline Several times & $0 \%$ & 0 \\
\hline Once & $13 \%$ & 4 \\
\hline Never & $9 \%$ & 3 \\
\hline All & $100 \%$ & 32 \\
\hline
\end{tabular}

Table E-30. "Would you recommend the monitor to a friend?"

\begin{tabular}{|l|c|c|}
\hline \multicolumn{1}{|c|}{ Response } & Working Now & Never Worked \\
\hline Definitely Yes & $78 \%(25)$ & $0 \%(0)$ \\
\hline Maybe & $13 \%(4)$ & $0 \%(0)$ \\
\hline Definitely No & $6 \%(2)$ & $60 \%(3)$ \\
\hline Other & $3 \%(1)$ & $40 \%(2)$ \\
\hline All & $100 \%(32)$ & $100 \%(5)$ \\
\hline
\end{tabular}

Table E-31. "Do any members of your household have special needs for heating and cooling that made it difficult for you to use less energy during higher price late afternoons and early evenings?"

\begin{tabular}{|l|c|c|c|}
\hline \multicolumn{1}{|c|}{ Special Needs } & $\begin{array}{c}\text { Information } \\
\text { Treatment } \\
\text { Group }\end{array}$ & All Others & All \\
\hline Reports special heating and cooling needs & $5 \%(4)$ & $12 \%(10)$ & $8 \%(14)$ \\
\hline All & 84 & 86 & 170 \\
\hline
\end{tabular}


Table E- 32. "This PowerChoice rate is scheduled to end in December (2008) Would you prefer to ..."

\begin{tabular}{|l|c|c|c|}
\hline \multicolumn{1}{|c|}{ Choice to Continue PowerChoice } & $\begin{array}{c}\text { Information } \\
\text { Treatment } \\
\text { Group }\end{array}$ & All Others & All \\
\hline Continue on the PowerChoice rate given the chance & $64 \%(54)$ & $45 \%(39)$ & $55 \%(93)$ \\
\hline Go back on the standard rate & $2 \%(2)$ & $5 \%(4)$ & $4 \%(6)$ \\
\hline $\begin{array}{l}\text { Or possibly continue on a time of use rate if changes } \\
\text { were made }\end{array}$ & $7 \%(6)$ & $13 \%(11)$ & $10 \%(17)$ \\
\hline Haven't made up minds & $23 \%(19)$ & $33 \%(28)$ & $28 \%(47)$ \\
\hline Don't Know/Refused & $4 \%(3)$ & $5 \%(4)$ & $4 \%(7)$ \\
\hline All & $100 \%(84)$ & $100 \%(86)$ & $100 \%(170)$ \\
\hline
\end{tabular}


APE-14 


\section{Appendix F}

Analytical Framework and Three Survey Instruments 
APF-2 
Framework for Gathering Data Across Three Survey Waves

\begin{tabular}{|c|c|c|}
\hline Framework Elements & Research Questions & $\begin{array}{l}\text { Survey Wave } \\
\text { and } \mathrm{W}-1 \mathrm{Q \#}\end{array}$ \\
\hline $\begin{array}{l}\text { CONCERNS: } \\
\text { Objective is to ascertain } \\
\text { and explain the variability } \\
\text { in levels of concerns } \\
\text { among TOU volunteers }\end{array}$ & $\begin{array}{l}\text { Why did the HH participate in the TOU program? } \\
\text { What do they expect from their participation in the } \\
\text { program? [e.g., to save } \$ \$ \text {, "do their part," have the } \\
\text { opportunity to support the environment, SMUD, and } \\
\text { /or their community, to help provide for energy } \\
\text { security, or what?]. } \\
\text { To what extent do participants recognize links } \\
\text { between energy-use in general and other non-energy } \\
\text { or energy-related benefits? [e.g., Reduce carbon } \\
\text { emissions, reduce future need to build power plants or } \\
\text { buy expensive power during peaks, cleaner } \\
\text { environment]. [Compare across treatment groups.] }\end{array}$ & $\begin{array}{l}W-1,5-6 \\
W-1,7-8,37\end{array}$ \\
\hline $\begin{array}{l}\text { CAPACITIES: } \\
\text { Objective is to } \\
\text { understand what DR } \\
\text { capacities are resident in } \\
\text { participant households } \\
\text { and to ascertain how they } \\
\text { are applied, and to test if } \\
\text { selected interventions } \\
\text { enhance their capacity to } \\
\text { act. }\end{array}$ & $\begin{array}{l}\text { How do customers understand the link between their } \\
\text { actions, reducing demand and/managing their utility } \\
\text { bills? } \\
\text { What usage patterns were in effect prior to } \\
\text { volunteering? Specific focus is on electricity use by } \\
\text { TOU period prior to volunteering for program. } \\
\text { What are the non-energy impacts, if any, of their TOU } \\
\text { practices (e.g., comfort, convenience, work } \\
\text { performed)? } \\
\text { Are new conservation or DR behaviors being } \\
\text { adopted? What DR behaviors are HHs willing to } \\
\text { adopt; which ones are not acceptable? [Review } \\
\text { SMUD tips and ascertain which ones were practiced } \\
\text { prior to participation, which ones they might consider } \\
\text { doing, and which are rejected] } \\
\text { Did they make changes their behaviors or use } \\
\text { patterns during July and Aug. (e.g., shifting use to } \\
\text { low/medium periods, reducing AC use, other)? } \\
\text { Do they plan to do any specific EE/conservation } \\
\text { upgrades (e.g., insulation, upgrade appliance, } \\
\text { remodel, install new windows or window treatments, } \\
\text { or change lighting)? } \\
\text { How much, if any, HH disagreements over these new } \\
\text { behaviors? } \\
\text { Who takes the lead in directing change or is this a } \\
\text { group process (more than one person monitors } \\
\text { usage, how are bills paid, knows the rate structure, } \\
\text { etc). }\end{array}$ & $\begin{array}{l}\text { W-1, 13, } 22 \\
\text { W-1, 25, } 28 \\
\text { W-1, 30-31 } \\
\text { W-2, } \\
\text { W-1, 15-17, } 24 \\
\text { W-2 review } \\
\text { adoption of } \\
\text { SMUD tips } \\
\text { W-1, 18-21 } \\
\text { W-2, } \\
\text { W-1, 23 } \\
\text { W-1, 4, 35 }\end{array}$ \\
\hline
\end{tabular}




\begin{tabular}{|c|c|c|}
\hline Framework Elements & Research Questions & $\begin{array}{c}\text { Survey Wave } \\
\text { and W-1 Q\# }\end{array}$ \\
\hline $\begin{array}{l}\text { CONDITIONS: } \\
\text { Objective - to understand } \\
\text { the conditions that are } \\
\text { conducive (or not) to } \\
\text { adopting and maintaining } \\
\text { DR behaviors }\end{array}$ & $\begin{array}{l}\text { What are the constraints or advantages operating } \\
\text { within the } \mathrm{HH} \text { [e.g., members at home during day, } \\
\text { cultural or lifestyle habits (eat in or out, home a lot or } \\
\text { not, etc.)]? } \\
\text { Are there any specific needs in } \mathrm{HH} \text { [e.g., age, physical } \\
\text { condition, home office, etc]? }\end{array}$ & $\begin{array}{l}\text { W-1, 32, } 33 \\
\& W-2, \\
W-2,\end{array}$ \\
\hline PRICE & $\begin{array}{l}\text { Have they received a TOU bill? Do they understand } \\
\text { the price structure and the discount/premium charge? } \\
\text { What are the patterns of consumption? [Are they } \\
\text { similar to the patterns seen during the PowerChoice } \\
2003 \text { program (shift to a lower rate period and/or to } \\
\text { weekend)?] } \\
\text { How effective are the reported behaviors in delivering } \\
\text { observable DR and how does this effectiveness map } \\
\text { to concern, capacity, and conditions? }\end{array}$ & $\begin{array}{l}\text { W-1, 38-41 } \\
\text { Analysis } \\
\text { Analysis }\end{array}$ \\
\hline HH DEMOGRAPHICS & $\begin{array}{l}\text { Own / Rent } \\
\text { Sex and age of respondent } \\
\text { Number of persons } \\
\text { Age distribution in } \mathrm{HH} \\
\text { Levels of education } \\
\text { Primary language spoken in } \mathrm{HH} \\
\text { Income }\end{array}$ & $\begin{array}{l}\text { W-1, 42 } \\
\text { W-1, 53, } 43 \\
W-1,44-45 \\
W-1,46 \\
W-1,47 \\
W-1,48-49 \\
W-1,54-55\end{array}$ \\
\hline $\begin{array}{l}\text { DWELLING } \\
\text { STRUCTURE }\end{array}$ & $\begin{array}{l}\text { Type } \\
\text { Age } \\
\text { Size } \\
\text { Electric appliance profile (A/C, water heater, heat, } \\
\text { pool/spa haters/pumps smaller appliances). Which } \\
\text { ones may be old enough to consider replacement? } \\
\text { What conservation/EE measures were installed prior } \\
\text { to going on the rate? } \\
\text { What, if any conservation/EE measures were installed } \\
\text { after going on the rate? Did they install these EE } \\
\text { measures to better adapt to the TOU rate or for some } \\
\text { other reason? }\end{array}$ & $\begin{array}{l}\text { W-1, } 50 \\
W-1,51 \\
W-1,52 \\
W-1,14,29 \\
W-2 \\
W-2\end{array}$ \\
\hline $\begin{array}{l}\text { PROGRAM } \\
\text { SATISFACTION }\end{array}$ & $\begin{array}{l}\text { Satisfaction with the process of signing up for the } \\
\text { SMUD TOU program, meter installation, level of } \\
\text { communication. } \\
\text { Satisfaction with SMUD overall. } \\
\text { Satisfaction with the level of information provided by } \\
\text { SMUD regarding the TOU rate? }\end{array}$ & $\begin{array}{l}\text { W-1, 1-2 } \\
W-1,3 \\
W-2,\end{array}$ \\
\hline
\end{tabular}




\begin{tabular}{|l|l|l|} 
Framework Elements & \multicolumn{1}{|c|}{ Research Questions } & \multicolumn{1}{|c|}{$\begin{array}{c}\text { Survey Wave } \\
\text { and W-1 Q\# }\end{array}$} \\
\hline EVALUATION & $\begin{array}{l}\text { How did the HHs learn about DR behaviors? [Already } \\
\text { knew, SMUD, research interventions, other sources?] } \\
\text { Which sources of information were most useful and } \\
\text { informative? } \\
\text { Evaluation of information interventions (usefulness of } \\
\text { info, motivation to take action, additional DR actions } \\
\text { considered or adopted)? } \\
\text { Did the HH adopt any new behaviors as a result of the } \\
\text { information provided or as a result of real-time } \\
\text { feedback? }\end{array}$ & W-2, \\
\hline
\end{tabular}




\section{Wave 1 Survey Instrument}

\section{RIA-SMUD WAVE-1 SURVEY}

\section{Introduction}

Hello, I'm calling on behalf of SMUD about your household's participation in the PowerChoice program. SMUD recently sent a letter to let you know that we'd be calling to see how you are doing on this new time-of-use electricity rate. Your opinions will help SMUD to assess the program. I'd like to speak with ____ [customer name] or another adult that knows about the PowerChoice program.

\section{Continue \\ Callback}

I'd like to assure you that your comments are confidential and feel free to skip over any questions that you'd rather not respond to.

\section{Interview}

My first questions about your satisfaction with SMUD's administration of the PowerChoice program.

1. How satisfied were you with the process of signing up for PowerChoice? Were you:

Very Satisfied [GO TO Q3]

Somewhat Satisfied [GO TO Q3]

Neither satisfied nor dissatisfied [GO TO Q3]

Somewhat Dissatisfied [GO TO Q2]

Very Dissatisfied [GO TO Q2]

2. [IF Q1 = Somewhat or Very Dissatisfied $]$ What would you say could have been handled better? (RECORD)

3. How satisfied are you with SMUD in general? Are you...

Very Satisfied

Somewhat Satisfied

Neither satisfied nor dissatisfied

Somewhat Dissatisfied

Very Dissatisfied

My next set of questions is about your decision to participate in this Time-of-Use pilot program.

4. Who in your household is paying attention to electricity use? Is it... (READ OPTIONS 1-4)

Only you (1)

Someone else (2)

You and someone else (3)

No one in particular pays attention (4)

Other (vol 5)

Don't Know (vol 8)

Refused (vol 9) 
5. Thinking back, why did you decide to participate in the Power Choice program? (RECORD; PROBE TO THE NEGATIVE)

6. What questions or concerns did you have about participating? (PROBE AS NEEDED TO CODE; MULTIPLE RECORD)

Had no reservations

Bill might increase

Lifestyle changes might be difficult (hard to do things in a new way)

Not sure it would be worth it

Confusing

Other, specify

7. Did any of the following factors play a part in your decision to participate? The opportunity... (ROTATE ORDER; RECORD YES OR NO FOR EACH)

a. to have greater control over your energy costs? Y/N/DK/R

b. to contribute to our energy security? Y/N/DK/R

c. to help SMUD avoid potential brown or blackouts? Y/N/DK/R

d. to save money by using electricity at lower cost times? Y/N/DK/R

e. to help the environment? Y/N/DK/R

8. Which one of the following best described your thinking about saving money when you decided to sign up for PowerChoice? Was it...

You can save money without changing much (01)

You can save money if you make some changes (02)

You can save if you make a lot of changes (03)

You didn't think about saving money when you decided to sign up (05)

Other (specify)

9. Would you say that your summer cost of electricity now will be...

A lot lower compared to your old rate (1)

Somewhat lower (2)

About the same (3)

Somewhat higher (4)

A lot higher (5)

Don't Know (vol 8)

Refused (vol 9)

10. [IF $\mathbf{Q}^{\mathbf{9}}=\mathbf{1}$ or 2$]$ How much money per month do you think you will save during the summer? $\$ \$ \$$ (CATI NOTE: RANGE IS O TO \$999) 
11. [ASK ALL] And would you say that your winter electricity bills will be...

A lot lower compared to your old rate (1)

Somewhat lower (2)

About the same (3)

Somewhat higher (4)

A lot higher (5)

Don't Know (vol 8)

Refused (vol 9)

12. [IF $Q 11=1$ or 2] How much money per month do you think you will save during the winter? $\$ \$ \$$ (CATI NOTE: RANGE IS O to \$999)

13. [ASK ALL] Have you participated in Peak Corp or any OTHER type of energy programs before Power Choice? [Interviewer Note: Peak Corp is an air conditioner cycling program - SMUD can turn off their AC remotely for some period of time]

13a Peak Corp Yes/No

$13 \mathrm{~b}$ Some other energy conservation program? Yes / No

14. Do the following appliances in your home use natural gas or electricity?

14a Water Heater: NG/ E / vol DK / vol R Other: Specify:

14b Stove top NG/ E / Not Applicable / vol DK / vol R

14c Oven: NG/ E / Not Applicable / vol DK / vol R

14d Clothes dryer: NG/ E / Not Applicable / vol DK / vol R

15. Now let's talk about changes you have made, after joining PowerChoice, to the way you use electricity. Changes might involve using less or shifting when you use electricity. After joining Power Choice would you say your household has .... [READ LIST] [IF NECESSARY: Later, I'll ask you about things you did before joining the program.]

(1) been doing some new things to change the ways you use electricity [GO TO Q16]

(2) or has NOT changed electricity use routines since joining [SKIP TO Q24]

(vol 8) Don't know [SKIP TO Q24]

(vol 9) Refused [SKIP TO Q24]

[INTERVIEWER NOTE. In the next OE response, steer away from structural changes to the dwelling such as insulating, weatherstripping, remodeling or new appliances. Do capture whole story verbatim about all behavioral changes related to reduced electricity use, eg, turning off things overall. Or capture if they just turn things off during specific time periods, or turn up the thermostat on the air conditioner at all times of the day or just during specific time periods, limiting TV or computer use, hanging clothes to dry, etc. Probe for anything else so that they remember as many changes as possible.] 
16. After going on PowerChoice, what has your household done to reduce the amount of electricity you use?

Gave response [GO TO 17]

Nothing [GO TO 18]

Don't know/Refused [GO TO 18]

(CATI: CREATE Q22 COUNTER. INCREMENT IF Q16=1)

17. What things have you been doing? (PROBE TO THE NEGATIVE)

[INTERVIEWER NOTE. For the next 2 questions probe to encourage a full disclosure - it takes a bit of time for people to think about this stuff.. Respondent might report changing the time that they do laundry, dish washing, pool filtering, house cleaning, or the time they turn on the AC, etc. Probe to capture WHAT, they are doing differently now that they are on a TOU rate. They may mention shifting to weekends, capture difference between weekday uses, just write it all down.]

18. [IF $15=1$ ] And after joining, what has your household done to shift activities that you used to do between 5 p.m. and 8 pm to lower cost periods? (IWR: PROMPT AND PROBE AS NEEDED)

Gave response [GOTO 19]

Nothing [GO TO 20]

Don't know/Refused [GO TO 20]

(CATI: INCREMENT Q22 COUNTER IF Q18=1)

19. Enter shifting away from 5-8pm response.

20. [IF $15=1$ ] And what has your household been doing to shift activities that you used to do between 12 noon and $5 \mathrm{pm}$ to either morning or night times when costs are lowest? (IWR: PROMPT AND PROBE AS NEEDED)

Gave response [GO TO 21]

Nothing [GO TO 22]

Don't know/Refused [GO TO 22]

(CATI: INCREMENT Q22 COUNTER IF Q20=1)

21. Enter actions used in shifting away from $12-5$ pm response (MAXIMUM LENGTH MEMO FIELD)

[IF Q22 COUNTER=0, SKIP TO Q23. IF Q22 COUNTER=1, AUTO INSERT VERBATIM RESPONSE INTO Q22 VERBATIM, THEN GO TO Q23. IF Q22 COUNTER > 1, ASK Q22]

22. Of the following changes:

(CATI: DISPLAY RESPONSES TO QS 16, 18, 20 (WHERE PRESENT)

Which one would you say is saving you the most? [IF ASKED: RESPONSE CAN BE REGARDING SAVING THE MOST ELECTRICITY OR MONEY] 
23. [IF $15=1$ I] If your household has more than one person, are there any disagreements over the changes you've been making?

Yes, disagreements [GO TO 23A]

No disagreements [SKIP TO Q 24]

(VOL) One-person household [skip to $Q 24$ ]

23a What would you say causes the most disagreement?

24. [IF 15 = 2: Not Done Anything To Change] Are the reasons for not changing electricity use patterns after joining PowerChoice because you... [READ LIST, RECORD EACH YES]

Just started on the new rate

Your electricity use patterns already fit the time-of-use periods

You already use little energy

You can't think of anything to do to cut energy usage

Your comfort is more important

Something else? (SPECIFY)

(VOL) Don't Know

(VOL) Refused

\section{ASK ALL:}

READ: Now I'd like to ask about the ways you managed your energy use before joining PowerChoice that you continue to do now.

25. Before joining Power Choice, did you already do things to keep your electricity use low or to conserve electricity that you're continuing to do now? (IWR: PROBE FOR ENERGY CONSERVING HABITS LIKE TURNING THINGS OFF WHEN NOT IN USE, TURNING UP THERMOSTAT ON AC, NOT USING AC AT ALL, ETC),

Yes [GO TO 28]

No [GO TO 29]

26. Please explain. (PROBE FOR CLARITY)

27. Before Power Choice, were you in the habit of doing things that require ELECTRICITY in the mornings or late at night rather than during the afternoon? (PROMPT IF NEEDED, "SUCH AS DOING LAUNDRY, RUNNING THE POOL PUMP, OR DOING DISHES BEFORE NOON”)

Yes [GO TO 30]

No [GO TO 31] 
28. What were you in the habit of doing in the morning or late at night? (DO NOT READ, MULTIPLE RESPONSE)

Laundry

Running pool pump

Running dishwasher

Other (SPECIFY)

(VOL) Don't Know

(VOL) Refused

Now let's talk about air conditioning.

29. How many of the following types of air-conditioners do you have in your home?
a. Central air conditioners? None / $1 / 2 / 3 / \mathrm{DK} / \mathrm{R}$
b. Central Evaporative coolers? None / $1 / 2$ / 3/ DK / R
c. Heat Pumps? None / 1/2/3/ DK / R
d. Window or wall air conditioners? None / 1/2/3/4/5 or more / DK / R
e. Portable fans or box fans? None / $1 / 2 / 3 / 4 / 5$ or more / DK / R
f. Ceiling fans? None / 1/2/3/4/5 or more / DK / R
f. Whole house fans? None / 1 / 2/ DK / R

30. [IF Q31"A", or “B”, or “C " or " $D$ " >=1] During afternoons and early evenings would you say that you .... (IWR: AS R DEFINES THESE THINGS; ENTER ONE RESPONSE)

Keep it feeling cool inside (1)

Keep the temperature at a comfortable level (2)

Let the temperature get somewhat warmer than a comfortable level (3)

Let it get uncomfortably warm inside (4)

(VOL) Not applicable, don't use the air conditioner (5)

(VOL) Don't Know

(VOL) Refused

\section{ALL:}

31. What would you say the temperature is inside your home on a hot summer afternoon?

Number (3 DIGIT LIMIT) (CATI RANGE 60 TO 120 DEGREES)

32. How often is someone at home on weekdays during the day between 8 am and 5 pm? Is it...
Almost all the time (1)
More than half the time (2)
About half the time (3)
Less than half the time (4)
Almost never (5)
Don't Know (vol 8)
Refused (vol 9) 
33. How often is someone at home weekdays between $5 \mathrm{pm}$ and $8 \mathrm{pm}$ ? Is it...
Almost all the time (1)
More than half the time (2)
About half the time (3)
Less than half the time (4)
Almost never (5)
Don't Know (vol 8)
Refused (vol 9)

34. Do you receive your electric bill by mail or do you receive it electronically?

Bill received in mail (1)

Bill received electronically (2)

Bill received both by mail and electronically (vol 3)

Other (4)

Don't Know (8)

Refused (9)

35. How does your household pay your electric bill? Is it by...

Mailing in a check (1)

Electronic Transfer of Funds [INTERVIEWER NOTE: WHERE SMUD AUTOMATICALLY DEBITS YOUR BANK ACCOUNT EACH MONTH] (2)

On-Line banking [R makes the payment on line] (3)

Over the phone pay by credit or debit card (4)

Other (5)

Don't Know (8 vol)

Refused (9 vol)

36. Not all PowerChoice participants got new meters at the same time, so we'd like to know if your household has received a time-of-use bill. [INTERVIEWER NOTE: THESE BILLS LIST SEPARATE CHARGES FOR OFF-PEAK, ON-PEAK, AND SUPER-PEAK PERIODS DURING THE SUMMER, SWING-1, SWING-2 AND WINTER RATE PERIODS]

Yes

No

Don't Know

Refused

37. [IF Q38= Yes] Would you say that the amount you have been charged on your summer PowerChoice time-of-use bill(s) was...

1 - Much higher than expected

2 - Higher than expected

3 - About what you expected

4 - Lower than expected

5 - Much lower than expected 
38. [IF Q38= Yes $]$ Were you able to understand the list of charges on your PowerChoice Time-of-Use Bill?

1 - Yes

2 - I have not looked at the bill

3 - No, Please describe what you find confusing:

\section{ALL:}

39. The PowerChoice Time of Use rate has three time periods: off-peak, on-peak, and super peak. Were you aware of this? (READ OPTIONS)

1-YES [GO TO Q42]

2-NO, but someone else in our household would be aware [GO TO Q42]

3-NO, no one [GO TO Q43]

(vol) Don't Know / Refused

40. Does someone in the household know the times of the day that the on-peak and super-peak periods start and stop? (INTERVIEWER PROBE: "You or anyone else")

$$
\begin{aligned}
& \text { Yes } \\
& \text { No }
\end{aligned}
$$

\section{ALL:}

41. PowerChoice bills include either a discount or an additional charge based on monthly usage. It's listed as a "consumption adjustment." on your electricity bill. Were you, aware of this when you signed up?

\section{1-YES}

2-NO, but someone else in our household probably knew

3-NO, no one knew about this

(vol) Don't Know / Refused

These following questions are needed for classification purposes only.

42. Do you own or rent your home?

Own

Rent

43. What is your age? \#\#

[IF Q23 = “One-person household”, AUTO RECORD “1”, THEN GO TO Q47]

44. Including you, how many people live there on a full-time basis? \#\# 
45. Since joining PowerChoice, has there been a change in the number of people in your household?

(1) No change

(2) An addition(s)

(3) A reduction in the number in the $\mathrm{HH}$

Don't Know (vol (8)

Refused (vol(9)

46. Including you, how many in your household are in the following age categories? (READ CATEGORIES; NOTE-TOTAL SHOULD ADD UP TO THE FULL-TIME PEOPLE REPORTED IN Q46 - IF NOT PROBE)

4 years old and under 5 to 17 years old 18 to 24 years old 25 to 34 years old 35 to 44 years old
45 to 54 years old 55 to 64 years old 65 to 74 years old 75 years and older

47. Would you please tell me the highest level of education you've completed? Is it...

Some high school, no diploma

High school diploma

Trade or technical school degree

Some college, no degree

Two-year college degree

Four college degree

Graduate or professional degree

(8) Don't know

(9) Refused

48. What is the primary language spoken in your home? (DO NOT READ)

English (1)

Spanish (2)

Other, Specify

Don't Know (8)

Refused (9)

49. How do you describe your race? (DO NOT READ)

White or Caucasian

Black or African American

Asian American

Native Hawaiian or other Pacific Islander

American Indian or Alaska Native

Mixed

Other (specify)

Don't know

Refused 
50. Do you live in a ...

Single family house

Duplex, Rowhouse, or Townhouse

Apartment or condominium

Mobile home

Other (please specify)

51. Was your home built...
Before 1950
1950-1977
1978-1992
1993-2001
2002-2005
2006 and Later
Don't Know
Refuse

52. How many rooms does your house have; please count living areas and bathrooms, but skip closets and hallways? (INTERVIEWER NOTE: IF R ASKS, THIS COUNT GIVES US A GOOD ESTIMATE THE SQUARE FOOTAGE OF THEIR HOME) [RANGE 1-20, DK=98, REF=99]

53. Gender (RECORD) :

Male

Female

54. Which of the following best describes your total household hold income in 2006. Just stop me when I get to the right category.
Less than $\$ 25,000 \quad 01$
$\$ 25,000$ up to $\$ 35,00002$
$\$ 35,000$ up to $\$ 50,000 \quad 03$
$\$ 50,000$ up to $\$ 75,000 \quad 04$
$\$ 75,000$ up to $\$ 100,00005$
$\$ 100,000$ up to 125,00006
$\$ 125,000$ or more $(07)$
(VOL) Don't Know
(VOL) Refused

55. [IF 56 =DK or Refuse] Would you say that your total household income for the year 2006, before taxes, was more or less than $\$ 50,000$ ?

More than $\$ 50,000 \quad 1$

Equal to or less than $\$ 50,000 \quad 2$

(VOL) Don't Know 8

(VOL) Refused 9 
56. And finally, is there anything that you'd like to add?

57. Thank you for your participation. It would be helpful to talk with you again in the fall to hear about your experiences with the rate then. Would it will be all right if we give you another call?
Yes
No
(VOL) Maybe
(VOL) Refused 


\title{
Wave-2 Survey Instrument
}

\section{SURVEY INTRODUCTION}

Hello, I'm calling on behalf of SMUD regarding your household's participation in the PowerChoice program. We spoke to someone in your household in August, and they said that we could call again to get an update on how you're doing on PowerChoice. Your opinions are very important since you are one of a select group on this new rate. I'd like to speak with [customer name] or another adult that knows about the PowerChoice program

Continue

\section{Callback}

I'd like to assure you that your comments are confidential.

All questions will be directed toWave-1 Survey Only group that agreed to be re-interviewed.

$A L L=$ [only those who said that we could contact them again from Wave-]

1. My first question is about how satisfied you are with the PowerChoice program in general? Are you...

\author{
Very Satisfied \\ Somewhat Satisfied \\ Neither satisfied nor dissatisfied \\ Somewhat Dissatisfied \\ Very Dissatisfied \\ (VOL) Don't Know \\ (VOL) Refused
}

2. While participating in PowerChoice, you may have used information provided by SMUD. Have you found the following information sources to be "Very Useful," Somewhat Useful," or "Not Useful at All"? If you haven't used the source, please tell me. [Repeat options only as needed]

2.1 Information on your electric bills?

Very Useful

Somewhat Useful

Not Useful

(VOL) Not Applicable - Don't read them

(VOL) Don't Know

(VOL) Refused

2.2 SMUD's "Connections" newsletter?

Very Useful

Somewhat Useful

Not Useful

(VOL) Not Applicable 1 - Don't get them

(VOL) Not Applicable 2 - Don't read them

(VOL) Don't Know

(VOL) Refused 
2.3 Postcard reminders of rate period changes?

Very Useful

Somewhat Useful

Not Useful

(VOL) Not Applicable 1 - Don't recall getting postcards

(VOL) Not Applicable 2 - Didn't read them

(VOL) Don't Know

(VOL) Refused

2.4 SMUD's Website savings tips?

Very Useful

Somewhat Useful

Not Useful

(VOL) Not Applicable - Don't go to the website

(VOL) Don't Know

(VOL) Refused

2.5 Letters from the PowerChoice program manager?

Very Useful

Somewhat Useful

Not Useful

(VOL) Not Applicable 1 - Don't recall getting letters

(VOL) Not Applicable 2 - Didn't read them

(VOL) Don't Know

(VOL) Refused

3. Have you used any other sources of information to help take advantage of the PowerChoice rate?

Yes

No SKIP TO TEXT BEFORE Q.5

(VOL) Don't know SKIP TO TEXT BEFORE Q.5

(VOL) Refused SKIP TO TEXT BEFORE Q.5

4. What other sources of information have you used? (To help take advantage of the PowerChoice rate)

[DO NOT READ, MULTIPLE RECORD]

Newspaper,

Radio

TV

Internet - (other than SMUD site)

Family

Neighbors

Co-Workers

Common Sense

Flex Your Power

Other (Specify)

(VOL) Don't Know

(VOL) Refused

ALL: Now let's talk about how you are using electricity now that the air conditioning season is over and winter rates are in effect. 
5. Is your household doing anything now to shift electricity usage from higher to lower cost times OR to conserve energy overall?
Yes
No SKIP TO TEXT BEFORE Q.7
(VOL) Don't know SKIP TO TEXT BEFORE Q.7
(VOL) Refused SKIP TO TEXT BEFORE Q.7

6. What things are you doing?- please be sure to mention things that you've continued to do since the summer. [MULTIPLE RECORD, RECORD ONE ACTION CODE FOR EACH ACTION THE HOUSEHOLD HAS DONE]

[CATI: there should be a separate verbatim record question for each action]
Action 1 [PROBE FOR CLARITY, PROBE AS TO WHY, PROBE “ANYHTING ELSE”]
Action 2 [PROBE FOR CLARITY, PROBE AS TO WHY, PROBE “ANYHTING ELSE”]
Action 3 [PROBE FOR CLARITY, PROBE AS TO WHY, PROBE “ANYHTING ELSE”]
Action 4 [PROBE FOR CLARITY, PROBE AS TO WHY, PROBE “ANYHTING ELSE”]
Action 5 [PROBE FOR CLARITY, PROBE AS TO WHY, PROBE “ANYHTING ELSE”]
Action 6 [PROBE FOR CLARITY, PROBE AS TO WHY, PROBE “ANYHTING ELSE”]
(VOL) Don't' know/Refused

Now let's talk about some things that people said they did last summer to shift use or to conserve. If you did any of these things, we'd like to know how they affected your household's convenience and comfort.

7. During July and August did you ever ...

[Read first action, and run through follow-up questions. Continue to cycle through each action and the follow-up questions]

A. Increase the temperature setting on your air conditioner during higher price periods?
Yes
No SKIP TO Q.7B
(VOL) Not Applicable SKIP TO Q.7B
(VOL) Don't know SKIP TO Q.7B
(VOL) Refused SKIP TO Q.7B

A1. How often would you say you did this? [READ LIST]
Always,
Usually, or
Occasionally?
(VOL) Don't know
(VOL) Refused

A2. Would you say this was very inconvenient, somewhat inconvenient, or not at all inconvenient to do?

Very inconvenient,

Somewhat inconvenient, or

Not at all inconvenient?

(VOL) Don't know

(VOL) Refused 
A3. Did taking this action make your house very uncomfortable, somewhat uncomfortable, or was it not at all uncomfortable?

Very uncomfortable, Somewhat uncomfortable, or

Not at all uncomfortable?

(VOL) Don't know

(VOL) Refused

B. (During July and August did you ever ...) Shut the air conditioner off during the afternoons or early evenings?

\begin{tabular}{ll} 
Yes & \\
No & \multicolumn{1}{c}{ SKIP TO Q.7C } \\
(VOL) Not Applicable & SKIP TO Q.7C \\
(VOL) Don't know & SKIP TO Q.7C \\
(VOL) Refused & SKIP TO Q.7C
\end{tabular}

B1. How often would you say you did this? [READ LIST]

Always,

Usually, or

Occasionally?

(VOL) Don't know

(VOL) Refused

B2. Would you say this was very inconvenient, somewhat inconvenient, or not at all inconvenient to do?

Very inconvenient,

Somewhat inconvenient, or

Not at all inconvenient?

(VOL) Don't know

(VOL) Refused

B3. Did taking this action make your house very uncomfortable, somewhat uncomfortable, or was it not at all uncomfortable?

Very uncomfortable,

Somewhat uncomfortable, or

Not at all uncomfortable?

(VOL) Don't know

(VOL) Refused

C. (During July and August did you ever ...) Shift when you did the laundry to mornings or to late at night?

Yes

No SKIP TO Q.7D

(VOL) Not Applicable SKIP TO Q.7D

(VOL) Don't know SKIP TO Q.7D

(VOL) Refused SKIP TO Q.7D 
C1. How often would you say you did this? [READ LIST]

Always,

Usually, or

Occasionally?

(VOL) Don't know

(VOL) Refused

C2. Would you say this was very inconvenient, somewhat inconvenient, or not at all inconvenient to do?

Very inconvenient,

Somewhat inconvenient, or

Not at all inconvenient?

(VOL) Don't know

(VOL) Refused

C3. Did taking this action make your house very uncomfortable, somewhat uncomfortable, or was it not at all uncomfortable?

Very uncomfortable,

Somewhat uncomfortable, or

Not at all uncomfortable?

(VOL) Don't know

(VOL) Refused

D. (During July and August did you ever ...) Turn off the lights when leaving the room?

Yes

No SKIP TO Q.7E

(VOL) Not Applicable SKIP TO Q.7E

(VOL) Don't know SKIP TO Q.7E

(VOL) Refused SKIP TO Q.7E

D1. How often would you say you did this? [READ LIST]

Always,

Usually, or

Occasionally?

(VOL) Don't know

(VOL) Refused

D2. Would you say this was very inconvenient, somewhat inconvenient, or not at all inconvenient to do?

Very inconvenient,

Somewhat inconvenient, or

Not at all inconvenient?

(VOL) Don't know

(VOL) Refused 
D3. Did taking this action make your house very uncomfortable, somewhat uncomfortable, or was it not at all uncomfortable?

Very uncomfortable,

Somewhat uncomfortable, or

Not at all uncomfortable?

(VOL) Don't know

(VOL) Refused

E. (During July and August did you ever ...) Tried to use less energy in general even in the low cost period?

Yes

No SKIP TO Q.7F

(VOL) Not Applicable SKIP TO Q.7F

(VOL) Don't know SKIP TO Q.7F

(VOL) Refused SKIP TO Q.7F

E1. How often would you say you did this? [READ LIST]

Always,

Usually, or

Occasionally?

(VOL) Don't know

(VOL) Refused

E2. Would you say this was very inconvenient, somewhat inconvenient, or not at all inconvenient to do?

Very inconvenient,

Somewhat inconvenient, or

Not at all inconvenient?

(VOL) Don't know

(VOL) Refused

E3. Did taking this action make your house very uncomfortable, somewhat uncomfortable, or was it not at all uncomfortable?

Very uncomfortable,

Somewhat uncomfortable, or

Not at all uncomfortable?

(VOL) Don't know

(VOL) Refused

F. (During July and August did you ever ...) Pre-cool-your home --that is, run the AC during late mornings before rates went up?

Yes

No SKIP TO Q.8

(VOL) Not Applicable SKIP TO Q.8

(VOL) Don't know SKIP TO Q.8

(VOL) Refused SKIP TO Q.8 
F1. How often would you say you did this? [READ LIST]

Always,

Usually, or

Occasionally?

(VOL) Don't know

(VOL) Refused

F2. Would you say this was very inconvenient, somewhat inconvenient, or not at all inconvenient to do?

Very inconvenient,

Somewhat inconvenient, or

Not at all inconvenient?

(VOL) Don't know

(VOL) Refused

F3. Did taking this action make your house very uncomfortable, somewhat uncomfortable, or was it not at all uncomfortable?

Very uncomfortable,

Somewhat uncomfortable, or

Not at all uncomfortable?

(VOL) Don't know

(VOL) Refused

ALL:

8. Are there any appliances that you never adjust or change during the peak period?

Yes

No SKIP TO Q10

(VOL) Don't know SKIP TO Q10

(VOL) Refused SKIP TO Q10

9. What appliances do you never adjust or change during the peak periods? [PROBE: Anything else?]

10. During last summer, would you say that some household members were more affected than others because of being on PowerChoice?

Yes

No $\quad$ SKIP TO Q13

(VOL) Not Applicable - only one member in the HH SKIP TO Q13

(VOL) Don't know SKIP TO Q13

(VOL) Refused SKIP TO Q13

11. Which members of the household were affected? [PROBE for specific relationship e.g. women/wife, men/husband, children, elderly HH members, all equally]

12. How were the household members affected? [PROBE FOR CLARITY] 
13. What household routines, if any, have been most affected by being on PowerChoice? [Reminder: showering habits, cooling and heating habits, laundry and cooking routines may have changed after joining PowerChoice?]

Gave response

None have been affected

Don't know

Now let's talk about lights and heating.

14. BEFORE GOING ON PowerChoice, about how many compact fluorescent light (CFLs) bulbs would you say you had installed throughout your home? [Provide time for a mental count of spiral or pin based compact fluorescent bulbs. If asked, count both inside and outside the home]

\#__ [RANGE: $0=$ None, $98=\mathrm{DK}, 99=\mathrm{Ref}]$

15. How many compact fluorescent bulbs have you installed SINCE GOING ON PowerChoice? \# [RANGE: $0=$ None, $98=$ DK, 99=Ref]

16. Now I'm going to ask you a few questions about heating. What is the main type of heating system you have in your home? [Don't read unless the interviewer obviously needs to help respondents clarify their answers; they don't always know]

1- Electric baseboard

2- Electric forced-air (central)

3- Heat pump (electric)

4- Electric wall heater

5- Gas forced-air (central)

6- Gas wall heater

7- Woodstove

8- Solar

9- Other (specify)

(VOL) Don't Know

(VOL) Refused

17. During this winter, are you trying to reduce the amount of heat you are using compared to last year, trying to keep it about the same, or do you think you'll use more heat?

Trying to reduce this winter

Keeping it about the same SKIP TO Q18

Using more this year SKIP TO Q18

(VOL) Don't Know SKIP TO Q18

(VOL) Refused SKIP TO Q18

17a. How do you plan to reduce the amount of heat you use this winter? [PROBE FOR CLARITY]

18. How do you control your furnace or heater's temperature setting? With a ... [READ LIST]

1. Programmable thermostat

2. Manual thermostat that you use to set the temperature higher or lower

3. Or a Manual thermostat that we use to switch the heating ON or OFF

4. Other (specify)

5. (VOL) Don't know

6. (VOL) Refused 
ASK Q19 IF Q18=1 (Programmable thermostat)

19. Which of the following best describes the way you use your programmable thermostat [READ LIST]

1. It is NOT programmed, you manually adjust the temperature as needed

2. It is programmed but you often adjust it manually -on a daily basis

3. It is programmed and you sometimes adjust it manually - one to three times a week

4. It is programmed and you rarely adjust it manually - one to three times a month

5. Something else (specify)

6. (VOL) Don't know

7. (VOL) Refused

20. On weekdays, what is your thermostat typically set on when someone is home during each of the following winter-rate time periods?

A1 During early evenings, $5 \mathrm{pm}$ to $8 \mathrm{pm}$ (super peak period) \# [RANGE: $0=\mathrm{OFF}, 50-90$, 98=DK, 99=Ref]

A2 Is this setting is higher, lower, or about the same as you used last winter?

Higher

Lower

About the same

(VOL) Don't Know

(VOL) Refused

B1 What about during the night between $10 \mathrm{pm}$ and $6 \mathrm{am}$ (off peak period)? \#

[RANGE: $0=\mathrm{OFF}, 50-90,98=\mathrm{DK}, 99=\mathrm{Ref}]$

B2. Is this setting is higher, lower, or about the same as you used last winter?

Higher

Lower

About the same

(VOL) Don't Know

(VOL) Refused

21. Compared to during the week, do you usually use the heater more or less on weekends?

More

Less

(VOL) Don't Know

(VOL) Refused

22. Do you turn off the heater, manually lower the temperature, or do have your thermostat programmed to a lower temperature when nobody is home?

Turn Off

Manually Lower

Programmed to Lower

Don't change it

(VOL) Don't Know SKIP TO Q24

(VOL) Refused SKIP TO Q24 
23. Before joining PowerChoice, did you control your heater in this same way?

[IF NEEDED: CATI display response to Q22]
Yes
No
(VOL) Don't know
(VOL) Refused

Now I have a couple of questions about the potential benefits of joining PowerChoice.

24. What personal, social or environmental benefits, if any, do you expect as a result of reducing and shifting energy use? [DO NOT READ, RECORD EACH MENTION, PROBE FOR CLARITY] Lower air pollution levels

Reducing the threat of global warming

Potential for SMUD to need fewer power plants

Reduce possibility of brownouts or blackouts

Save money

Help my power company (SMUD)

Other (specify)

(VOL) Nothing/None

(VOL) Don't Know

(VOL) Refused

25. What is the MOST important to you and your household? [READ LIST]

Saving money

Helping SMUD [pronounce as a word that rhymes with "mud"]

Helping the environment

(VOL) Don't Know

(VOL) Refused

26. If every household were on a time of use rate, what size of impact do you think would be made on...[read options]

a Lowering air pollution levels?

Large impact

Small impact

No impact

(VOL) Don't know

(VOL) Refused

b Reducing the threat of Global warming?

Large impact

Small impact

No impact

(VOL) Don't know

(VOL) Refused

c Reducing the need for more power plants?

Large impact

Small impact

No impact

(VOL) Don't know

(VOL) Refused 
d Lowering the future risk of brown or blackouts?

Large impact

Small impact

No impact

(VOL) Don't know

(VOL) Refused

I'm going to read a few things that people might do to save energy. We'd like to know if you already do each thing, might consider doing it, or would likely never do it

27. Have you done weather-stripping and caulking around your home?

Yes ASK 27a

No SKIP TO Q27b

(VOL) Don't know SKIP TO Q28

(VOL) Refused $\quad$ SKIP TO Q28

27a Did you do this before or after deciding to go on PowerChoice?

Before SKIP TO Q28

After SKIP TO Q28

(VOL) Don't know SKIP TO Q28

(VOL) Refused $\quad$ SKIP TO Q28

$27 \mathrm{~b}$ Is this something you are planning on doing within the next year?

Yes SKIP TO Q28

No

(VOL) Don't know SKIP TO Q28

(VOL) Refused $\quad$ SKIP TO Q28

27c Why not? [PROBE FOR CLARITY]

ASK Q28 IF HH HAS CLOTHES DRYER (SAMPLE ELEMENT), ELSE SKIP TO Q29

28. Have you dried clothes on a rack or line instead of in the clothes dryer?

Yes ASK 28a

No SKIP TO Q28c

(VOL) Don't know SKIP TO Q29

(VOL) Refused SKIP TO Q29

28a Did you start doing this before or after deciding to go on PowerChoice?

Before

After

(VOL) Don't know

(VOL) Refused

28b Would you say you tend to dry clothes on a rack or line "Always", "Usually", or "Occasionally"?

Always SKIP TO Q29

Usually SKIP TO Q29

Occasionally SKIP TO Q29

(VOL) Don't know SKIP TO Q29

(VOL) Refused SKIP TO Q29 
$28 \mathrm{c}$ Is this something you are planning on doing within the next year?
Yes SKIP TO Q29
No
(VOL) Don't know SKIP TO Q29
(VOL) Refused SKIP TO Q29

28d Why not? [PROBE FOR CLARITY]

29. If you have a pool, have you reset the timer on the pool filter to run during the morning or late at night?

Yes ASK 29a

No SKIP TO Q29b

(VOL) Not Applicable - doesn't have a pool SKIP TO Q30

(VOL) Don't know SKIP TO Q30

(VOL) Refused SKIP TO Q30

29a Did you do this before or after deciding to go on PowerChoice?

Before SKIP TO Q30

After SKIP TO Q30

(VOL) Don't know

SKIP TO Q30

(VOL) Refused

SKIP TO Q30

$29 \mathrm{~b}$ Is this something you are planning on doing within the next year?
Yes SKIP TO Q30
No
(VOL) Don't know SKIP TO Q30
(VOL) Refused $\quad$ SKIP TO Q30

29c Why not? [PROBE FOR CLARITY]

30. Have you had a home energy audit done - either done by some else or by someone in your household? [Interviewer, energy audits can be done on line on the SMUD website]

Yes ASK 30a

No SKIP TO Q30b

(VOL) Not Applicable - doesn't have a pool SKIP TO Q31

(VOL) Don't know SKIP TO Q31

(VOL) Refused $\quad$ SKIP TO Q31

30a Did you do this before or after deciding to go on PowerChoice?

Before SKIP TO Q31

After SKIP TO Q31

(VOL) Don't know

SKIP TO Q31

(VOL) Refused

SKIP TO Q31

30b Is this something you are planning on doing within the next year?

Yes SKIP TO Q31

No

(VOL) Don't know SKIP TO Q31

(VOL) Refused $\quad$ SKIP TO Q31 
30c Why not? [PROBE FOR CLARITY]

31. Thinking just of walls, roof, doors, and windows, what energy efficient upgrades have you installed during 2007? [DO NOT READ, MULTIPLE RECORD]

Ceiling Insulation - installed or added

Wall Insulation

Double paned windows

Insulating window treatments, e.g., curtains

New siding

Insulated door(s)

Weatherstripping around doors and windows

New reflective roof

Reflective window coating

Radiant barrier in attic

Planted shade trees

Other (specify)

(VOL) Nothing

(VOL) Don't Know

(VOL) Refused

Now let's talk a bit about appliances.

32. During 2007 have you installed or replaced any major appliances such as a furnace, air conditioner, water heater, spa, dishwasher, large screen televisions or the like?

Yes

No SKIP TO Q.36

(VOL) Don't know SKIP TO Q.36

(VOL) Refused SKIP TO Q.36

33. During 2007 which major electric appliances have you replaced with gas appliances? [DO NOT READ, MULTIPLE RECORD]

Central Electric furnace for a Central Gas model

Wall Electric furnace or heater for a Gas model

Electric stove top for a gas model

Electric oven (without cook top) for gas model

Electric stove or range (combined oven and cook top) for gas model

Electric Spa/hot tub heater for gas model

Electric Pool heater for gas model

Electric Air Conditioner for a gas fueled model

Electric clothes dryer for gas fueled model

Other (specify)

None

(VOL) Don't Know

(VOL) Refused 
34. Have you replaced any other major appliances during 2007? [Don't read the list, but do an "anything else" prompt as needed to jog memories Pick list includes:]

Refrigerator

Standalone Freezer

Central Air Conditioner

Wall or Window Air Conditioner

Central Gas Furnace

Heat Pump

Gas Water heater

Electric Water heater

Pool Pump

Spa / hot tub

Clothes dryer

Clothes washer

Dishwasher

Large screen Television

Other 1 (specify)

Other 2 (specify)

(VOL) Don't Know

(VOL) Refused

ASK Q.34a FOR EACH APPLIANCE MENTIONED IN Q.34

34a Is the new [READ-IN APPLIANCE] an ENERGY STAR model?

Yes

No

(VOL) Don't know

(VOL) Refused

35. Have you added any of the following additional appliances in 2007 - something new that didn't replace an appliance that you got rid of? [READ AS NEEDED, MULTIPLE RECORD]

Second Refrigerator

Freezer

Spa/ Hot Tub

Pool heater

Pool pump

Whole house fan

Heat Pump

Central air conditioner

Wall air conditioner

Large Screen TV

Other (specify)

(VOL) Don't Know

(VOL) Refused 
ASK Q.35a IF 35=Large Screen TV

35a. Is the large screen TV a ... [READ LIST]

Plasma

Flat screen CRT [Cathode Ray Tube]

Flat screen LCD (liquid crystal display)

Rear projection

Other (specify)

(VOL) Don't know

(VOL) Refused

ASK ALL:

36. During 2007, did you get rid of any major appliances that you haven't replaced?

$\begin{array}{ll}\text { Yes } & \\ \text { No } \quad \text { SKIP TO Q38 } & \\ \text { (VOL) Don't know } & \text { SKIP TO Q38 } \\ \text { (VOL) Refused } & \text { SKIP TO Q38 }\end{array}$

37. What appliances did you get rid of? [PROBE FOR CLARITY]

38. How would you rate the overall efficiency of your dwelling considering things like air leaks around doors and windows, and insulation levels? Would you say that it is...

Very Efficient - (way above average) doesn't need any retrofits or upgrades to improve efficiency

Moderately Efficient (somewhat above average) - could use some retrofits or upgrades

Neither efficient or inefficient (average)

Moderately Inefficient (somewhat below average) - needs some retrofits or upgrades

Very inefficient (way below average) - everything needs efficiency upgrades

(VOL) Don't Know

(VOL) Refused

39. Has the number of full-time members in your household increased, decreased, or stayed the same since the beginning of the summer 2007?

Increased (specify HOW MANY)

Decreased (specify HOW MANY)

Stayed the same

(VOL) Don't Know

(VOL) Refused

40. Can you think of any reasons why you might be more or less successful than some other households at saving money on the PowerChoice rate. . [Probe for how much control they have over their electricity bill and what limits their ability to control cost. Record verbatim response.]

Yes, more successful

Yes, less successful

No SKIP TO Q41

(VOL) Don't Know SKIP TO Q41

(VOL) Refused SKIP TO Q41 
40a. Would you please explain why you think you are (MORE/LESS) successful? [PROBE FOR CLARITY]

41. Do any members of your HH have special needs for heat or cooling that made it difficult for you to use less energy during the higher price afternoons and early evenings? [Probe: This might include an illness, a home office, being home all day, young children, etc.]
Yes
No SKIP
(VOL) Don't know
(VOL) Refused
SKIP
SKIP TO Q43

TO

42. Would you please describe these special needs? [PROBE FOR CLARITY]

43. PowerChoice bills include either a discount or an additional charge based on monthly usage. It's listed as a "consumption adjustment" on your electricity bill. Have you received an additional charge on any of your PowerChoice bills?

Yes (on at least one bill)

No (not on any bill)

(VOL) Don't know

(VOL) Refused

Gender (RECORD) : Male Female

IF the interviewer can tell they can indicate Male or Female. If not, they should ask....

44. Is there anything else you want to add about your experience on PowerChoice?

Gave

No/Nothing/Don't know

response

45. Thank you for your participation. It would be helpful to talk with you again in October 2008 to hear about your experiences after your second summer on PowerChoice. Would it will be alright if we give you another call?

Yes

No

(VOL) Maybe 


\section{Wave-3 Survey Instrument}

Programming notes - Skipping is all over the place in this instrument because we will direct some questions to "ALL," some to $W-1$ respondents/or non-respondents, $W$-2 respondents/or non-respondents, and to Summer07 participants. Monitor Q's only go to Monitor group. Information section goes to all.

W-1 opt outs have been deleted from the call list except for 2 that completed the W-2 survey.

The Call list spreadsheet currently includes these columns of data to be used for the skip patterns:

- "On_Summer07": "1" indicates 191 cases that were on PowerChoice Summer 07

- "ALL": " 1 " indicates 237 cases actively on PowerChoice at end of June 2008

- "Wave1_R": "1" indicates 106 Wave-1 survey completes (0's are non-respondents)

- "Wave2_R": "1" indicates 83 case that completed Wave-2 ("0's" are non-W-2 respondents)

- "Monitor_Grp": "1" flags 49 cases in Monitor Intervention group

- Info Treatment column in spreadsheet will not be used for skip patterns since ALL households will be asked these questions. However this info is to be added to the dataset for analytic purposes.

- "No_SMUD_contact" just flags a few cases that didn't receive any information from SMUD. They provide a small control group for the Information questions. This info is simply to be added to the dataset but not used for skips.

\section{The Wave-3 survey has 7 sections:}

Intro

Summer 2008 Actions, etc [All]

Questions on Information [All: for validity purposes]

Questions for Monitor Treatment Group [ $<50$ in treatment group]

House and appliances (asked in W-2, will skip those folks based on screening questions at the top of this section)

Demographics [mostly for W-1 Non-Respondents but 1 or two Qs in this section are for All]

Closing: ask about opinion about continuing on PowerChoice and to see if we can pick up W-1 for non-W-1 respondents.

Begin:

Hello, I'm calling on behalf of SMUD about your participation in the PowerChoice program. We recently sent a letter to let you know that we'd be calling. I'd like to speak with [customer name]__or another adult that knows about the PowerChoice program .

I'd like to assure you that your comments are confidential and feel free to skip over any questions that you'd rather not respond to.

My first questions about your satisfaction with SMUD's administration of the PowerChoice program.

IF "ALL"=1: 
1. How satisfied have you been with the PowerChoice Program during Summer 2008? Have you been:

(1) Very Satisfied GOTO Q1a

(2) Somewhat Satisfied GOTO Q1a

(3) Neither satisfied nor dissatisfied

(4) Somewhat Dissatisfied $\Rightarrow$ go to Q1b

(5) Very Dissatisfied => go to Q1b

1a. (IF Q 1 = somewhat or very SATISFIED) Why is that? (RECORD)

1b. (IF Q $1=$ somewhat or very dissatisfied) Why is that? (RECORD)

2. In response to PowerChoice, would you say that this summer you and your household have been making... [READ]

(1) a great deal of effort to change how and when you use electricity

(2) a moderate effort

(3) a little effort

(4) or making no real effort to change how and when you use electricity

(8) DK

(9) Refused

IF Q2 = "1" or "2" or " 3 ":

3. "Would you say your efforts have been
(1) Very successful
(2) Somewhat successful
(3) Barely successful
(4) Not at all successful
(8) DK
(9) Refused (9)

\section{SUMMER 2008}

IF"ALL"=1:

4. Would you say the PowerChoice rate prompted you to [READ]

(1) Change times when you used electricity

(2) Conserve, use less electricity, or use it more efficiently

(3) Both shift and conserve

(4) Didn't make much difference

(8) DK

(9) Refused 
(see col in the calling list to identify these cases):

IF "On_Summer07" = 1:

5. Summer 2008 is your second summer on PowerChoice. Compared to LAST summer, how would rate THIS summer's efforts to change how and when you used electricity? Would you say that you ... [READ]

(1) $\quad$... made about the same effort in both summers

(2) $\quad$...made a greater effort THIS summer

(3) ... or made a greater effort to change LAST summer

(4) (VOL) Other, Specify

(8) Don't know

(9) Refused

6. If Q5=3 You said that you made a greater effort last summer. Why is that - what's changed since then? Specify.

7. IF "ALL"=1 and Q2= "3" or " 4 ": There may be many reasons for not paying close attention to PowerChoice's time-of-use electricity rate periods. Would you say that any of the following reasons fit your household... [MULTIPLE RESPONSE, READ LIST],

a. You already used little energy before joining PowerChoice $\mathrm{y} / \mathrm{n} / \mathrm{dk} / \mathrm{r}$

b. Your electricity use patterns already fit the time-of-use periods $\mathrm{y} / \mathrm{n} / \mathrm{dk} / \mathrm{r}$

c. After joining, you couldn't think of things to do to cut energy usage $\mathrm{y} / \mathrm{n} / \mathrm{dk} / \mathrm{r}$

d. It was very difficult to change when you use electricity $\mathrm{y} / \mathrm{n} / \mathrm{dk} / \mathrm{r}$

e. Comfort and convenience are also important $\mathrm{y} / \mathrm{n} / \mathrm{dk} / \mathrm{r}$

f. You couldn't see any difference to your energy bills $\mathrm{y} / \mathrm{n} / \mathrm{dk} / \mathrm{r}$

g. $\quad$ Something else (SPECIFY ? y/n

IF "ALL"=1:

8. [NEW] Tell me if any of the following describe your household's electricity use habits during July and August? READ [Multiple Response ROTATE ORDER]

a) we used electricity whenever we wanted regardless of the rate $\mathrm{Y} / \mathrm{N} / \mathrm{DK} / \mathrm{R}$

b) we lowered usage during the SUPER-PEAK $-5 \mathrm{pm}$ to $8 \mathrm{pm}$ Y/N/ DK/ R

c) we shifted as much usage as possible to OFF-PEAK hours (10pm to noon) $\mathrm{Y} / \mathrm{N} /$ $\mathrm{DK} / \mathrm{R}$

d) we generally tried to use less energy, regardless of the hour Y/N/ DK/ R

e) to get ready for higher summer rates we increased the energy efficiency of our home $\mathrm{Y} / \mathrm{N} / \mathrm{DK} / \mathrm{R}$ 
9. Some households have fairly set routines for when they are home, meal time, and getting chores done. How much would you say that your household sticks to a general routine: Is it.. [READ]
(1) "Almost Always
(2) "Occasionally"
(3) "Rarely - we don't have much of a routine"
(8) (VOL) Don't Know
(9) (VOL) Refused

Note: Did ask in W-1 but may have changed since then (just ask ALL again versus putting in a screening question that may have recall error):

10. Do the following appliances in your home use natural gas (NG) or electricity $(\mathrm{E})$ ?

(1) Water Heater: NG/ E / vol DK / vol R Other: Specify (e.g., solar):

(2) Stove top NG/ E / Not Applicable-don't have one / vol DK / vol R

(3) Oven NG/E / Not Applicable-don't have one / vol DK / vol R

(4) Range: NG/ E / Not Applicable-don't have one / vol DK / vol R

(5) Clothes dryer: NG/ E / Not Applicable-don't have one / vol DK / vol R

11. Do you have an automatic dishwasher?
(1) Yes
(2) No
(8) Don't know
(9) Refused

Now let's talk about specific things that use electricity...

12. [IF "ALL"=1, new to $\mathrm{W}-3]$ Do you have a swimming pool?
(1) Yes
(2) No
(8) Don't know
(9) Refused

13. If $\mathrm{Q} 12=1$ (yes) How do you heat your pool? (Don't read)
(1) Don't heat it
(2) Gas
(3) Electricity
(4) Solar
(5) (VOL) "not maintained at all right now"
(6) Other - specify:
(8) DK
(9) Refused 
14. If $\mathrm{Q} 12=1$ (yes) Do you use a pool cover?
(1) Yes, usually
(2) Yes, sometimes
(3) No
(8) DK
(9) Refused

[IF Q12 = 1-(yes) and Q13-“5" is not selected - have pool and it is maintained]

15. Do you run your pool pump any differently now than before going on PowerChoice rates? [note - some joined PC in winter 2007]
(1) Yes,
(2) No,
(8) DK
(9) Refused

16. (If Q15=yes) Would you say you now run it: (READ)
(1) Less Often
(2) More Often
(3) Or about the same as before joining
(vol) (8) DK
(vol) (9)Refused

[IF Q12 = 1-Yes and Q13-“5” is not selected ]

17. Do you avoid running the pool pump between $5 \mathrm{pm}$ and $8 \mathrm{pm}$, the "super-peak" time? [Don't read]
(1) Yes, Specify 17a. Why is that?
(2) No, Specify 17b. Why is that?
(8) DK
(9) Refused

18. (If Q10 (5) Clothes Dryer = "NG" or "E" Compared to before joining PowerChoice, would you say that when it comes to drying your clothes you run the dryer..." [READ ]
(1) less often now
(2) more often now
(3) about the same as before
(8) DK
(9) Refused

19. And now do you tend to run it at:
(1) different times of the day
(2) or at about the same time as before PowerChoice
(3) VOL don't run it all now
(8) DK
(9) Refused 
20. (If Q18="1" or “2" OR Q19="1" Would you say that you've changed your clothes drying habits ...
(1) Because of the PowerChoice time-of-use rate - Yes/N/ DK/ Refused
(2) For any other reason? Specify: Yes/ No/ DK/ Refused

21. (If Q10 (5) Clothes Dryer = "NG" or "E")... and since joining PowerChoice are you running the dryer between $5 \mathrm{pm}$ and $8 \mathrm{pm}$-the super peak period)? [READ]
(1) Less often now
(2) More often now
(3) About the same
(4) or never did run it between $5 \mathrm{pm}$ and $8 \mathrm{pm}$
(8) DK
(9) Refused

22. .... compared to before joining PowerChoice, do you line or rack dry laundry ...
(1) less often now
(2) more often now
(3) about the same as before joining PowerChoice
(8) DKI
(9) Refused

IF "ALL"=1:

23. Have you altered cooking times or practices since joining?
(1) Yes
(2) No
(8) DK
(9) Refused

24. (If Q23=Yes)Did you change by (Multiple Response)
(1) Shifting cooking to a different time period Y/N/DK/R
(2) By Changing Methods such as cooking outdoors more often Y/N/DK/R
(3) By Cooking Less - such as preparing cold meals Y/N/DK/R
(4) Or any other way (SPECIFY)
(8) DK
(9) Refused

25. Because of PowerChoice have you changed Dishwashing routines?
(1) Yes
(2) No
(8) DK
(9) Refused 
26. (If Q25=1 AND Q11=1) Did you change by [Multiple Response]

(1) Shifting dishwashing to a different time Yes/No/DK/Refused

(2) Doing dishes by hand rather than machine Yes/No/DK/Refused

(3) Otherwise changing Methods - such as air drying or "energy saving" setting Yes/No/DK/Refused

(4) Washing less often (running full loads only) Yes/No/DK/Refused

(5) Or any other way? Yes/No/DK/R IF YES, SPECIFY how changed dish washing:

(8) DK

(9) Refused

27. (If Q10.1= "E" have an Electric hot water heater) Have you changed clothes washing routines because of PowerChoice?
(1) Yes
(2) No
(8) DK
(9) Refused

28. (If Q27=1 “yes” Did you change by [Multiple Response]

(1) Shifting clothes washing to a different time period Yes/No/DK/Refused

(2) Changing methods like using cold water, or using "light" wash cycles Yes/No/DK/Refused

(3) Running clothes washer less often -(only doing full loads, wearing clothes longer Yes/No/DK/Refused

(4) Or any other way? Yes/No/DK/Refused IF YES, SPECIFY how changed clothes washing:

(8) DK

(9) Refused

IF "ALL"=1:

29. Because of PowerChoice have you changed lighting either by (MULTIPLE RESPONSE - READ)

(1) Installing more CFL or twisty bulbs since joining Yes/No/DK/Refused

(2) Installing lower wattage bulbs $\mathrm{Yes} / \mathrm{No} / \mathrm{DK} / \mathrm{Refused}$

(3) Other than CFLs, replacing regular fixtures with fluorescent ones Yes/No/DK/Refused

(4) Installing timers to reduce run times since joining Yes/No/DK/Refused

(5) Or any other way Yes/No/DK/Refused IF YES, SPECIFY how changed lighting _

(8) DK

(9) Refused

30. Including you, how many people are living in your household? \#\# IF Q30 = 1 person GOTO Q33 
31. Have there been any discussions or disagreements over PowerChoice relating to the changes you've been making?
(1) Yes discussion
(2) Yes, disagreements
(3) No disagreements or discussion => skip to Q33

32. What would you say causes the most disagreement [or discussion]? Specify:

READ: Now let's talk about air conditioning

IF"ALL"=1:

33. How many of the following types of air-conditioners do you have in your home?

(1) Central air conditioners? None / 1 / 2/ 3/ (8) DK / (9) Refused

(2) Central Evaporative coolers? None / $1 / 2$ / 3/ (8) DK / (9) Refused

(3) Window or wall air conditioners? None / 1 / 2/ 3 / 4 / 5 or more / (8) DK / (9) Refused

(4) Whole house fans? None / 1 / 2/ (8) DK / (9) Refused

34. (If Q33 = “1," “2,” or “3”) PRIOR to joining PowerChoice , would you say that in July and August you typically used the Air Conditioning:
(1) Everyday
(2) On Most days,
(3) Only a few times a week,
(4) Only a few times a month,
(5) Less than a few times a month
(6) Never [Never's will be Skips for questions 39-43]
(8) DK
(9) Refused

35. [new W-3] When it comes to air conditioning your home now, would you say that you've been running your AC differently now -- compared to before joining PowerChoice?"
(1) Yes
(2) No-about the same
(8) DK
(9) Refused

36. (If Q35 = Yes) Why is that? [Multiple Response] READ:
(1) Because of the PowerChoice Time-of-Use rate (1) Yes/(2) No/(8) DK/(9) Refused
(2) For any other reason? (1) Yes/(2) No/(8) DK/(9) Refused

36a Specify 
37. (If Q33=“1,” “2,” or “3” AND Q34 NE “6” - Never”) Would you say that between noon and 5pm you use the "AC" (air conditioner) [READ] ...

(1) somewhat less than you used to - before PowerChoice,

(2) a lot less,

(3) somewhat more than you used to use between noon and $5 \mathrm{pm}$

(4) a lot more

(5) About the same as before on PowerChoice

(6) [Vol] Other Specify

(8) DK

(9) Refused

38. How about between $5 \mathrm{pm}$ to $8 \mathrm{pm}$ - would you say you now use the "AC"... [READ]

(1) somewhat less than you used to

(2) a lot less,

(3) somewhat more than you used to between 5 and $8 \mathrm{pm}$

(4) a lot more

(5) About the same as before on PowerChoice

(6)

(7) Other Specify

(8) DK

(9) Refused

39. How about during the off-peak period from $10 \mathrm{pm}$ to noon - would you say you now use the AC...

(1) somewhat less than you used to,

(2) a lot less,

(3) somewhat more than you used to from 10 pm to noon

(4) a lot more

(5) About the same as before on PowerChoice

(6)

(7) Other Specify

(8) DK

(9) Refused

40. (If Q33=“1," "2," or "3") Would you say that this summer you've run the air conditioner in the morning or afternoon just to pre-cool your home before super- peak period [READ]

(1) Regularly

(2) Once in awhile

(3) Or Never

(8) DK

(9) Refused 
41. (If Q33 = “1," “2," or “3”) [New W-3] During part of this summer, air quality was poor in parts of the Sacramento region due to smoke from wild fires. On those days, did smoke or air quality concerns change how you used your air conditioning? [Probe as needed: say by staying indoors more, closing windows, turning on the AC more or leaving the area.]
(1) Yes
(2) No
(3) NA (wasn't here, left area)
(8) DK
(9) Refused

42. (IF Q41 = YES) How did your AC use change during that smoky time? (prompt for a little more detail - "Did you use more or less AC? Why")

$$
\text { IF "ALL"=1: }
$$

43. If cost was no object, how would you prefer to keep your house on a hot summer afternoon or early evening?
1) Feeling "cool or almost cold" inside
2) Just at a comfortable level
3) Would let the temperature get somewhat warmer than a comfortable level
4) Would let it get uncomfortably warm inside
5) (VOL) Other. Specify
(8) (VOL) DK
(9) (VOL)Refused

44. On hot afternoons or early evenings this summer how would you say that your house actually felt ....
(1) Cool or almost cold inside
(2) Just comfortable
(3) somewhat warmer than a comfortable level
(4) uncomfortably warm inside
(8) (VOL) DK
(9) Refused

45. [W-1] What would you say the temperature was inside your home on a hot afternoon this summer? Number (3 digit limit) (CATI RANGE 60 to 120 degrees)

46. Do you regularly use the following methods for cooling your home? [Multiple Response]
a) ceiling fans (1) yes/(2) no/(3)NA-don't have/(8) DK/(9) Refused
b) portable fans (1) yes/(2) no/(3)NA-don't have/(8) DK/(9) Refused
c) closing blinds/curtains to keep the sun out (1) yes/(2) no/(3)NA-don't have/(8) $\mathrm{DK} /(9)$ Refused
d) opening windows during cooler times (1) yes/(2) no/(3)NA-don't have/(8) $\mathrm{DK} /(9)$ Refused


47. (If Q30 >1 more than 1 person Household) [Similar to W-2] During summer 2008, would you say that some household members were more affected than others because of being on PowerChoice?
(1) Yes
(2) No SKIP TO Q49
(3) (VOL) Don't know SKIP TO Q49
(4) (VOL) Refused $\quad$ SKIP TO Q49

48. How were they affected - comfort, convenience, effort or what? Specify:

IF "Wave1_R" = 0 [Wave-1 NON-respondents only - see column in call list]

49. $[\mathrm{W}=1]$ This summer, how often was someone at home on weekdays during the day between 8 am and 5 pm? Is it...
(1) Almost all the time
(2) More than half the time
(3) About half the time
(4) Less than half the time,
(5) Almost never
(8) (VOL) DK
(9) (VOL) Refused

50. How often was someone at home weekdays between $5 \mathrm{pm}$ and $8 \mathrm{pm}$ ? Is it...
(1) Almost all the time
(2) More than half the time
(3) About half the time
(4) Less than half the time,
(5) Almost never
(8) (VOL) DK
(9) (VOL) Refused

IF "ALL"=1:

51. Would you say that your summer 2008 PowerChoice time-of-use bills have been ...
(1) Much higher than expected
(2) Higher than expected
(3) About what you expected
(4) Lower than expected
(5) Much lower than expected
(8) (VOL) DK
(9) (VOL) Refused

52. (If Q $51=$ " 1 " or " 2 " or " 3 " or " 4 " or " 5 ") ) Why do you think that is? 
IF "ALL"=1:

53. [New W-3] Compared to your old electricity rate, would you say that since joining you have ...

(1) Saved money on PowerChoice

(2) Came out about even - didn't save or spend more on PowerChoice

(3) Or spent more for electricity compared to your old rate

(8) (VOL) DK

(9) (VOL) Refused

\section{Sources of Information Section}

ALL (for validity must ask non-Info group about Manager's letters too)

READ: Now let's talk about sources of information related to PowerChoice or electricity use in general. Have you found the following information sources to be "Very Useful," Somewhat Useful," or "Not Useful at All"? If you haven't used the source or gotten the information, please tell me. [Repeat options only as needed]

54. Have you found the information provided on your SMUD Time-of -Use electric bill to be [READ options again here to begin with]

(1) Very Useful

(2) Somewhat Useful

(3) Not Useful at all

(4) (VOL) Not Applicable - "Don't read the bill"

(8) (VOL) DK

(9) (VOL) Refused

55. Is there any additional information you like to see included on your bill?

(1) No

(2) Yes , Specify what they would like to see on bill:

56. How about SMUD's "Connections" newsletter? How useful are they to you?

(1) Very Useful

(2) Somewhat Useful

(3) Not Useful at all

(4) (VOL) Not Applicable 1 - Don't get them

(5) (VOL) Not Applicable 2 - Don't read them

(8) (VOL) DK

(9) (VOL) Refused

57. And Postcard reminders of seasonal rate period changes (e.g., Swing, Summer, Winter)?

(1) Very Useful

(2) Somewhat Useful

(3) Not Useful at all

(4) (VOL) Not Applicable 1 - Don't recall getting postcards

(5) (VOL) Not Applicable 2 - Didn't read them

(8) (VOL) DK

(9) (VOL) Refused 
58. Periodic letters from Carol Novak, the PowerChoice program manager?
(1) Very Useful
(2) Somewhat Useful
(3) Not Useful at all
(4) (VOL Not Applicable 1 - Don't recall getting letters
(5) (VOL) Not Applicable 2 - Didn't read them
(8) (VOL) DK
(9) (VOL) Refused

59. (If Q58 = 1 or 2) In what ways did you find the letters useful to you? Specify:

60. (If Q58 = 3) Would you find a different type of letter useful? (1) Yes /(2) No/(3) maybe/(8) DK/(9) Refused

60a. (if q60=1)Specify what information it would contain:

\section{Monitor Questions - Treatment Group Only (New W-3)}

Sub Group: see "Monitor_Grp" col in call list (1 in group, 0 not in group) IF "Monitor_Grp" = 1 GOTO Q61

IF "Monitor_Grp"=0 GOTO Next Section

Note: PowerCost monitors were mailed out in late May. Most customers got them installed by mid to late June 2008. Some had more problems than others.

61. Your free PowerCost monitor arrived in June. Is it operating properly now? (Probe as needed:)

(1) Yes

(2) No, never did install it. Specify why [Prompt: didn't have time too difficult or what?]

(3) No, tried to install but was never able to get it to work. Specify what seemed to be the problem

(4) No - it was working, but now it isn't Specify: What seems to be the problem with it? [Prompt did it quit altogether, start malfunctioning, did the batteries die or what?]

(5) NA - never got a monitor (GOTO Q73)

(6) Uncertain if monitor is currently operating properly (GOTO Q63)

(8) (VOL) DK (probe to see if either respondent doesn't know monitor is working (punch 6), or if respondent doesn't know about the monitor in general (punch 8)

(9) (VOL) Refused (GOTO Q73) 
62. (If Q61 = "2" “3” or "4” (no’s): Did you try to get help from SMUD or at Blue Line, the manufacturer? [Multiple response possible for both SMUD and Blue Line]
(1) Yes, SMUD
(2) Yes, Manufacturer / Blue Line
(3) No
(8) DK
(9) Refused

(IF Q61 = 1 or 4 AND IF Q30 > 1 (Household > 1)

63. Did the monitor prompt any discussions about energy use in your household?

(1) Yes/(2)No/(8) DK/(9) Refused

63a IF YES: Specify: What about mostly?

IF Q61 = 1 or 4 or 6

64. When you FIRST got your Monitor set up and working, how often would you say household members looked at it to check electricity usage? Stop me when I get to the right answer...

(1) More than once a day

(2) Once a day

(3) Several times a week

(4) Once a week

(5) Never Specify Why?

(8) (VOL) DK

(9) (VOL) Refused

64a Did you find the fact that you could move the display round your home [Multiple Response] (ROTATE A-C)
a. Not useful
b. useful because it helped you check usage in different rooms
c. useful for placing it (or putting it?) where you would see it most often
d. Or useful for some other reason? Specify

65. (If Q61=1) In the PAST WEEK, how often would you say household members looked at it for usage information? Stop me when I get to the right answer...

(1) More than once a day

(2) Once a day

(3) Several times in the past week

(4) Once in the past week

(5) Never Specify Why not?

(8) DK

(9) Refused 
66. (If Q61=1 or 4 ((working now or had monitor working at least initially) Besides the monitor, you were sent a booklet titled "Blue Line PowerCost Monitor Extra Tips Bulletin \#1." Do you recall getting the booklet?
(1) Yes
(2) No GOTO Q69
(8) DK GOTO Q69
(9) Refused GOTO Q69

67. On a scale of 1 to 5 with " 1 " meaning "Not useful at all" and " 5 " meaning "Very useful" how would you rate the usefulness of the Tip Bulletin for figuring out how to use your monitor?
(1) Not useful at all $2 \quad 3 \quad 4 \quad 5$ Very Useful
(6) (Vol) Didn't read the bulletin
(7) (Vol) Didn't receive the bulletin
(8) DK
(9) Refused

NOTE: For interviewer training - send SRBI a page from the TIPS bulletin that shows the display. The monitor can display the kilowatts you are using now, the kilowatt hour cost of that usage, and the total kilowatts you've used.

68. Which information displayed on the monitor did you find the most useful and why? Specify:

69. Did using the monitor prompt you to make changes in how you use energy, for example shifting when you used some things or turning some things off?
(1) Yes
(2) No
(8) DK
(9) Refused

70. (If Q69="1" Yes) What did it prompt you change? Specify:

71. (If Q61=1) The monitor is yours to keep. Do you plan to continue using it on a regular basis to monitor electricity use in your household?
(1) Yes
(2) No
(8) DK
(9) Refused

72. Would you recommend the monitor to a friend?
(1) Definitely yes;
(2) maybe;
(3) definitely no
(8) DK
(9) Refused 
Dwelling and Appliance Section (these questions were asked in W-2, but we need to ask W-2 respondents in Q73 if any changes have been made since we interviewed them)

IF "Wave2_R" on call spreadsheet = 1 (Wave-2 respondent) GOTO Q 73

IF "Wave2_R"=0 (W-2 non-respondent) GOTO Q74

73. Have you remodeled or bought any major appliances since December - when we last talked to you [or someone else in your household]?
1) Yes
2) No GOTO Q79
(8) DK GOTO Q79
(9) Refused GOTO Q79

74. Thinking just of walls, roof, doors, and windows, what energy efficient upgrades have you installed since joining PowerChoice? [DO NOT READ, MULTIPLE RECORD]
(1) Ceiling Insulation - installed or added
(2) Wall Insulation
(3) Double paned windows
(4) Insulating window treatments, e.g., curtains
(5) New siding
(6) Insulated door(s)
(7) Weatherstripping around doors and windows
(8) New reflective roof
(9) Reflective window coating
(10) Radiant barrier in attic
(11) Planted shade trees
(12) Major remodeling
(13) Other (specify)
(14) (VOL) Nothing
(88) DK
(99) Refused

75. Now let's talk a bit about appliances that use quite a bit of electricity. Since joining, have you installed or replaced any major appliances such as a furnace, air conditioner, water heater, spa, dishwasher, large screen televisions or the like?
(1) Yes
(2) No SKIP TO Q.79
(8)(VOL) Don't know
SKIP TO Q.79
(9) (VOL) Refused SKIP TO Q. 79 
76. If any, which major electric appliances have you replaced with gas appliances? [DO NOT READ, MULTIPLE RECORD]

(1) Central Electric furnace for a Central Gas model

(2) Wall Electric furnace or heater for a Gas model

(3) Electric Water Heater for a Gas model

(4) Electric stove top for a gas model

(5) Electric oven (without cook top) for gas model

(6) Electric stove or range (combined oven and cook top) for gas model

(7) Electric Spa/hot tub heater for gas model

(8) Electric Pool heater for gas model

(9) Electric Air Conditioner for a gas fueled model

(10) Electric clothes dryer for gas fueled model

(11) Other (specify)

(12) None

(88) DK

(99) Refused

77. Have you replaced any other electrical appliances with a new model since joining [DO NOT read the list, but prompt as needed:]

a) Refrigerator (1) Yes/(2) No/(8) DK/(9) Refused

b) Stand alone Freezer (1) Yes/(2) No/(8) DK/(9) Refused

c) Central Air Conditioner (1) Yes/(2) No/(8) DK/(9) Refused

d) Wall or Window Air Conditioner (1) Yes/(2) No/(8) DK/(9) Refused

e) Heat Pump (1) Yes/(2) No/(8) DK/(9) Refused

f) Electric furnace/heater (1) Yes/(2) $\mathrm{No} /(8) \mathrm{DK} /(9)$ Refused

g) Electric Water heater (with an new elec. water heater) (1) Yes/(2) $\mathrm{No} /(8) \mathrm{DK} /(9)$ Refused

h) Pool Pump (1) Yes/(2) No/(8) DK/(9) Refused

i) Spa / hot tub (1) Yes/(2) No/(8) DK/(9) Refused

j) Large screen Television (1) Yes/(2) $\mathrm{No} /(8) \mathrm{DK} /(9)$ Refused

k) Other 1 (specify)

l) Other 2 (specify) 
78. Have you added any of additional appliances since joining - something new that didn't replace an appliance that you got rid of? [DO NOT READ , MULTIPLE RECORD]
(1) Second Refrigerator
(2) Freezer
(3) Spa/ Hot Tub
(4) Pool heater
(5) Pool pump
(6) Whole house fan
(7) Heat Pump
(8) Central air conditioner
(9) Wall air conditioner
(10) Large Screen TV
(11) Other (specify)
(88) DK
(99) Refused

\section{Capacity Issues [covered in W-2]}

IF "Wave2_R"=0 (W-2 non-respondent)

79. Can you think of any reasons why you might be more or less successful than some other households at saving money on the PowerChoice rate? [Probe for how much control they have over their electricity bill and what limits their ability to control cost. Record verbatim response.]
(1) Yes, more successful
(2) Yes, less successful
(3) No $\quad$ SKIP TO Q81
(8) (VOL) DK SKIP TO Q 81
(9) (VOL) Refused SKIP TO Q81

80. Would you please explain why you think you are (MORE/LESS) successful? [PROBE FOR CLARITY] SPECIFY:

81. Do any members of your household have special needs for heat or cooling that made it difficult for you to use less energy during the higher price afternoons and early evenings? [Probe: This might include an illness, a home office, being home all day, young children, etc.]
(1) Yes
(2) No SKIP TO Q83
(8) (VOL) Don't know
(9) (VOL) Refused (9)

\section{SKIP TO Q83 SKIP TO Q83}

82. Would you please describe these special needs? [PROBE FOR CLARITY]

\section{Demographics}

READ: My remaining questions are needed for classification purposes only. 
IF "ALL"=1:

83. What is your age? \#\#

IF "Wave1_R"=1 ( Wave-1 respondents only)

84. Since joining PowerChoice, has the number of people in your household now changed?

(1) No change

(2) An addition(s) in the number of household members SPECIFY age(s) of additional person(s)-

(3) A reduction(s) in the number in the household members SPECIFY age(s) of person(s) leaving-

(8) DK

(9) Refused

IF "Wave1_R"=0 (W-1 Non-respondents only - demographics not asked in W-2)

85. Do you own or rent your home?
(1) Own
(2) Rent
(8) DK
(9) Refused

86. (skip if $\mathrm{Q} 30=1$ (number of people in $\mathrm{HH}$ ) [From W-1] Including you, how many in your household are in the following age categories? READ CATEGORIES - [Note -total should add up to the people reported in Q30 - if not probe]

4 YEARS OLD \& UNDER
5 TO 17 YEARS OLD
18 TO 24 YEARS OLD
25 TO 34 YEARS OLD
35 TO 44 YEARS OLD
45 TO 54 YEARS OLD 55 TO 64 YEARS OLD 65 TO 74 YEARS OLD 75 YEARS AND OLDER

87. Would you please tell me the highest level of education you've completed? Is it...
1) Some high school, no diploma
2) High school diploma
3) Trade or technical school degree
4) Some college, no degree
5) Two-year college degree
6) Four college degree
7) Graduate or professional degree
(8) DK
(9) Refused 
88. What is the primary language spoken in your home? [Do not read]
(1) English
(2) Spanish
(3) Other, Specify
(8) DK
(9) Refused

89. How do you describe your race? [Do not read]
(1) White or Caucasian
(2) Black or African American
(3) Asian American
(4) Native Hawaiian or other Pacific Islander
(5) American Indian or Alaska Native
(6) Mixed
(7) Other (specify)
(8) DK
(9) Refused

90. Do you live in a ... ]
(1) Single family house
(2) Duplex, Rowhouse, or Townhouse
(3) Apartment or condominium
(4) Mobile home
(5) Other (please specify)
(8) DK
(9) Refused

91. Was your home built...
(1) Before 1950
(2) $\quad 1950-1977$
(3) 1978-1992
(4) 1993-2001
(5) 2002-2005
(6) 2006 and Later
(8) DK
(9) Refused

92. How many rooms does your house have; please count living areas and bathrooms, but skip closets and hallways? [INTERVIEWER NOTE: If R asks, this count gives us a good estimate the square footage of their home)

[RANGE 1-20, DK=98, REF=99]

ALL

93. Gender (RECORD) : Male Female 
ALL since in W-1 we asked for 2006 income.

94. Which of the following best describes your total household hold income in 2007. Just stop me when I get to the right category.

(1) Less than $\$ 25,000$

(2) $\$ 25,000$ up to $\$ 35,000$

(3) $\$ 35,000$ up to $\$ 50,000$

(4) $\$ 50,000$ up to $\$ 75,000$

(5) $\$ 75,000$ up to $\$ 100,000$

(6) $\$ 100,000$ up to 125,000

(7) $\$ 125,000$ or more

(8) (VOL) DK

(9) (VOL) Refused

95. [IF Q $94=$ DK or Refuse] Would you say that your total household income for the year 2007 , before taxes, was more or less than $\$ 50,000$ ?

(1) More than $\$ 50,000$

(2) Equal to or less than $\$ 50,000$

(8) (VOL) Don't Know

(9) (VOL) Refused

\section{Closing}

ALL

96. [New] This PowerChoice rate is scheduled to end in December (2008) - Would you prefer to ...

(1) continue on the PowerChoice rate - if given the chance

(2) go back onto the standard rate

(3) Or possibly continue on a time-of-use rate if changes were made to PowerChoice

(4) Undecided

(8) DK

(9) Refused

Note to SRBI - We want to try to go back and pick up W-1(you did this survey last year) for Wave-3 respondents who didn't complete a W-1 survey. This will require loading W-1into CATI but also creating a skip over the demographics at the end of W-1 since those demographic Q's were added to W-3. Discuss with Carla first.

97. Stream info from call list data on W-1 survey status (Wave1_R=0). If W-1 survey not completed: READ: We didn't get a chance to talk with you last year. We'd very much like get your reactions to the questions we asked others on PowerChoice. May I make an appointment to call you back so that we can get your perspective? DATE: TIME: First name or initials of person to talk with:

98. And finally, is there anything that you'd like to add related to PowerChoice? -OE

READ - Thank you for your participation. Have a good day/evening. 
APF-54 